\title{
Bewusstsein und Selbstbewusstsein bei Kant
}

\author{
Inauguraldissertation \\ zur \\ Erlangung der Doktorwürde \\ der Philosophischen Fakultät \\ der Ruprecht-Karls-Universität Heidelberg
}

vorgelegt von: Yibin Liang

aus Xuzhou, Jiangsu, China

Erstgutachter: Anton Friedrich Koch

Zweitgutachter: Peter McLaughlin

Datum: 24.10.2017 


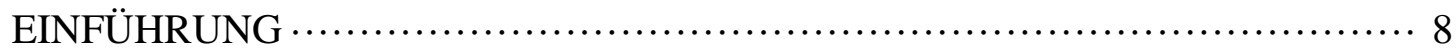

KAPITEL 1. TRANSZENDENTALES SELBSTBEWUSSTSEIN $\ldots \ldots \ldots \ldots \ldots \ldots \ldots 18$

1.1 Die Anfangspassage des $\S 16$ und das Apperzeptionsprinzip $\ldots \ldots \ldots \ldots \ldots \ldots \ldots \ldots \ldots \ldots \ldots \ldots$

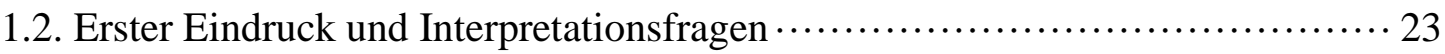

1.3. „Vorstellungen“, „Vorstellungen in mir“ und „meine Vorstellungen“............ 25

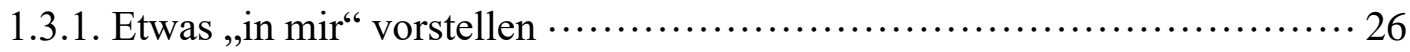

1.3.2. „Meine Vorstellung““................................................. 30

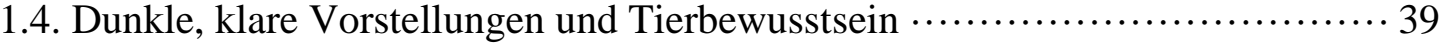

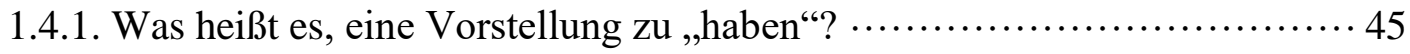

1.4.2. Was heißt es, sich einer Vorstellung bewusst zu sein? .................... 49

1.4.2.1. Das fehlende Bewusstsein in der dunklen Vorstellung $\ldots \ldots \ldots \ldots \ldots \ldots \ldots$

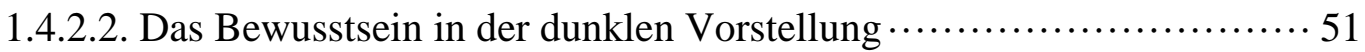

1.4.3. Die kognitive Funktion des Bewusstseins: Unterscheidung und Bewusstsein

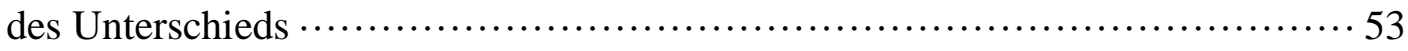

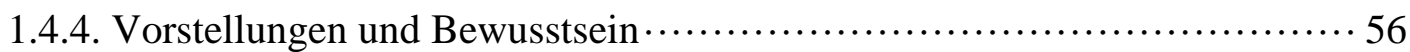

1.4.5. Die Struktur des Bewusstseins im Apperzeptionsprinzip $\cdots \ldots \ldots \ldots \ldots \ldots \ldots \ldots \ldots \ldots$

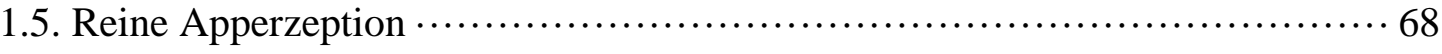

1.5.1. Apperzeption, reine Apperzeption, transzendentale Apperzeption,

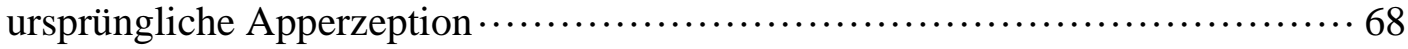

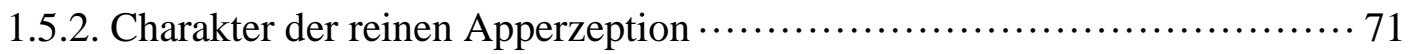

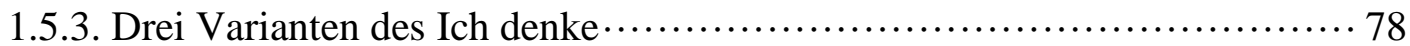


1.5.3.1. Die Vorstellung „Ich denke“ als intellektuelle Vorstellung der

Selbsttätigkeit

1.5.3.2. Die Vorstellung „Ich denke“ als Urteil der inneren Erfahrung •..

1.5.3.3. Die dritte Variante des Ich denke:

1.6. Bewusstsein, Transzendentale Apperzeption und innerer Sinn 92

1.7. Zwei Gewahrseinsweisen des Gedankens: Loses Blatt Kiesewetter 103

KAPITEL 2. DER INNERE SINN

2.1. Einführung

2.2. Die speziellen Sinnesdaten des inneren Sinnes?

2.2.1. Einwand aus der Mehrdeutigkeit des Begriffs Vorstellung ... 125

2.2.2. Einwand aus dem tierischen und infantilen Bewusstsein 127

2.2.3. Unterschied des inneren Sinns und des äußeren Sinnes 129

2.3. Das Material der affizierenden Synthesis 132

2.4. Die resultierende Vorstellung des inneren Sinnes: Wahrnehmung der

Selbsttätigkeit oder Wahrnehmung der inneren Zustände? •

2.4.1. Anschauung des inneren Zustands und Anschauung des Ichs 142

2.4.2. Liefert der innere Sinn nur zeitlich geordnete äußere Anschauungen?… 146

2.5. Selbstbezug des inneren Sinnes 153

2.6. Bewusstseinstheoretischer Status des inneren Sinnes

2.7. Das Empirisches Bewusstsein „an Sich“ 163

2.7.1. Empirisches Bewusstsein, Formales Bewusstsein und Grad des Bewusstseins 163

2.7.2. Empirisches Bewusstsein per se. 164 
3.1. Die erste Selbstaffektion in der Aufnahme der Sinnesdaten in den inneren Sinn

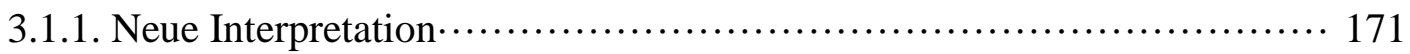

3.1.2. Ein rezeptiv gegebenes Mannigfaltiges? $\ldots \ldots \ldots \ldots \ldots \ldots \ldots \ldots \ldots \ldots \ldots \ldots \ldots \ldots \ldots \ldots \ldots \ldots$

3.1.3. Bestimmung des Mannigfaltigen aus dunklen Vorstellungen...$\ldots \ldots \ldots \ldots 189$

3.1.4. Anhang: Ein Kommentar über A99 …............................ 196

3.2. Die zweite Selbstaffektion in der Zusammensetzung der Anschauung ……. 205

3.2.1. Synthesis der Apprehension, der Reproduktion und der Rekognition …. 206

3.2.1.1. Synthesis der Apprehension …............................... 207

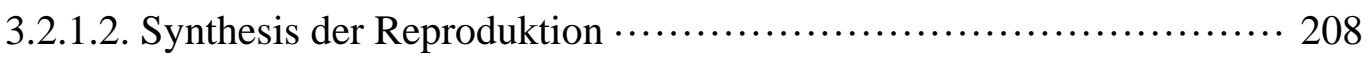

3.2.1.3. Synthesis der Rekognition im Begriff $\ldots \ldots \ldots \ldots \ldots \ldots \ldots \ldots \ldots \ldots \ldots \ldots \ldots \ldots \ldots \ldots \ldots \ldots \ldots$

3.2.2. Einbildungskraft und Synthesis der Einbildungskraft $\ldots \ldots \ldots \ldots \ldots \ldots \ldots \ldots \ldots \ldots \ldots \ldots$

3.2.2.1. Einteilungen der Synthesis (der Einbildungskraft) $\ldots \ldots \ldots \ldots \ldots \ldots \ldots \ldots \ldots \ldots \ldots \ldots$

3.2.2.2. Synthesis der Einbildungskraft in der B-Deduktion $\cdots \ldots \ldots \ldots \ldots \ldots \ldots \ldots \ldots$

3.2.2.3. Transzendentale Synthesis der Einbildungskraft $\ldots \ldots \ldots \ldots \ldots \ldots \ldots \ldots \ldots \ldots \ldots \ldots$

3.2.2.4. Dreifache Synthesis, transzendentale Synthese der Einbildungskraft und

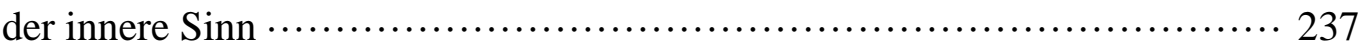

3.2.3. Transzendentale Synthesis der Einbildungskraft, innerer Sinn und das

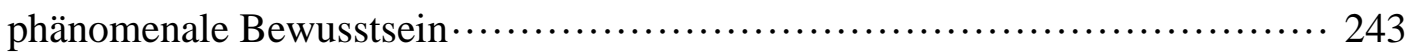

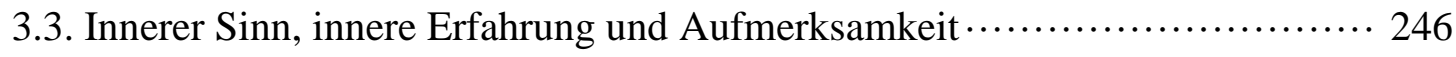

3.3.1. Bestimmung des inneren Sinnes und Aufmerksamkeit: Analyse der Schlüsselstellen B68 und B154f. 250 
3.3.1.1. Introspektion, innerer Sinn und Selbstaffektion: Kritik an Corey Dycks

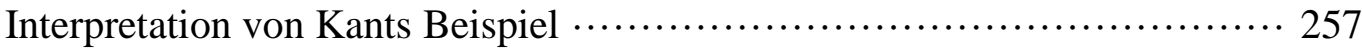

3.3.1.2. Das Linien-Beispiel: formale Anschauung und Selbstbewusstsein ‥ 259

3.3.1.3. Widerlegung von repräsentativen Interpretationen der Struktur der

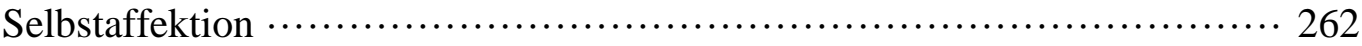

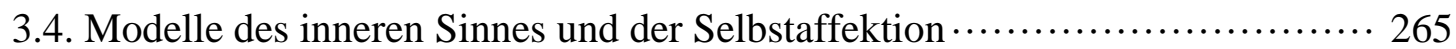

3.4.1. Die Theorie des unabhängigen Bewusstseinsflusses $\ldots \ldots \ldots \ldots \ldots \ldots \ldots \ldots \ldots \ldots$

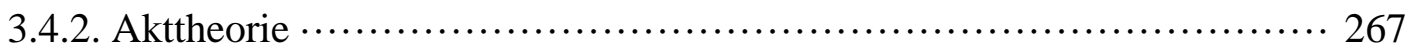

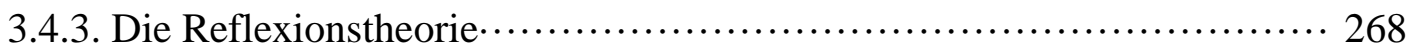

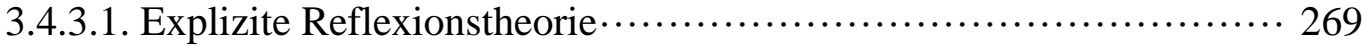

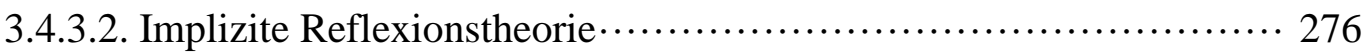

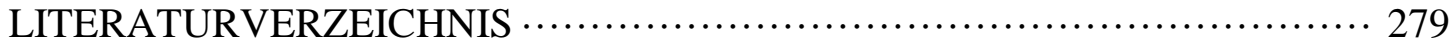




\section{Vorwort und Danksagung}

Vor etwa sechzehn Jahren, als ich noch die Mittelschule in einer ostchinesischen Provinzstadt besuchte, stieß ich, bereits von philosophischen Fragen angezogen, in einem Buchladen zufälligerweise auf die chinesische Übersetzung der Kritik der reinen Vernunft. In der Werbung des Verlages wurde dieses Buch als eines der wichtigsten Werke der abendländischen Philosophie bezeichnet. Ich kaufte mir umgehend das Buch, weil mir neben seiner Rolle in der Geschichte der Philosophie auch ein weiterer, mir damals zumindest schon ansatzweise bekannter Umstand zu Herzen ging: Der Übersetzer Zhuomin Wei war einer der ersten Studenten, die nach dem Untergang der späten Qing-Dynastie nach Europa gingen und dort Philosophie studierten. Nach seiner Heimkehr setzte er sich als Professor und später als Rektor einer berühmten christlichen Universität in Wuhan lebenslang unermüdlich und unnachgiebig - mit Höhen und Tiefen, die mit den großen Umwälzungen Chinas im zwanzigen Jahrhunderten einhergingen - dafür ein, sein Volk in Wissen und Fortschritte einzuweihen und insbesonders das Land für die Hochkultur der ganzen Menschenheit zu öffnen. Die Übersetzung des Buchs fertigte er zum großen Teil unter für uns unvorstellbaren Bedingungen - materieller Not und zeitweiliger Lebensgefahr - während der menschenverachtenden und absurden Verfolgungen der Kulturrevolution an. Damals hatte ich natürlich nur eine vage Vorstellung über die Bedeutung der Entstehungsgeschichte des Buchs: Was der Professor in den Strömungen und Strudeln der Geschichte erlebte und dachte, konnte ich - ohne Zweifel auch bis heute - nicht annähernd in konkreten Details vor Augen sehen. Ähnliches gilt auch für das Buch Kritik der reinen Vernunft: Ich ahnte nur dunkel, dass das Buch mir eine völlig neue, faszinierende Dimension des Weltverständnisses eröffnen würde, zu der ich keine Parallele im Gedankengut der Kultur kannte, in der ich geboren wurde. Einige Tage nach der Erwerbung der Kritik wurde mir eines klar: Ich wollte nach dem Abitur an einer Universität Philosophie studieren. Ich würde versuchen, dieses Buch zu verstehen 
und mich der Philosophie zu widmen, da einer der weisesten und weitschauendesten Köpfe Chinas es für bedeutungsvoll gehalten hatte, sein Leben für dieses Buch und das altüberlieferte Unternehmen, das hinter ihm steckt, einzusetzen. Diese Gesinnung habe ich bisher - obwohl meine persönliche Neigung in der Philosophie sich in den letzten Jahren leicht verschoben hat - immer beibehalten: Sie begleitete mich zum Philosophiestudium an einer chinesischen Universität, motivierte mich nach Heidelberg zu kommen und kristallisierte sich schließlich in der vorliegenden Dissertation. Es ist zwar wohl melancholisch und sicherlich kitschig, den eigenen geistigen Werdegang im Vorwort einer Dissertation mit dramatischen Worten zu dokumentieren; gänzlich unnötig mag es zudem für eine Dissertation erscheinen, die lediglich als exegetische Übung und ideelle Vorbereitung für reifere, ausgefeiltere Publikationen in Fachzeitschriften konzipiert wurde und deswegen nur in elektronischer Form erscheinen wird. Jedoch muss diese kleine persönliche Geschichte an dieser Stelle aufgeschrieben werden. Sie gehört nämlich nicht nur zu dieser Dissertation. Hoffentlich kann sie auch diejenigen chinesischen Kollegen und Kolleginnen ermutigen, die gleicher Gesinnung sind, ähnlich heftige innere Kämpfe wie ich erlebt haben und eines Tages im Meer der Online-Dissertationen der Universität Heidelberg zufälligerweise auf diese Dissertation stoßen warden.

Viele Menschen und Einrichtungen haben den Entstehungsprozess dieser Dissertation mit Geduld und Anteilnahme begleitet. Ihnen bin ich zu großem Dank verpflichtet. In besonderer Weise habe ich meinen Doktorvater, Herrn Prof. Dr. Anton Koch, zu danken. Er hat mir von Anfang an die größste akademische Freiheit gewährt. Damit konnte ich nicht nur während der Promotion Lehrveranstaltungen in anderen Fächern (Mathematik, Informatik und Psychologie) als Abwechslung und Ergänzung zur jahrelangen Beschäftigung mit Philosophie besuchen, um meine Neugier zu stillen. Auch konnte ich ohne Stress verschiedene philosophische Strömungen, darunter insbesonders die analytische Philosophie des Geistes, kennenlernen und mit neuen 
Ideen aus den Kognitionswissenschaften experimentieren. Herrn Professor Dr. Peter McLaughlin danke ich für die Betreuung und auch für Ratschläge hinsichtlich der wissenschaftlichen Publikation in Englisch. Ein herzlicher Dank gilt beiden Betreuern für ihre uneingeschränkten Unterstützungen bei verschiedenen, manchmal umständlichen Bewerbungen. Für ihre jahrelange großzügige finanzielle Unterstützung und ideelle Förderung für einen unbekannten Studenten aus ärmeren Verhältnissen bin ich der Friedrich-Ebert-Stiftung zutiefst dankbar. Herrn Dr. Wei Cheng danke ich für viele unschätzbare Ratschäge und Ermutigung. Professor Jost Jonas, meinem Augenarzt, sei vom Herzen für seine zur Weltspitze gehörenden medizinischen Kompetenzen, seine Warmherzigkeit und Einfühlsamkeit gedankt.

Gewidmet ist diese Arbeit meinen Eltern, die meine für chinesische Verhältnisse ungewöhnliche und (zumindest wirtschaftlich) ertragsarme Studien in Deutschland immer mit Verständnis, Geduld und Liebe ermutigt haben. 


\section{Einführung}

In der transzendentalen Analytik stößt man immer wieder auf drei eng miteinander verwandte Begriffe der Subjektivität, nämlich die Begriffe der Apperzeption, des Bewusstseins und des Selbstbewusstseins. Kombiniert mit Attributen wie „transzendental“, „rein“ und „empirisch“, ergeben sich daraus weitere Varianten von Begriffen des Bewusstseins und Selbstbewusstseins: transzendentale(s) Apperzeption/Bewusstsein, reine(s) Apperzeption/Bewusstsein/ Selbstbewusstsein und empirische(s) Apperzeption/Bewusstsein usw. ${ }^{1}$ Ein exaktes Verständnis von Kants Doktrin des Bewusstseins und des Selbstbewusstseins ist für die adäquate Auslegung vieler Momente der $K r V$ unentbehrlich. Um nur zwei zentrale davon zu nennen. Im $§ 16$ der Kritik der reinen Vernunft (B-Auflage) fängt Kant mit der eigentlichen Argumentation der transzendentalen Deduktion an. Den Eröffnungssatz bildet das berühmte Apperzeptionsprinzip:

Das: Ich denke, muß alle meine Vorstellungen begleiten können; denn sonst würde etwas in mir vorgestellt werden, was gar nicht gedacht werden könnte, welches eben so viel heißt als: die Vorstellung würde entweder unmöglich, oder wenigstens für mich nichts sein. (B131-132)

Die Vorstellung des Ich denke ist die reine Apperzeption (B132). Bei dieser handelt es sich um ein Selbstbewusstsein, das alle Vorstellungen begleiten können muss und in allen Episoden des Bewusstseins identisch bleiben muss (ibid.). Die Beziehung aller „meiner“ Vorstellungen auf ein identisches Subjekt nennt Kant die „transzendentale Einheit des Selbstbewusstseins“ (ibid.). Die gesamte transzendentale Deduktion fängt mit der These an, dass alle kognitiv relevanten Vorstellungen unter dieser Einheit stehen müssen (B133). Die synthetische Einheit der Apperception macht gar den „höchste[n] Punkt“ aus, „an dem man allen Verstandesgebrauch, selbst die ganze Logik

\footnotetext{
${ }^{1}$ Ich nenne nur diejenigen Kombinationen, die tatsächlich in den beiden Auflagen der $K r V$ erscheinen. Für die genauen Fundstellen siehe die späteren Ausführungen in dieser Dissertation.
} 
und nach ihr die Transscendental-Philosophie heften muß“ (B134 Anm.). Es ist ganz deutlich, dass der Schlüssel zur richtigen Interpretation des ersten und zentralen Schrittes der transzendentalen Deduktion im Begriff der Einheit der Apperzeption (oder Einheit des Selbstbewusstseins oder Einheit des Bewusstseins, siehe B132-133) liegt. Für ein adäquates Verständnis von diesem ist wiederum entscheidend, die Begriffe Apperzeption, Selbstbewusstsein und Bewusstsein richtig zu interpretieren. ${ }^{2}$

Das zweite Moment, das mit Kants Doktrin des Bewusstseins und Selbstbewusstseins in einem wesentlichen Zusammenhang steht, ist der Begriff des inneren Sinnes. Der innere Sinn wird von Kant mit der empirischen Apperzeption identifiziert (A107, Anth 7:134 Anm.). Er erzeugt das empirische Bewusstsein (A176/B217-8, A107). Dieser Begriff spielt unter anderen in zwei wichtigen Komponenten der transzendentalen Analytik eine wichtige Rolle. Die erste ist die sogenannte These der „Idealität des inneren Sinnes“ (B66). Der innere Sinn gilt als Vermögen des Gemüts, die inneren Zustände oder Ereignisse wahrzunehmen (B66 ff.). In den empirischen Anschauungen des inneren Sinnes wird das Gemüt anhand seiner inneren Zustände als Erscheinung, nicht aber als Ding an sich vorgestellt (B66ff. und B152ff.). In dem exkursiven Einschub zur Idealität des inneren Sinnes im $\$ 24$ (B152ff.) wird nicht nur das Verhältnis zwischen der reinen Apperzeption und dem inneren Sinn thematisiert, sondern Kant deckt mit einem vieldiskutierten Beispiel auch die komplizierte Bewusstseinsstruktur der Selbstaffektion bei einem speziellen Fall der Introspektion bzw. der expliziten Selbstwahrnehmung auf. Die zweite Komponente der transzendentalen Analytik, die mit dem inneren Sinn in enger Verbindung steht, ist die Doktrin der transzendentalen Zeitbestimmung. Diese wird als ein übergreifender Aspekt von Kants Theorie der Erfahrung sowohl in dem Schematismus-Kapitel, als auch in den Axiomen-, Antizipationen- und Analogienkapiteln ausgeführt. Durch diese

\footnotetext{
${ }^{2}$ Dasselbe gilt auch für die A-Auflage der transzendentalen Deduktion. Siehe $§ 1.1$.
} 
Doktrin wird erklärt, wie die Kategorien überhaupt auf die Sinnesgegenstände Gültigkeit haben können. Bei der transzendentalen Zeitbestimmung operiert die transzendentale Synthesis der Einbildungskraft gemäß den Schemata (A142/B181) auf dem Mannigfaltige der sinnlichen Anschauung a priori - d.h. dem Mannigfaltige des Zeitlichen (A177/B220). Dieses wird in einer einheitlichen Zeitordnung organisiert, damit es mit der synthetischen Einheit der Apperzeption konform ist (B150). Der innere Sinn wird durch den Verstand, der hier in der Form der transzendentalen Synthesis der Einbildungskraft auftritt, gemäß den Kategorien bestimmt, da die Form des inneren Sinnes die Zeit ist (A142/B181). Bei der Zeitbestimmung a priori werden, mit anderen Worten, die Verhältnisse der verschiedenen Episoden des empirischen Bewusstseins in eine zeitliche Ordnung gebracht, damit sie zur Einheit der Apperzeption gehören (A177/B220) - d.h. damit sie von der über die Zeit hinweg identischen Vorstellung des Ich denke begleitet werden können. Im Prozess der Zeitbestimmung wird der innere Sinn außerdem von den Verstandesakten affiziert, wodurch das empirische Bewusstsein der Erscheinungen überhaupt aktiviert wird. Aus der obigen Darstellung lässt sich entnehmen, dass die Doktrin des inneren Sinns, die mit zentralen Komponenten von Kants Theorie der empirischen Erkenntnis zusammenhängt, sich in diesem Zusammenhang mit verschiedenen (Selbst-)Bewusstseinsbegriffen verwickelt. Um diese Komponenten und damit auch die Hauptargumente der ersten Hälfte der $\mathrm{Kr} V$ möglichst präzise auszulegen, muss man Kants Dokrin des Bewusstseins und Selbstbewusstseins möglichst exakt rekonstruieren.

In der Kritik der reinen Vernunft gibt Kant für diese Begriffe selten klare und unmißverständliche Definitionen, noch seltener konkrete Beispiele. Die Verhältnisse dieser Begriffe sind ebenfalls unbestimmt: Es ist nicht nur unklar, ob sie sich auf dieselben mentalen Zustände, Ereignisse oder Prozesse beziehen, sondern auch, wenn dies nicht der Fall sein sollte, wie sich die jeweiligen Bezugsgegenstände voneinander unterscheiden. Diese Unbestimmtheit ist gewissermaßen nachvollziehbar, denn 
schließlich ist eine Theorie des (Selbst-)Bewusstseins nicht das Hauptanliegen der eher epistemologisch ausgerichteten $K r V$. Es kann sein, dass Kant davon ausgeht, dass sein zeitgenössisches Publikum, das mit den damals gängigen Theorien des (Selbst-)Bewusstseins vertraut ist, auch ohne explizite Erläuterungen ein richtiges Verständnis dieser Begriffe erlangen kann. Wenn diese Annahme auch wahr sein könnte, liefert ein eingehender Blick auf die Vorgängertheorien dennoch keine entscheidenen Anhaltspunkte für die Interpretation von Kants Lehre. Hinsichtlich der Theorie des (Selbst-)Bewusstseins ist Kant nämlich von verschiedenen Autoren beeinflußt. ${ }^{3}$ Es ist sehr schwierig, für jede in Frage stehende These von Kants Doktrin eine eindeutige Quelle zu identifizieren und dann mittels dieser Quelle die jeweilige These selbst näher zu beleuchten. In verschiedenen Punkten modifizierte er zudem die Lehren seiner Vorgänger in teils gravierender Weise. Auch wenn man von diesen Einschränkungen absieht, kann man generell Zweifel haben, ob es angebracht ist, sich in einer rigiden, detaillierten exegetischen Analyse von Kants originalem Text auf den Wortlaut anderer Philosophen zu verlassen.

Man kann auch vermuten, dass Kant davon ausgeht, dass seine Leser allein anhand seiner Ausführungen, die die Thematik des (Selbst-)Bewusstseins auch nur verstreut und nach dem jeweiligen kontextuellen Zweck bestimmen, die genaue Bedeutung der Grundbegriffe verstehen können. Auch dies scheint mir jedoch nicht der Fall zu sein. Als Leser kann man zwar nach und nach ein bestimmtes „Sprachgefühl“ entwickeln und sich ein intuitives Urteil von den Bedeutungen und Verhältnissen dieser Begriff bilden. Letztes bleibt jedoch philosophisch oder exegetisch unbegründet und mithin unzuverlässig. Wenn man allein anhand des Texts von $K r V$ den Versuch wagt, diese Begriffe sowie ihre Verhältnisse exakt zu klären, wird man schnell mit anscheinend unüberwindbaren Problemen konfrontiert. Nicht nur ist die Textressource zu diesen

\footnotetext{
${ }^{3}$ Siehe Sturm und Wunderlich (2010), Wunderlich (2005), Dyck (2006).
} 
speziellen Begriffen spärlich. Man erhält auch leicht den Eindruck, dass diese Begriffe inkonsequent, unreflektiert und unsystematisch verwendet werden. Zudem sind Kants Ausführungen, die diese Begriffe involvieren, ohnehin selbst äußerst dunkel und mehrdeutig. All diese Umstände erschweren es, sich ein klares Bild von Kants Doktrin des Bewusstseins und Selbstbewusstseins zu verschaffen.

Vermutlich deswegen ist Klemme der Ansicht, dass Kant sich nicht dafür interessiere, „wie das Selbstbewusstsein selbst verfasst ist, sondern, welche Begründungsrolle es übernehmen kann [..] Kant hat keine ausgearbeitete Theorie des Selbstbewusstseins. “4 Manche Interpreten bezweifeln sogar, ob sich bei Kant überhaupt eine konsistente Theorie des Bewusstseins findet. ${ }^{5}$ Wenn man die einschlägige Sekundärliteratur sowohl Werke, die die transzendentale Analytik übergreifend kommentieren, als auch die, die sich auf spezielle Aspekte derselben konzentrieren - betrachtet, bekommt man leicht den Eindruck, dass sich in den vergangenen 30 Jahren erstaunlich wenige etablierte Kant-Forscher einer umfassenden Studie über Kants Theorie des (Selbst-)Bewusstseins gewidmet haben. ${ }^{6}$ Im unüberschaubaren Meer der Forschungsliteratur über Kants Kritik der reinen Vernunft gibt es unter den neueren Publikationen in Buchform nur einige wenige, die speziell auf Kants Lehre des Subjekts und bestimmte Aspekte dieser Lehre eingehen. ${ }^{7}$ Diese Werke, darunter auch diejenigen,

\footnotetext{
${ }^{4}$ Klemme (1996: 377).

5 Siehe Wunderlich (2005:133,145) and Brook (1994:46).

6 Guyer (1987), Kitcher (1990), Carl (1992), Longuenesse (2001), Allison (2004), Haag (2007), Schulting (2013) und Allison (2015) sind die meist diskutierten oder zitierten Werke, die die transzendentale Analytik (und zum Teil auch das Paralogismen-Kapitel) übergreifend analysieren und kommentieren. Allerdings finden sich darin meistens lediglich Interpretationsansätze, aber keine detaillierten Behandlungen von Kants Doktrin der (Selbst-)Bewusstseinsstruktur.

${ }^{7}$ Powell (1990), Rosefeldt (2000) und Ameriks (2000) thematisieren hauptsächlich den ParalogismenKapitel und widmen dem Begriff des (Selbst-)Bewusstseins lediglich ein bis zwei Kapitel. Mohr (1991), Klemme (1996), Brook (1994), Wunderlich (2010), Kitcher (2014), Longuenesse (2017) sind Werke, die sich vergleichsweise stärker diesem Thema zuwenden.
} 
die sich mit vergleichweise größerem Umfang dem Thema des (Selbst-)Bewusstseins widmen, weisen zudem jeweils den Mangel auf, dieses Thema nicht systematisch zu behandeln. Entweder berücksichtigen sie nicht sämtliche über das Kantsche Opus verstreuten erhellenden Ausführungen über das Thema oder versäumen es, die relevanten und zusammenhängenden Theoriekomponenten in den beiden Auflagen der $K r V$ in einer Einheit zu beleuchten. Deswegen gelingt es ihnen nicht, eine auf Kants Aussagen beruhende rigide Analyse und umfassende Rekonstruktion der fraglichen Doktrin herauszuarbeiten.

In der vorliegenden Abhandlung möchte ich einen Beitrag für ein umfassendes Verständnis von Kants Lehre der Struktur des Selbstbewusstseins und Bewusstseins leisten und damit die erwähnte Lücke in der Kant-Forschung schließen. Dabei möchte ich wie folgt vorgehen. Ich werde alle Aussagen über den Begriff des Bewusstseins und Selbstbewusstseins in den beiden Auflagen der $\mathrm{KrV}$ einer sorgfältigen, strukturierten und kritischen Analyse unterziehen. Dabei werde ich auch einschlägige Passagen aus anderen Schriften mit einbeziehen. Basierend auf einer gesamten Betrachtung dieser Textpassagen, argumentiere ich für die Annahme, dass Kant entgegen der von einigen Interpreten geäußerten Skepsis über eine facettenreiche Theorie der Struktur des Bewusstseins verfügt. Es wird demonstriert, dass sich eine einheitliche Theorie des Bewusstseins und Selbstbewusstseins aus den verstreuten Textressourcen herausarbeiten lässt. Aus einer derartigen systematischen Rekonstruktion lassen sich viele anscheinend unüberwindbare exegetische Unklarheiten aufhellen, die man ohne sie leicht als laxe Formulierungen, Unbedachtheit, Obskuritäten oder gar Inkonsistenzen Kant zu Last legen könnte. Des Weiteren wird präsentiert, wie diese Rekonstruktion völlig neues Licht auf einige feine Details von Kants Ausführung des (Selbst-)Bewusstseins werfen kann.

Man könnte hier Bedenken über die Verlässlichkeit solcher Passagen hegen. Es kann sein, dass Kant im Verlauf der Zeit seine Meinungen verändert. Es ist nicht einmal 
theoretisch ausgeschlossen, dass Kant in verschiedenen Schriften der gleichen Zeit verschiedene Positionen vertreten hat. Dieser Vorwurf kann der Beweiskraft der Herangehensweise dieser Abhandlung nicht abträglich sein. Ich stütze die Argumentationen hauptsächlich auf die Passagen aus der beiden Auflagen der $\mathrm{Kr} V$ (1781 und 1787), Prolegomena (1783) und Metaphysische Anfangsgründe der Naturwissenschaft (1786). Beinahe alle wichtige Momente der Argumentation werden durch mindestens eine Passage aus den drei Schriften direkt order indirekt belegt (fortan werden diese drei Werken einfachheitshalber als „Haupttexte“ bezeichnet). Etliche Passagen aus dem zur Kants Lebzeit publizierten, von Kant selbst vorbereiteten Vorlesungsskript Anthropologie aus pragmatischer Hinsicht (1798) enthalten seine Auffassungen über sogenannte dunkle Vorstellungen, nicht-apperzeptives Bewusstsein und auch direkt über das Selbstbewusstsein. Diese Passagen sind sehr aufschlußreich und detaillierter als die sporadischen Aussagen in den Haupttexten. Ich betrachte solche Stellen ebenfalls als verlässlich und gebrauche sie bei der Rekonstruktion. Da aber die Anthropologie einige Jahre nach der B-Auflage der $\mathrm{KrV}$ erschien, versuche ich bei der Verwendung der Passagen daraus immer zu zeigen, dass es in den drei Haupttexten Parallelen, Andeutungen oder Tendenzen gibt, die mit solchen Passagen übereinstimmen. Für diejenigen Stellen aus der Anthropologie, für die sich keine direkte oder indirekte Unterstützung in den drei Haupttexten vorfinden lassen, versuche ich durch Parallelstellen aus Kants Briefen, seinem schriftlichen Nachlass oder aus den Vorlesungsmitschriften zur gleichen Zeit zu untermauern. Materialien aus diesen Schriften, der unzuverlässigen Jäsche Logik sowie den vorkritischen Schriften verwende ich nur dann, wenn sie mit Kants Position in den Haupttexten im Einklang stehen oder wenn sie bis in Kants kritischer Zeit konstant bleiben. Manche Auffassungen - z.B. über die dunklen Vorstellungen oder die Struktur und Eigenschaft des (Sellbst-)Bewusstseins - hat Kant über mehrere Jahre in verschiedenen Kontexten in seinen Vorlesungen wiederholt. In manchen Briefen (wie in dem immer wieder 
zitierten Brief an Marcus Herz im Jahr 1789) versucht er seinen Kollegen seine Positionen in der $K r V$ zu erläutern. Solche Ausführungen halte ich für verlässlich. Dieser Umgang mit Kants Schriften ist gängige Praxis in der Kant-Forschung. ${ }^{8}$ In einem Wort, es wird versucht, durch eine minuziöse kritische Analyse der Schlüsselpassagen und gemeinsame Betrachtung verschiedener Theorienkomponenten von Kants Doktrin der Wahrnehmung und empirischer Erkenntnis ein einheitliches Bild von Kants Konzeption der Struktur des Bewusstseins sowie des Selbstbewusstseins auszuarbeiten. In dieser Untersuchung findet sich zudem eine Auseinandersetzung mit fast allen neueren einflußreichen Interpretationen der einschlägigen Themen, um die von mir vorgeschlagenen Lesart zu verteidigen.

Diese Abhandung besteht aus drei Kapiteln. Im ersten Kapitel wird zuerst das Apperzeptionsprinzip in den beiden Auflagen der $K r V$ vorgestellt. Kants Ausführungen darüber enthalten die wichtigesten Aussagen über die Struktur des Selbstbewusstseins und Bewusstseins. Bei der Analyse dieser Aussagen wird ein erster Eindruck von Kants Doktrin des (Selbst-)Bewusstseins vermittelt und die wichtigsten Interpretationsfragen werden vorgestellt. Dabei wird das Apperzeptionsprinzip in verschiedenen Momenten zerlegt. Im zweiten Teil des ersten Kapitels wird das Apperzeptionsprinzip in seine unterschiedlichen Momente genauer analysiert. Zuerst wird Kants Konzeption der Vorstellung vorgestellt. Dabei wird gezeigt, dass Kant Vorstellungen hinsichtlich ihres epistemischen Status unterscheidet. Danach wird Kants Doktrin der dunklen Vorstellung vorgestellt. Anhand dieser Doktrin wird das Bewusstsein in apperzeptives und nicht-apperzeptives Bewusstsein untergeteilt. Mittels dieser Unterscheidung wird das komplexe Verhältnis zwischen Vorstellung und Bewusstsein skizziert. Danach wird die Bewusstseinsstruktur im Apperzeptionsprinzip erläutert und eine Rekonstruktion dieses Prinzips geliefert. Am Ende dieses Teils werden anhand einschlägiger Passagen

${ }^{8}$ Z.B. Kitcher (2014), Kitcher (2017), Wunderlich (2005). 
das Bewusstsein, die transzendentale und die empirische Apperzeption begrifflich differenziert und in Zusammenhang gebracht. Im dritten Teil des ersten Kapitels wird die reine Apperzeption charakterisiert. Nach einer ersten begrifflichen Klärung ähnlicher Begriffe werden Kants Aussagen über die Charaktere derselben zusammengefasst. Danach wird das bewusstseinstheoretische Status der transzendentalen Apperzeption geklärt. In den daran anschließenden Abschnitten werden drei Varianten der Vorstellung „Ich denke“ und zwei Arten der mit ihr zusammenhängenden Selbstanschauungen unterschieden und jeweils charakterisiert. Anhand einer feinen Analyse einer Passage in der B- $K r V$ wird das damit einhergehende Problem der unbestimmten Selbstwahrnehmung gelöst. Im letzten Teil dieses Kapitels wird anhand der Analyse einer berühmten Passage aus Kants Nachlass zwei Bewusstseinsmodi des Denkens a priori - die reine sowie die empirische Apperzeption des Denkens - miteinander verglichen und das Problem des intellektuellen Bewusstseins behandelt. Das zweite Kapitel befasst sich mit dem inneren Sinn. Unklarheiten bezüglich der empirischen Materialien der Wahrnehmung des inneren Sinnes, des Umfangs der Vorstellungen, die vom Bewusstsein des inneren Sinnes begleitet werden können, sowie des intentionalen Gegenstands der Anschauung des inneren Sinnes werden nacheinander behandelt. Anschließend wird die Frage behandelt, ob der innere Sinn einen Selbstbezug haben muss. Nachdem daraufhin der Begriff des empirischen Bewusstseins analysiert wird, wird argumentiert, dass der innere Sinn eine empirische Vorstellung höherer Stufe sein muss. Beim dritten Kapitel handelt es sich um eine detaillierte Untersuchung des Prozesses der Selbstaffektion. Zuerst wird gezeigt, worin die bewusstseinstheoretische Rolle der Selbstaffektion bei der Aufnahme des sinnlichen Mannigfaltigen besteht. Anhand des Ergebnisses der Analyse der Doktrin der dunklen Vorstellungen und des ersten Schritts der Apprehension wird gezeigt, dass bei der Selbstaffektion das rein rezeptiv gegebene sinnlichen Mannigfaltige apperzeptiv bewusst wird. Danach werden verschränkte Begriffe der 
Synthesis der Einbildungskraft analysiert und verglichen. Dadurch wird gezeigt, was die Bestimmung des inneren Sinnes durch den Verstand genau bedeutet und einige gängige Fehler der Interpretationen dieses Begriffs zurückgewiesen. Zugleich wird eine gravierende Interpretationsschwierigkeit der Bestimmung des inneren Sinnes vorgestellt. Um diese zu überwinden, wird der Prozess der Selbstaffektion bei der Entstehung der äußeren Erfahrung und die dabei involvierten Begriffe des Bewusstseins analysiert. Dabei wird dieser Prozess nach Kants Unterscheidung der mathematischen und der dynamischen Kategorien in zwei Schritte aufgeteilt. Daraufhin wird gezeigt, wie das bestimmte Zeitbewusstsein in zwei Schritten generiert wird, so dass die obige Interpretationsschwierigkeit gelöst wird. Am Ende werden verschiedene alternative Interpretationen des inneren Sinnes und der Selbstaffektion vorgestellt und jeweils kritisch betrachtet. Ich verzichte am Ende dieser Dissertation auf ein abschließendes Kapitel, da eine zusammenfassende Darstellung der im Zuge der Arbeit entwickelten differenzierten Analyse nicht wirklich gerecht werden kann. 


\section{Kapitel 1. Transzendentales Selbstbewusstsein}

\subsection{Die Anfangspassage des $§ 16$ und das Apperzeptionsprinzip}

In der Darstellung des Apperzeptionsprinzips in $§ 16$ wird die reine oder ursprüngliche Apperzeption vorgestellt und mit der Vorstellung des Ich denke in Verbindung gebracht (B132). ${ }^{9}$ Die reine Apperzeption wird von der empirischen Apperzeption unterschieden und als eine besondere Art des Selbstbewusstseins, nämlich als das reine und invariable Selbstbewusstsein als Bestandteil jeglichen Bewusstseins bezeichnet. ${ }^{10}$ Im folgenden werden die wichtigen Aussagen über die reine Apperzeption sowie „Ich denke“ systematisch behandelt.

Es ist vielleicht hilfreich, alle wichtigen Aussagen Kants über die transzendentale Apperzeption zu sortieren und daraus zentrale Aussagen über die transzendentale Apperzeption zu klassifizieren, um auf diesem Wege einen Gesamteindruck von ihnen zu erhalten. Vorab muss bemerkt werden, dass Kant manchmal mit dem Wort „Apperzeption“ die transzendentale Apperzeption meint (B68, 134, 154; A216/B263 f.; Anth 7: 141) und manchmal die Apperzeption tout court. Beide Bedeutungen müssen je nach Kontext sorgfältig unterschieden werden. In der Tat differenziert er in seinen Schriften in der kritischen Periode meistens zwischen Apperzeption, transzendentaler Apperzeption und empirischer Apperzeption (siehe §1.6.). In den Ausführungen dieser Dissertation werde ich terminologisch an dieser Unterscheidung festhalten.

\footnotetext{
${ }^{9}$ Wie wir noch sehen werden, werde beide in Verbindung gebracht, nicht jedoch gleichgesetzt. Fortan benutze ich die Schreibweisen „die Vorstellung des Ich denke“ und „die Vorstellung des Ich“. Dies sind vereinfachte Ausdrücke dafür, dass der propositionale Gehalt der reinen Apperzeption durch den Satz „Ich denke“ oder den (Quasi-)Begriff des Ich beschrieben werden kann.

10 Siehe auch Schulting (2012: 272).
} 
Am Anfang des $\S 16$ der B-Deduktion stellt Kant die reine Apperzeption zum ersten Mal vor:

(IDB) 1) Das: Ich denke, muß alle meine Vorstellungen begleiten können; 2a) denn sonst würde etwas in mir vorgestellt werden, was gar nicht gedacht werden könnte, welches eben so viel heißt, 2b) als die Vorstellung würde entweder unmöglich, 2c) oder wenigstens für mich nichts sein. 3) Diejenige Vorstellung, die vor allem Denken gegeben sein kann, heißt Anschauung. 4) Also hat alles Mannigfaltige der Anschauung eine nothwendige Beziehung auf das: Ich denke, in demselben Subject, darin dieses Mannigfaltige angetroffen wird. 5) Diese Vorstellung aber ist ein Actus der Spontaneität, d. i. sie kann nicht als zur Sinnlichkeit gehörig angesehen werden. 6) Ich nenne sie die reine Apperception, um sie von der empirischen zu unterscheiden, oder auch die ursprüngliche Apperception, weil sie dasjenige Selbstbewußtsein ist, was, in dem es die Vorstellung Ich denke hervorbringt, die alle andere muß begleiten können, und in allem Bewußtsein ein und dasselbe ist, von keiner weiter begleitet werden kann. 7) Ich nenne auch die Einheit derselben die transscendentale Einheit des Selbstbewußtseins, um die Möglichkeit der Erkenntniß a priori aus ihr zu bezeichnen. 8) Denn die mannigfaltigen Vorstellungen, die in einer gewissen Anschauung gegeben werden, würden nicht insgesamt meine Vorstellungen sein, wenn sie nicht insgesamt zu einem Selbstbewußtsein gehörten, d. i. als meine Vorstellungen (ob ich mich ihrer gleich nicht als solcher bewußt bin) müssen sie doch der Bedingung nothwendig gemäß sein, unter der sie allein in einem allgemeinen Selbstbewußtsein zusammenstehen können, weil sie sonst nicht durchgängig mir angehören würden. 9) Aus dieser ursprünglichen Verbindung läßt sich vieles folgern. (B131-132, Nummierung von mir)

Diese Passage ist argumentativ natürlich sehr dicht. In ihr wird eines der wichtigsten Prinzipien der transzendentalen Deduktion vorgestellt:

(APB) 1) Das: Ich denke, muß alle meine Vorstellungen begleiten können; 2a) denn sonst würde etwas in mir vorgestellt werden, was gar nicht gedacht werden könnte, welches eben so viel heißt als: 2b) die Vorstellung würde entweder unmöglich, 2c) oder wenigstens für mich nichts sein.

Den Kern dieses Prinzips bildet somit eine Relation zwischen zwei Relata, die durch eine verschachtelte Modalität eingeschränkt wird. Die Kernkomponenten dieser im weiteren als „Begleitrelation“ bezeichneten Relation lassen sich wie folgt zusammenfassen:

R1. Alle meine Vorstellungen [kurzum: Meinigkeit] 
R2. Die Vorstellung „ich denke“ [kurzum: Apperzeption]

R3. Die notwendig mögliche Begleitung (aller meiner Vorstellungen) (durch die Vorstellung „Ich denke“) [kurzum: notwendige Begleitungsmöglichkeit]

Die Analyse dieses Prinzips (APB) und der mit ihm zusammenhängenden relevanten Themen bildet den Kerninhalt dieses Kapitels. Wie Cramer gehe ich davon aus, dass dieses Prinzip ,auf eigene[n] Füßen“, d.h. unabhängig von seiner Funktion in der Argumentation der transzendentalen Deduktion, steht. ${ }^{11}$ Der Grund dafür ist einfach dieser: An keiner Stelle vor der oben zitierten Passage (IBD) führt Kant dieses Prinzip aus. Außer den Sätzen 2a), 2b) und 2c) sind alle übrigen Sätze in der Passage (IDB) keine Begründung, sondern entweder Erläuterung und terminologische Bestimmung (5, 6, 7), oder konkrete Anwendung dieses Prinzips (wie die Sätze 3, 4, 8). Der Satz 9 macht explizit, dass Kant im anschließenden Text zur Implikation des Prinzips übergeht. In den übrigen Teilen der B-Deduktion findet man nur Anwendungen, aber keine Begründungen des Prinzips. Folglich scheint Kant davon auszugehen, dass in der Passage (IDB) das Apperzeptionsprinzip ausreichend begründet und erläutert wird.

Aber die Textquellen über das Apperzeptionsprinzip sind damit nicht erschöpft, da es andere Stellen gibt, die wertvollen Aufschluss geben können. Entscheidend ist die Parallelstelle in der A-Deduktion:

(IDA) 1) Alle Vorstellungen haben eine nothwendige Beziehung auf ein mögliches empirisches Bewußtsein: 2) denn hätten sie dieses nicht, und wäre es gänzlich unmöglich, sich ihrer bewußt zu werden, so würde das so viel sagen, sie existirten gar nicht. 3) Alles empirische Bewußtsein hat aber eine nothwendige Beziehung auf ein transscendentales (vor aller besondern Erfahrung vorhergehendes) Bewußtsein, nämlich das Bewußtsein meiner selbst als die ursprüngliche Apperception. 4) Es ist also schlechthin nothwendig, daß in meinem Erkenntnisse alles Bewußtsein zu einem Bewußtsein (meiner selbst) gehöre. 5) Hier ist nun eine synthetische Einheit des Mannigfaltigen (Bewußtseins), die a priori erkannt wird und gerade so den Grund zu synthetischen Sätzen a priori, die das reine Denken betreffen, als Raum und Zeit zu solchen Sätzen, die die Form der bloßen Anschauung angehen, abgiebt. 6) Der

\footnotetext{
${ }^{11}$ Cramer (1987:178).
} 
synthetische Satz: daß alles verschiedene empirische Bewußtsein in einem einigen Selbstbewußtsein verbunden sein müsse, ist der schlechthin erste und synthetische Grundsatz unseres Denkens überhaupt. 7) Es ist aber nicht aus der Acht zu lassen, daß die bloße Vorstellung Ich in Beziehung auf alle andere (deren collective Einheit sie möglich macht) das transscendentale Bewußtsein sei. 8) Diese Vorstellung mag nun klar (empirisches Bewußtsein) oder dunkel sein, daran liegt hier nichts, ja nicht einmal an der Wirklichkeit desselben; 9) sondern die Möglichkeit der logischen Form alles Erkenntnisses beruht nothwendig auf dem Verhältniß zu dieser Apperception als einem Vermögen. (A117 Anm., meine Hervorhebung und Nummierung)

Diese Anmerkung sowie die Passage, die sie enthält (A116-7), gilt wegen ihrer augenscheinlichen Ähnlichkeit als eine Parallelstelle der Passage (IDB). Die A-Version des Apperzeptionsprinzips in dieser Passage lautet:

(APA) 1) Alle Vorstellungen haben eine nothwendige Beziehung auf ein mögliches empirisches Bewußtsein: 2) denn hätten sie dieses nicht, und wäre es gänzlich unmöglich, sich ihrer bewußt zu werden, so würde das so viel sagen, sie existirten gar nicht. 3) Alles empirische Bewußtsein hat aber eine nothwendige Beziehung auf ein transscendentales (vor aller besondern Erfahrung vorhergehendes) Bewußtsein, nämlich das Bewußtsein meiner selbst als die ursprüngliche Apperception. 4) Es ist also schlechthin nothwendig, daß in meinem Erkenntnisse alles Bewußtsein zu einem Bewußtsein (meiner selbst) gehöre.

Die Begründung für das Apperzeptionsprinzip ist neben den Sätzen 2) und 4) in (APA) auch eine Passage im Haupttext in A116:

(AA) Alle Anschauungen sind für uns nichts und gehen uns nicht im mindesten etwas an, wenn sie nicht ins Bewußtsein aufgenommen werden können, sie mögen nun direct oder indirect darauf einfließen, und nur durch dieses allein ist Erkenntniß möglich. (A116, meine Hervorhebung) $)^{12}$

Anscheinend gibt Kant sich auch hier mit einer kürzen Begründung des Prinzips zufrieden. Diese Begründung ist wie in der B-Auflage (siehe den Satz IBD.1) eine Beschreibung der (unmöglichen) erkenntnis- und bewusstseinstheoretischen Situation,

\footnotetext{
${ }^{12}$ Hier ist mit dem Wort „Bewusstsein“ dem Kontext nach das transzendentale Bewusstsein gemeint. Obwohl diese Passage eine direkte Anwendung des Apperzeptionsprinzips auf den Fall der Anschauung ist, enthält sie eine einfache Begründung dieses Prinzips, die aufgrund starker Ähnlichkeit an die Formulierung in B131-2 erinnert.
} 
in der das Prinzip nicht erfüllt ist. Fortan wird dies als „nicht-apperzeptives Szenario“ und eine Vorstellung in diesem Szenario als „nicht-apperzeptive Vorstellung“ bezeichnet. Wie bei der B-Auflage scheint Kant zu glauben, dass diese Beschreibung der negativen Situation unumstritten ist und zur plausiblen Begründung des Prinzips hinreicht. Bei der folgenden detaillierten Analyse des Apperzeptionsprinzips werde ich auf diese hilfreiche Parallelstelle zurückgreifen.

Nun stellt sich jedoch eine Interpretationsfrage: Sollen wir von zwei verschiedenen Versionen des Apperzeptionsprinzips ausgehen? Meines Erachtens eher nicht. Beide Ausführungen des Prinzipis laufen auf dasselbe hinaus: Die Vorstellung des Ich denke muss alle meine Vorstellungen begleiten können. Die A-Version des Apperzeptionsprinzips enthält nämlich alle der oben genannten Kernkomponenten des Apperzeptionsprinzips in der B-Version. Die Begleitrelation ist aus der Ausführung über das Verhältnis zwischen den Vorstellungen und der reinen Apperzeption in A117 Anm. indirekt zu entnehmen:

Alle Vorstellungen haben eine nothwendige Beziehung auf ein mögliches empirisches Bewußtsein. [...] Alles empirische Bewußtsein hat aber eine nothwendige Beziehung auf ein transscendentales (vor aller besondern Erfahrung vorhergehendes) Bewußtsein, nämlich das Bewußtsein meiner selbst als die ursprüngliche Apperception. (A117 Anm.)

Die Meinigkeit wird zwar in (APA) nicht explizit formuliert, ist aber ebenfalls dem kursiven Text im Zitat (AA) zu entnehmen. Obwohl Kant in der A-Version der Ausführung des Apperzeptionsprinzips im Gegensatz zur B-Version die Vorstellung des Ich denke nicht explizit erwähnt, bleibt sie stets relevant, denn er bezeichnet an anderen Stellen der A-Auflage der $K r V$ das Ich denke als „formal[en] Satz der Apperzeption“ (A354, siehe auch A398). Was das Zitat (APA) der Stelle (APB) anscheinend voraushat, ist, dass die Ausführung der Begleitrelation darin auf ein kompliziertes Bewusstseinsmodell angewiesen ist: Jede Vorstellung muss vom empirischen Bewusstsein begleitet werden können, das wiederum eine notwendige 
Beziehung zur transzendentalen Apperzeption hat. Die gleiche Struktur liegt in der Tat auch der B-Version des Apperzeptionsprinzips zugrunde:

[...], weil sie [die ursprüngliche Apperzeption] dasjenige Selbstbewußtsein ist, was, in dem es die Vorstellung: Ich denke, hervorbringt, die alle andere muß begleiten können und in allem Bewußtsein ein und dasselbe ist, von keiner weiter begleitet werden kann (B132)

In den folgenden Ausführungen gehe ich davon aus, dass beide Versionen des Apperzeptionsprinzips wesentlich gleich sind, weswegen die Analyse dieses Prinzips unter Zuhilfenahme der Parallelstelle in der A-Version erfolgen kann.

\subsection{Erster Eindruck und Interpretationsfragen}

Wir beginnen mit dem Apperzeptionsprinzip in der B-Version (APB). Übersichtshalber wird es nochmals zitiert:

1) Das: Ich denke, muß alle meine Vorstellungen begleiten können;

2a) denn sonst würde etwas in mir vorgestellt werden, was gar nicht gedacht werden könnte, welches eben so viel heißt als:

2b) die Vorstellung würde entweder unmöglich,

2c) oder wenigstens für mich nichts sein.

Die Argumentation in dieser Passage ist äußerst dicht. Wir können anhand Kants Formulierung die inneren Verhältnisse zwischen den Sätzen teilweise bestimmen, was für unsere weitere Arbeit eine gute Orientierung bietet:

T1. Die mögliche Begleitung des Ich denke ist eine notwendige Bedingung dafür, dass eine Vorstellung gedacht wird. (aus 1 und 2a)

T2. Gedachtwerden ist äquivalent zu „möglich“ und „für mich etwas“. (aus 2a, 2b und 2c) 
Unklar bleibt jedoch, wie diese beiden Thesen begründet werden sollen. Außerdem sind viele Begriffe in diesem Prinzip zwar auf den ersten Blick verständlich, aber nicht klar und präzise anhand der Passage (APB) sowie der Parallelstelle zu bestimmen. Es stellen sich hinsichtlich des (APB) folgende Fragen:

F1. Wie qualifizieren sich Vorstellungen als „meine Vorstellungen“? Ist die Begleitung des „Ich denke" eine notwendige Bedingung der Meinigkeit "meiner Vorstellungen“ oder eher eine Bedingung dafür, dass die bereits zu mir gehörigen Vorstellungen zusätzlich „gedacht" werden?

F2. Was bedeutet die verschachtelte Modalität „begleiten können muss“?

F3. Was ist „in mir"? Was ist der Unterschied zwischen „in mir" und der Meinigkeit meiner Vorstellungen?

F4. Was heißt "unmöglich" und „für mich nichts"? Warum ist eine nicht gedachte Vorstellung unmöglich oder für mich nichts?

Wie schon erwähnt, ist die Ausführung des Apperzeptionsprinzips in der A-Auflage auf eine Zweiteilung der Bewusstseinsstruktur angewiesen: Alle Vorstellungen müssen vom empirischen Bewusstsein begleitet werden können; dieses enthält wiederum einen notwendigen Bezug auf die transzendentale Apperzeption. Diese Bewusstseinsstruktur muss genau analysiert werden, also erhalten wir eine weitere zu erörternde Frage:

F5. Was ist unter der Bewusstseinsstruktur zu verstehen?

Die wichtigste Frage ist jedoch selbstverständlich diejenige danach, wie das Apperzeptionsprinzip, also der Satz (1) im (APB), zu verstehen und zu begründen ist. In den folgenden Kapiteln werde ich nacheinander auf diese Fragen eingehen. 


\section{3. „Vorstellungen“, „Vorstellungen in mir“ und „meine}

\section{Vorstellungen“"}

Eine Vorstellung ist nach Kant, wie bereits erwähnt, „,nichts anderes, als wenn sich in meiner Seele etwas befindet, was mit der vorgestellten Sache eine Ähnlichkeit hat““ (Logik Bauch, S. 30) oder eine „Bestimmung der Seele, die sich auf andere Dinge bezieht“ (Refl 16:76f.). „Vorstellung bedeutet eine Bestimmung in uns, die wir auf etwas Anderes beziehen (dessen Stelle sie gleichsam in uns vertritt)“ ( $\mathrm{Br} 11: 395)$. In der Logik Blomberg sagt Kant, dass „sich eine Vorstellung wie ein Bild verhalte, welches die mahlerische Geschicklichkeit der Seele in ihrem innwendigen zeichnet.“(V-Lo/Blomberg 24:40) „[J]ede Vorstellung ist etwas in uns, das aber sich beziehet auf etwas anderes, welches das Object ist" (V-Lo/Blomberg 24:40, siehe auch V-Lo/Philippi 24:340). Eine Vorstellung gehört sozusagen als eine „Bestimmung[] des Gemüths [...] zum innern Zustande“(A34/B50), der durch seine Strukturähnlichkeit mit einem Gegenstand diesen repräsentiert. Eine Bestimmung eines Dings ist ein „reales“ Prädikat (BDG 2:72, A571f./B599f.). Dieses ist ein Prädikat, das man diesem Ding zuschreiben kann und das ,über den Begriff des Subjects hinzukommt und ihn vergrößert“(A598/B626). Eine „Bestimmung der Seele“ kann folglich ein Zustand, eine Eigenschaft oder eine Handlung der Seele sein. Als ein „Etwas“ in der Seele kann eine Vorstellung auch einen Bestandteil der Seele bedeuten. Welchen ontologischen Status eine Bestimmung der Seele hat, ist jedoch sehr schwierig zu bestimmen. Kant will diese Frage offensichtlich offenlassen. Fortan bezeichne ich, wie viele Interpreten, einfachheitshalber die Vorstellung als „Zustand“ der Seele oder des Gemüts, denn alle anderen Kandidaten können im weiten Sinn als Zustand der Seele betrachtet werden. Übrigens muss die Vorstellung immer einen intentionalen Gegenstand haben. Dieser Gegenstand muss nicht die Objektivität in vollem Umfang besitzen, sonst würden Tiere 
keine Vorstellung haben können. Kant spricht aber zumindest manchen Tieren explizit die Fähigkeit der Vorstellung zu (V-Met-L1/Pölitz 28: 276ff.).

\subsubsection{Etwas ,in mir“ vorstellen}

Zuerst untersuchen wir die genaue Bedeutung des Ausdrucks „etwas in mir [vorstellen]“, weil dieser im Vergleich zu anderen Begriffen leichter zu bestimmen ist. Der Ausdruck „,in mir“ ist offensichtlich mit den Ausdrücken „in meiner Seele“ sowie „meinem Gemüt“ verwandt. Der Ausdruck „etwas in mir vorstellen“ bedeutet entsprechend „etwas in meiner Seele vorstellen“. Dies bedeutet wiederum gemäß der obigen Definition der Vorstellung, etwas durch die Bestimmung meiner Seele vorzustellen. Das heißt, dass die Bestimmung meiner Seele durch ihre strukturelle Ähnlichkeit einen Gegenstand repräsentiert. Diese Auslegung lässt sich in diesen Passagen exakt bestätigen:

Nun drückt selbst diese Vorstellung, daß alle diese Erscheinungen, mithin alle Gegenstände, womit wir uns beschäftigen können, insgesammt in mir, d.i. Bestimmungen meines identischen Selbst sind, eine durchgängige Einheit derselben in einer und derselben Apperception als nothwendig aus. (A129, meine Hervorhebung)

[...] alle Bestimmungsgründe meines Daseins, die in mir angetroffen werden können $[\ldots](\mathrm{BXXXIX,Anm.)}$

Nun ist ein möglicher Einwand zu untersuchen. Cramer zufolge gibt es zwei mögliche Auslegungen des Ausdrucks „etwas in mir vorstellen“ (Cramer 1987:181f.). Erstens könnte Kant damit den Eigentümer der Vorstellung betonen. Demnach will Kant hervorheben, dass ich etwas in mir und nicht in einem anderen vorstelle. Diese Interpretation ist allerdings unangebracht oder zumindest unpräzise, weil die Möglichkeit der Fremdzugehörigkeit im Kontext des Apperzeptionsprinzips 
(zumindest aus der Perspektive der dritten Person) ${ }^{13}$ gar nicht thematisiert wird und mithin irrelevant ist. Deppermann meint, der Ausdruck „in mir“ gibt eher den Ort der Vorstellung an: „es handelte sich also um Vorstellungen, die im Subjekt anzutreffen sind, ohne deshalb jedoch schon Vorstellungen für das Subjekt zu sein“ (Deppermann 2001:137). Der Ausdruck „in mir“ ist natürlich metaphorisch, weil das Subjekt nicht räumlich ist. Mit der oben zitierten Bemerkung erklärt Deppermann jedoch nur die Implikation des Ausdrucks „in mir“, nicht die eigentliche Bedeutung desselben. Sie lässt die Metapher völlig unerklärt.

Cramer (1987:181f.) selbst bevorzugt die Auffassung, dass die Wörter „etwas in mir“ im Ausdruck „etwas in mir vorstellen“ zusammengehören und ein mentales Ereignis oder einen mentalen Zutand bezeichnen. Demnach bedeutet der Ausdruck in dem Kontext des Apperzeptionsprinzips, einen Vorstellungszustand als Gegenstand vorzustellen (Cramer 1987: 182, 184). „Etwas in mir wird vorgestellt“ bedeutet entsprechend ungefähr: Ich stelle vor, dass ich eine Vorstellung [= „etwas“] habe [=,,in mir"]. (Cramer: 1987:185). Cramers Interpretation ist zu verwerfen. Wenn sie nämlich richtig wäre, wäre die erste Hälfte des APB so zu paraphrasieren:

(CAPB) Die mögliche Begleitung des Ich denke ist für meine Vorstellung deswegen wichtig, weil sonst der Vorstellungszustand zwar vorgestellt würde, aber nicht gedacht werden könnte.

Einen Vorstellungszustand bloß vorzustellen, aber nicht zu denken, kann nach Kants Terminologie des Bewusstseins nur eine Vorstellung des inneren Sinns an sich sein, die frei von jeglichen Verstandesleistungen ist. (CAPB) zufolge ist es denkbar, dass eine Vorstellung, die die Bedingung der transzendentalen Apperzeption nicht erfüllt, vom inneren Sinn begleitet werden kann. Diese Möglichkeit ist nicht nur explizit von Kants

\footnotetext{
${ }^{13}$ Die Formulierung „denn sonst würde etwas in mir vorgestellt werden“ in APB thematisiert eine bewusstseinstheoretische Situation aus der Perspektive der dritten Person anstatt aus der der ersten Person.
} 
berühmten und viel zitierten Brief an Herz ( $\mathrm{Br} 11: 52,1789)$ ausgeschlossen. Es gibt weitere exegetische und sachliche Gründe gegen die These, dass man sich seinen mentalen Zustand rein sinnlich, d.h. ohne begriffliche Mittel, vorstellen kann. Die Vorstellung eines Vorstellungszustands muss einen Bezug auf das Subjekt enhalten. Wenn man sich vorstellt, dass man sich in einem Vorstellungszustand befindet, dann muss man sich dabei auf sich selbst beziehen. Ohne diesen Bezug kann man einen Vorstellungszustand nicht vorstellen. Denn ein Vorstellungszustand ist eine Relation zwischen dem Subjekt und einem Gegenstand. Diese Relation und der Bezug auf das Subjekt kann nur begrifflich, nicht aber sinnlich vorgestellt werden. Außerdem ist der Vorstellungszustand an sich nichts Wahrnehmbares. Kant lässt zwar zu, dass man durch den inneren Sinn seine inneren Zustände wahrnehmen kann, aber er sagt auch, dass die Vorstellungen äußerer Sinne „den eigentlichen Stoff“ ausmachen, „womit wir unser Gemüth besetzen“ (B67, BXXXIX Anm.). Die inneren Zustände liefern selbst keine speziellen Eindrücke durch den inneren Sinn. Man muss die Eindrücke des äußeren Sinnes in Wahrnehmungen des inneren Zustands umdeuten (siehe §2.5). Das heißt, man muss die äußeren Wahrnehmungen als „meine Vorstellungen“ umdeuten. Diese Umdeutung setzt Denken und reine Apperzeption voraus. Ich gehe folglich davon aus, dass Cramers Lesart unzutreffend ist.

Die passendere Interpretation lautet meines Erachtens wie folgt: Eine Vorstellung kann in dem Sinn als ,,in mir“" oder ,im Subjekt“ bezeichnet werden, als es sich bei ihr um eine Bestimmung bzw. einen Zustand der Seele handelt. Es gibt dazu jedoch ein Problem. Eine Vorstellung ist der Definition zufolge eine Bestimmung der Seele, die etwas repräsentiert. Wenn der Ausdruck „,in mir vorstellen“ wirklich „durch eine Bestimmung meiner Seele vorstellen“ bedeutet, dann fügt der Ausdruck ,in mir“ dem Begriff Vorstellung nichts Neues hinzu und ist keine echte Einschränkung. „Eine Vorstellung in mir“" wäre äquivalent zu „eine Vorstellung“. Was will Kant dann mit der räumlichen Metapher ,in mir“ ausdrücken? Meines Erachtens dient diese Metapher 
dazu, einen speziellen Aspekt der Vorstellung hervorzuheben. Nach Satz 1 im (APB) enthält der Zustand, etwas in mir vorzustellen, per definitionem nicht den kognitiven Akt, diesen Gegenstand zu denken. Ansonsten wäre die Rede vom möglichen Szenario, wo etwas in mir vorgestellt wird, was gar nicht gedacht werden kann, gar nicht sinnvoll. Also muss es möglich sein, dass etwas vorgestellt aber nicht gedacht wird. In der Tat kann man über eine Vorstellung verfügen, ohne sich dessen bewusst zu sein. ${ }^{14}$ Weil eine Bestimmung der Seele nicht automatisch bewusst wird, ist eine Vorstellung in mir nicht notwendig eine Vorstellung für mich bzw. „für das Subjekt“. Im $§ 1.4$ wird diese These ausführlich behandelt. An dieser Stelle soll nur das präsentiert werden, was für die Begriffsklärung wesentlich und relevant ist. Dunkle Vorstellungen sind diejenigen Vorstellungen, die man zwar hat, aber derer man sich nicht direkt bewusst ist. Man kann sich solcher Vorstellungen nur auf indirektem Wege, etwa durch Schlussfolgerung, bewusst werden (Anth 7:134-5). Einige Zitate über die dunkle Vorstellung belegen wörtlich, dass die dunklen Vorstellungen zwar „in mir“ oder „,in meiner Seele“ sind, aber nicht gedacht oder bewusst werden:

Klarheit ist nicht, wie die Logiker sagen, das Bewußtsein einer Vorstellung; denn ein gewisser Grad des Bewußtseins, der aber zur Erinnerung nicht zureicht, muß selbst in manchen dunkelen Vorstellungen anzutreffen sein (B414 Anm., meine Hervorhebung).

Wenn das Vermögen sich bewußt zu werden das, was im Gemüthe liegt, aufsuchen (apprehendiren) soll, (B68)

[...] den in mir noch dunkel liegenden Begrif zu entwikeln [...] (Refl 18:64).

[...] durchs Gebet die in der Seele vorhandenen dunkeln und verworrenen Vorstellungen deutlicher gemacht [...] (Refl 19:637)

Es gibt folglich Vorstellungen, derer man sich nicht bewusst ist und die nicht gedacht werden, über die man jedoch sagen kann, dass sie in der Seele vorhanden sind - d.h., dass sie faktische Zustände der Seele sind. Ein mentaler Zustand ist schon dann eine

\footnotetext{
${ }^{14}$ Wohlgemerkt schließt dies nicht aus, dass man sich dieser Vorstellung irgendwann bewusst werden kann.
} 
Vorstellung, wenn er durch seine Ähnlichkeit einen Gegenstand repräsentiert. Gilt dies für diesen mentalen Zustand, dann ist eine Vorstellung „,in der Seele“ oder „,in mir“ vorhanden, und mehr wird nicht verlangt. Die Ausdrücke ,in der Seele“ oder „,in mir“" heben gerade ein derartiges ,unsichtbares“"Vorhandensein der Vorstellung hervor. Mit dem Satz ,denn sonst würde etwas in mir vorgestellt werden, was gar nicht gedacht werden könnte“ im (APB) will Kant gerade ausschließen, dass eine Vorstellung, die als Bestimmung der Seele vorhanden ist, aber nicht gedacht werden kann, als „meine“ Vorstellung zu bezeichnen ist.

Zu Kants Terminologie ist noch eine weitere Bemerkung vonnöten: der Ausdruck ,eine Vorstellung haben“ ist synonym zu dem Ausdruck „eine Vorstellung in mir/in meiner Seele“. Der Erstere bezeichnet, genauso wie der Letzere auch dunkle Vorstellungen (Anth 7:135). Somit bezeichnen beide Ausdrücke den Sachverhalt, dass eine Vorstellung als Zustand des Subjekts faktisch präsent ist, egal ob sie bewusst oder nicht bewusst ist.

\subsection{2. „Meine Vorstellung“}

Nun stellt sich die Frage, was „meine Vorstellungen“ im Satz 1 des (APB) bedeutet. Zunächst ist es wichtig, das Verhältnis zwischen der möglichen Begleitung der Vorstellung des „Ich denke“ und der Meinigkeit zu klären. Ist eine Vorstellung erst dann „,meine Vorstellung“, wenn sie von der Vorstellung „Ich denke“ begleitet werden kann, oder ist sie unabhängig von der möglichen Begleitung schon aus anderen Gründen „meine Vorstellung“'? Cramer behandelt die zweite Möglichkeit als eine ernsthaft $\mathrm{zu}$ überlegende Lesart. ${ }^{15} \mathrm{Ihm}$ zufolge ist eine Vorstellung „meine

\footnotetext{
15 Cramer (1987:179f.).
} 
Vorstellung“, wenn ich mir vorstelle, dass ich sie habe oder sie ,in mir“ oder „meine“ sind. Diese Selbstzuschreibung setze nicht die Begleitung des Ich denke voraus. Das Ich denke garantiere etwas Anderes. ${ }^{16}$ Ich bin der Meinung, dass diese Lesart aus textuellen und sachlichen Gründen einfach auszuschließen ist. Erstens gibt es, wie bereits argumentiert, keine nicht-begriffliche Selbstzuschreibung einer Vorstellung. Jede Selbstzuschreibung geschieht durch die Begleitung der zugeschriebenen Vorstellung durch die Vorstellung des „Ich denke“. ${ }^{17}$ Zweitens sagt Kant schon in der Passage (IDB) selbst:

APB-8) [D]ie mannigfaltigen Vorstellungen, die in einer gewissen Anschauung gegeben werden, würden nicht insgesammt meine Vorstellungen sein, wenn sie nicht insgesamt zu einem Selbstbewußtsein gehörten, d.i. als meine Vorstellungen (ob ich mich ihrer gleich nicht als solcher bewußt bin) müssen sie doch der Bedingung nothwendig gemäß sein, unter der sie allein in einem allgemeinen Selbstbewußtsein zusammenstehen können, weil sie sonst nicht durchgängig mir angehören würden (B132-3)

Eine Vorstellung ist erst dann meine, wenn sie mit anderen Vorstellungen in mir zu einem Selbstbewusstsein gehört. Dies bedeutet gerade, dass sie mit anderen von einem identischen „Ich denke“ begleitet werden kann (siehe den Satz 6 in IDB bzw. B132). Daher ist die mögliche Begleitung des „Ich denke“ die notwendige Bedingung der Meinigkeit von „meinen Vorstellungen“. Eine Vorstellung ist erst dann meine Vorstellung, wenn sie vom Ich denke begleitet werden kann. Im anschließenden Text schreibt er sogar: ,als meine Vorstellungen (ob ich mich ihrer gleich nicht als solcher bewußt bin)“(B132). Offensichtlich ist es für die Meinigkeit meiner Vorstellung nicht nötig, dass ich mir explizit vorstelle, dass diese Vorstellung in mir ist bzw. meine ist. Der erste Satz des (APB) kann demnach so paraphrasiert werden:

\footnotetext{
${ }^{16}$ Cramer (1987: 186).

17 Die Vorstellung „Ich denke“ kann klar oder dunkel sein (A117 Anm.). Dazu mehr siehe §1.5. Zugegebenerweise weist Cramer aus anderen Gründen selbst die zweite Option zurück.
} 
(APB 1') Vorstellungen sind nur dann „meine Vorstellungen“, wenn die Vorstellung „Ich denke" sie begleiten können.

Meine Vorstellungen gehören genau dann zu mir, wenn ich sie durch die Vorstellung des Ich denke als meine vorstellen kann. Oder anders gesagt, sie sind meine, wenn ich sie mir selbst zuschreiben kann. Nebenbei bemerkt, lässt sich durch diese Paraphrase die verschachtelte Modalität in der Formulierung „Das: Ich denke, muß alle meine Vorstellungen begleiten können“" wegerklären. Ihr zufolge drückt das Wort „muß“ keine Notwendigkeit aus, sondern nur, dass die Möglichkeit der Begleitung eine notwendige Bedingung dafür ist, dass eine Vorstellung überhaupt zu mir gehört. Oder anders gesagt, der Satz APB1 mit dem Wort „muß“ drückt insgesamt implizit einen konditionalen Satz aus, der keine verschachtelte Modalität enthält.

Die These APB 1' gibt jedoch nur eine notwendige Bedingung dafür an, dass eine Vorstellung zu mir gehört. Der tiefe Grund der Meinigkeit einer Vorstellung bleibt unaufgeklärt, wenn man die Meinigkeit damit gleichsetzt, dass diese Vorstellung durch das Ich denke begleitet werden kann. Die genaue Bedeutung der Meinigkeit wird in der Tat durch den Satz 2) des (APB) angegeben. Der Satz 2) beschreibt nämlich die Konsequenz des Falls, dass das Ich denke eine Vorstellung nicht begleiten kann und diese folglich nicht als „meine Vorstellung“ gilt: Die Vorstellung kann nicht gedacht werden. Dies wird weiterhin in den Sätzen 2b) und 2c) des (APB) dadurch erklärt, dass die nicht zu denkenden Vorstellungen ,entweder unmöglich, oder für mich nichts“ wären. Das Gegenteil dieser Konsequenz zeigt gerade, was die „Meinigkeit“" meiner Vorstellungen in sich enthält: Sie können von mir gedacht werden. Dies bedeutet gemäß 2b) und 2c): Eine Vorstellung, soweit sie möglich ist, ist etwas für mich. Wir haben also folgende Zwischenbilanz:

(MV3) Nur wenn eine Vorstellung gedacht werden kann, ist sie meine. Dass eine Vorstellung gedacht werden kann, bedeutet „eben so viel“ wie: Die Vorstellung ist für mich etwas, soweit sie möglich ist. 
Wir müssen nunmehr die einzelnen Momente der Meinigkeit genauer untersuchen. Zunächst gehen wir zu Kants Erläuterung der Meinigkeit über, und zwar zu den Sätzen 2b) und 2c). Die Bedeutung des Satzes 2a) werden wir später behandeln. Übersichtshalber wird die relevante Passage nochmals zitiert:

(APB) 2a) denn sonst würde etwas in mir vorgestellt werden, was gar nicht gedacht werden könnte, welches eben so viel heißt, 2b) als die Vorstellung würde entweder unmöglich, oder 2c) wenigstens für mich nichts sein (B131-2).

Der Fall 2b) ist relativ unumstritten und unproblematisch. Es handelt sich dabei um das „Unding“, d.h. um einen (unmöglichen) Gegenstand, dessen Vorstellung wegen eines logischen Widerspruchs „sich selbst aufhebt““(A292/B348). ${ }^{18}$ Damit erübrigt sich die Frage, ob diese Vorstellung überhaupt gedacht werden kann. Wir können also den Fall 2b) bei weiterer Untersuchung außer Acht lassen, weil er für die Frage irrelevant ist, warum nicht-apperzeptive Vorstellungen, die auf jeden Fall existieren und nicht „unmöglich“ sind, nicht „meine Vorstellungen“ sind - schließlich handelt es sich im Fall 2b) gar nicht um eine Vorstellung. Wenn man nun fragt, warum eine Vorstellung meine Vorstellung ist, dann ergibt sich die Antwort: „Meine“ Vorstellungen sind diejenigen, die für mich etwas sind. Die Begriffe „meine“ und „für mich“ erweisen sich folglich als äquivalent und müssen von dem Begriff ,in mir“ unterschieden werden. ${ }^{19}$ Der Fall 2c) gibt für die Frage der Meinigkeit eine klare Antwort: Die nicht zu denkenden Vorstellungen haben für mich keine Bedeutung. Kants Formulierung „für mich nichts" ist an sich jedoch hoffnungslos mehrdeutig. Bedeutet sie, dass solche Vorstellungen keine Bedeutung „für mich“ als Erkenntnissubjekt, als handelnde Person, oder gar als Lebewesen haben? Oder will Kant mit der Formulierung „für mich nichts“ vielmehr, wie Cramer vorschlägt, ausdrücken, dass man sich einer Vorstellung

\footnotetext{
${ }^{18}$ Klemme (1996:187) zufolge kann damit auch ein Gegenstand gemeint sein, der die Forderung der transzendentalen Ästhetik nicht erfüllt.

${ }^{19} \mathrm{Zu}$ demselben Ergebnis kommt auch Deppermann (2001:135).
} 
gar nicht bewusst sein kann? Die Parallelstelle in der A-Version gibt jedoch einen wertvollen Aufschluß darüber. Bezüglich der nicht-apperzeptiven Anschauungen sagt Kant, sie „sind vor uns nichts, und gehen uns nicht im mindest etwas an“(A116). In einer anderen Stelle der A-Deduktion bemerkt Kant ebenfalls zu nicht-apperzeptiven Anschauungen, dass sie „niemals Erkenntnis, also für uns so viel als gar nichts“ wären (A111). Die nicht-apperzeptiven Vorstellungen sind „ohne Objekt, und nichts als ein blindes Spiel der Vorstellungen, d.i. weniger, als ein Traum.“(A112). Dem Kontext nach kann dies nur bedeuten, dass nicht-apperzeptive Vorstellungen für uns keine epistemische Bedeutung haben. In dem berühmten Brief an Herz gibt Kant explizit eine Stellungnahme zu solchen nicht-apperzeptiven Vorstellungen:

Ich würde gar nicht einmal wissen können, daß ich sie habe, folglich würden sie für mich, als erkennendes Wesen, schlechterdings nichts seyn, wobey sie (wenn ich mich in Gedanken zum Thier mache) als Vorstellungen, die nach einem empirischen Gesetze der Association verbunden wären und so auch auf Gefühl und Begehrungsvermögen Einflus haben würden, in mir, meines Daseyns unbewust, (gesetzt daß ich auch jeder einzelnen Vorstellung bewust wäre, aber nicht der Beziehung derselben auf die Einheit der Vorstellung ihres Obiects, vermittelst der synthetischen Einheit ihrer Apperception,) immer hin ihr Spiel regelmäßig treiben können, ohne daß ich dadurch in mindesten etwas, auch nicht einmal diesen meinen Zustand, erkennete. (Br 11:51-52, 1789, meine Hervorhebung)

Der erste Satz bekräftigt, dass der Ausdruck „nichts für mich“ auf den epistemischen Wert der Vorstellung beschränkt ist, denn diejenigen Vorstellungen, die „für mich nichts“ sind, können durchaus vermittels einfacher, nichtbegrifflicher Verbindungen kausalen Einfluß auf nicht-kognitive Aspekte meines Lebens ausüben. Das heißt, diese Vorstellungen sind nicht „nichts“ aus anderen Perspektiven. Dadurch ist auch die Relation zwischen „,nicht gedacht werden [kann] “ und „für mich nichts“ verständlich. Eine Vorstellung, die nicht gedacht werden kann, ist deswegen „für mich nichts“, weil sie für mich als diskursiv erkennendes Wesen keine epistemische Bedeutung hat. Zusammengefasst bedeutet dies: Eine Vorstellung ist genau dann meine, wenn sie gedacht werden kann und somit für mich epistemische Bedeutung hat. 
Für Meinigkeit muss jedoch noch eine weitere, fundamentale Bedingung erfüllt werden. Die Vorstellungen müssen nämlich zu einem über die Zeit hinweg numerisch identischen Ich gehören, weil „sie sonst nicht durchgängig mir angehören würden“ (B133). Anders gesagt, muss die „durchgängige Identität der Apperzeption“ bewahrt werden (B133), „sonst würde ich ein so vielfärbiges verschiedenes Selbst haben, als ich Vorstellungen habe, deren ich mir bewußt bin“ (B134). Das heißt, nur wenn ein identisches Ich-Bewusstsein bewahrt wird, kann man von der Meinigkeit sprechen. Kants Doktrin der Identität des Selbstbewusstseins bildet wegen seiner Unklarheit und Verwickeltheit ein separates Forschungsthema, auf das ich an dieser Stelle nicht eingehen kann. Weniger kontrovers ist jedoch die folgende Beobachtung: Das Bewusstsein der Identität des Subjekts wird nicht durch die Identität des repräsentationalen Gehalts des Begriffs Ich garantiert. Das Ich ist nämlich eine „einfache und für sich selbst an Inhalt gänzlich leere Vorstellung [...] von der man nicht einmal sagen kann, daß sie ein Begriff sei, sondern ein bloßes Bewußtsein, das alle Begriffe begleitet.“ (B404) Es gibt auch kein wahrnehmbares inneres Beharrliches, auf dem die Identität des Ich basieren könnte. Kants Lösung besteht darin, das Bewusstsein der Identität des Subjekts dadurch zu garantieren, dass das Selbstbewusstsein selbst über die Zeit hinweg, d.h. in verschiedenen Bewusstseinsepisoden, unverändert bleibt. Kants Ausführung sieht so aus: Eine Vorstellung ist meine Vorstellung, wenn sie mit allen anderen in einem Selbstbewußtsein (= die reine Apperzeption, vgl. B132) vereinigt werden kann (vgl. auch B134). Auf dem ersten Blick ist der Begriff des Vereinigens metaphorisch und der des Selbstbewusstseins unklar. Aber Kant gibt in der Tat einen klaren Hinweis auf den bewusstseinstheoretischen Status der reinen Apperzeption: Dieses Selbstbewusstsein ist nicht die Vorstellung „Ich denke“, sondern „dasjenige Selbstbewußtsein [...] was, indem es die Vorstellung Ich denke hervorbringt, die alle andere muß begleiten können, und in allem Bewußtsein ein und dasselbe ist“ (B132). Die reine Apperzeption ist nicht gleich der Vorstellung des Ich denke, 
sondern eine Art des Selbstbewusstseins, das die Vorstellung des Ich denke bewirken kann. Dieses Selbstbewusstsein ist sozusagen verantwortlich für den Akt der Selbstzuschreibung. Es bleibt numerisch identisch über die Zeit hinweg. Als Zwischenbilanz erhalten wir somit folgende These:

(MV2) Eine Vorstellung ist "meine“, wenn sie ein über die Zeit hinweg identisch bleibendes Selbstbewusstsein begleiten kann, das einen Akt der Selbstzuschreibung die Vorstellung des Ich denke - bewirken kann.

Nun sind wir in der Lage, die Frage nach dem Verhältnis zwischen meinen Vorstellungen und den Vorstellungen (in mir) $\mathrm{zu}$ behandeln. ${ }^{20}$ Sind nicht alle Vorstellungen (in mir) meine Vorstellungen? Gibt es Vorstellungen, die nicht vom Ich denke begleitet werden können und die ich mir selbst nicht zuschreiben kann? Die AVersion des Apperzeptionsprinzips schließt solche Vorstellungen aus, weil es für ,alle Vorstellungen“" gilt (siehe APA). Über die Vorstellungen, die nicht vom empirischen und mithin auch transzendentalen Bewusstsein begleitet werden können, bemerkt Kant dort, „sie existierten gar nicht“. In den Ausführungen der B-Version des Apperzeptionsprinzips und in späteren Stellungnahmen ist Kants Position jedoch zurückhaltender. Er bezeichnet solche Vorstellungen als „unmöglich, oder wenigstens für mich nichts“ in (APB). Die zweite Möglichkeit scheint zu implizieren, dass einige von diesen Vorstellungen zwar keinen epistemischen Sinn für mich haben, aber durchaus möglich sind. Zudem spricht Kant in einigen Stellen über den Tiergeist (siehe den Brief an Herz 1789 und Log 9:64f.) explizit von unapperzeptiven Vorstellungen (siehe §2.2.2.). Meines Erachtens ist es kaum plausibel, die Existenz von Vorstellungen zu leugnen, die zwar keine epistemische Bedeutung, aber doch einen kausalen Einfluß auf das Verhalten und Gefühl haben. Daher gehe ich davon aus, dass Kants spätere Stellungnahme eher seine reife Position widerspiegelt. Kurzgefasst: „Meine“ Vorstellungen sind nicht notwendigerweise alle Vorstellungen in meiner Seele;

\footnotetext{
${ }^{20}$ Wie schon dargelegt, sind die Begriffe „Vorstellungen in mir“ und „Vorstellungen“ synonym.
} 
„meine“ Vorstellungen sind Vorstellungen, die durch mein Selbstbewusstsein begleitbar sind. Meine Vorstellungen sind sozusagen nur eine Teilmenge der Vorstellungen (,in mir“ oder ,,in meiner Seele“). Damit erweist sich eine weitere, nur scheinbar plausible Interpretation des Satzes 1 im APB als falsch:

Es kann keine Vorstellung in mir geben, die nicht vom Ich denke begleitet werden kann. ${ }^{21}$

Am Ende dieses Abschnitts sollten wir eine berühmte und berüchtigte Zweideutigkeit aufklären: Der Begriff der Vorstellung in dem Ausdruck „meine Vorstellungen“ kann nicht nur den Vorstellungszustand selbst, sondern auch das Vorgestellte, d.h. den repräsentationalen Gehalt des Vorstellungszustands, bedeuten (B129, 137; KU 5:217, 219). Was aber bedeutet dann der Begriff „meine Vorstellungen“ genau? Ist damit „meine Vorstellungszustände“ oder eher „die Gegenstände, die ich vorstelle“ gemeint? Natürlich kann man sachliche Überlegungen darüber vorbringen, welche Lesart zutreffender ist. Aber wegen der komplexen Textlage muss eine sachliche Herangehensweise sehr kompliziert sein und von vielen umstrittenen Aspekten des Originaltexts abhängen (siehe Cramer 1987: §3). Die Textlage zeigt: Kant selbst ist sich hierüber nicht im Klaren. Die Ausführung des Apperzeptionsprinzips in der B-Auflage spricht zwar eindeutig für die erste Lesart. So schreibt Kant zum Beispiel: ,indem es die Vorstellung Ich denke hervorbringt, die alle andere [Vorstellungen] muß begleiten können“ (B132). Die erste Erwähnung von „Vorstellung“ bedeutet alternativlos „Vorstellungszustand“, denn die andere Option hat hier keinen Sinn. Der Ausdruck „alle andere“ deutet an, dass beide Erwähnungen des Wortes „Vorstellung“ die gleiche Bedeutung haben. Außerdem ist die zweite Lesart kaum mit einer Stelle in IDB vereinbar: ,als meine Vorstellungen (ob ich mich ihrer gleich nicht als solcher bewußt bin) müssen sie $[\ldots]$ in einem allgemeinen Selbstbewußtsein zusammenstehen

\footnotetext{
${ }^{21}$ Für eine ähnliche Position siehe auch Cramer (1987: 176).
} 
können“(B132). An anderer Stelle jedoch finden sich Gegenbeispiele. Das auffälligste ist wohl das folgende: „[Die Vorstellung des] Ich denke, welche sogar alle transscendentale Begriffe möglich macht, in welchen es heißt: Ich denke die Substanz, die Ursache etc.“ (B401). Demnach begleitet das Ich denke nicht den Vorstellungszustand, sondern den Vorstellungsgehalt. Meiner Meinung nach hat Kant selbst die Worte „Vorstellung“ und „,begleiten“ zweideutig benutzt, weil wir der Sache nach für den Fall des expliziten Selbstbewusstseins in beiden Sinnen von Begleitung und Vorstellung sprechen können, d.h. für den Fall, dass der Gedanke „Ich denke“ eine Vorstellung bewusst begleitet. Erstens muss der propositionale Gehalt „Ich denke“ in diesem Fall mit dem propositionalen oder begrifflichen Gehalt der gegenstandsbezogenen Vorstellung verbunden werden. ${ }^{22}$ In diesem Sinne begleitet der Vorstellungsgehalt des Ich denke den Vorstellungsgehalt meiner gegenstandsbezogenen Vorstellung. Zweitens steht man in der Tat in zwei Vorstellungszuständen: Man stellt sowohl den Gegenstand durch den propositionalen Gehalt im von „Ich denke“ eingeleiteten Satz, als auch den Vorstellungszustand durch die Vorstellung des „Ich denke“ vor. In diesem Sinne kann man sagen, dass das Ich denke meinen (gegenstandsbezogenen) Vorstellungszustand begleitet. Ich würde behaupten, dass von diesem Punkt nicht viel abhängt, sofern man je nach Kontext die passende Bedeutung bestimmt.

In der B-Version der transzendentalen Deduktion operiert Kant mit der Vorstellung „Ich denke“, um die Bedingung der Zu-Mir-Gehörigkeit anzugeben, in der A-Version jedoch hauptsächlich mit dem Begriff des empirischen und des transzendentalen

${ }^{22}$ Fortan nenne ich generell diejenigen Vorstellungen „gegenstandsbezogen“ oder „Vorstellungen ersterer Ordnung“, die von der apperzeptiven Vorstellung höherer Ordnung begleitet werden. Die gegenstandsbezogenen Vorstellungen sind diejenigen, die Informationen über äußere oder innere Sachverhalte liefern und deren Gehalt durch synthetische Handlungen zur Erfahrung gemacht werden können. Die begleitenden Vorstellungen (die Apperzeption tout court) machen die gegenstandsbezogenen Vorstellungen apperzeptiv bewusst. 
Bewusstseins, sowie mit dem Begriff des Bewusstseins tout court. Es ist nötig, aus der Perspektive der Ich-Denke-Begleitung das Verhältnis zwischen diesen drei Begriffen zu klären, denn dieses Verhältnis betrifft einen fundamentalen Aspekt der Begründung des Apperzeptionsprinzips. Um dieser Aufgabe nachzugehen, muss man jedoch zuerst einige relevante Begriffe analysieren.

\subsection{Dunkle, klare Vorstellungen und Tierbewusstsein}

Die dunkle Vorstellung wird in der $K r V$ nicht eigens thematisiert, sondern von Kant lediglich an verschiedenen Stellen erwähnt. Wichtige Aussagen über die dunklen Vorstellungen in anderen Texten, vor allem in der Anthropologie in pragmatischer Hinsicht und der Jäsche Logik, sind wertvoll im Hinblick auf den Charakter des Bewussteins an sich in einer immanenten Hinsicht. Sie zeigen, dass der Begriff des Bewusstseins wesentlich mit dem Begriff der Dunkelheit bzw. Klarheit zusammenhängt. Um dies zu demonstrieren, werden zuerst Beispiele und Definitionen der dunklen Vorstellung vorgestellt. Danach wird der Begriff der dunklen Vorstellung unter Zuhilfenahme relevanter Passagen genauer analysiert.

In der Anthropologie werden dunkle und klare Vorstellungen wie folgt definiert:

$\S 5$. Vorstellungen zu haben und sich ihrer doch nicht bewußt zu sein, darin scheint ein Widerspruch zu liegen [...] Allein wir können uns doch mittelbar bewußt sein eine Vorstellung zu haben, ob wir gleich unmittelbar uns ihrer nicht bewußt sind. Dergleichen Vorstellungen heißen dann dunkele; die übrigen sind klar.

Anhand der Beispiele, die Kant für dunkle Vorstellungen gibt, ist klar, dass sie eine Familie von kognitiven Phänomenen umfassen, die jeweils eine ähnliche Struktur 
aufweisen. Solche Beispiele können grob in zwei Arten eingeteilt werden. Die erste Arte betrifft die Wahrnehmung. Typische Beispiele hierzu lauten: ${ }^{23}$

B.1 Obwohl wir mit bloßen Augen nur die Milchstraße, nicht die einzelnen Sterne von ihr sehen können, haben wir von jedem Stern eine dunkle Vorstellung. Denn ein Teleskop bringt nicht mehr Lichtstrahlen in unseren Augen, sondern breitet sie nur aus. Deswegen affiziert jeder Lichtstrahl unsere Netzhaut, woraus eine dunkle Vorstellung des Sterns entsteht (Anth 7:135. Siehe auch V-Met/Mron 29:879. V-Met-L1/Pölitz 28: 227, siehe Kitcher 99:347)

B. 2 ,Wenn ich weit von mir auf einer Wiese einen Menschen zu sehen mir bewußt bin, ob ich gleich seine Augen, Nase, Mund usw. zu sehen mir nicht bewußt bin, so schließe ich eigentlich nur, daß dies Ding ein Mensch sei“. Ein derartiger Schluß soll nach Kant nur dann möglich sein, wenn man dunkle Vorstellungen von Augen, Nase, Mund usw. hat. Man schließt sozusagen unterschwellig von den dunklen Vorstellungen der Augen, Nase und Mund darauf, dass es sich um einen Menschen handelt. Nur „aus diesen Theilvorstellungen“ ist „die ganze (des Kopfs oder des Menschen)“ möglich. (Anth $7: 135)$

B.3 Ein Musiker spielt eine Improvisation mit zehn Fingern und beiden Füßen auf einer Orgel und spricht zugleich mit dem Publikum. Dabei nimmt er eine große Menge von Tönen zugleich wahr. Er ist sich zwar der einzelnen Töne nicht bewusst, muss aber von jedem Ton zumindest eine dunkle Vorstellung haben, denn falls nur einer davon nicht mit den anderen zusammenklingt, weiß er es sofort. (Anth 7:136. Siehe auch VAnth/Fried 25:479)

Die zweite Art der Beispiele betrifft das Denken. Bei Schlussfolgerungen könnten sich nach Kant manchmal Begriffe oder Prinzipien einschleichen und eine Rolle spielen, obwohl man sich gar nicht bewusst ist, diese zu haben. Solche dunkle Vorstellung könnte etwa

B.4 der „Rechtsgrund“, der Monarchen dunkel vorschwebt (MS 6: 345),

oder

B.5 Begriffe der Metaphysik sein, d.h. „dunkel gedachte Metaphysik, die jedem Menschen in seiner Vernunftanlage beiwohnt“ (MS 6: 216, 376). ,[A]lles was in der

\footnotetext{
${ }^{23}$ Um längeres Zitieren zu vermeiden, nehme ich das Wesentliche auf und teile es in Gruppen ein.
} 
Metaphysik und Moral gelehrt wird, das weiß schon ein jeder Mensch; nur war er sich dessen nicht bewußt.“(V-Met-L1/Pölitz 28: 227)

Sie kann auch ganz Alltägliches sein wie

B.6 die implizite Voreingenommenheit wie „Kleider macht Leute“ (Anth 7:137) oder die „Antipathie beym Anblik eines Menschen.“ (Refl 15:65)

Dunkle Vorstellungen sind diejenigen, die wir tatsächlich haben, obwohl wir uns nicht unmittelbar bewusst sind, dass wir sie haben. ${ }^{24}$ Wir können uns dieser Vorstellung nur auf mittelbarem Wege bewusst werden. Kant führt die Frage, worin solche mittelbaren Wege bestehen könnten, nicht systematisch aus. Anhand relevanter Passagen in verschiedenen Schriften lassen sich drei verschiedene Weisen des mittelbaren Bewusstwerdens der dunklen Vorstellungen zusammenfassen:

1. Man erlangt Bewusstsein einer dunklen Vorstellung durch Schlussfolgerung. Man schließt aus der Wirkung der dunklen Vorstellung auf ihre Existenz:

Unsere Vorstellungen sind entweder dunkel oder klar etc. Dunkle Vorstellungen sind die, deren ich mir nicht unmittelbar bewußt bin, durch Schlüsse aber doch mittelbar bewußt werden kann. (V-Met/Mron 29:879. Siehe auch Anth 7:135; V-Met-L1/Pölitz 28: 227).

Unmittelbar weiß ich sie nicht, indeßen kann ich aus ihren Würkungen schlüßen daß ich sie haben muß. (V-Anth/Mron 25:1221)

Es ist im Fall der Wahrnehmung aus den obigen Beispielen B.2 und B.3 unmittelbar klar, was mit diesen Aussagen gemeint ist. Über das Beispiel der Beobachtung der Milchstraße bemerkt Kant:

„Wir wissens freilich immediate nicht, aber durch Schlüße doch, z.E. wir sind es uns nicht bewußt, daß die Milchstraße, wenn wir sie mit bloßen Augen betrachten, aus lauter kleinen Sternen bestehe, aber durchs Telescop sehen wirs. Nun schließen wir, da

\footnotetext{
${ }^{24}$ Es geht nach Kants Wortlaut sehr deutlich nicht darum, dass wir uns des Inhalts der Vorstellungen nicht bewusst sind, sondern darum, dass wir uns nicht bewusst sind, dass wir die Vorstellungen haben. Vgl. Anth 7: 135. Bei dem fehlenden Bewusstsein handelt es sich auch hier eher um die apperzeptive Vorstellung zweiter Ordnung. Für näheres siehe Liang (2017).
} 
wir die ganze Milchstraße gesehen haben, so müßen wir auch alle einzelnen Sterne gesehen haben. Denn wäre das nicht, so hätten wir nichts gesehen. Was wir aber gesehen haben, müßen wir uns auch vorgestellt haben. Da wir von diesen Vorstellungen nichts wissen, so müssen sie dunkel gewesen sein“(V-Met/Mron 29:879)

Im Fall der zweiten Gruppe der dunklen Vorstellungen - der dunklen Vorstellungen beim Denken - geschieht dies durch Reflexion. Zum Beispiel gibt es, wie bereits erwähnt, eine ,dunkel gedachte Metaphysik, die jedem Menschen in seiner Vernunftanlage beiwohnt“, so dass man „nach dunkel vorgestellten Principien, urtheilt.“ Diese Prinzipien kann man durch Schlussfolgerung auffinden, indem man darüber reflektiert, was seiner Schlussfolgerung als Begründung bzw. versteckte Prämisse zugrundeliegt. Das mittelbare Bewusstwerden der dunklen Vorstellung durch Schlussfolgerung ist wohlgemerkt nicht unbedingt ein unmittelbares Bewusstsein des Gehalts der Vorstellung. Durch Schlussfolgerung kann man sich zwar der dunkel vorgestellten Prinzipien, die man beim Denken verwendet hat, direkt bewusst werden, aber man kann in manchen Fällen von Wahrnehmungen, wie z.B. bei den Beispielen [B1], [B2] und [B3], nicht durch Schlussfolgerung den repräsentationalen Gehalt der jeweiligen Wahrnehmung selbst (z.B. den phänomenalen Charakter dieser Vorstellungen) wieder ins Bewusstsein holen. Was man dadurch erlangt, ist nur das Bewusstsein der Existenz dieser dunklen Vorstellungen.

2. Man erlangt ein direktes Bewusstsein des Gehalts einer dunklen Vorstellung durch einen Wechsel der Aufmerksamkeit.

Wir können unsre Vorstellungen klar machen und auch wieder verdunkeln. Jenes heißt attendiren dieses abstrahiren (V-Anth/Mron 25:1239)

Durch die Aufmerksamkeit erlangt man ein direktes Bewusstsein des Gehalts der vorher dunklen Vorstellung. Solch eine Vorstellung kann entweder eine Wahrnehmung, ein Begriff, oder ein Teil der beiden - d.h. das sogenannte „Merkmal“ eines Begriffs oder einer Anschauung sein. 
3. Man erlangt ein direktes Bewusstsein des Gehalts eines verworrenen Begriffs durch Analyse. Dieser Begriff selbst wird dadurch deutlich gemacht. Dabei werden die Merkmale, die in diesem Begriff dunkel enthalten sind, klargemacht:

Unser Erkenntniß kann auf zweierley Art deutlich gemacht werden. a) per Synthesin, b) per Analysin. wir machen nemlich entweder einen deutlichen Begrif, und dieses geschiehet per Synthesin oder wir machen einen Begrif, der zuvor verworren war, deutlich, und dieses geschiehet per Analysin. (V-Lo/Blomberg 24:130. Siehe auch $134)^{25}$

4. Im Fall [B6] kann man durch Beobachtung einer dritten Person seine eigene implizite Voreingenommenheit indirekt erkennen.

Die vorletzte Weise, die dunklen Vorstellungen klarzumachen, kann als Variante der ersten betrachtet werden, insofern sich die Analyse als eine Art von Schlussfolgerung im weiten Sinn betrachten lässt. Damit haben wir nun das Wesentliche von Kants Ausführungen über die dunklen Vorstellungen ausgeführt. Bevor wir fortfahren, sind zwei Bemerkungen zu den klaren Vorstellungen nötig.

Erstens kann man, wie wir gesehen haben, durch einen Wechsel der Aufmerksamkeit eine dunkle Vorstellung klarmachen. Dabei wird man sich des Gehalts der dunklen Vorstellung unmittelbar bewusst. Daher muss die Definition der dunklen Vorstellung leicht modifiziert werden. Um Kants Ausführungen nicht zu großem Abbruch zu tun und gleichzeitig die Formulierung nicht überflüssig umständlich zu machen, schlage ich vor, den Begriff „unmittelbar“ weiter zu fassen als bisher. Die Definition der dunklen Vorstellung wird dahingehend interpretiert, dass man sich dieser Vorstellung unmittelbar - d.h. ohne weitere Aktionen des Subjekts, die bewusstseinstheoretische Konsequenzen haben - nicht bewusst sein kann. Weil in unserem Zusammenhang an

\footnotetext{
${ }^{25}$ Ich zähle die Erzeugung eines neuen deutlichen Begriffs nicht dazu, einen dunklen Begriff klar zu machen.
} 
diesem Begriff nichts Entscheidendes hängt, werde ich in meinen weiteren Ausführungen weiterhin mit dem modifizierten Begriff „unmittelbar“ operieren.

Kant hat die Klarheit der klaren Vorstellung weder eigens thematisiert noch mittels Beispielen illustriert, da dunkle Vorstellungen offensichtlich theoretisch viel interessanter sind. Zudem könnte dieses Versäumnis daran liegen, dass er davon ausgeht, dass wir uns intuitiv klar sind, was eine klare Vorstellung bedeutet. Der Begriff der klaren Vorstellung ist jedoch begrifflich in deutliche und undeutliche Vorstellungen untergliedert. Diese Untergliederung ist zwar nicht trivial, jedoch für den Zweck dieser Abhandlung nicht entscheidend. Dieses Begriffspaar definiert Kant nämlich wie folgt:

Alle klaren Vorstellungen, auf die sich allein die logischen Regeln anwenden lassen, können nun unterschieden werden in Ansehung der Deutlichkeit und Undeutlichkeit. Sind wir uns der ganzen Vorstellung bewußt, nicht aber des Mannigfaltigen, das in ihr enthalten ist: so ist die Vorstellung undeutlich (Log 9:34).

Wir haben klare Vorstellung von der „Zusammensetzung“ der deutlichen Vorstellungen (Anth 7:138). Eine Vorstellung ist deutlich, wenn die „Klarheit sich auch auf die Theilvorstellungen eines Ganzen derselben und ihre Verbindung erstreckt.“ (Anth 7:135) Da das Ziel dieser Abhandlung die Klärung von Kants Begriff des Bewusstseins ist, werde ich im folgenden Vorgehen direkt auf die Klarheit der deutlichen Vorstellung fokussieren, falls Kants Ausführungen der deutlichen Vorstellung nützlich sind.

Zwei wichtige Momente in der Definition der dunklen Vorstellung werden von Kant nicht explizit behandelt. Diese sollen nun präzisiert werden:

1. Was heißt es, eine Vorstellung zu haben im Unterschied dazu, sich einer Vorstellung bewusst zu sein?

2. Was bedeutet es genau, sich einer Vorstellung unmittelbar nicht bewusst zu sein? Was bedeutet es dementsprechend genau, sich einer Vorstellung unmittelbar bewusst zu sein? 
Im Folgenden werden diese Fragen untersucht. Dabei wird versucht, die Fragen nur anhand der theoretischen und textuellen Ressourcen bezüglich dunkler Vorstellungen zu beantworten. Denn das Ziel der Betrachtung der dunklen Vorstellungen ist es, den Begriff des Bewusstseins aus anderer Perspektive zu beleuchten.

\subsubsection{Was heißt es, eine Vorstellung zu „haben“?}

Eine Vorstellung ist nach Kant, wie bereits gesagt, „nichts anderes, als wenn sich in meiner Seele etwas befindet, was mit der vorgestellten Sache eine Ähnlichkeit hat" (Logik Bauch, S. 30) oder eine „Bestimmung der Seele, die sich auf andere Dinge bezieht" (Refl 16:76f.). Eine Vorstellung ist dementsprechend ein Zustand oder ein Bestandteil des Gemüts, der durch seine Strukturähnlichkeit mit einem Gegenstand diesen repräsentiert. Nun sind die dunklen Vorstellungen diejenigen, die man zwar hat, aber derer man sich nicht bewusst ist. Es stellen sich die Fragen, was es bedeutet, eine Vorstellung zu haben, und was eine bewusste Vorstellung von einer solchen, bloß gehabten dunklen Vorstellung unterscheidet. Dass man eine Vorstellung hat, ist im Kontext von Kants Ausführungen über die dunkle Vorstellung äquivalent dazu, dass eine Vorstellung sich in der Seele befindet (V-Met-L1/Pölitz 28: 227, siehe auch UD 2:290, Refl 15:665). Eine solche Erklärung ist aber metaphorisch und mithin philosophisch nicht allzu hilfreich. Gerade Kants Beispiele der dunklen Vorstellungen können jedoch hilfreiche Hinweise geben. Demzufolge können wir hinsichtlich der dunklen Vorstellungen deswegen sinnvoll sagen, dass wir sie „haben“ bzw. dass sie „,in“ unserer Seele sind, weil sie offensichtlich in dem Erkenntnisprozess eine Rolle 
spielen. ${ }^{26}$ In dem Teleskop-Beispiel [B1] werden die einzelnen Sterne wahrgenommen und diese Wahrnehmungen sind im Gemüt vorhanden, weil sie Bestandteile der Vorstellung der Milchstraße sind und ohne Bestandteile keine ganze Vorstellung möglich ist (V-Met/Mron 29:879). Im Beispiel [B2] schließt man gar von den dunklen Vorstellungen der Nase, Augen und Mund darauf, dass das in der Ferne Gesehene ein Mensch ist. Damit spielen solche dunklen Vorstellungen in der Erkenntnis, dass es sich um einen Menschen handelt, eine Rolle. In dem Beispiel [B3] muss der Musiker zu jedem Ton unbewusst ein Urteil gegeben haben. Dies zeigt sich darin, dass jeder unharmonische Ton ihm sofort auffällt. Das heißt, der Musiker hat unbewusst einen kognitiven Zugriff auf die Vorstellungen einzelner Töne. Im Fall des Denkens ist die kognitive Rolle der dunklen Vorstellungen noch deutlicher: Sie dienen als implizite Prämissen bei der Schlussfolgerung. In der Definition der dunklen Vorstellung sagt Kant, dass man nur von der „Wirkung“ auf die Existenz einer dunklen Vorstellung schließen kann (V-Anth/Mron 25:1221). Diese Wirkung ist nichts anderes als ihre kognitive Rolle. Damit können wir vorerst schließen, dass eine Vorstellung zu „haben“ bedeutet, dass diese Vorstellungen irgendeine kognitive Rolle spielen.

Man kann hier einwenden, dass wir auch im metaphorischen Sinne sagen können, dass wir eine Vorstellung „haben“, wenn sie in der Seele bloß „gespeichert“ ist. Zwei Möglichkeiten sind hierbei denkbar:

(1) Eine Vorstellung ist nur in der Seele „gespeichert“, sie spielt kognitiv noch keine Rolle, aber ist mittelbar oder unmittelbar abrufbar.

(2) Eine Vorstellung ist in der Seele lediglich „gespeichert“, ohne dass sie eine kognitive Rolle spielen könnte.

\footnotetext{
${ }^{26}$ Ich vereinfache dies fortan durch den Ausdruck ,eine kognitive Rolle spielen“. Im weitesten Sinne bedeutet er, sich an dem Prozess der Entstehung der Erkenntnisse zu beteiligen oder das Verhalten des Subjekts zu beeinflussen. Im Kontext der $K r V$ bedeutet dies für den Fall der Wahrnehmung, dass diese eine Rolle für mein empirisches Urteil spielt. Beim Denken bedeutet es, dass ein Begriff oder eine Proposition eine Rolle bei der Schlussfolgerung spielt.
} 
Über die Vorstellung in (2) können wir nichts wissen, da wir nur anhand ihrer möglichen kognitiven Rolle auf ihre Existenz schließen. Solche Vorstellungen, wenn sie auch tatsächlich existieren, sind weder epistemologisch noch psychologisch interessant, da sie keinerlei epistemische oder psychische Wirkung haben. Meines Wissens nach hat Kant solche Vorstellungen im Endeffekt ausgeschlossen (Prol. 4:307). Ein informationstragender mentaler Zustand, der keine kognitive Rolle spielen kann, bedeutet für das Subjekt nichts. Man kann nicht in einem untrivialen Sinn sagen, dass man diesen Zustand „hat“. Daher kann man in der folgenden Überlegung diese Variante außer Acht lassen.

In der ersten Variante (1) kann das „Haben“ als eine Fähigkeit der Seele betrachtet werden, bestimmte gespeicherte Information bei Bedarf zur Verfügung zu stellen. Ich nenne diese Lesart „dispositionale Lesart“. Im Gegensatz dazu vertritt die oben vorgeschlagene Lesart die Ansicht, dass das „Haben“ einer Vorstellung gerade den Zugriff auf den Gehalt der Vorstellung bedeutet. Ich nenne diese Lesart „okkurente Lesart“". Die Frage ist nun, wie man sich zwischen diesen beiden Lesarten entscheiden kann.

Der Sinn des Habens einer Vorstellung in (1) kann meines Erachtens weder der Sinn des Habens einer Vorstellung in der Definition der dunklen Vorstellungen sein, noch als eine Möglichkeit in dem Letzteren mitenthalten sein. Diese Definition lässt sich wie folgt herausarbeiten:

[Def. DV] Eine Vorstellung ist dunkel, wenn ich sie habe, aber mir ihrer unmittelbar nicht bewusst bin. (Siehe UD 2:290; Anth 7:135; Log 9:33; Refl 15:665; Refl 18:332; V-Lo/Blomberg 24:119, 409; V-Lo/Pölitz 24:510; V-Lo/Busolt 24:616)

Im letzten Nebensatz von verschiedenen Formulierungen dieser Definition benutzt Kant, wohlbemerkt, ausschließlich das Präsens. In dieser Definition sagt Kant auch nicht, dass man sich einer dunklen Vorstellung nicht unmittelbar bewusst sein kann. Wenn der Ausdruck „wenn ich sie habe“ den Sinn „wenn sie irgendwie in einer Seele 
gespeichert ist" hätte oder diesen als eine Möglichkeit enthalten würde, müsste man aufgrund dieses Ausdrucks und des Präsens im letzten Nebensatz der (Def.DV) den Begriff der dunklen Vorstellung zu weit fassen. Dieser würde dann auch die Vorstellungen im Gedächtnis miteinschließen. Das aber ist problematisch: Ich habe zu jeder Zeit unzählige Vorstellungen im Gedächtnis bzw. in der Seele. Natürlich bin ich mir dieser nicht unmittelbar bewusst, weil ich mir nicht jederzeit jeder Vorstellung im Gedächtnis bewusst sein kann. Diese als dunkle Vorstellungen zu thematisieren hat jedoch keine große theoretische Bedeutung.

Wenn man die okkurente Lesart wählt, dann kann man das Präsens der Definition gut erklären: Eine Vorstellung ist dunkel, wenn sie zwar ihre kognitive Wirkung ausübt, ich mir aber ihrer nicht bewusst bin. Das Präsens im letzten Nebensatz der (Def.DV) bedeutet gerade eine Art der Aktualität: „Zu der Zeit, als diese Vorstellung ihre kognitive Rolle spielt, bin ich mir ihrer nicht bewusst“. Diese Darstellung stimmt nicht nur mit Kants Beispielen der dunklen Vorstellungen weitgehend überein. Auch eine Stelle in Kants früheren Schriften kann die okkurente Lesart belegen:

„Dunkle Vorstellungen sind diejenigen, deren man sich nicht bewußt ist. [...] Hier ist das Bewußtsein von zwiefacher Bedeutung. Man ist sich entweder einer Vorstellung nicht bewußt, daß man sie habe, oder, daß man sie gehabt habe. Das erstere bezeichnet die Dunkelheit der Vorstellung, so wie sie in der Seele ist; das zweite zeigt weiter nichts an, als daß man sich ihrer nicht erinnere." (UD 2:290, Hervorhebung durch den Autor)

Aus dem hervorgehobenen Satz sieht man deutlich, dass das Haben einer Vorstellung offenbar ein mentales Ereignis ist, nicht aber ein bloßer Zustand in dem Sinne, dass die Vorstellung in der Seele irgendwie gespeichert ist und zur weiteren Verfügung bereit steht. Wenn dieses Ereignis nach der Definition nicht das (apperzeptive) Bewusstsein der Vorstellung ist, dann kann es nur der (apperzeptive unbewusste) kognitive Zugriff des Erkenntnisvermögens auf den Gehalt der Vorstellung sein. ${ }^{27}$ Anders gesagt, man

\footnotetext{
${ }^{27}$ Für das apperzeptive und das nicht-apperzeptive Bewusstsein siehe Liang (2017).
} 
„hat" eine Vorstellung, wenn sie gerade im Erkentnnisprozess zur Geltung kommt. Damit lässt sich auch das fragliche Präsens in der Definition der dunklen Vorstellung erklären: Es ist irrelevant, ob man sich nach dem Zugriff noch des Inhalts der Vorstellung dieser Vorstellung bewusst ist oder nicht - was zählt ist nur, ob man sich ihm während dieses Zugriffs bewusst ist.

Als Konklusion lässt sich festhalten, dass die „gehabten“ Vorstellungen nicht die bloß „gespeicherten“ Vorstellungen sind, sondern diejenigen, die gerade ihre kognitive Rolle spielen - d.h. diejenigen, auf die im kognitiven Prozess zugegriffen wird.

Nun ist eine Bemerkung zur Modalität des letzten Nebensatzes nötig. Wie schon erwähnt, sagt Kant auffälligerweise, dass man sich der dunklen Vorstellungen nicht unmittelbar bewusst ist, aber nicht, dass man sich der dunklen Vorstellungen nicht unmittelbar bewusst sein kann. Kant will offensichtlich nicht die Möglichkeit ausschließen, dass man sich der dunklen Vorstellungen unmittelbar bewusst ist. Die dunklen Vorstellungen sind damit nicht bloß diejenigen, derer man sich wegen ihres Charakters nicht unmittelbar bewusst sein kann, wenn sie gerade ihre Wirkung ausüben. Diejenigen Vorstellungen, derer man sich kontingenterweise nicht bewusst ist, wenn sie gerade ihre Wirkung ausüben, können ebenfalls als dunkel bezeichnet werden. Diese Überlegung kann dadurch bestätigt werden, dass Kant erlaubt, dass der Wechsel der Aufmerksamkeit und die Analyse eine dunkle Vorstellung in eine klare überführen können.

\subsubsection{Was heißt es, sich einer Vorstellung bewusst zu sein?}

Der Definition der dunklen Vorstellungen zufolge ist man sich der dunklen Vorstellungen nicht bewusst. Wie lässt sich dieses Bewusstsein, an dem es hier mangelt, 
charakterisieren? Meines Erachtens ist dieses Bewusstsein ein Bewusstsein des Vorstellungszustands, also eine Vorstellung höherer Ordnung. Zuerst werde ich Textbelege für diese Position anführen und dann zeigen, warum diese dunklen Vorstellungen fehlende Bewusstsein nicht bloß ein Bewusstsein des Gehalts der Vorstellung ist. $^{28}$

\subsubsection{Das fehlende Bewusstsein in der dunklen Vorstellung}

Das fehlende Bewusstsein bei der dunklen Vorstellung ist eine Vorstellung höherer Ordnung. Es handelt sich bei ihr, genauer gesagt, um eine Vorstellung des Vorstellungsakts, oder äquivalenterweise, um eine Vorstellung des repräsentationalen Zustands des Gemüts. ${ }^{29}$ Kant explizierte diesen Punkt zwar nicht, deutet ihn aber an mehreren Textstellen aus verschiedenen Zeiten an:

Wenn ich weit von mir auf einer Wiese einen Menschen zu sehen mir bewußt bin, ob ich gleich seine Augen, Nase, Mund u.s.w. zu sehen mir nicht bewußt bin, so schließe ich eigentlich nur, daß dies Ding ein Mensch sei [...] (Anth 7:135, meine Hervorhebung)

Man ist sich entweder einer Vorstellung nicht bewußt, daß man sie habe, oder, daß man sie gehabt habe. Das erstere bezeichnet die Dunkelheit der Vorstellung, so wie sie in der Seele ist; das zweite zeigt weiter nichts an, als daß man sich ihrer nicht erinnere. (UD 2:290, meine Hervorhebung)

sich einer [...] Vorstellung bewust seyn, ist: wißen, daß man diese Vorstellung hat (Refl 16:80, meine Hervorhebung)

Sachlich verknüpft Kant dieses fehlende Bewusstsein mit dem inneren Sinn:

\footnotetext{
${ }^{28}$ Für Näheres siehe Liang (2017).

29 Über diese Äquivalenz siehe $\$ 2.4$.
} 
Ein dunkler Begrif ist nicht der, dessen wir uns nicht bewust sind sondern dessen wir uns nicht unmittelbar bewust sind, dessen wir durch Schlüsse uns bewust werden können; aber nicht durch den innern Sinn (V-Lo/Philippi 24:410) ${ }^{30}$

Da der innere Sinn als die empirische Vorstellung des eigenen Zustandes (im Kontext der KrV: des eigenen repräsentationalen Zustands) definiert wird (siehe Kapitel 2), bestätigt das obige Zitat, dass das fehlende Bewusstsein der dunklen Vorstellung eine Vorstellung des eigenen mentalen Zustands ist. Der innere Sinn ist, wie in $§ 1.6$ argumentiert, faktisch unzertrennlich mit der reinen Apperzeption verbunden. Beide sind Aspekte der Apperzeption tout court. Daher kann man sagen, dass das dunklen Vorstellungen fehlende Bewusstsein bzw. (positiv ausgedrückt) das Bewusstsein, das eine Vorstellung zu einer klaren Vorstellung macht, die Apperzeption tout court ist. Diese ist ein implizites oder explizites empirisches Bewusstsein der Vorstellung ersterer Ordnung als eines zu dem Subjekt gehörenden Zustands. Diese Beobachtung lässt sich durch den folgenden Text belegen:

Diejenige Vorstellung, der wir uns durch die apperception bewust seyn, ist klar. (VMet-L2/Pölitz 28: 84)

\subsubsection{Das Bewusstsein in der dunklen Vorstellung}

Bei der obigen Auffassung handelt es sich um eine relativ anspruchsvolle These. Sie besagt, dass das der dunklen Vorstellung fehlende Bewusstsein Kants Definition zufolge eine Vorstellung des Vorstellungszustands ist. Dies hat eine starke Implikation: Die dunkle Vorstellung ist deswegen dunkel, weil eine solche Vorstellung höherer Stufe fehlt, nicht weil man sich des Gehalts der (dunklen) Vorstellung nicht unmittelbar bewusst ist. Es lassen sich sozusagen zwei Arten von Bewusstsein unterscheiden: die

\footnotetext{
${ }^{30}$ Siehe auch DfS 2:59-60. Für eine genaue Erklärung siehe unten.
} 
erste als Vorstellung des eigenen Zustands und die zweite als Vergegenwärtigung des Vorstellungsgehalts in diesem Zustand. ${ }^{31}$ Zur Verteidigung der vorgeschlagenen Lesart müsste man also beweisen, dass man sich des Gehalts der dunklen Vorstellung unmittelbar bewusst sein kann. Dies mag zwar befremdlich klingen, ist aber in der Tat gerade das, was Kant behauptet. Um dies deutlich werden zu lassen, empfiehlt es sich, eine äußerst wichtige Passage im Paralogismen-Kapitel genauer zu untersuchen:

Klarheit ist nicht, wie die Logiker sagen, das Bewußtsein einer Vorstellung; denn ein gewisser Grad des Bewußtseins, der aber zur Erinnerung nicht zureicht, muß selbst in manchen dunkelen Vorstellungen anzutreffen sein, weil ohne alles Bewußtsein wir in der Verbindung dunkeler Vorstellungen keinen Unterschied machen würden, welches wir doch bei den Merkmalen mancher Begriffe (wie der von Recht und Billigkeit und des Tonkünstlers, wenn er viele Noten im Phantasiren zugleich greift) zu thun vermögen. Sondern eine Vorstellung ist klar, in der das Bewußtsein zum Bewußtsein des Unterschiedes derselben von andern zureicht. Reicht dieses zwar zur Unterscheidung, aber nicht zum Bewußtsein des Unterschiedes zu, so müßte die Vorstellung noch dunkel genannt werden. Also giebt es unendlich viele Grade des Bewußtseins bis zum Verschwinden (B414-5 Anm.)

Dieser Passage nach kommt auch manchen dunklen Vorstellungen ein zumindest schwaches Bewusstsein zu. Ein so geartetes Bewusstsein ist offenbar von dem Bewusstsein, durch das eine Vorstellung klar und ohne das eine Vorstellung dunkel ist, $\mathrm{zu}$ unterscheiden. Ich nenne letzteres Bewusstsein „Bewusstsein ${ }_{1}$ “ und ersteres „Bewusstsein 2 “. Worin unterscheiden sich die beiden Arten des Bewusstseins voneinander? Bevor wir uns später dieser Frage im Detail widmen, begnügen wir uns zunächst mit der folgenden Beobachtung, die unmittelbar aus der obigen Passage folgt:

Die beiden Arten des Bewusstseins unterscheiden sich in den folgenden Hinsichten:

1. Verbreitung: Das Bewusstsein ${ }_{1}$ begleitet jede klare Vorstellung. Das Bewusstsein 2 begleitet nur manche der dunklen Vorstellungen.

2. Grad: Das Bewusstsein 2 ist schwächer als das Bewusstsein ${ }_{1}$.

\footnotetext{
${ }^{31}$ Siehe Mohr (1991: Kap. V.2 und 119 f.)
} 
3. Ontologischer Status: Das Bewusstsein ${ }_{1}$ ist eine Vorstellung höherer Stufe und steht im engen Zusammenhang mit dem inneren Sinn. Daraus lässt sich schließen, dass das Bewusstsein $_{2}$ keine solche Vorstellung ist, weil es die dunklen Vorstellungen ohne Bewusstsein $_{1}$ begleitet.

4. Kognitive Funktion: Das Bewusstsein 2 ermöglicht dem Gemüt, die von ihm begleitete Vorstellung bei der Verknüpfung mit anderen Vorstellungen zu unterscheiden. Das Bewusstsein ${ }_{1}$ hat nicht nur diese Funktion. Es ermöglicht außerdem, dass das Gemüt sich des Unterschieds der von ihm begleiteten Vorstellung von anderen bewusst wird. ${ }^{32}$

\subsubsection{Die kognitive Funktion des Bewusstseins: Unterscheidung und}

\section{Bewusstsein des Unterschieds}

Kant verbindet die kognitive Funktion der Unterscheidung generell sehr eng mit dem

Bewusstsein. Zuweilen machen Kants Ausführungen gar den Eindruck, dass das

Bewusstsein und das Vermögen der Unterscheidung identisch sind:

sich einer [...] Vorstellung bewust seyn, ist: wißen, daß man diese Vorstellung hat; das heißt: diese Vorstellung von den andern unterscheiden. (Refl 16:80)

Dieser Eindruck ist jedoch trügerisch. Der Begriff des Bewusstseins ${ }_{1}$, das bei der klaren Vorstellung vorhanden ist, schließt jedenfalls neben dem Unterscheidungsakt auch das Bewusstsein des Vorstellungsgehalts selbst mit ein:

Alle Klarheit ist entweder absolute (innere) oder relative (außere) Klarheit. Jene ist das Bewustseyn der Vorstellung an sich selbst, diese das Bewustseyn ihres Verhaltnißes (der identitaet und diversitaet) in der Vergleichung mit andern (Refl 16:84)

\footnotetext{
${ }^{32}$ Für Näheres über diesen Punkt siehe Liang (2017). Zugegebenerweise hält Kant nicht immer an diesem kognitiven Unterschied der beiden Arten des Bewusstseins fest: „Das Bewußtsein seiner Vorstellungen, welches zur Unterscheidung eines Gegenstandes von anderen zureicht, ist Klarheit“ (Anth 7:137). Hier folge ich der $K r V$.
} 
Nun können wir zu der eigentlichen Frage übergehen, wie genau die kognitive Funktion der beiden Arten des Bewusstseins hinsichtlich des Unterscheidungsakts zu charakterisieren ist. Dazu gibt eine oft zitierte Passage äußerst wichtige Hinweise:

Ich gehe noch weiter und sage: es ist ganz was anders Dinge von einander unterscheiden und den Unterschied der Dinge erkennen. Das letztere ist nur durch Urtheilen möglich und kann von keinem unvernünftigen Thiere geschehen. Folgende Eintheilung kann von großem Nutzen sein.

Logisch unterscheiden, heißt erkennen, daß ein Ding A nicht B sei, und ist jederzeit ein verneinendes Urtheil, physisch unterscheiden, heißt, durch verschiedene Vorstellungen $\mathrm{zu}$ verschiedenen Handlungen getrieben werden. Der Hund unterscheidet den Braten vom Brote, weil er anders vom Braten, als vom Brote gerührt wird (denn verschiedene Dinge verursachen verschiedne Empfindungen), und die Empfindungen vom erstern ist ein Grund einer andern Begierde in ihm als die vom letztern, der natürlichen Verknüpfung seiner Triebe mit seinen Vorstellungen. Man kann hieraus die Veranlassung ziehen, dem wesentlichen Unterschiede der vernünftigen und vernunftlosen Thiere besser nachzudenken. Wenn man einzusehen vermag, was denn dasjenige für eine geheime Kraft sei, wodurch das Urtheilen möglich wird, so wird man den Knoten auflösen. Meine jetzige Meinung geht dahin, daß diese Kraft oder Fähigkeit nichts anders sei als das Vermögen des innern Sinnes, d. i. seine eigene Vorstellungen zum Objecte seiner Gedanken zu machen. Dieses Vermögen ist nicht aus einem andern abzuleiten, es ist ein Grundvermögen im eigentlichen Verstande und kann, wie ich dafür halte, blos vernünftigen Wesen eigen sein. Auf demselben aber beruht die ganze obere Erkenntnißkraft (DfS 2:59-60)

Das logische Unterscheiden als Erkennen des Unterschieds der Vorstellungen ist ihrer Definition zufolge offensichtlich synonym mit dem „Bewusstsein des Unterschieds“ in B414, das durch das Bewusstsein ${ }_{1}$ ermöglicht wird. In dieser Passage stellt Kant es dem psychologischen Unterscheiden gegenüber. Letzteres ist bloß die kausale physiologische Verknüpfung zwischen den Vorstellungen und Handlungen, die als solche gar keinen echten Unterscheidungsakt voraussetzt. Im Gegensatz dazu ist das logische Unterscheiden das Erkennen des Unterschieds, das nur „durch Urteilen möglich“ ist. Die Fähigkeit des Urteilens setzt der obigen Passage zufolge wiederum voraus, dass man „,seine eigenen Vorstellungen zum Objecte seiner Gedanken“ machen kann. Diese Fähigkeit zur Vorstellung höherer Ordnung ist gerade das Bewusstsein ${ }_{1}$, 
weil dieses, wie bereits ausgeführt, eine Vorstellung des eigenen repräsentationalen Zustands ist. Aus dieser Überlegung lässt sich schließen, dass das Bewusstsein 1 deswegen das Bewusstsein des Unterschieds der Vorstellung ermöglicht, weil es als Vorstellung höherer Ordnung die Fähigkeit des Urteils ermöglicht. Das Bewusstsein 1 muss somit eng mit der Verstandeshandlung zusammenhängen. Diese These kann durch weitere Textbelege untermauert werden:

Da das Bewußtsein die wesentliche Bedingung aller logischen Form der Erkenntnisse ist: so kann und darf sich die Logik auch nur mit klaren, nicht aber mit dunkeln Vorstellungen beschäftigen ( $\log 9: 33)$

Die logische Form der Erkenntnisse ist nichts anderes als die Form der Urteile und der Schlüsse. Diese ist wiederum die Funktion des Verstands und der Vernunft. Wenn nun das Bewusstsein die wesentliche Bedingung aller logischen Form der Erkenntnisse ist, dann ist es eine Bedingung der Funktion des Verstandes und der Vernunft. Dieser in dem obigen Zitat erwähnte Bewusstseinsbegriff ist offenbar die Bedingung der Verstandes- und Vernunfthandlung. Dieses Bewusstsein ist aus folgendem Grund gerade das klaren Vorstellungen zukommende Bewusstsein ${ }_{1}$ : Die Logik, die die Form des Verstands und der Vernunft erforscht und die das erste Bewusstsein voraussetzt, beschäftigt sich „nur mit klaren, nicht aber mit dunklen Vorstellungen“. Kurz gefasst besteht die kognitive Funktion des Bewusstseins $1_{1}$ darin, Verstandes- und Vernunfthandlungen zu ermöglichen, wohingegen das Bewusstsein 2 diese Funktion nicht hat, weil es offenbar keine Vorstellung des eigenen Denkakts ist. 


\subsubsection{Vorstellungen und Bewusstsein}

Es stellt sich weiterhin die Frage, ob es unbewusste Vorstellungen gibt. Diese Frage ist deswegen sinnvoll, weil sie entscheidend dafür ist, Vorstellungen und das Bewusstsein ontologisch zu unterscheiden. Es muss angemerkt werden, dass Interpreten mit diesem Begriff nicht die Vorstellungen meinen, die im Gedächtnis vorliegen - darüber gibt es keine Kontroverse -, sondern diejenigen, von denen man sinnvoll sagen kann, dass man sie hat, nicht aber, dass man sich ihrer in irgendeinem Sinn bewusst ist. Wir suchen sozusagen nach Vorstellungen, die gar nicht bewusstseinsfähig sind. Vor dem weiteren Vorgehen sollte angemerkt werden, dass Kant entgegen der Meinung einiger Kommentatoren sehr selten mit dem Begriff „unbewusste Vorstellung“ operiert. Noch seltener verbindet er „unbewusst“" mit „dunkel“. Daher muss man nachweisen, dass Kant wirklich glaubt, dass es Vorstellungen als mentale Zustände gibt, die von keinem Bewusstsein begleitet werden.

Viele Kommentatoren sehen den Bewusstseinsaspekt des Geistes eng mit dem repräsentationalen Aspekt verbunden. Dieses Verhältnis zeigt sich in drei Varianten, die von verschiedenen Kommentatoren vertreten werden:

(1) Die mögliche Begleitung der Vorstellung des Ich denke ist eine notwendige Bedingung dafür, dass ein mentaler Zustand eine Vorstellung ist.

(2) Die aktuale Begleitung der Vorstellung des Ich denke ist eine notwendige Bedingung dafür, dass ein mentaler Zustand eine Vorstellung ist.

(3) Die aktuale Begleitung des Bewusstseins ist eine notwendige Bedingung dafür, dass ein mentaler Zustand eine Vorstellung ist.

(4) Die mögliche Begleitung des Bewusstseins ist eine notwendige Bedingung dafür, dass ein mentaler Zustand eine Vorstellung ist.

Im Folgenden werde ich argumentieren, dass es sich bei der ersten und der dritten These um Fehlinterpretationen handelt. Die zweite ist eine stärkere Version der ersten These, die man durch Widerlegung vom (1) automatisch zurückweist. Es muss an dieser Stelle noch angemerkt werden, dass Befürworter der These (3) eigentlich meinen, dass die 
aktuale Begleitung des faktischen Bewusstseins eine notwendige Bedingung für den Vorstellungstatus ist. $\mathrm{Ob}$ dieses Bewusstsein die transzendentale Apperzeption in irgendeiner Form enthalten muss, ist für manchen von ihnen eine offene Frage. Daher ist die These (3) eine von (1) und (2) unabhängige These und muss als solche separat behandelt werden.

Die These (1) ist in der Tat eindeutig als eine Paraphrasierung der zweiten Satz des Apperzeptionsprinzips aufzufassen. Nach Allison sind Vorstellungen ohne die effektive Begleitung der transzendentalen Apperzeption zwar möglich, aber ohne die mögliche Begleitung der transzendentalen Apperzeption bleiben sie ohne Objektbezug und somit ohne „representational value“ und bleiben damit verborgen „,in the inmost recesses of the mind“, d.h. sie sind epistemisch „nichts für uns“. In einer noch stärkeren Lesart können mentale Zustände ohne mögliche Begleitung der transzendentalen Apperzeption - d.h. nicht-apperzeptive Vorstellungen - gar keine repräsentationale Zustände sein, sondern bilden nur „undifferentiated subjective affects““. ${ }^{33}$ D.h. die Möglichkeit der Begleitung der transzendentalen Apperzeption ist die notwendige Bedingung der Vorstellung tout court. ${ }^{34}$ Tatsächlich findet man für diese Position folgenden Textbeleg:

Wir sind uns a priori der durchgängigen Identität unserer selbst in Ansehung aller Vorstellungen, die zu unserem Erkenntniß jemals gehören können, bewußt, als einer nothwendigen Bedingung der Möglichkeit aller Vorstellungen (weil diese in mir doch nur dadurch etwas vorstellen, daß sie mit allem andern zu einem Bewußtsein gehören, mithin darin wenigstens müssen verknüpft werden können). (A116, meine Kursivierung)

Meines Erachtens sind beide Ansichten einseitig. Die erste fasst den „representational value“ zu eng. Demnach ist eine Vorstellung kognitiv relevant und wertvoll genau dann, wenn sie nach den Kategorien unter der Einheit der Apperzeption mit anderen

\footnotetext{
${ }^{33}$ Pippin (1982: 38-39). Siehe auch Kitcher (2011:141).

${ }^{34}$ Schulting (2012: 282, 291).
} 
Vorstellungen steht und eine genuine Objekterkenntnis ermöglicht. Wie wir jedoch gesehen haben, spricht Kant bei einem nicht-apperzeptiven Gemüt von assoziativen Verbindungen der Vorstellungen, die das Gefühl oder das Verhalten beeinflussen können. Solche assoziativen Verbindungen sind natürlich von genuiner Erkenntnis weit entfernt. Dennoch kann man nicht sagen, dass sie keinen repräsentativen oder epistemischen Wert haben, denn schließlich spiegeln sie die Regelmäßigkeit der Natur wider, wenn auch in einer unzuverlässigen Weise. Zudem spricht Kant Tieren an mehreren Stellen explizit die Fähigkeit zu Vorstellungen zu. Man hat keinen Grund, auszuschließen, dass auch bei einem erkennenden Subjekt wie dem menschlichem Geist unter bestimmten Umständen kategorisch unbestimmte Vorstellungen in primitiven, nicht-apperzeptiven Verbindungen stehen und eine Wirkung auf andere „Geistesmodule“ ausüben. ${ }^{35}$ Was die stärkere Variante angeht, so spricht neben obigen Punkten auch die Definition der Vorstellung als „Bestimmung der Seele, die sich auf andere Dinge bezieht“ (Refl 16:76f.) bzw. als „etwas [in meiner Seele], was mit der vorgestellten Sache eine Ähnlichkeit hat" (Logik Bauch, S. 30) gegen sie. Die Bedingung dafür, eine Vorstellung zu sein, ist gemäß dieser Definition überhaupt nicht voraussetzungsvoll und kann somit von einer ,gedankenlosen Anschauung“ (A111) ohne weiteres erfüllt werden. Nach der B-Version des Apperzeptionsprinzips kann eine Vorstellung ohne mögliche apperzeptive Begleitung „nichts für mich“ sein. Dies schließt nicht aus, dass sie eine Vorstellung für sich ist. ${ }^{36}$ Der Gegenstand einer Vorstellung braucht nicht unbedingt ein kategorisch bestimmtes Objekt zu sein, sondern ein simples ,irgendetwas“. Kurz gesagt, ist die Vorstellung eine mentale Entität, die unabhängig von der transzendentalen Apperzeption einen repräsentationalen Gehalt haben kann. Transzendentale Apperzeption verleiht den

\footnotetext{
${ }^{35}$ Hoppe (1983: §14).

${ }^{36}$ Siehe Kants Bemerkungen über die gedankenlose Anschauung in A111 und A119.
} 
Vorstellungen eher einen Bezug auf ein kategorisch bestimmtes Objekt als den Status der Vorstellung.

Nun betrachten wir die dritte Variante. Zunächst steht fest, dass Kant das Bewusstsein und die Vorstellung begrifflich eindeutig trennt. In der berühmten Stufenleiter deutet Kant an, dass es Vorstellung ohne Bewusstsein gibt: „Die Gattung ist Vorstellung überhaupt (repraesentatio). Unter ihr steht die Vorstellung mit Bewußtsein (perceptio).“(A320/B376). Weitere Stellen, an denen Kant beide Begriffe klar trennt, sind z.B. A363 Anm., A197/B242. In V-Met-K3/Arnoldt 29:1000 betrachtet Kant beides gar als verschiedenartige mentale Größen. In einer äußerst wichtigen Stelle der A-Deduktion bemerkt Kant:

Alle Vorstellungen haben eine nothwendige Beziehung auf ein mögliches empirisches Bewußtsein: denn hätten sie dieses nicht, und wäre es gänzlich unmöglich, sich ihrer bewußt zu werden (A117 Anm., meine Hervorhebung)

Die Einschränkung „mögliches“ macht ganz deutlich, dass die Vorstellung nicht unbedingt immer vom Bewusstsein begleitet wird. In B414 Anm. deutet Kant, wie bereits erwähnt, die Existenz völlig unbewusster Vorstellungen an: „denn ein gewisser Grad des Bewußtseins, der aber zur Erinnerung nicht zureicht, muß selbst in manchen dunkelen Vorstellungen anzutreffen sein.“ Hier macht Kant deutlich, dass nur manche dunklen Vorstellungen von schwachen Bewusstsein begleitet werden. In Jäsche Logik (9:64), einigen Parallelstellen in Logik Vorlesung (V-Lo/Blomberg 24:132; V-Lo/Pölitz 24: 417) und einer Stelle in Reflexionen zur Logik (Refl 16:343) präsentiert Kant eine weitere Rangordnung der Erkenntnis „,in Ansehung des objectiven Gehaltes unserer Erkenntniß überhaupt ${ }^{“}$. Die erste Stufe ist Erkenntnis ohne Bewusstsein. Ich zitiere nur die ersten vier Stufen:

Der erste Grad der Erkenntniß ist: sich etwas vorstellen;

Der zweite: sich mit Bewußtsein etwas vorstellen oder wahrnehmen (percipere) 
Der dritte: etwas kennen (noscere) oder sich etwas in der Vergleichung mit andern

Dingen vorstellen sowohl der Einerleiheit als der Verschiedenheit nach;

Der vierte: mit Bewußtsein etwas kennen, d.h. erkennen (cognoscere). Die Thiere kennen auch Gegenstände, aber sie erkennen sie nicht. (Log 9:64)

Wohlgemerkt ist der vierten Stufe zufolge das in dieser Passage erwähnte Bewusstsein nicht das menschliche apperzeptive Bewusstsein, sondern dasjenige, über das auch Tiere verfügen. Damit zeigt die erste Stufe, dass es durchaus unbewusste Vorstellungen gibt.

Nun erwäge ich einige Einwände gegen die These, dass Kant die Existenz unbewusster Vorstellungen ablehnt. Generell gesagt, glauben Befürworter dieser Auffassung, dass die faktische Begleitung des Bewusstseins eine notwendige Bedingung dafür ist, dass ein mentaler Zustand überhaupt eine Vorstellung ist. ${ }^{37}$ Guyer behauptet: „,[that] representations just are impingements on consciousness, and thus cannot exist except as states of consciousness, is incontestable“(Guyer 1980: 209). Das Verfügen über eine Vorstellung wird demnach als eine Form des Bewusstseins klassifiziert. Schulting behauptet: ,a perception is the minimally instantiatable form of representation for a mind such as ours“ (Schulting 2012:288). Es gäbe keine „actual representations with no intensity of consciousness“" geben (Schulting 2012:293). Schulting stützt seine Position auf zwei Stellen in den Antizipationen der Wahrnehmung (Schulting 2012:291). Dort behauptet Kant, dass, abstrahiert von der extensiven Größe der Wahrnehmung, die Empfindung als Material der Wahrnehmung immer einen intensiven Grad hat (B207f., A167/B209 f., siehe auch B414.). Bei der Apprehension der Empfindung wird sozusagen durch Affektion des inneren Sinns ein empirisches Bewusstsein eines bestimmten Grades bewirkt (A176/B218). Dieser kann vom Null bis

\footnotetext{
37 Der Begriff des Bewusstseins ist hier ganz weit gefasst. Er schließt sowohl das apperzeptive Bewusstsein als auch das schwache Bewusstsein in B414 Anm. mit ein.
} 
„beliebige Größ““ (B208) oder umgekehrt variieren, wobei der Grad Null gerade einen „Mangel“ der Empfindung oder „nichts“ darstellt, d.h. Negation der Empfindung ist (B209). Daraus schließt Schulting, "any sensation is necessarily (empirically) consciously apprehended, as consciousness is the measure of intensity". Schulting glaubt, dass es keine sinnliche Vorstellung gibt - sei sie nun apperzeptiv und objektiv gültig, oder unapperzeptiv und nur subjektiv gültig - die von keinem Bewusstsein begleitet wird. ${ }^{38}$ Bei genauer Betrachtung jedoch ist Schultings Darstellung völlig verfehlt. Betrachten wir eine Stelle in der B-Auflage des Antizipationen-Kapitels:

Nun ist vom empirischen Bewußtsein zum reinen eine stufenartige Veränderung möglich, da das Reale desselben ganz verschwindet, und ein bloß formales Bewußtsein (a priori) des Mannigfaltigen im Raum und Zeit übrig bleibt: also auch eine Synthesis der Größenerzeugung einer Empfindung von ihrem Anfange, der reinen Anschauung $=0$, an bis zu einer beliebigen Größe derselben. (B208)

Hieraus lässt sich entnehmen, dass das Bewusstsein selbst nicht verschwindet, sondern zum „formalen Bewusstsein“ wird, wenn das Reale der Empfindung ganz verschwindet. In diesem Prozess variieren die Empfindungsqualitäten, also „Farben, Geschmack“ (A175/B217, B211), nicht aber das Bewusstsein selbst. Die Empfindungsqualitäten betrachtet Kant nicht als das Bewusstsein, das diese Vorstellung begleitet, sondern als Gehalt der Vorstellung. Man kann den Grund dafür deutlich sehen, wenn man Kants Terminologie der Wahrnehmung analysiert: Das Reale ist der „Gegenstand der Empfindung“ (B207), oder dasjenige, was mit „den Empfindungen überhaupt korrespondiert“ (A175/B217). Das Reale ist somit das Repräsentierte, während die Empfindung das Reale durch die Empfindungsqualitäten repräsentiert. Die Empfindungsqualitäten sind sozusagen das repräsentationale Vehikel (B211, A175/B217). Daher gehört das Erlebnis von ihnen zum repräsentationalen Gehalt der Vorstellung - nicht aber das Bewusstsein, das diese Vorstellung begleitet.

\footnotetext{
${ }^{38}$ Schulting (2012:291).
} 
Das Bewusstsein selbst fügt dem repräsentationalen Gehalt der Vorstellung nichts hinzu: „Durchs Bewustseyn entspringt kein Bild, sondern man erkent es nur deutlich oder klar.“ (Refl 15:291). Wenn Kant also von dem variierenden „Realen“ oder der „,intensiv[en] Größe“ der Empfindung spricht, meint er damit nicht das Bewusstsein selbst, sondern die Qualität der Empfindung. Daher betrifft die Doktrin der intensiven Größe der Empfindung in dem Antizipationen-Kapitel das Bewusstsein selbst gar nicht.

Zugegebenerweise findet man für Schultings Position anscheinend einen indirekten Textbeleg in den Prolegomena:

[A]llein es ist zwischen Realität (Empfindungsvorstellung) und der Null, d.i. dem gänzlich Leeren der Anschauung, in der Zeit doch ein Unterschied, der eine Größe hat, da nämlich zwischen einem jeden gegebenen Grade Licht und der Finsterniß, zwischen einem jeden Grade Wärme und der gänzlichen Kälte, jedem Grad der Schwere und der absoluten Leichtigkeit, jedem Grade der Erfüllung des Raumes und dem völlig leeren Raume immer noch kleinere Grade gedacht werden können, so wie selbst zwischen einem Bewußtsein und dem völligen Unbewußtsein (psychologischer Dunkelheit) immer noch kleinere stattfinden; daher keine Wahrnehmung möglich ist, welche einen absoluten Mangel bewiese, z.B. keine psychologische Dunkelheit, die nicht als ein Bewußtsein betrachtet werden könnte, welches nur von anderem, stärkerem überwogen wird, und so in allen Fällen der Empfindung (Prol. 4:307, siehe auch V-Met/Mron 29:834)

In dieser Passage scheint Kant die Existenz der psychologischen Dunkelheit oder des völligen Unbewusstseins komplett zu leugnen. Meiner Meinung nach ist diese Stelle, die sich in $\$ 24$ der Prolegomena befindet, jedoch kein Einwand gegen meine Interpretation. Der Abschnitt ist dem Kontext nach ersichtlich parallel zu den Antizipationen. Aus der obigen Analyse des Begriffs des formalen Bewusstseins in der B-Version des Antizipationen-Kapitels wissen wir, dass Kants Rede von der graduellen Variation des emprischen Bewusstseins sehr irreführend ist, denn diese Variation betrifft das Bewusstsein selbst überhaupt nicht. So könnten wir vermuten, dass die graduelle Variation des Bewusstseins in der obigen Passage aus der Prolegomena eher auch die Variation der Empfindungsqualität bedeutet. Das zeigt sich deutlich im ersten 
Satz: „,Zwischen Realität (Empfindungsvorstellung) und der Null“. Es handelt sich hier also um eine ähnliche, irreführende Formulierung, in der Kant nicht über das Bewusstsein selbst, sondern über die Empfindungsqualität redet, die mit dem Realen korrespondiert. Außerdem thematisiert Kant im hervorgehobenen Text offensichtlich die Möglichkeit der unbewussten Wahrnehmung, die einen absoluten Mangel des Bewusstseins aufweist. Wahrnehmung selbst ist Bewusstsein der empirischen Anschauung (B160), und auch der „Stufenleiter“ zufolge muss Wahrnehmung von Bewusstsein begleitet werden. Es wäre absurd, würde man die oben zitierte Passage so interpretieren, dass darin thematisiert wird, ob es unbewusste Wahrnehmung gibt.

Selbst wenn wir Schultings Auffassung als richtig ansähen, ergäbe sich aus ihnen eine Absurdität. Über die dunklen Vorstellungen bemerkt Kant:

Daß das Feld unserer Sinnenanschauungen und Empfindungen, deren wir uns nicht bewußt sind, ob wir gleich unbezweifelt schließen können, daß wir sie haben, d.i. dunkeler Vorstellungen im Menschen (und so auch in Thieren), unermeßlich sei, die klaren dagegen nur unendlich wenige Punkte derselben enthalten, die dem Bewußtsein offen liegen. (Anth 7:135)

Wenn man keine Vorstellungen akzeptiert, die nicht durch das Bewusstsein begleitet sind, oder das Verfügen über Vorstellungen gar als eine Variante des Bewusstseins betrachtet, dann muss man gemäß diesem Zitat schließen, dass man über Unmengen dunkler Vorstellungen Bewusstsein hat. Dies ist jedoch besonders unplausibel hinsichtlich des Beispiels der Milchstraße. Niemand würde ernsthaft glauben, dass man ein schwaches Bewusstsein von jedem Stern im sichtbaren Bereich der Milchstraße hat.

Nach Deppermann (2001:135, 141) schließt Kant in denjenigen Abschnitten der transzendentalen Deduktion, die die These der transzendentalen Apperzeption behandeln, zweimal die Möglichkeit der unbewussten Vorstellungen aus:

„Also hat alles Mannigfaltige der Anschauung eine notwendige Beziehung auf das: Ich denke, in demselben Subjekt, darin dieses Mannigfaltige angetroffen wird“" (B132). 
„Alle Vorstellungen haben eine notwendige Beziehung auf ein mögliches empirisches Bewußtsein; denn hätten sie dieses nicht, und wäre es gänzlich unmöglich sich ihrer bewußt zu werden; so würde das sagen, sie existierten gar nicht“(A117 Anm.).

Auf den ersten Blick unterstützen beide Stellen Deppermans Behauptung: Wenn alle Vorstellungen notwendigerweise vom Bewusstsein begleitet werden, dann gibt es keine bewusstseinsunfähigen Vorstellungen. Bei nährer Betrachtung stellt sich folgendes heraus: Die Zitate implizieren zwar, dass eine Vorstellung nur aufgrund einer notwendigen Beziehung auf „das Ich denke“ oder auf „ein mögliches empirisches Bewusstsein überhaupt“ als „,meine Vorstellung“ qualifiziert werden kann, aber über die Art dieser Beziehung macht Kant darin keine Aussage. Es kann sein, dass das Subjekt sich nur indirekt einer bestimmten Vorstellung bewusst wird, das heißt, z.B. durch Schlussfolgerung. Die Mittelbarkeit dieser Beziehung ist aber damit vereinbar, diese Vorstellung als „meine Vorstellung“ zu betrachten. Denn soweit sich diese Vorstellung durch die Kategorien in die Einheit der Erfahrung integrieren lässt, spielt die Mittelbarkeit der Beziehung keine Rolle. Eine so geartete Vorstellung, die nur mittelbar bewusst werden kann, fällt nach Kants Klassifizierung gerade nicht unter die apperzeptiv bewusstseinsfähigen Vorstellungen. Dem Apperzeptionsprinzip (B131-2) zufolge ist die Meinigkeit meiner Vorstellung dann gegeben, wenn sie von mir gedacht werden kann. Soweit man eine Vorstellung denken kann, d.h. soweit man eine Vorstellung mit bewusstem Denken begleiten kann, ist es irrelevant, wie man zu ihr gelangt - ob direkt oder indirekt. Eine Stelle in der A-Deduktion bestätigt die obige These:

Alle Anschauungen sind für uns nichts und gehen uns nicht im mindesten etwas an, wenn sie nicht ins Bewußtsein aufgenommen werden können, sie mögen nun direct oder indirect darauf einfließen, und nur durch dieses allein ist Erkenntniß möglich. (A116. Vgl. auch 4:149) $)^{39}$

\footnotetext{
39 Über Kants Verwendung des Begriffs des mittelbaren oder unmittelbaren Bewusstseins siehe BXXXIX Anm.
} 
Wenn die hier vertretene Auffassung die richtige ist, stellt sich ferner die Frage, welche Rolle die völlig unbewussten Vorstellungen spielen, wenn sie völlig unbewusst sind. Sie müssen eine Rolle im gesamten Leben des Gemüts spielen können, damit man mit Recht sagen kann, dass solche Vorstellungen überhaupt existieren. Die gesuchte Rolle kann dabei keine kognitive sein, denn eine solche setzt, wie bereits ausgeführt, das Bewusstsein voraus. Obwohl sich Kant hierzu nicht explizit geäußert hat, lässt sich plausiblerweise vermuten, dass die gesuchte Rolle in einem potenziellen kausalen Einfluss der unbewussten Vorstellung auf das Gefühl oder Verhalten des Subjekts zu finden ist (siehe die Beispiele in Anth 7:136-7). Zusammenfassend zeigt die obige Analyse, dass es Kant zufolge völlig unbewusste (im Sinne von nichtbewusstseinsfähigen) Vorstellungen gibt. Mithin muss man Vorstellungen und Bewusstsein ontologisch voneinander unterscheiden.

\subsubsection{Die Struktur des Bewusstseins im Apperzeptionsprinzip}

Hinter der Forderung einer möglichen Begleitung der Vorstellung des Ich denke im Apperzeptionsprinzip steckt eine Doktrin bezüglich der Struktur des Bewusstseins, die leicht zu Missverständnissen führen kann. Betrachten wir die Passage IDB aus B131132 ganz genau, so lassen sich folgende Beobachtungen anstellen:

(TB1). Meine Vorstellung kann vom Bewusstsein begleitet werden. 
(TB2). Die reine Apperzeption ist ein Selbstbewusstsein, das in "allem [gesundmenschlichen] Bewusstsein“ nicht nur vorhanden, sondern auch "ein und dasselbe" ist. (IDB 6) ${ }^{40}$

(TB3). Es ist die reine Apperzeption, die die Vorstellung des Ich denke gegebenfalls hervorbringen kann. (IDB 6)

Die These TB1 ist zwar nicht direkt aus IDB zu entnehmen, doch ist sie unumstritten. Sie impliziert, dass uns einige unserer Vorstellungen unter Umständen nicht bewusst sind. Jede Episode des Bewusstseins enthält nur eine begrenzte Anzahl von Vorstellungen, während die anderen sich teilweise im Gedächtnis befinden. In jedem Moment sind wir uns übrigens nur jener begrenzten Anzahl von Vorstellungen bewusst, die in diesem Moment eine epistemische Rolle spielen. Die anderen Vorstellungen sind nur dunkel vorhanden und können nur unter Umständen und auf verschiedenen speziellen Wegen bewusst gemacht werden (siehe §1.4). Die reine Apperzeption braucht nicht faktisch in allen Episoden des Bewusstseins die klare Vorstellung des Ich denke hervorzubringen, denn Kant sagt explizit: „als meine Vorstellungen (ob ich mich ihrer gleich nicht als solcher bewußt bin).“ (APB 8). Wohlgemerkt bedeutet dies aber nur, dass eine klare Vorstellung des Ich denke nicht nötig ist. Kant bestreitet nicht, dass eine dunkle Vorstellung des Ich denke notwendig in sämtlichen Episoden des Bewusstseins eingebettet werden muss. Wenn die transzendentale Apperzeption dennoch die klare Vorstellung des Ich denke hervorbringt, dann handelt es sich dabei um eine explizite Begleitung des Ich denke bzw. um ein explizites Selbstbewusstsein. Die reine Apperzeption selbst muss (zumindest in Form einer dunklen Vorstellung) ${ }^{41}$ alle Episoden des Bewusstseins begleiten, d.h. in allen Episoden enthalten sein:

\footnotetext{
${ }^{40}$ Wie wir gesehen haben, enthalten das Tierbewusstsein sowie manche Episoden des menschlichen Bewusstseins an sich keinen Selbstbezug.

${ }^{41}$ Siehe $§ 1.5$.
} 
Er wird also aus dem Ich, welches alle Vorstellungen zu aller Zeit in meinem Bewußtsein und zwar mit völliger Identität begleitet, ob er es gleich einräumt, doch noch nicht auf die objective Beharrlichkeit meiner selbst schließen (A362-3)

Das Apperzeptionsprinzip kann anders formuliert werden: Alle meine Vorstellungen müssen von dem Bewusstsein begleitet werden können, das die reine Apperzeption enthält. Es muss jedoch angemerkt werden, dass die Interpretationslage zu Kants Ausführungen in der A-Auflage der $K r V$ schwierig ist. Zwar sind die obigen beiden Punkte ebenfalls vorhanden: TB3 kann durch viele Textstellen bekräftigt werden und ist insofern unproblematisch. ${ }^{42}$ Hinsichtlich der TB2 unterliegt Kants Position in der A-Version einer gravierenden Ambivalenz. Es gibt zwar viele Stellen, die belegen, dass die reine Apperzeption in allen Episoden des Bewusstseins eingebettet ist und identisch bleibt. Für den ersten Teil dieser These sprechen z.B. „[D]as Ich ist zwar in allen Gedanken immer wiederum vorkömmt“ (A350), ,[das] Ich, welches alle Vorstellungen zu aller Zeit in meinem Bewußtsein und zwar mit völliger Identität begleitet [...]“ (A362-3). Beleg für den zweiten Teil der These ist z.B. der gerade zitierte Satz, wie auch A107. Das Problem ist jedoch, das eine Stelle in der A-Version des Apperzeptionsprinzips mit der TB 2 nicht übereinstimmt:

IDA 7) Es ist aber nicht aus der Acht zu lassen, daß die bloße Vorstellung Ich in Beziehung auf alle andere (deren collective Einheit sie möglich macht) das transscendentale Bewußtsein sei. 8) Diese Vorstellung mag nun klar (empirisches Bewußtsein) oder dunkel sein, daran liegt hier nichts, ja nicht einmal an der Wirklichkeit desselben; 9) sondern die Möglichkeit der logischen Form alles Erkenntnisses beruht nothwendig auf dem Verhältniß zu dieser Apperception als einem Vermögen. (A117 Anm.)

Dieser Passage zufolge ist es gar nicht nötig, dass eine wirkliche Vorstellung des Ich oder Ich denke eine empirische Vorstellung begleitet, damit diese unter der Einheit der

\footnotetext{
${ }^{42}$ Siehe A343/B401, A354 und besonders A398.
} 
Apperzeption steht und als empirische Erkenntnis gilt. ${ }^{43}$ Es kommt nach dieser Passage vielmehr darauf an, dass sie prinzipiell davon begleitet werden kann. Folglich könnte diese Passage implizieren, dass es Episoden des Bewusstseins (wohlgemerkt nicht Vorstellungen) gibt, die die reine Apperzeption gar nicht enthält. Dies könnte als Beleg gegen die Interpretationsthese TB 2 gelten. Diese Stelle wird später eingehend behandelt, nachdem wir uns mehr mit der Apperzeption vertraut gemacht haben. Vorerst gehe ich davon aus, dass diese einzelne Stelle kein entscheidendes Argument gegen die hier vorgeschlagene Lesart darstellt.

\subsection{Reine Apperzeption}

1.5.1. Apperzeption, reine Apperzeption, transzendentale Apperzeption, ursprüngliche Apperzeption

Eng verwandt mit dem Begriff der reinen Apperzeption sind die Begriffe der transzendentalen Apperzeption und der ursprüchlichen Apperzeption. Die ursprüchliche Apperzeption wird in B132 explizit mit der reinen Apperzeption identifiziert und ist insofern unproblematisch. Den Begriff der transzendentalen Apperzeption verwendet Kant nur selten in der B-Auflage (A158/B197), aber öfter in der A-Auflage der Kritik (A106-7, 114 usw.). Besonders aus A106-7 wird deutlich, dass die transzendentale Apperzeption sachlich mit der reinen Apperzeption identisch ist, denn sie ist „das reine, ursprüngliche, unwandelbare Bewusstsein“, das die

\footnotetext{
${ }^{43}$ Wir werden noch sehen, dass Kant beides - „Ich“ und „Ich denke“ - als repräsentationalen Gehalt der reinen Apperzeption betrachtet.
} 
transzdentale Bedingung der Einheit des Bewusstseins ist. Also könnten wir die folgenden Gleichsetzungen konstatieren:

transzendentale Apperzeption = reine Apperzeption = ursprüchliche Apperzeption

Den Terminus „Apperzeption“ verwendet Kant offenbar sehr frei. Mehrheitlich meint er damit die reine Apperzeption (Z.B. B134, 153). Aber ist die Apperzeption eigentlich synonym zu der reinen Apperzeption? Meines Erachtens ist dies nicht der Fall. An einer Stelle scheint die Apperzeption die Vorstellung der Zeit zu enthalten:

„denn in der Apperception ist die Zeit eigentlich nur in mir vorgestellt” (A363)

Dies widerspricht dem Charakter der reinen Apperzeption, denn darin ist kein Sinnliches enthalten. Diese Stelle bringt dennoch keine Inkonsistenz in Kants Terminologie, denn mit Apperzeption bezieht er sich nicht bloß auf die reine Apperzeption, sondern auf einen mentalen Akt, der sowohl die reine Apperzeption als auch die empirische Apperzeption als verschiedene Aspekte enthält. ${ }^{44}$ Dies macht Kant explizit in A115:

Es sind drei subjective Erkenntnißquellen, worauf die Möglichkeit einer Erfahrung überhaupt und Erkenntniß der Gegenstände derselben beruht: Sinn, Einbildungskraft und Apperception; jede derselben kann als empirisch, nämlich in der Anwendung auf gegebene Erscheinungen, betrachtet werden, alle aber sind auch Elemente oder Grundlagen a priori, welche selbst diesen empirischen Gebrauch möglich machen. Der Sinn stellt die Erscheinungen empirisch in der Wahrnehmung vor, die Einbildungskraft in der Association (und Reproduction), die Apperception in dem empirischen Bewußtsein der Identität dieser reproductiven Vorstellungen mit den Erscheinungen, dadurch sie gegeben waren, mithin in der Recognition.

Die Apperzeption wird hier als ein Vermögen betrachtet. Sie hat zwei Aspekte, einen reinen und einen empirischen, wie es auch bei der Sinnlichkeit und der Einbildungskraft der Fall ist. Der reine Aspekt, die reine Apperzeption, ist eine Voraussetzung des empirischen Aspekts, der empirischen Apperzeption. Aus dem obigen Zitat ist nämlich

\footnotetext{
${ }^{44}$ Vgl. Ameriks (2006:54), Kitcher (2015:281-2).
} 
eindeutig klar, dass diese Unterscheidung auf verschiedene Betrachtungsweisen zurückgeführt werden kann. Es handelt sich bei der Apperzeption um ein mentales Vermögen. Die Tätigkeit dieses Vermögens kann angesichts seiner Anwendung auf die empirischen Vorstellungen empirisch genannt werden, aber abstrahiert davon betrachtet lässt sich der repräsentationale Gehalt dieser Tätigkeit durch den formalen Satz „Ich denke“ erfassen (siehe besonders A354). Entsprechend kann die Vorstellung, die durch solche Tätigkeit generiert wird, nämlich die Vorstellung „Ich denke“ (die entweder dunkel oder klar ist), auf zweierlei Weise betrachtet werden. Jedes Auftreten des „Ich denke“ (ob dunkel oder klar), das eine empirische Vorstellung begleitet, ist ein Auftreten der empirischen Apperzeption. Der Typ einer derartigen Vorstellung „Ich denke“" ist die reine Apperzeption (A343/B401). Die Unterscheidung der reinen und empirischen Apperzeption impliziert daher nicht, dass es zwei verschiedene Arten von Apperzeption gibt. Dies kann durch weitere Stellen bestätigt werden:

[...] so wird das Bewußtsein in das discursive (welches als logisch, weil es die Regel giebt, voran gehen muß) und das intuitive Bewußtsein eingetheilt werden; das erstere (die reine Apperception seiner Gemüthshandlung) ist einfach. Das Ich der Reflexion hält kein Mannigfaltiges in sich und ist in allen Urtheilen immer ein und dasselbe, weil es blos dies Förmliche des Bewußtseins, dagegen die innere Erfahrung das Materielle desselben und ein Mannigfaltiges der empirischen inneren Anschauung, das Ich der Apprehension, (folglich eine empirische Apperception) enthält (Anth 7:141, siehe auch ganz deutlich OP 22:31)

Die reine und die empirische Apperzeption sind somit jeweils der formale und der materialle Aspekt ein und desselben mentalen Phänomens, die von einander unzertrennlich sind. Im Folgenden wird davon ausgegangen, dass die reine Apperzeption nicht mit der Apperzeption tout court identisch, sondern nur ein formaler Aspekt von ihr ist. 


\subsubsection{Charakter der reinen Apperzeption}

Zunächst möchte ich einige einführende Bemerkungen über die reine Apperzeption machen. Diese hoch vereinfachte Darstellung dient bloß dazu, einen vorbereitenden Überblick in das Thema zu ermöglichen. Wir sind bereits mit einigen grundlegenden Eigenschaften von ihr und der Vorstellung des Ich denke vertraut. Die reine Apperzeption ist das ursprüngliche Selbstbewusstsein, das die Vorstellung des Ich denke, die entweder klar oder dunkel ist, hervorbringt (B132, A117 Anm). Die reine Apperzeption bleibt in ,allem Bewußtsein ein und dasselbe“(B132). Insofern kann man sagen, dass ,alles Bewußtsein [...] zu einer allbefassenden reinen Apperzeption [gehört]“"(A123). Die reine Apperzeption ist eine intellektuelle Vorstellung des eigenen Verstandesakts, die nicht durch Affektion generiert ist (B153, 158f.). Dieser Verstandesakt ist eine Handlung der Verbindung, die Vorstellungen in einer Einheit des Bewusstseins - d.h. in einem Begriff oder Urteil - miteinander verknüpft (B133).

Das „Ich denke“ ist der formale Satz der reinen Apperzeption. Die Vorstellung des Ich ist „das stehende und bleibende“ in allem Bewusstsein. Als Vorstellung ist sie „ein Aktus der Spontaneität, d.i. sie kann nicht als zur Sinnlichkeit gehörig angesehen werden“ (B132). Es ist außerdem eine allgemeine Vorstellung, als Kant „ich denke“ präzise als einen „allgemeinen Ausdruck“ (B138) oder ,allgemein[en] Satz“ (A398, siehe auch B421, B422f.) bezeichnet, d.h. dabei wird nicht weiter spezifiziert, welchen Denkakt diese Vorstellung genau bezeichnet. Bei der Vorstellung „Ich denke“ wird sowohl vom konkreten Vorstellungsgehalt, den sie begleitet, als auch von der Art des von ihr begleiteten Denkakts abstrahiert. Bezüglich des logischen Status dieser Vorstellung bemerkt Kant: „Dieses ist der Begriff, oder, wenn man lieber will, das Urteil: Ich denke. Man sieht aber leicht, daß er das Vehikel aller Begriffe überhaupt, und mithin auch der transzendentalen sei, und also unter diesen jederzeit mit begriffen werde, und daher ebensowohl transzendental sei“ (A341/B399). Die reine Apperzeption ist folglich ein begriffliches Selbstbewusstsein. Als ein Vermögen 
betrachtet ist sie ein spontanes, begriffliches Vermögen: „Diese Apperception ist es nun, welche zu der reinen Einbildungskraft hinzukommen muß, um ihre Function intellectuell zu machen.“(A124).

Die Vorstellung „Ich“ ist „eine Vorstellung vom transzendentalen Subjekt der Gedanken $=\mathrm{x}$, welches nur durch die Gedanken, die seine Prädikate sind, erkannt wird, und wovon wir, abgesondert, niemals den mindesten Begriff haben können“ (A3456/B404). Solche Prädikate des Ichs, also die Gedanken, werden von Kant missverständlich als „meine Vorstellungen“ charakterisiert. Sie sind „meine“, bloß weil sie - als dessen Zustände - zu dem transzendentalen Subjekt gehören, nicht aber weil sie dieses Subjekt selbst repräsentieren. ${ }^{45}$ Brook gibt dazu eine paradigmatische Darstellung:

The cognitive and semantic machinery used to obtain consciousness of self as subject is quite unusual. In it, we "denote" but do not "represent" ourselves (A382). Put otherwise, we designate ourselves without noting "any quality whatsoever" in ourselves (A355) [...] In attaching "I" to our thoughts, we designate the subject only transcendentally. . . without noting in it any quality whatsoever-in fact, without knowing anything of it either directly or by inference. (A355) (Brook 1995:94)

Deswegen repräsentiert die Vorstellung „Ich“ lediglich die „Beziehung der innern Erscheinungen [d.h. die wahrgenommenen Gedanken] auf das unbekannte Subjekt derselben“ (Prol 4:334) nicht aber „Erscheinungen des Subjekts“. Kant schließt aus, dass die Vorstellung „Ich“ ein Begriff ist (Prol 4:334 Anm., MAN 4:543). ${ }^{46}$ Vielmehr soll es nur eine „Bezeichnung des Gegenstandes des innern Sinnes“ sein (Prol 4:334). Als Grund dafür nennt Kant seinen semantischen Charakter: es darf nicht selbst Prädikat anderer Dinge sein oder solche Prädikate enthalten. Dieser Charakter führt

\footnotetext{
45 Allison (2015).

${ }^{46}$ In seiner späteren Schrift rückt er von dieser Position jedoch ab: "blos ein Begrif sich irgend einen Gegenstand correspondirend zu setzen” (OP 22: 69). Da die Vorstellung des Ich einen Teil des Urteils „Ich denke“ darstellt, bezeichne ich sie durchgehend als „Quasi-Begriff“.
} 
dazu, dass die Vorstellung des Ich aufgrund der Dichotomie der Vorstellungsart nur eine Anschauung sein kann. Das Denken bezieht sich nie direkt auf einen Einzelgegenstand, sondern immer nur mittels eines Begriffs. Ein Begriff ist eine Vorstellung eines Merkmals, das viele Gegenstände teilen (A68-9/B93-4). Daher kann das Selbstbewusstsein nicht begrifflich vermittelt sein. Andererseits distanziert Kant die Vorstellung des Ichs von einer Anschauung im eigentlichen Sinne, weil man introspektiv keine speziellen sinnlichen Eindrücke vom Subjekt hat. Die Vorstellung ist „an Inhalt gänzlich [leer]“ und kann nicht „,den mindesten Begriff“ motivieren (A345-6/B404). Die Vorstellung des Ich ist somit entgegen der obigen vorläufigen Charakterisierung gerade keine Anschauung: „Das Bewusstsein meiner selbst in der Vorstellung Ich ist gar keine Anschauung, sondern eine bloße intellektuelle Vorstellung der Selbsttätigkeit eines denkenden Subjekts“ (B278. Siehe auch B413, 429; A350, A345-6/B404)

Nach dem Überblick sollen nun einige wichtige Eigenschaften der reinen Apperzeption behandelt werden. Als erstes ist die reine Apperzeption ein „einfaches Bewußtsein“(A360). Die reine Apperzeption wird zudem als ein intellektuelles Bewusstsein der Denkakte dargestellt. „Das Bewußtsein meiner selbst in der Vorstellung Ich ist [...] eine bloß intellektuelle Vorstellung der Selbsttätigkeit eines denkenden Subjekts“ (B278. Siehe auch B153, A546/B574, Anth 7:140). „Die Apperzeption ist das Bewußtsein des Denkens“ (Refl 17:647). Die reine Apperzeption ist „ein Bewußtsein dessen, was der Mensch thut“ ist (Anth 7:161). Genauer gesagt, es ist „Bewußtsein der Thätigkeit in Zusammenstellung des Mannigfaltigen der Vorstellung nach einer Regel der Einheit desselben, d. i. Begriff und (vom Anschauen unterschiedenes) Denken überhaupt“"(Anth 7:142). Diese Charakterisierung der reinen Apperzeption ist sehr problematisch. Kant hat sie nämlich andernorts als eine einfache inhaltsleere Vorstellung des Subjekts dargestellt. Gemäß dieser Darstellung soll sie sich auf einen unbekannten und unbestimmten Gegenstand beziehen. Wie aber kann sie 
zugleich ein Bewusstsein des Denkens sein, das als ein mentales Ereignis die Handlung des unbestimmten Gegenstands ist?

Meiner Meinung nach gibt es hinsichtlich des repräsentationalen Gehalts der transzendentalen Apperzeption zwei verschiedenen Möglichkeiten: Er enthält entweder den Satz „Ich denke“ oder den (Quasi-)Begriff „Ich“. Sowohl in der ersten Darstellung des Apperzeptionsprinzips in B131f. als auch in der A-Auflage der Kritik (A341/B399, A342/B400, A343, passim) wird der „formale Satz“ der reinen Apperzeption mit „Ich denke“ beschrieben. In manchen Stellen der $K r V$ bezeichnet Kant die reine Apperzeption jedoch auch als „die einfache Vorstellung des Ich“ (B68. Siehe auch A355 f., B278). „Die Vorstellung der Apperzeption“ ist „das Ich“ (Prol. 4:334). „[D]ie bloße Vorstellung Ich in Beziehung auf alle anderen (deren kollektive Einheit sie möglich macht) [ist] das transzendentale Bewußtsein.“(A117 Anm.). Ähnliche Aussagen sind auch in späteren Schriften zu finden: „das Ich als Subject des Denkens (in der Logik), welches die reine Apperception bedeutet" (Anth, 7:134). Zur Einfachheit der Vorstellung erklärt Kant: „Zum Grunde derselben können wir aber nichts anderes legen, als die einfache und für sich selbst an Inhalt gänzlich leere Vorstellung: Ich; von der man nicht einmal sagen kann, daß sie ein Begriff sei, sondern ein bloßes Bewußtsein, das alle Begriffe begleitet“"(B404). Die zwei möglichen Kandidaten für die reine Apperzeption scheinen für Kant äquivalent zu sein. In A341/B399ff., in unmittelbarem Kontext, bezeichnet Kant sowohl den Satz „Ich denke“ als auch „Ich“ als Gehalt der reinen Apperzeption. An manchem Orten dagegen unterscheidet er die Vorstellung des Ich denke und die Vorstellung des Ich durchaus voneinander und erteilt der Vorstellung des Ich denke und der Vorstellung des Ich sogar einen jeweils unterschiedlichen epistemischen Status:

Denn es ist zu merken, daß, wenn ich den Satz: ich denke, einen empirischen Satz genannt habe, ich dadurch nicht sagen will, das Ich in diesem Satze sei empirische Vorstellung, vielmehr ist sie rein intellektuell, weil sie zum Denken überhaupt gehört. (B422 Anm.) 
Kant beschreibt nicht explizit, wie die Denkhandlungen im intellektuellen Bewusstsein vorgestellt werden. Grundsätzlich gibt es zwei Möglichkeiten: 1) Die Verstandesakte werden in der reinen Apperzeption in der Form eines Satzes beschrieben. Denn alle Handlungen des Verstands lassen sich auf die Urteile zurückführen (A69/B94). 2) Die Verstandesakte werden nur als Denken überhaupt vorgestellt.

Die erste Option ist nicht angebracht. Die einfache Vorstellung des Ich ist der Darstellung im letzten Abschnitt zufolge eine Vorstellung des unspezifizierten Subjekts der Gedanken. Der Sinn dieses Quasibegriffs „Ich“ ist nur: Subjekt oder Grund des Gedankens, den die Vorstellung des Ich begleitet. Im repräsentationalen Gehalt der Vorstellung Ich darf dieser Gedanke gar nicht spezifiziert werden, sonst wäre die reine Apperzeption je nach Vorstellung, die sie begleitet, wandelbar und würde gegebenfalls empirische Begriffe enthalten. Dies würde zwei Charakteren der reinen Apperzeption, der Unwandelbarkeit und Inhaltslosigkeit, Abbruch tun. Daher repräsentiert die reine Apperzeption die einzelnen Denkakte, die sie begleitet, gar nicht, obwohl sie als das intellektuelle Bewusstsein der Selbsttätigkeit beschrieben wird. Vielmehr enthält der Sinn des Quasibegriffs „Ich“ oder der repräsentationale Gehalt der reinen Apperzeption nur einen Bezug auf das Denken überhaupt (B423). Diese Auslegung kann durch folgende Bemerkungen belegt werden: „Das Bewusstsein meiner selbst in der Vorstellung Ich ist gar keine Anschauung, sondern eine bloße intellektuelle Vorstellung der Selbsttätigkeit eines denkenden Subjekts“ (B278). Die inhaltsleere und einfache Vorstellung des Ich soll demnach das Bewusstsein des Denkens enthalten. Der Grund dafür ist der folgende: Durch die Vorstellung des Ich wird das Ich als das Subjekt des Denkens vorgestellt. Diese Vorstellung muss sich auf den Denkakt, den die Vorstellung Ich begleitet, beziehen. Dabei wird dieser Denkakt in der Vorstellung des Ich als Denken allgemein, das ein Bestandteil des Sinnes des Begriffs des Ichs ist, vorgestellt.

Aus der obigen Darstellung sieht man, dass durch die reine Apperzeption ein Verstandesakt auf das Subjekt bezogen wird. Das heißt, dass die reine Apperzeption 
neben dem intellektuellen Bewusstsein eine weitere Komponente enthält, und zwar die Selbstzuschreibung: „das Ich [ist das] Subjekt des Denkens (in der Logik), welches die reine Apperzeption bedeutet (das bloß reflektierende Ich)“ (Anth 7:134). ${ }^{47}$ Die reine Apperzeption „dient [dazu], alles Denken, als zum Bewußtsein gehörig, aufzuführen“ (A341f./B400). Das Ich ist „die Vorstellung desjenigen, worauf alles Denken in Beziehung steht“"(Prol. 4:334 Anm.). Wohlgemerkt, sind die Vorstellungen, die die reine Apperzeption direkt begleitet und auf das Subjekt bezieht, nicht „alle meine Vorstellungen“, sondern lediglich die Denkakte: „Ich, als ein denkend Wesen, bin das absolute Subject aller meiner möglichen Urtheile“(A348, siehe auch A349). Denn nur Anschauungen, die zumindest minimal konzeptualisiert sind, können direkt von der Vorstellung des Ich denke begleitet werden. Als ein Urteil kann die Vorstellung des Ich denke nur Begriffe oder Urteile begleiten, nicht aber eine Anschauung (A68/B92-3, V-Lo/Pölitz 24:577). Die sinnlichen Vorstellungen werden indirekt durch den Denkakt, und zwar hier durch die ihnen korrespondierenden Begriffe, gedacht. Dadurch werden sie indirekt von der reinen Apperzeption begleitet. Zusammenfassend lässt sich folgendes bemerken:

a) Das „Ich denke“ bezeichnet die „Handlung des Denkens“, die das Mannigfaltige einer möglichen Anschauung des Gegenstands zur Einheit der Apperzeption bringt (B157). Diese Handlung vollzieht sich nicht im Akt des „Ich denke“, sondern im Akt, der durch den Nebensatz beschrieben wird, den der Ausdruck „Ich denke“ einleitet.

b). Das „Ich denke“ ist selbst eine „Handlung des Denkens“, die gegebenenfalls das Mannigfaltige einer möglichen Anschauung der Selbsttätigkeit zur Einheit der Apperzeption bringen kann. ${ }^{48}$ Im Gedanken „Ich denke“ wird das Subjekt bloß durch einen „allgemeinen“, unbestimmten Begriff, „denken“, als ein nicht näher

\footnotetext{
${ }^{47}$ Für eine weitere Darstellung dieses Punkts siehe Kitcher (1990:92-3).

${ }^{48}$ Siehe unten.
} 
spezifizierbares Objekt, ein „X“, gedacht (B158) - und dieser Begriff des Denkens hat keinen Bezug auf einen konkreten Einzelakt des Denkens.

Einer der wichtigsten Eigenschaften der reinen Apperzeption ist ihre „durchgängige Identität“ (B133). Genauer gesagt, wird eine Gruppe von Vorstellungen von der durchgängig identischen Apperzeption begleitet, wenn man sich bewusst ist, dass diese Vorstellungen „durchgängig mir angehören“ (B133, siehe auch B134) - d.h. wenn man „die Identität des Bewußtseins in diesen Vorstellungen selbst vorstell[t]““(B133). Die reine Apperzeption ist sozusagen ein Selbstbewusstsein, das „ein und dasselbe“ in allem Bewusstsein (B132) bleibt. Alle Episoden des Bewusstseins sollen eine „Beziehung auf die Identität des Subjekts“ enthalten (B133), das heißt so viel wie „Ich bin mir also des identischen Selbst bewußt“" (B135, siehe auch B138). Das Subjekt muss in der reinen Apperzeption als numerisch identisch „,vorgestellt“ werden (A107, A362). Hinsichtlich der Identität der Apperzeption gibt es viele Unklarheiten. Es ist vor allem unklar, was numerisch identisch bleiben soll. Es bedürfte einer separaten Abhandlung, um dieser Frage und angrenzenden relevanten Themen gerecht $\mathrm{zu}$ werden. Hier begnüge ich mich mit einer vorsichtigen Analyse. Drei Möglichkeiten kommen meines Erachtens in Frage. Numerisch identisch bleibt:

1) der repräsentationale Gehalt der Vorstellung des Ich

oder

2) das Bewusstsein des Ich selbst (als ein mentaler Zustand oder anders gesagt, hinsichtlich repräsentationaler Vehikel der Vorstellung des Ichs);

oder

3) der Bezug des Begriffs des Ich.

Belege für alle drei Optionen können in den Zitaten des obigen Absatzes gefunden werden, von denen einige mehrdeutig sind. Gegen Option 2) spricht ihre Implikation, dass die reine Apperzeption selbst hinsichtlich ihres Grades veränderlich ist und somit 
als ein mentaler Zustand oder Akt nicht numerisch identisch bleibt. Zudem leugnet der dritte Paralogismus jegliche Basis der persönlichen Identität über die Zeit hinweg in der reinen Apperzeption, was die Option 2) klar ausschließt. Die letzte Option ist ebenfalls nicht haltbar. Der Bezug des Quasi-Begriffs „Ich“ ist nämlich das „transzendentale Subjekt der Gedanken“ (A345-6/B404) bzw. das „unbekannte Subjekt“ der inneren Erscheinungen (Prol 4:334, dessen Identität nicht zu bestimmen ist. Daher bleibt nur die erste Option denkbar: Was über die Zeit hinweg identisch bleibt, ist der repräsentationale Gehalt der Vorstellung des Ich. In dieser Vorstellung hält das Subjekt sich für das identische Subjekt der verschiedenen Gedanken. Dieses FürIdentisch-Halten bleibt im repräsentationalen Gehalt der Vorstellung des Ichs eingebettet.

\subsubsection{Drei Varianten des Ich denke}

Die Vorstellung „Ich denke“ tritt in der $K r V$ in drei verschiendenen Varianten auf. Es ist sinnvoll, diese drei Varianten einmal genauer unter der Lupe zu nehmen. ${ }^{49}$ Die erste beiden Varianten stellt Kant in der „Allgemeine[n] Anmerkung, den Übergang von der rationalen Psychologie zur Kosmologie betreffend“ (B428ff.) einander gegenüber.

\footnotetext{
${ }^{49}$ Für eine ähnliche Darstellung, siehe Longuenesse (2017:86-92)
} 
1.5.3.1. Die Vorstellung „Ich denke“ als intellektuelle Vorstellung der Selbsttätigkeit

Die Vorstellung „Ich denke“ wird offiziell als eine intellektuelle Vorstellung vorgestellt. In der Einführung des Apperzeptionsprinzips im $§ 16$ bezeichnet Kant die Vorstellung des „Ich denke“ ausdrücklich als „Actus der Spontaneität, d.i. sie kann nicht als zur Sinnlichkeit gehörig angesehen werden“ (B132). Das Subjekt hat durch diese rein intellektuelle Vorstellung eine direkte Kenntnis der Existenz seines Selbsts - obwohl es keine über die bloße Existenzbehauptung hinausgehende Erkenntnisse über dieses Selbst hat - und einen nicht-empirischen Kontakt mit ihm selbst:

Das: Ich denke, drückt den Actus aus, mein Dasein zu bestimmen. Das Dasein ist dadurch also schon gegeben, aber die Art, wie ich es bestimmen, d.i. das mannigfaltige zu demselben Gehörige in mir setzen solle, ist dadurch noch nicht gegeben. (B157 Anm. $)^{50}$

„[S]o bedarf ich auch zum Erkenntnisse meiner selbst außer dem Bewußtsein oder außer dem, daß ich mich denke, noch einer Anschauung des Mannigfaltigen in mir“". (B158)

Die Vorstellung des „Ich denke“ ist deswegen eine intellektuelle Vorstellung, weil sie auf keinem sinnlichen Mannigfaltigen des Subjekts basiert. Weder liegt ihr ein spezielles inneres, sinnliches Mannigfaltiges zugrunde, das ein Subjekt direkt repräsentieren kann, noch basiert sie auf einem speziellen sinnlichen Mannigfaltigen, das das Denken selbst bewirkt (siehe B155) - d.h. es gibt in der ersten Variante des Ich denke keinen mit der Kognition verbundenen phänomenalen Gehalt] im heutigen

\footnotetext{
${ }^{50}$ Wohlgemerkt besagt diese Passage nicht, dass das Mannigfaltig zur Bestimmung meines Daseins gegeben ist und die Art, dieses Dasein anhand des Mannigfaltigen zu bestimmen, nicht gegeben ist, weil zahlreiche Stellen gegen diese Auslegung sprechen, wie später noch gezeigt wird. Hier handelt es sich offenbar um eine unglückliche Formulierung.
} 
Sinne. ${ }^{51}$ Noch weniger enthält das Ich denke in der ersten Variante ein reines zeitliches Mannigfaltiges, durch das man den Zustand des Subjekts in der Zeit lokalisieren könnte:

Ich denke ist ein Satz a priori; ist eine bloße Categorie des Subjects, intellectuale Vorstellung ohne irgendwo und irgendwenn, also nicht empirisch. (NTKrV 23:39, meine Hervorhebung).

Das heißt, das „Ich denke“ ist insbesondere kein Urteil, das auf dem empirischen Bewusstsein des eigenen Zustands durch den inneren Sinn basiert. In dieser Variante ist das Ich denke als „der formale Satz der Apperzeption“ „keine Erfahrung [...] sondern die Form der Apperzeption“(A354, siehe auch A382).

Was genau ist diese intellektuelle Vorstellung in unserem bewussten Erleben? Sie ist ein „Bewußtsein meiner Selbst beim bloßen Denken“ (B429). Das bloße Denken ist wiederum „bloß die logische Funktion, mithin lauter Spontaneität der Verbindung des Mannigfaltigen einer bloß möglichen Anschauung“ (B428). Im bloßen Denken wird das Subjekt vorgestellt „wie ein jedes Objekt überhaupt, von dessen Art der Anschauung ich abstrahiere“ (B429). Genauer gesagt, wird das Ich als „Subjekt der Gedanken, oder auch als Grund des Denkens“ vorgestellt (B429). Kant lehnt es ab, diese Vorstellung als Anwendung der Kategorien der Substanz oder der Ursache zu bezeichnen, weil die Kategorien ,jene Funktionen des Denkens (Urteilens) schon auf unsere sinnlichen Anschauun angewandt" sind. Das bloße Denken als logische Funktion ist folglich der Verbindungsakt in den unschematisierten Kategorien, und was es verbindet, ist das Mannigfaltige einer Anschauung überhaupt. ${ }^{52}$ Allem Anschein

\footnotetext{
${ }^{51}$ Hier werden das Mannigfaltiges des Ichs und das der Denkhandlung getrennt thematisiert, weil das Ich als „Subjekt der Gedanken, oder als Grund des Denkens“ (B429) vom Denken selbst begrifflich zu unterscheiden ist.

52 Das Mannigfaltige einer Anschauung überhaupt ist keine sinnliche Vorstellung, sondern die ganz allgemeine begriffliche Bestimmung einer möglichen Anschauung, abstrahiert von ihrem besonderen sinnlichen Charakter. Eine derartige Betrachtungsstufe, abgesehen von jeglicher empirischen Gegebenheit, ist nicht empirisch, sondern transzendental (A343/B401).
} 
nach ist mit dem bloßen Denken die sogenannte Verstandesverbindung (synthesis intellectualis) gemeint (siehe \$3.2.2.1.). Diese ist diejenige Synthesis, „welche in Ansehung des Mannigfaltigen einer Anschauung überhaupt in der bloßen Kategorie [d.h. unschematisierten Kategorie] gedacht würde“ (B151) und „ohne alle Einbildungskraft, bloß durch den Verstand“" (B152). Unschematisierte Kategorien sind in der Tat nichts anderes als „blos auf Objecte überhaupt angewandte logische Functionen“ (ÜGTP 8:184, 1788). Das repräsentationale Vehikel des Selbstbewusstseins in der ersten Variante ist demnach das rein intellektuelle Denken. Der Satz „Ich denke“ drückt in dieser Variante einen selbstbewussten Denkakt aus, dessen Bestandteile reine Begriffe sind. Das Subjekt wird sozusagen in diesem Satz durch das reine Denken vorgestellt. Ganz wichtig ist es aber auch, dass das Subjekt bei der ersten Variante nicht nur durch das reine Denken, sondern auch als das Subjekt des reinen Denkens vorgestellt wird:

Wenn ich mich hier als Subject der Gedanken oder auch als Grund des Denkens vorstelle, so bedeuten diese Vorstellungsarten nicht die Kategorien der Substanz oder der Ursache [...] Nun will ich mich meiner aber nur als denkend bewußt werden; wie mein eigenes Selbst in der Anschauung gegeben sei, das setze ich bei Seite. (B429)

Das, was durch die Vorstellung „Ich denke“ in der ersten Variante repräsentiert ist, sind ein reiner Denkakt im Sinne einer reinen logischen Funktion und sein sowohl empirisch als auch begrifflich unbestimmtes Subjekt.

Der reine Denkakt, der mit dem „Ich denke“ semantisch korrespondiert, ist nicht der reine Denkakt des „Ich denke“ selbst. Wenn dies der Fall wäre, würde die Vorstellung „Ich denke“ einen reflexiven Denkakt darstellen, der auf sich selbst referiert und keine weitere gegenstandsbezogene Vorstellung erster Ordnung begleitet. Derartige Denkakte sind aber im Kontext des Apperzeptionsprinzips in $§ 16$ der transzendentalen Deduktion nicht relevant, da es dort in erster Linie um die Vorstellung des Ich denke geht, die eine empirische gegenstandsbezogene Vorstellung begleitet. Die Notwendigkeit, von dieser Vorstellung begleitet $\mathrm{zu}$ sein, stellt eine fundamentale 
Bedingung dafür dar, dass eine Vorstellung für das Subjekt eine epistemische Relevanz besitzt. Folglich muss sich die Vorstellung des Ich denke in der ersten Variante nicht auf sich selbst, sondern in erster Linie auf einen fremden Denkakt beziehen. Der Denkakt, den der Ausdurck „Ich denke“ bezeichnet, ist vielmehr der Denkakt, der in dem vom „Ich denke“ eingeleiteten Nebensatz ausgedrückt wird. Dieser ist im Kontext der Transzendentalen Deduktion wiederum das Urteil, das das sinnliche Mannigfaltige kategorial organisiert. Dieses Urteil ist die intellektuelle Komponente der Synthesis der Einbildungskraft, wodurch sich eine empirische, bestimmte Anschauung ergibt.

Die obige Analyse hat den bewusstseinstheoretischen und semantischen Charakter der Vorstellung des Ich denke als intellektuelles Bewusstsein gezeigt. Es gibt vereinzelte Stellen, die belegen, dass Kant tatsächlich die Wirklichkeit dieser Variante der Vorstellung des Ich denke behauptet (Refl 18:611, Refl 18:319-20). Meines Erachtens gibt es jedoch ein theoretisches Problem, das verhindert, dass diese reinen Denkakte einen realen mentalen Akt darstellen, der selbstständig vollzogen werden kann. Die Vorstellung des Ich denke repräsentiert Denkakte, derer sich das Subjekt intellektuell bewusst ist. Dabei soll sich diese Vorstellung auf einen einzelnen Denkakt beziehen dies ist tief durch unsere Intuition begründet. Jedoch kann das Urteil des Ich denke sich wegen seines allgemeinen diskursiven Charakters nicht auf einen einzelnen Gegenstand beziehen. Jeglicher Bezug auf einen einzelnen Gegenstand muss mittels einer Anschauung geschehen, denn nur eine Anschauung kann einen individuellen Gegenstand repräsentieren (B157, 158; OP 22:95). Das intellektuelle Bewusstsein ist aber keine Anschauung (B158). Zudem ist kaum vorstellbar, wie man sich faktisch rein gedanklich auf einen Denkakt als einen Denkakt beziehen sollte, ohne diesen als ein Ereignis in der Zeit aufzufassen. Das Individualisierungsprinzip des Denkakts ist die Zeit. Folglich muss das Bewusstsein der Denkakte de facto durch eine Anschauung durch den inneren Sinn geschehen. Daher kann meiner Meinung nach die erste Variante des Ich denke nicht ein faktischer mentaler Akt sein, sondern nur das Ergebnis davon, 
die zweite Variante der Vorstellung „Ich denke“ unter Abstraktion ihres empirischen Gehalts zu betrachten. ${ }^{53}$

\subsubsection{Die Vorstellung „Ich denke“ als Urteil der inneren Erfahrung}

Das Ich denke in der ersten Variante ist ein Satz a priori (NTKrV 23:39). Im Gegensatz dazu stellt Kant die Vorstellung des Ich denke auch als empirische Vorstellung vor:

Der Satz: Ich denke, oder: Ich existire denkend, ist ein empirischer Satz. Einem solchen aber liegt empirische Anschauung, folglich auch das gedachte Object als Erscheinung zum Grunde [...] (B428).

Der Satz aber: Ich denke, so fern er so viel sagt, als: Ich existire denkend, ist nicht bloße logische Function, sondern bestimmt das Subject (welches dann zugleich Object ist) in Ansehung der Existenz und kann ohne den inneren Sinn nicht stattfinden, dessen Anschauung jederzeit das Object nicht als Ding an sich selbst, sondern bloß als Erscheinung an die Hand giebt. In ihm ist also schon nicht mehr bloße Spontaneität des Denkens, sondern auch Receptivität der Anschauung, d.i. das Denken meiner selbst auf die empirische Anschauung eben desselben Subjects angewandet. (B429-430, meine Hervorhebung)

Nach Kant ist der Satz „Ich denke“ in dem Sinne von „Ich existiere denkend“ ein empirischer Satz. Beiden Sätzen liegt die empirische innere Anschauung durch den inneren Sinn zugrunde. Haben wir nicht schon einen apriorischen Satz „Ich denke“ als ein bloßes Denken, das unmittelbar die augenscheinlich ähnliche Existenzaussage „Ich bin“ miteinschließt? Den entscheidenen Hinweis liefert der folgende Satz: „Der Satz aber: Ich denke, so fern er so viel sagt, als: Ich existire denkend, ist nicht bloße logische Function, sondern bestimmt das Subjekt (welches dann zugleich Object ist) in

\footnotetext{
${ }^{53}$ Mehr über den Unterschied zwischen empirischem und intellektuellem Bewusstsein der Denkakte, siehe $\S 1.7$.
} 
Ansehung der Existenz“ (B429). Das heißt, in diesem Satz wird das Subjekt nicht bloß unmittelbar bewusst, sondern „bestimmt“. Bestimmen heißt hier, dass ein Prädikat A einem Ding zugesprochen und damit das kontradiktorische Prädikat non-A abgesprochen wird (PND 1:391; A571f./B599f.). Anders gesagt, Bestimmen heißt zu entscheiden, ob eine Eigenschaft einem Ding zukommt oder nicht. Das ist im Endeffekt ein Synomym dafür, dieses Ding zu erkennen (B166 Anm.). Der kognitive Akt für die Bestimmung ist „synthetisch urtheilen“ (FM 20:268). Das Bestimmen eines Gegenstands heißt folglich, ein synthetisches Urteil über ihn zu fällen. Dafür ist sinnliche Anschauung erforderlich (B148, siehe auch B166 Anm.). Die Bestimmung der Existenz des Subjekts bedeutet entsprechend, sinnliche Erkenntnis von ihr zu erzielen. Eine Stelle in der Widerlegung des Idealismus belegt und erklärt den Unterschied zwischen dem Bewusstsein der Existenz des Subjekts und der Bestimmung des Subjekts ganz explizit:

Allein hier wird bewiesen, daß äußere Erfahrung eigentlich unmittelbar sei, daß nur vermittelst ihrer zwar nicht das Bewußtsein unserer eigenen Existenz, aber doch die Bestimmung derselben in der Zeit, d.i. innere Erfahrung, möglich sei. Freilich ist die Vorstellung: ich bin, die das Bewußtsein ausdrückt, welches alles Denken begleiten kann, das, was unmittelbar die Existenz eines Subjects in sich schließt, aber noch keine Erkenntni $\beta$ desselben, mithin auch nicht empirische, d.i. Erfahrung; denn dazu gehört außer dem Gedanken von etwas Existirendem noch Anschauung und hier innere, in Ansehung deren, d.i. der Zeit, das Subject bestimmt werden muß. (B276-7, meine Hervorhebung)

Zunächst sollte angemerkt werden, dass Kant anscheinend nicht zwischen Bestimmung des Subjekts und Bestimmung der Existenz des Subjekts unterscheidet. Hier begeht er keinen Fehler der Verwechslung, denn dem Subjekt wahrheitsgemäß ein Prädikat zuzuschreiben und das Gegenteil abzusprechen bedeutet nichts anderes als zu bestimmen, auf welche Weise das Subjekt existiert. Wir können hier beide Begriffe ohne weiteres gleichsetzen. 
In der zweiten Variante ist die Vorstellung des „Ich denke“ deswegen eine empirische Vorstellung, weil sie sich auf die innere Anschauung des inneren Sinnes bezieht (siehe die zweite Hervorhebung und auch den letzten Satz des vorletzten Zitats aus B429-430). Aber das bedeutet nicht, dass der Denkakt „Ich denke“ selbst eine mentale Aktivität des Sinnes ist. Als ein Denkakt bleibt er eine kognitive Handlung des Verstandes und kein Produkt des Sinnes. Abgesehen von der inneren Anschauung des inneren Sinnes, auf die er sich bezieht, gehört er als spontane Handlung zum Verstand.

Was ist nun die innere Anschauung des inneren Sinnes, die bei der Bestimmung des Subjekts erforderlich ist? Sie ist Kants Definition des inneren Sinnes zufolge gerade ein empirisches Bewusstsein des Gemütszustands in der Zeit. ${ }^{54}$ Der Gemütszustand ist in dem Kontext der $K r V$ vor allem der Zustand der Vorstellung oder der repräsentationale Zuststand. Kants Bemerkung im obigen Zitat, dass die Existenz des Subjekts in Ansehung der Zeit anhand der inneren Anschauung bestimmt wird, bedeutet deswegen gerade, dass das Subjekt sich darüber bewusst ist, dass es sich zu einer bestimmten Zeit in einem bestimmten Vorstellungszustand oder im repräsentationalen Zustand des Gemüts befindet. Der Vorstellungszustand ist beim Menschen als denkendes Wesen vor allem ein Denkzustand, denn später erfahren wir, dass der innere Sinn nach Kant nur durch den spontanen Denkakt des Subjekts affiziert werden kann und somit wesentlich ein empirisches Bewusstsein des Denkaktes ist. Die innere Anschauung ist sozusagen das empirische Bewusstsein, dass sich das Subjekt zur bestimmten Zeit in einem bestimmten Zustand des Denkens befindet. Diese Auslegung stimmt mit dem folgenden Zitat überein:

ich existire denkend, so ist er empirisch und enthält die Bestimmbarkeit meines Daseins bloß in Ansehung meiner Vorstellungen in der Zeit. (B420, meine Hervorhebung)

\footnotetext{
${ }^{54}$ Die Zeit ist deswegen wichtig, weil sie die Form des inneren Sinnes ist. Die zweite Hervorhebung des obigen Zitats betont gerade den zeitlichen Charakter der inneren Anschauung, was zeigt, dass dort von der inneren Anschauung durch den inneren Sinn die Rede ist.
} 
Wenn dem Gedanken „Ich existire denkend“ eine Wahrnehmung meines Vorstellungszustands in der Zeit zugrundeliegt, dann beschreibt er die Tatsache, dass das Subjekt zum Zeitpunkt seines Aufkommens einen Gedanken denkt, was auch der Modus der Existenz des Subjekts zu diesem Zeitpunkt ist. Damit enthält er „die Bestimmbarkeit meines Daseins bloß in Ansehung meiner Vorstellung in der Zeit"“. Im Lichte dessen besagt die wahre Bedeutung des „Ich denke“ folgendes:

(ED) Ich existiere (jetzt) denkend.

Anhand der inneren Anschauung kann das „Ich denke“ in der zweiten Variante die Existenz des Subjekts deswegen bestimmen, weil es dem Subjekt einen konkreten Denkakt zu einem bestimmten Zeitpunkt als Prädikat zuschreibt. Dabei wird der Denkakt im Gegensatz zur ersten Variante nicht durch intellektuelles Bewusstsein, sondern durch empirische Wahrnehmung als ein inneres Ereignis in der Zeit - d.h. in der Erscheinungswelt - vorgestellt. Die Vorstellung des Denkens in (ED) und mithin die Existenz ist zeitlich bestimmt. Damit bezieht das Prädikat „Denken“ sich wegen des Zeitindikators ,jetzt“ auf ein objektives Ereignis und hat mithin eine objektive Bedeutung. Der Satz „Ich denke“ drückt entsprechend ein empirisches Urteil über ein Ereignis in der Zeit aus und stellt somit einen Erfahrungssatz dar. Durch ihn wiederum wird das Ich empirisch bestimmt. Im Gegensatz dazu bezieht sich der reine Gedanke „Ich denke“ auf kein Ereignis in der objektiven Welt. Daher kann letzteres auch das Subjekt nicht bestimmen. Die Vorstellung des Ich denke in der zweiten Variante ist somit nicht mehr ein bloßer „Gedank[e] von etwas Existirendem“ (B276-7) und „sich lediglich ihres Verbindungsvermögens bewusst“ (B158). Diese rein intellektuelle Vorstellung der Existenz ist keine empirische Erkenntnis der inneren Erscheinung, denn diese soll zeitlich sein. Dagegen drückt die Vorstellung des Ich denke in der zweiten Variante ein empirisches Urteil aus und stellt einen Satz der inneren empirischen Erkennisse dar. In der Tat handelt es sich bei dem Urteil „Ich denke“ gerade um eine begriffliche Bestimmung der inneren Wahrnehmung des 
inneren Zustands, die rein rezeptiv durch die Selbstaffektion generiert wird und begrifflich noch nicht bestimmt ist. Anhand dieses Urteils wird somit die unbestimmte innere Anschauung zur kategorial und damit zeitlich bestimmten inneren Anschauung. Dass die Existenz der Gedanken durch das Urteil „Ich denke“ kategorisch bestimmt wird, kann auch durch einige Stellen im vierten Paralogismus bestätigt werden:

Denn ich bin mir doch meiner Vorstellungen bewußt; also existiren diese und ich selbst, der ich diese Vorstellungen habe [...] Also existiren eben sowohl äußere Dinge, als ich selbst existire, und zwar beide auf das unmittelbare Zeugniß meines Selbstbewußtseins [...] Ich habe in Absicht auf die Wirklichkeit äußerer Gegenstände eben so wenig nöthig zu schließen, als in Ansehung der Wirklichkeit des Gegenstandes meines innern Sinnes (meiner Gedanken); denn sie sind beiderseitig nichts als Vorstellungen, deren unmittelbare Wahrnehmung (Bewußtsein) zugleich ein genugsamer Beweis ihrer Wirklichkeit ist (A370-371, meine Hervorhebung)

Aus der obigen Analyse ergibt sich folgende Beobachtung: Was die erste und die zweite Variante des Ich denke unterscheidet, ist, ob der Denkakt „Ich denke“" sich durch ein direktes intellektuelles Bewusstsein auf den Denkakt erster Ordnung bezieht oder mittels einer inneren Anschauung, die der innere Sinn infolge der Selbstaffektion durch den Denkakt erster Stufe generiert. Diesen beiden Varianten liegen zwei unterschiedliche Arten des epistemischen Zugangs zum Denkakt zugrunde: Man kann ein direktes intellektuelles Bewusstsein von einem Denkakt haben oder ein empirisches Bewusstsein mittels des inneren Sinnes. Die erste Variante ist in der Tat gerade die reine Apperzeption. Die zweite ist die Apperzeption tout court, die aus der reinen und der empirischen Apperzeption (= dem inneren Sinn) als ihren zwei Aspekten besteht. ${ }^{55}$

\footnotetext{
55 Siehe den Anhang über das Lose Blatt Kiesewetter.
} 


\subsubsection{Die dritte Variante des Ich denke:}

Das wohl rätselhafteste an Kants Ausführungen zur Apperzeption sind seine ambivalenten Bemerkungen über die reine Apperzeption. Diese fallen besonders an einer Stelle am Anfang des Paralogismus (A341/B399-A343/B401) ins Auge, die im Folgenden genauer untersucht werden soll.

Zunächst bezeichnet Kant das Ich denke als einen speziellen transzendentalen Begriff oder ein „Urteil““, das das „Vehikel aller Begriffe überhaupt“ ist (A341/B399). Es ist transzendental und dient dazu, ,alles Denken, als zum Bewußtsein gehörig, aufzuführen“ (A341/B400). Soweit handelt es sich hier offenbar um das Ich denke in der ersten Variante, d.i. die reine Apperzeption. Dies macht Kant auch explizit, indem er schreibt, dass das Ich denke „rein [...] vom Empirischen (dem Eindrucke der Sinne) ist" (A342/B400). Sehr überraschend und unmissverständlich behauptet Kant jedoch im weiteren Verlauf des Texts, dass die Vorstellung des Ich denke in der ersten Variante im Wesentlichen eine innere Wahrnehmung ist:

Man darf sich daran nicht stoßen, daß ich doch an diesem Satze, der die Wahrnehmung seiner selbst ausdrückt, eine innere Erfahrung habe, und mithin die rationale Seelenlehre, welche darauf erbaut wird, niemals rein, sondern zum Teil auf ein empirisches Prinzipium gegründet sei. Denn diese innere Wahrnehmung ist nichts weiter, als die bloße Apperzeption: Ich denke; welche sogar alle transzendentalen Begriffe möglich macht, in welchen es heißt: Ich denke die Substanz, die Ursache usw. (A342/B400f)

Laut dieser Passage hat man „eine innere Erfahrung“ „an dem Satz [Ich denke], der die Wahrnehmung seiner selbst ausdrückt“. Auf den ersten Blick suggeriert diese Bemerkung leicht den Eindruck, dass es sich dabei um die zweite Variante der Vorstellung des Ich denke handeln könnte: Das Ich denke ist eine begriffliche Bestimmung der inneren Anschauung des Denkakts, der wiederum die Vorstellung erster Ordnung begrifflich bestimmt. Denn der Satz „Ich denke“ soll die „Wahrnehmung seiner selbst ausdrück[en]“. Damit drückt das Urteil „Ich denke“ eine 
empirische Erkenntnis des inneren Zustandes, mithin eine innere „Erfahrung“, aus. Das Urteil „Ich denke“ selbst bleibt aber eine spontane Handlung des Verstandes. Es ist, wie wir schon gesehen haben, eine empirische Vorstellung, weil es die innere Anschauung begrifflich bestimmt. Damit wäre die im Zitat gemeinte „bloße Apperzeption“, die mit der inneren Anschauung identifizierbar ist, die Apperzeption tout court, die sowohl die reine Apperzeption als auch die empirische Apperzeption miteinschließt. Tatsächlich ist dieser Eindruck jedoch trügerisch, denn die Textlage ist deutlich komplizierter.

Die fragliche innere Wahrnehmung wird mit der bloßen Apperzeption „Ich denke“ identifiziert. Diese Identifikation ist selbst sehr problematisch und wir werden sie noch genauer untersuchen, doch bleibt unbezweifelbar, dass diese innere Wahrnehmung daran beteiligt ist, „sogar alle transzendentalen Begriffe möglich“ zu machen (A342/B400f.). Sie kann folglich auf keinen Fall die Wahrnehmung der inneren Zustände durch den inneren Sinn sein. Die transzendentalen Begriffe sind diejenigen, gemäß denen die transzendentale Synthesis der Einbildungskraft die reine und formale Anschauung gestaltet. Damit sind sie die transzendentale Bedingung der Erfahrung, umso mehr der inneren Erfahrung. Erst durch diese Synthesis wird der innere Sinn affiziert. Daher müssen die Vorstellung des „Ich denke“ und die innere Wahrnehmung „an diesem Satz“ offenbar vor und unabhängig von der Selbstaffektion und dem inneren Sinne schon vorhanden sein.

Wenn die im Zitat erwähnte innere Wahrnehmung nicht die innere Wahrnehmung durch den inneren Sinn ist, wie ist sie genauer zu verstehen? Im letzten Satz des Zitats wird „dies[e] innere Wahrnehmung“, die offensichtlich auf „die Wahrnehmung seiner selbst“ bezogen ist, gar mit der „bloß[en] Apperzeption: Ich denke“ identifiziert. Anderswo in der $\mathrm{KrV}$ ist die bloße Apperzeption eindeutig mit der reinen Apperzeption identifiziert, die an sich eine Vorstellung des Verstandes ist und keine sinnlichen 
Eindrücke beinhaltet. ${ }^{56}$ Weil außerdem diese „,bloße Apperzeption“ dem obigen Zitat zufolge ,sogar alle transzendentalen Begriffe möglich“" machen soll, ist sie von ihrer transzendentalen Rolle her auch mit der reinen Apperzeption zu identifizieren. Infolgedessen muss man schließen, dass die reine Apperzeption eine ,innere Wahrnehmung“ ist. Dies würde eine große terminologische Ungereimtheit bedeuten, denn die reine Apperzeption soll frei von allen sinnlichen Eindrücken und selbst ein spontaner Akt des Verstandes sein.

Bei genauem Hinsehen deutet alles darauf hin, dass der Satz „diese innere Wahrnehmung ist nichts weiter, als die bloße Apperzeption“ eine unglückliche Formulierung ist. Streng genommen identifiziert Kant im ersten Satz der zitierten Passage die reine Apperzeption (mit ihrem begrifflichen Gehalt „Ich denke“) weder wörtlich noch sachlich mit der inneren Wahrnehmung. Die Relation der beiden macht Kant ganz explizit: Der Satz „Ich denke“ solle die Wahrnehmung seines Selbst ausdrücken. In der Anmerkung in B422, die eine Parallelstelle zum obigen Zitat aus A342/B400f. ist, verweist Kant auch darauf, dass „Er [das Ich denke] drückt eine unbestimmte empirische Anschauung, d.i. Wahrnehmung, aus.“ Kant behauptet also nicht, dass der Gedanke „Ich denke“ selbst eine Wahrnehmung sei. Es kann nur sein, dass der Gedanke „Ich denke“ auf einer inneren Wahrmehmung basiert. Dies lässt sich auch gut durch Kants Bemerkung ,,ich doch an diesem Satze [,Ich denke'] eine innere Erfahrung habe“ untermauern: Nur, wenn man die bloße Apperzeption so versteht, dass sie sich als ein Urteilsakt auf eine innere Wahrnehmung bezieht und nicht selbst eine

\footnotetext{
56 „Allein der Mensch, der die ganze Natur sonst lediglich nur durch Sinne kennt, erkennt sich selbst auch durch bloße Apperzeption, und zwar in Handlungen und inneren Bestimmungen, die er gar nicht zum Eindrucke der Sinne zählen kann, und ist sich selbst freilich einesteils Phänomen, anderenteils aber, nämlich in Ansehung gewisser Vermögen, ein bloß intelligibler Gegenstand, weil die Handlung desselben gar nicht zur Rezeptivität der Sinnlichkeit gezählt werden kann“. (A546/B574. Siehe auch A400). Diese Bemerkung schließt jeden Deutungsversuch aus, die „bloße Apperzeption“ als eine empirische Vorstellung zu interpretieren. Zur Definition der reinen Apperzeption siehe z.B. BXL, B132.
} 
innere Wahrnehmung ist, kann sie selbst eine empirische innere Erkenntnis (synonym zu ,eine innere Erfahrung“) ausmachen. Es ist außerdem schwierig, die Aussage, dass die reine Apperzeption bzw. der Gedanke „Ich denke“ selbst eine innere Wahrnehmung ist, wörtlich zu nehmen. Meiner Meinung nach kann die einzig sinnvolle Interpretationsoption von dieser Aussage nur diese sein: Man hat ein phänomenales Erlebnis von dem reinen Verstandesakt „Ich denke“ selbst. Man hat somit eine sogenannte „kognitive Phänomenologie“ vom Urteilsakt „Ich denke“. Es ist jedoch nicht plausibel, dass das Ich denke als eine transzendentale Bedingung der Erfahrung immer phänomenal bewusst sein muss. Diese Lesart hat eine problematische Implikation angesichts von Kants Aussage in der oben zitierten Passage, dass das Urteil „Ich denke“ die fragliche innere Wahrnehmung ausdrückt. Infolge dieser Lesart würde gelten: Der Gedanke Ich denke bezieht sich auf das phänomenale Erlebnis, das genau mit dem Gedanken selbst verbunden ist. Wenn dies die richtige Lesart wäre, lässt sich das Apperzeptionsprinzip im B132 nicht mehr sinnvoll erklären. Denn was würde dann der völlig selbstbezogene Gedanke „Ich denke“ mit der von ihm zu begleitenden Vorstellung zu tun haben? An dem Satz „Ich denke die Substanz, die Ursache usw.“ der oben zitierten Passage erkennt man auch deutlich, dass sich der Gedanke „Ich denke“ semantisch vielmehr auf die begriffliche Komponente der Vorstellung erster Ordnung als auf ihn selbst oder auf irgendeinen Aspekt von ihm selbst bezieht.

Wohlgemerkt ist auch mit „,innere[r] Erfahrung“ in der oben zitierten Passage nicht diejenige innere Erfahrung gemeint, die durch Anwendung der (transzendentalen) Begriffe auf die unbestimmte Wahrnehmung des inneren Sinnes entsteht. Denn die Vorstellung „Ich denke“, an der man die fragliche „innere Erfahrung“ haben soll, ist Bedingung „all[er] transzendentalen Begriffe“ und damit Bedingung der äußeren und der inneren Erfahrung durch den inneren Sinn. Die „innere Erfahrung“ „an diesem Satz“ steht somit logisch „vor“ der inneren Erfahrung durch den inneren Sinn und der äußeren Erfahrung. 
Zusammengefasst bedeutet dies: Der Urteilsakt des Ich denke als die reine Apperzeption lässt sich mit der in A342/B400f. erwähnten inneren Wahrnehmung nicht identifizieren. Diese innere Wahrnehmung muss vielmehr durch einen anderen Akt des Gemüts affiziert werden.

\subsection{Bewusstsein, Transzendentale Apperzeption und innerer Sinn}

Oft scheint Kant zu meinen, dass das Bewusstsein notwendigerweise einen Bezug auf das transzendentale Subjekt und damit die transzendentale Apperzeption enthält:

Weil das Bewußtsein das einzige ist, was alle Vorstellung zu Gedanken macht, und worin mithin alle unsere Wahrnehmungen, als dem transzendentalen Subjekte, müssen angetroffen werden (A350)

Mit der Repräsentation läßt sich noch die Apperzeption verbinden — das Bewußtsein der Vorstellung. (V-Lo/Dohna 24:752) ${ }^{57}$

Passagen wie die zweite führen zu der Auffassung, dass Kant das Bewusstsein und die transzendentale Apperzeption nicht voneinander abgrenzt. ${ }^{58}$ Derartige Stellen sind in der Tat zahlreich und über Kants kritische und nachkritische Zeiten hindurch zu finden. ${ }^{59}$ Diese starke Position ist nicht haltbar. Aus einer ganz wichtigen Passage über das Thema Bewusstsein in A117 Anm. geht deutlich hervor, dass Kant das (empirische)

\footnotetext{
${ }^{57}$ Siehe auch $\log 9: 33$.

${ }^{58}$ Z.B. Schulting (2015:106): "almost all cases where Kant uses the term Bewustseyn, he means ... transcendental apperception.”. Pippin (1987:459): „Whenever I am conscious of anything, I also apperceive that it is I who am thusly conscious."

${ }^{59}$ Z.B. Anth 7: 141f.; V-Met-L2/Pölitz 28: 584; V-Met-K3/Arnoldt 29:970.
} 
Bewusstsein und die transzendentale Apperzeption (dort unter dem Namen „transzendentale Bewusstsein“) begrifflich unterscheidet. Dieses ist ein Bewusstsein des Selbsts, während der Selbstbezug ,alles verschieden[en] empirisch[en] Bewußtsein[s]" erst durch die synthetische Handlung des Denkens herzustellen ist. ${ }^{60}$ In der Tat ist sogar die schwache Position falsch. Das Bewusstsein an sich enthält nämlich nicht notwendigerweise die transzendentale Apperzeption bzw. einen Bezug auf das Subjekt:

das empirische Bewußtsein, welches verschiedene Vorstellungen begleitet, ist an sich zerstreut und ohne Beziehung auf die Identität des Subjects. Diese Beziehung geschieht also dadurch noch nicht, daß ich jede Vorstellung mit Bewußtsein begleite, sondern daß ich eine zu der andern hinzusetze und mir der Synthesis derselben bewußt bin. (B133)

Um diese Passage richtig zu verstehen, ist eine vorbereitende Bemerkung nötig. Obwohl diese Passage das empirische Bewusstsein thematisiert, gilt ihre Aussage für das Bewusstsein selbst. Denn aus dem Antizipationen-Kapitel (B207) wissen wir, dass das empirische Bewusstsein deswegen empirisch ist, weil der Gehalt der Vorstellung, die es begleitet, aus der Empfindung stammt. Sein empirischer Charakter hat nichts mit dem Bewusstsein selbst zu tun, weil die Empfindung kein Bestandteil des Bewusstseins ist. ${ }^{61}$ In B207 stellt Kant dem empirischen Bewusstsein das formale Bewusstsein gegenüber. Dieser Gegenüberstellung liegt die Dichotomie der Form-Materie zugrunde, so dass die Einteilung des Bewusstseins im empirischen und formalen Bewusstsein das ganze Spektrum von „Bewusstseinarten“ erschöpft. Das formale und das empirische Bewusstsein unterscheiden sich bloß im Grad der Qualität der Empfindung und sind in anderen bewusstseinstheoretischen Hinsichten miteinander

\footnotetext{
${ }^{60}$ Am Anfang des $§ 16$ der $K r V$ (B132) ist die begriffliche Unterscheidung des Bewusstseins und des Selbstbewusstseins ebenfalls ersichtlich: „weil sie [die transzendentale Apperzeption] dasjenige Selbstbewußtsein ist, was, in dem es die Vorstellung: Ich denke, hervorbringt, die alle andere muß begleiten können und in allem Bewußtsein ein und dasselbe ist, von keiner weiter begleitet werden kann.“ (B132, meine Hervorhebung).

${ }^{61}$ Refl 18:72, 1776-1778.
} 
identisch. Daher kann die Ausführung in der obigen zitierten Stelle aus B133 nicht bloß für das empirische Bewusstsein, sondern auch für das Bewusstsein tout court gelten.

Nun zurück zur schwachen Position. Die Beziehung der Vorstellungen auf die Identität des Subjekts bedeutet im Kontext der B133, dass die bewussten Vorstellungen durch die transzendentale Apperzeption begleitet werden, die sich auf ein identisches Ich bezieht. Kants Bemerkung, dass die bloße Begleitung des Bewusstseins für diese Beziehung nicht ausreicht, impliziert gerade, dass das Bewusstsein an sich keinen Bezug auf das Subjekt beziehungsweise keine transzendentale Apperzeption enthält.

In der Tat gibt es in anderen Schriften von Kant starke Belege dafür, dass das Bewusstsein an sich nicht notwendigerweise die transzendentale Apperzeption enthält. Betrachten wir eine oft diskutierte Passage aus dem Brief an Herz: ${ }^{62}$

Denn wenn wir darthun können, daß unser Erkentnis von Dingen selbst das der Erfahrung nur unter jenen Bedingungen allein möglich sey, so sind nicht allein alle andere Begriffe von Dingen (die nicht auf solche Weise bedingt sind) für uns leer und können zu gar keinem Erkentnisse dienen, sondern auch alle data der Sinne zu einer möglichen Erkentnis würden ohne sie niemals Obiecte vorstellen, ja nicht einmal zu derjenigen Einheit des Bewustseyns gelangen, die zum Erkentnis meiner selbst (als obiect des inneren Sinnes) erforderlich ist. Ich würde gar nicht einmal wissen können, daß ich sie habe, folglich würden sie für mich, als erkennendes Wesen, schlechterdings nichts seyn, wobey sie (wenn ich mich in Gedanken zum Thier mache) als Vorstellungen, die nach einem empirischen Gesetze der Association verbunden wären und so auch auf Gefühl und Begehrungsvermögen Einflus haben würden, in mir, meines Daseyns unbewust, (gesetzt daß ich auch jeder einzelnen Vorstellung bewust wäre, aber nicht der Beziehung derselben auf die Einheit der Vorstellung ihres Obiects, vermittelst der synthetischen Einheit ihrer Apperception,) immer hin ihr Spiel regelmäßig treiben können, ohne daß ich dadurch in mindesten etwas, auch nicht einmal diesen meinen Zustand, erkennete. (Br 11:51-52, 1789)

Die Passage thematisiert ein primitives Gemüt, für das die Bedingungen der Einheit der Apperzeption nicht erfüllt sind. Für dieses Gemüt ist zwar die transzendentale und die

\footnotetext{
${ }^{62}$ Für eine genauere Analyse dieser Passage siehe Liang (2017).
} 
empirische Apperzeption nicht möglich, aber Kant spricht explizit vom Bewusstsein ,jeder einzelnen Vorstellung“(Br 11:52). In demselben Brief schreibt Kant:

die synthetische Einheit der Apperception, durch welche allein das Mannigfaltige der Anschauung (deren jedes ich mir besonders immerhin bewust seyn mag) in ein vereinigtes Bewustseyn, zur Vorstellung eines Obiects überhaupt, (dessen Begrif durch jenes Mannigfaltige nun bestimmt wird) zu bringen ( $\mathrm{Br}$ 11:50, meine Hervorhebung).

Auch hier scheint Kant zu behaupten, dass ein primitiver Geist sich unabhängig der Einheit der Apperzeption der einzelen Sinnesdaten bewusst sein kann. Es wurde zudem schon erwähnt, dass Kant auch in der Ausführung der Rangordnung der Erkenntnisse in mehreren Schriften andeutet, dass (zumindest manche) Tiere über Bewusstsein verfügen. All dies ist ein Beleg dafür, dass eine bewusste Vorstellung nicht unbedingt ein Selbstbewusstsein enthalten muss.

Andererseits definiert Kant den inneren Sinn (= empirische Apperzeption, siehe Anth 7:134, A107) als die Anschauung oder Wahrnehmung der eigenen Vorstellung:

Der innere Sinn, vermittelst dessen das Gemüth sich selbst oder seinen inneren Zustand anschauet (A22/B37). ${ }^{63}$

Eine derartige Darstellung klingt ähnlich wie Kants Definition des Bewusstseins als Vorstellung oder Anschauung der eigenen Vorstellung. ${ }^{64}$ Sowohl die Vorstellung des inneren Sinnes als auch das Bewusstsein werden als Vorstellungen höherer Ordnung charakterisiert, die einen repräsentationalen Zustand niedriger Stufe als ihren Gehalt haben. Bei beiden ist die Vorstellung höherer Stufe eine Wahrnehmung. Dies suggeriert die Auffassung, dass Kant die Vorstellung des inneren Sinns mit dem Bewusstsein

\footnotetext{
${ }^{63}$ Siehe auch A197/B242, V-Met/Mron 29:882.

64 „Das Bewustseyn begleitet jeden unserer Zustände, es ist gleichsahm das Anschauen unserer selbst.“ (V-Lo/Blomberg 24:40f., 1771; siehe auch V-Lo/Philippi 24:341, 1772). „Bewustseyn ist das Anschauen seiner Selbst“ (Refl 18:72, 1776-1778). „Das Bewußtseyn ist ein Wissen dessen, was mir zukommt. Es ist eine Vorstellung von meinen Vorstellungen, es ist eine Selbstwahrnehmung, Perception.“(V-Met-L1/Pölitz 28: 227, 1777-80).
} 
identifiziert, besonders wenn man die Position vertritt, dass die transzendentale Apperzeption nicht ein faktisches Bewusstsein, sondern eine epistemische oder formale Bedingung der Erkenntnis ist. Kant identifiziert beides in manchen Stellen gar explizit: „Der innre Sinn ist das Bewußtsein unserer Vorstellungen selbst.“ (V-Mo/Mron II 29:882) ${ }^{65}$ Der innere Sinn begleitet nämlich als das faktische, empirische Bewusstsein (A176/B217, A177/B220) alle bewussten Vorstellungen. Wenn die transzendentale Apperzeption, die der innere Sinn als seine transzendentale Voraussetzung enthält, kein faktisches Bewusstsein ist, dann lässt sich schließen, dass das Bewusstsein mit dem inneren Sinn koextensiv ist. Dies zeigt sich darin, dass Kant gelegentlich die „unmittelbare Wahrnehmung“ der Vorstellungen mit „Bewußtsein“ gleichsetzt (A371). Es ist jedoch auch unangebracht, den inneren Sinn ohne weiteres mit dem Bewusstsein zu identifizieren. Zu einem solchen Schritt fehlt es an eindeutiger Textevidenz.

Meines Erachtens zeigt Kants Ausführung über das Thema Bewusstsein und Selbstbewusstsein in seinen späteren Schriften (vor allem in der Anthropologie) deutlich den Tenor, der sich wie folgt zusammenfassen lässt:

1. Die transzendentale und die empirische Apperzeption sind nicht zwei separate mentale Akte, sondern können jeweils als der formale und der materiale Aspekt der Apperzeption betrachtet werden.

2. Die Apperzeption und das Bewusstsein sind ein und dasselbe.

Meines Erachtens lassen sich beide Thesen in $\mathrm{KrV}$ wiederfinden. Fangen wir zuerst mit Kants späteren Ausführung über das Thema Bewusstsein und Selbstbewusstsein an. In der Anthropologie, in der die systematischen und wohlüberlegsten Aussagen über dieses Thema in Kants Schriften zu finden sind, findet man detaillierte Aussagen über

\footnotetext{
65 Ähnliches siehe bei Schulting (2015:92, 97f.), Zöller (2015), Wunderlich (2005:135). Wunderlich hält dies für die Verwechselung des Bewusstseins mit dem inneren Sinn, die nur in vorkritischer Zeit zu finden ist. Aber in Schriften aus anderen Perioden findet man ähnliche Aussagen. Siehe V-Lo/Philippi 24:341; V-Met/Dohna 28:673, 952; V-Met/Mron 29:882; 4:31.
} 
die Verhältnisse zwischen transzendentaler und empirischer Apperzeption, Apperzeption überhaupt und Bewusstsein:

[...] so kann das Bewußtsein seiner selbst (apperceptio) in das der Reflexion und das der Apprehension eingetheilt werden. Das erstere ist ein Bewußtsein des Verstandes, das zweite der innere Sinn; jenes die reine, dieses die empirische Apperception, da dann jene fälschlich der innere Sinn genannt wird [...] (Anth 7:134 Anm.)

Hier setzt Kant das Selbstbewusstsein mit der Apperzeption gleich, die wiederum die empirische und die transzendentale Apperzeption einschließt. Einige Passage später sagt Kant:

[...] so wird das Bewußtsein in das discursive (welches als logisch, weil es die Regel giebt, voran gehen muß) und das intuitive Bewußtsein eingetheilt werden; das erstere (die reine Apperception seiner Gemüthshandlung) ist einfach. Das Ich der Reflexion hält kein Mannigfaltiges in sich und ist in allen Urtheilen immer ein und dasselbe, weil es blos dies Förmliche des Bewußtseins, dagegen die innere Erfahrung das Materielle desselben und ein Mannigfaltiges der empirischen inneren Anschauung, das Ich der Apprehension, (folglich eine empirische Apperception) enthält (Anth 7:141)

Demnach besteht das Bewusstsein gerade aus der transzdentalen und der empirischen Apperzeption. Offensichtlich enthält das Bewusstsein die transzendentale Apperzeption als seinen formalen Aspekt und den inneren Sinn als seinen materiellen Aspekt. ${ }^{66}$ Abgesehen von der schwierigen Frage, wie diese Passage genau zu verstehen ist, scheint eines ganz unumstritten zu sein: die beiden sind unzertrennliche Aspekte des Bewusstseins als eines mentalen Phänomens. Dies sieht man ebenfalls deutlich aus der folgenden Passage:

Wir müßen uns ein doppeltes Bewustseyn vorstellen, eine reine und eine empirische Apperception. Das Denken ist Actus der reinen Spontaneitaet, also intellectuelle Apperception; die empirische ist Receptivität, sezt etwas gegebnes voraus, wodurch wir afficirt werden. (V-Met/Dohna 28:654)

\footnotetext{
${ }^{66}$ Schon in der $K r V$ deutet Kant dies an: ,,dasjenige Selbstbewusstsein [..] was, in dem es die Vorstellung: Ich denke, hervorbringt, die alle andere muß begleiten können und in allem Bewußtsein ein und dasselbe ist, von keiner weiter begleitet werden kann“ (B132, Hervorgehoben durch den Autor).
} 
Der Interpretationsversuch, die transzendentale Apperzeption oder den inneren Sinn mit dem Bewusstsein zu identifizieren, scheitert somit. Das obige Zitat verstärkt zudem den Eindruck, dass Kant mit dem Begriff des Bewusstseins wesentlich das Selbstbewusstsein meint. Denn das Bewusstsein schließt sowohl die transzendentale Apperzeption, i.e. das direkte, intellektuelle Bewusstsein der eigenen Geistesakte, als auch die empirische Apperzeption, i.e. die empirische Anschauung des eigenen inneren Zustands (A22/B37), ein. Das Bewusstsein enthält wesentlich einen Selbstbezug. Es ist die höherstufige Vorstellung eines Vorstellungszustands erster Stufe, der wiederum ein Objekt als seinen Inhalt hat. Da dieser Vorstellungszustand erster Stufe bei den Menschen wesentlich eine Relation der Repräsentation zwischen dem Subjekt und einem Objekt ist, enthält das Bewusstsein unzertrennlich einen Bezug auf das Subjekt. ${ }^{67}$ Diese Überlegung über das Verhältnis zwischen der empirischen und der reinen Apperzeption lässt sich durch die folgende Passage weiter verstärken:

Wie ist es möglich daß ein Subject sich seiner Selbst als bloßer Erscheinung und unmittelbar bewust werde und doch zugleich als Ding an sich selbst? Jenes durch empirische dieses durch reine Apperception (Br 10: 340, meine Hervorhebung).

Das Wort „zugleich“ ist ein sehr starker Beleg dafür, dass die empirische sowie die reine Apperzeption keine getrennte mentale Akte, sondern zwei Aspekte desselben Akts sind.

Die gerade skizzierte Doktrin über das Verhältnis zwischen den beiden Apperzeptionen und dem Bewusstsein beschränkt sich nicht auf Kants spätere Schriften. In der Tat lassen sich alle Elemente dieser Doktrin in der $\mathrm{KrV}$ und anderen zeitgleichen Schriften finden. Erstens ist die transzendentale Apperzeption mit dem inneren Sinn im menschlichen Gemüt unzertrennlich verbunden. Beide hängen voneinander ab: Die Erstere ist „,in allem Bewußtsein ein und dasselbe“ (B132). Weil der innere Sinn das

\footnotetext{
${ }^{67}$ Siehe Liang (2017).
} 
faktisches empirisches Bewusstsein ist (A176/B217, A177/B220), muss er die transzendentale Apperzeption enthalten. ${ }^{68}$ Es gibt einen wichtigen sachlichen Grund für diese Abhängigkeit: Der innere Sinn ist dasjenige, ,,vermittelst dessen das Gemüth sich selbst oder seinen inneren Zustand anschauet" (A22/B37, A38/B55). Er ist eine Vorstellung, „daß eine andre Vorstellung in mir ist“ (Log 9:33). Der innere Sinn repräsentiert also den inneren Zustand als etwas, das zu meinem Gemüt gehört - d.h. etwas ,in mir“ ist. Der innere Sinn muss folglich wesentlich einen Akt enthalten, durch den der innere Zustand als ,mein[] eigen[er]“ erfasst wird (A122; V-Met/Mron 29:882, 1782/3). Wie bereits gesagt, liefert der innere Sinn keinen eigenen Stoff oder Sinnesqualitäten. Die transzendentale Synthesis der Einbildungskraft, die den inneren Sinn affiziert, bewirkt keine spezielle Anschauung von ihr selbst. Die Materie der Vorstellung des inneren Sinnes liefern ausschließlich die Vorstellungen der äußeren Gegenstände. Um die Vorstellungen der äußeren Gegenstände als eigene Zustände zu erfassen, braucht der innere Sinn zusätzlich einen gedanklichen Akt, der dem Subjekt diese Vorstellung zuschreibt. Dieser gedankliche Akt ist nichts anders als die transzendentale Apperzeption. Diese Abhängigkeit zeigt sich auch darin, dass Kant gelegentlich das Identitätsbewusstsein, das im inneren Sinn (bzw. der empirischen Apperzeption) enthalten ist, betont (siehe den kursiven Text in der unten zitierten Passage A115-7). Dieses Identitätsbewusstsein verdankt der innere Sinn der transzendentalen Apperzeption. Im Lichte all bisher Gesagten ist dieses Zitat nun verständlich: „Die Apperception liegt dem innern Sinn zum Grunde“ (V-Met/Mron 29:882) ${ }^{69}$ Mit anderem Wort, wegen des speziellen sinnlichen Charakters des inneren

68 „Der innre Sinn ist das Bewußtsein unserer Vorstellungen selbst. (Die Apperception liegt dem innern Sinn zum Grunde). Es hat zum Object die Seele. Wenn die Seele sich selbst ihrer bewußt ist, ohne ihres Zustandes bewußt zu sein, so ists Apperception. Ist sie auch ihres Zustandes bewußt, so ist es Empfindung oder Wahrnehmung.“(V-Met/Mron 29:882, 1782/83)

69 Ameriks verweist auf eine Stelle, wonach man den inneren Sinn ohne die transzendentale Apperzeption haben kann: „Es ist aber merkwürdig: daß das Kind, was schon ziemlich fertig sprechen 
Sinnes ist die transzendentale Apperzeption entscheidend für die Innerlichkeit des inneren Sinnes. Andererseits ist die transzendentale Apperzeption wesentlich auf dem inneren Sinn angewiesen. Sie ist nämlich in der Tat das Bewusstsein der „durchgängig[en] Identität seiner selbst bei allen möglichen Vorstellungen“ (A115). Hier bezieht sich der Begriff ,all[e] mögliche Vorstellung“ nicht auf dunkle oder nur im Gedächtnis vorhandenen Vorstellungen, sondern auf Vorstellungen im empirischen Bewusstsein (A115-7). Das heißt, die transzendentale Apperzeption ist wesentlich ein transzendentales Bewusstsein, das in allen Episoden des empirischen Bewusstseins unverändert bleibt und diese zusammenbindet. Sie setzt die empirische Vorstellung im inneren Sinn voraus (B422 Anm.). Daher hängt die transzendentale Apperzeption auch unzertrennlich mit dem inneren Sinn zusammen.

kann, doch ziemlich spät (vielleicht wohl ein Jahr nachher) allererst anfängt durch Ich zu reden, so lange aber von sich in der dritten Person sprach (Karl will essen, gehen u.s.w.). [...] Vorher fühlte es bloß sich selbst, jetzt denkt es sich selbst“" (Anth 7:127). Das Kind scheint zwar das empirische Bewusstsein seines Gemütszustands, aber kein Bewusstsein des Selbsts zu haben. Das genannte Fühlen des Selbsts ist anscheinend ein nicht-begriffliches Selbstbewusstsein. Meines Erachtens liefert diese Stelle keinen entscheidenden Beleg gegen die Abhängigkeit des inneren Sinnes von der transzendentalen Apperzeption. Es kann sein, dass Karl das Vermögen der transzendentalen Apperzeption bereits hat, denn die Fähigkeit des Denkens, die Einheit des Bewusstseins und die Kohärenz der Erfahrung - Karl scheint all dies bereits zu haben - setzen dieses Vermögen voraus. Er hat bloß nicht die Fähigkeit, das Wort „Ich“ zu verwenden. Kant selbst scheint übrigens zu bestreiten, dass der in der dritten Person ausgedrückte Gedanke „Karl will essen“ überhaupt ein empirisches Selbstbewusstsein ausdrückt (siehe Ko 76, Anthropologie Dohna-Wundlacken). Zudem ist es auffällig, dass Kant selbst das Beispiel des kleinen Karls nicht ernstnimmt oder gravierend findet, obwohl es nach Ameriks Interpretation ziemlich problematisch für Kant sein kann. Schließlich liefert es sicher ein Beleg für die Möglichkeit der empirischen Erkenntnisse ohne die transzendentale Apperzeption (es scheint unumstritten zu sein, dass der kleine Karl manche empirischen Erkenntnisse haben kann) oder zumindest einen Beleg für das Denken ohne die transzendentale Apperzeption. Beides widerspricht den fundamentalen Thesen der transzendentalen Deduktion. 
Eine Stelle in der A-Deduktion zeigt das Verhältnis zwischen der transzendentalen und der empirischen Apperzeption am deutlichsten. Sie steht auch mit dem oben zitierten Hauptbeleg für die hier vertretene Auffassung (Anth 7:141) in Übereinstimmung:

[...] Es sind drei subjektive Erkenntnisquellen, worauf die Möglichkeit einer Erfahrung überhaupt, und Erkenntnis der Gegenstände derselben beruht: Sinn, Einbildungskraft und Apperzeption; jede derselben kann als empirisch, nämlich in der Anwendung auf gegebene Erscheinungen betrachtet werden, alle aber sind auch Elemente oder Grundlagen a priori, welche selbst diesen empirischen Gebrauch möglich machen. Der Sinn stellt die Erscheinungen empirisch in der Wahrnehmung vor, die Einbildungskraft in der Assoziation (und Reproduktion), die Apperzeption in dem empirischen Bewußtsein der Identität dieser reproduktiven Vorstellungen mit den Erscheinungen, dadurch sie gegeben waren, mithin in der Rekognition. ${ }^{70}$

Es liegt aber der sämmtlichen Wahrnehmung die reine Anschauung (in Ansehung ihrer als Vorstellung die Form der inneren Anschauung, die Zeit), der Association die reine Synthesis der Einbildungskraft und dem empirischen Bewußtsein die reine Apperception, d.i. die durchgängige Identität seiner selbst bei allen möglichen Vorstellungen, a priori zum Grunde. (A115-7)

Diese Passage hat den gleichen Tenor wie die schon zitierte aus Anth 7:141. Die Apperzeption tout court besteht aus einem empirischen und einem apriorischen Aspekt - d.i. der empirischen und der reinen Apperzeption. Die Apperzeption hat bei unserer Erfahrung vor allem einen empirischen Gebrauch, der wiederum den apriorischen Gebrauch derselben voraussetzt. Wegen dieses empirischen Gebrauchs ist die Apperzeption faktisch eine empirische Vorstellung bzw. eine Wahrnehmung, in diesem Sinne spricht Kant davon, dass die Wahrnehmung eine „Bestimmung der Apperzeption" ist (A368).

Nachdem gezeigt wurde, dass es sich bei der reinen und der empirischen Apperzeption um zwei Aspekte einer mentalen Aktivität, der Apperzeption, handelt, soll noch gezeigt werden, dass die Apperzeption im Kontext des menschlichen Gemüts synonym zum

\footnotetext{
${ }^{70}$ Hier betont Kant das Identitsbewusstsein an der empirischen Apperzeption.
} 
Bewusstsein ist. Historisch wird der Begriff der Apperzeption erstmals von Leibniz eingeführt:

Ainsi il est bon de faire distinction entre la perception, qui est l'état intérieur de la monade représentant les choses externes, et l'aperception qui est la conscience, ou la connaissance réflexive de cet état intérieur, laquelle n'est point donnée à toutes les âmes, ni toujours à la même âme. ${ }^{71}$

Johann Christian Wolff führt den Leibnizschen Ausdruck Apperzeption zuerst mit dem Ausdruck „Bewußtsein“, später aber mit „Apperzeption“ in die deutsche philosophische Terminologie ein. ${ }^{72}$ Bei ihnen ist die Apperzeption ein mentaler Akt, der alles Denken, Vorstellen oder Erfahren begleitet und sich primär auf den Gegenstand der Vorstellung als auf das Subjekt derselben bezieht. ${ }^{73}$ Kant betont bei der Verwendung des Begriffs der Apperzeption vor allem den Bezug auf das Subjekt der Vorstellung und steht somit der Leibnizschen Verwendung nahe.

In der $K r V$ und Schriften zur gleichen Zeit verwendet Kant den Begriff „Einheit des Bewusstseins“, wenn er in der Tat „Einheit der Apperzeption“ meint (A107, 117Anm.; B411, 427). Ebenfalls verwendet er anscheinend die Begriffe „Apperzeption“ und „Bewusstsein“ synonym (z.B. A117 Anm., 304, 361). ${ }^{74}$ Wenn er sich auf die Apperzeption als Vermögen bezieht, bezeichnet er diese manchmal gar als "Vermögen des Bewußtseins” (MAN, 4:542, 1786. Siehe auch A117 Anm.). Das „bloße Bewußtsein“ bezeichnet er als das Bewusstsein, „welches in allem Denken enthalten

\footnotetext{
71 „Daher muß man zwischen der Perzeption, welche der innere, die Außendinge darstellende Zustand der Monade ist, und der Apperzeption unterscheiden, welche das Bewußtsein oder reflexives Wissen dieses inneren Zustands ist, welches weder allen Seelen noch derselben Seele immerwährend verliehen ist.“ (Leibniz: Die in der Vernunft begründeten Prinzipien der Natur und der Gnade, §4, Übersetzung modifiziert durch den Autor).

${ }^{72}$ Carl (1992:61).

73 Ibid.

${ }^{74}$ Weitere Belege aus seinen späteren Schriften sind z.B. V-Met-K3/Arnoldt 29:970, 1794/5.
} 
ist“" (B812). Das ist, sachlich betrachtet, gerade die transzendentale Apperzeption. In einer Stelle in der Vorlesung Metaphysik $L_{2}$ sagt Kant gar:

Eine Art der Vorstellung kann alle unsere Vorstellungen begleiten, diese ist die Vorstellung von uns selbst. Die Vorstellung von uns selbst heißt das Bewustseyn, apperceptio. (V-Met-L2/Pölitz 28: 584).

Ganz deutlich sagt Kant auch:

Dieses [Das Bewusstsein] ist die Vorstellung seiner Vorstellungen und heißt auch darum Apperception. (V-Met/Mron 29:889, 1782/3).

Aus diesen Gründen scheint der Begriff des Bewusstseins mit dem der Apperzeption bedeutungsgleich zu sein. Kants Terminologie betreffend das Bewusstsein und das Selbstbewusstsein ist nach meiner Analyse, entgegen vielen Kommentatoren, in der Tat ziemlich konsequent und sauber. ${ }^{75}$

\subsection{Zwei Gewahrseinsweisen des Gedankens: Loses Blatt Kiesewetter}

Um die Relation von der reinen und der empirischen Apperzeption und ihren bewusstseinstheoretischen Status zu klären, muss man einen enorm wichtigen Aufsatz aus Kants Nachlass, und zwar den Aufsatz mit dem Titel „Beantwortung der Frage, ist es eine Erfahrung, daß wir denken?“ (Refl 18:319-20, 1788-9), untersuchen. Er könnte wertvolles Licht auf ein Rätsel werfen, das in §1.5.4.3. erwähnt wird, nämlich den Unterschied zwischen dem intellektuellen Bewusstsein und dem empirischen

\footnotetext{
${ }^{75}$ Vgl. Zoeller (2015), Kitcher (2015), Wunderlich (2010).
} 
Bewusstsein des Denkakts. Fortan wird dieser Aufsatz „Loses Blatt Kiesewetter" genannt.

Am Anfang dieses Aufsatzes werden drei Stufen der empirischen Vorstellung unterschieden. Im Gegensatz zur Wahrnehmung, die „eine empirische Vorstellung [ist], deren ich mir bewußt bin“, werden die empirische Erkenntnis und die Erfahrung eingeführt:

[Z.1] Eine empirische Vorstellung, deren ich mir bewust bin, ist Wahrnehmung; das, was ich zu der Vorstellung der Einbildungskraft vermittelst der Auffassung und Zusammenfassung (comprehensio aesthetica) des Mannigfaltigen der Wahrnehmung denke, ist die empirische Erkenntniß des Objects, und das Urtheil, welches eine empirische Erkenntniß ausdrückt, ist Erfahrung. (Refl 18:318)

Die empirische Erkenntnis ist eine Vorstellung, die die Sinnesdaten in der Wahrnehmung vermittels der Einbildungskraft unter Begriffe begreift. Gegenstand der empirischen Erkenntnis sind raumzeitliche Dinge, Ereignisse oder Zustände. Die Erfahrung ist das Urteil, das diese Gedanken ausdrückt. Im Gegensatz zur Erfahrung, behauptet Kant:

[Z.2] (1) wenn ich mir a priori ein Quadrat denke, so kann ich nicht sagen, dieser Gedanke sey Erfahrung; (2) wohl aber kann dieses gesagt werden, wenn ich eine schon gezeichnete Figur in der Wahrnehmung auffasse, und die Zusammenfassung des Mannigfaltigen derselben vermittelst der Einbildungskraft unter dem Begriff eines Quadrats denke. (3) In der Erfahrung und durch dieselbe werde ich vermittelst der Sinne belehrt; allein wenn ich ein Object der Sinne mir blos willkührlich denke, so werde ich von demselben nicht belehrt und hänge bei meiner Vorstellung in nichts vom Objecte ab, sondern bin gänzlich Urheber derselben. (Refl 18:318-9)

Es gibt einige Unklarheiten bezüglich dieser Passage. Obwohl Kant am Anfang des Aufsatzes wichtige Begriffe definiert, bleibt der wichtigste Begriff des Denkens ohne Klärung, was leicht zur Verwirrung führt. Die Rede über die apriorische Vorstellung eines Quadrats könnte den Eindruck suggerieren, dass der Begriff des Denkens in dem Zitat nicht nur die gedankliche Vergegenwärtigung des Begriffs des Quadrats enthält, 
sondern auch eine mentale Imagination der Gestalt des Quadrats. ${ }^{76}$ Der Satz Z.2.(2) stellt kein entscheidendes Argument gegen diesen Eindruck dar, weil es sich dort um eine „gezeichnete Figur in der Wahrnehmung“ - d.h. eine wahrgenommene, nicht aber eine a priori eingebildete Figur - handelt. Gegen diese Auffassung der Konzeption des Denkens sprechen jedoch drei Überlegungen. Erstens handelt es sich in diesem Aufsatz, wie es ganz deutlich in seinem Titel hervorgehoben wird, um das begriffliche „Denken“, wie der Ausdruck „ein Object der Sinne mir blos willkührlich denke“ andeutet. Das Denken wird in Kants Schrift immer als spontane Funktion des Verstandes — als Verbindung begrifflicher Vorstellungen bzw. Urteile_-im Gegensatz zur Anschauung charakterisiert. ${ }^{77}$ In B746ff. wird das Denken des Dreiecks gerade als rein diskursive Vorstellung der Definition desselben ohne jegliche Beteiligung der reinen Anschauung dargestellt. Zweitens gehört laut dem weiteren Text des Aufsatzes das Denken zum „Denkungsvermögen“, d.i. zum Verstand, statt zur Sinnlichkeit. Offensichtlich geht es hier eher um rein begriffliche Vorstellungsakte als um reine Anschauung. Drittens wird die Interpretation des „Denkens“ als Urteil, das keine reine Anschauung enthält, auch durch das unten zitierte Zitat [Z.4] bestätigt, das eine Parallelstelle zum Losen Blatt Kiesewetter darstellt. Das Beispiel im Z.4 ist wegen des rein begrifflichen Charakters des Denkens an Gott weniger mißverständlich. Dort sollte klar sein, was für Kant in einem solchem Beispiel wichtig ist, ist der Kontrast zwischen dem diskursiven Denken

\footnotetext{
${ }^{76}$ Mit „Imagination“ meine ich die Vorstellung eines Gegenstands ohne dessen Gegenwart, um sie von Kants Begriff der „Einbildung“ zu unterscheiden, die sowohl in als auch ohne Gegenwart des Gegenstands ausgeübt werden kann.

77 Denken ist „,soviel als Urteilen oder Vorstellungen auf Urteile überhaupt beziehen.“ (Prol 4:304). Das Vermögen zu urteilen ist „eben soviel, als das Vermögen zu denken“ (B106). Das Denken besteht „,in der Handlung, die Synthesis des Mannigfaltigen [...] zur Einheit der Apperzeption zu bringen.“ (B145). „Denken ist das Erkenntnis durch Begriffe“ (B94). Siehe auch Eisler (1994:86-7). Ameriks z.B. intepretiert das „Denken“ in dem Losen Blatt Kiesewetter als „lesser awareness“ (Ameriks 2001:247). Das halte ich für falsch. „Awareness“ ist ein unspezifisches Bewusstsein, was sowohl sinnliche als auch begriffliche Vorstellungen sein kann, während „Denken“ ein Akt des Urteils sein muss.
} 
selbst und dem empirischen Bewusstsein derartigen Denkens als einen mentalen Zustand oder als „Bestimmung des Gemüths“. Am Ende spricht auch eine entscheidende Aussage gegen die obige Auffassung: Der Unterschied zwischen Erfahrung und apriorischem Denken ist, dass die Erfahrung uns über die Eigenschaft der Figur „,belehr[en]“ kann (siehe Z.2.3). Sachlich betrachtet, kann die Imagination des Quadrats des Subjekts dies tun, während das reine apriorische Denken an die Figur dieses nicht vermag. Im [Z.3.3] bezeichnet Kant übrigens den mentalen Akt „eine Figur von vier gleichen Seiten und rechten Winkeln so in Gedanken [zu] fassen, daß ich davon die Eigenschaften demonstrieren kann“ als Erfahrung. Dies bezieht sich offenbar auf die Imagination des Quadrats. Man muss auch bedenken, dass Kant auch in B154ff. die Imagination geometrischer Figuren als Produkt des inneren Sinnes auffasst. Daher muss auch die am Anfang des Losen Blattes Kiesewetter erwähnte Imagination der Figur des Quadrats zur Erfahrung gehören. Das heißt, all diese Indizien zeigen, dass man den Satz 2 des Z.2 „eine schon gezeichnete Figur in der Wahrnehmung auffasse, und die Zusammenfassung des Mannigfaltigen derselben vermittelst der Einbildungskraft unter dem Begriff eines Quadrats denke“ dahingehend deuten muss, dass durch diese Behauptung auch die Imagination des Quadrats nicht ausgeschloßen wird. Der Punkt des Beispiels ist also nicht, dass die Imagination der geometrischen Figur durch den inneren Sinn keine Erfahrung liefert, sondern vielmehr, dass apriorisches Denken, das rein begrifflich ist und dem gar keine sinnlichen Daten korrespondieren, keine Erfahrung liefert.

Ferner muss beachtet werden, dass es das Denken apriori ist, dem Kant den epistemischen Status der Erfahrung entziehen will, nicht aber das Denken tout court, obwohl der Titel des Losen Blattes Kiesewetter auf dem ersten Blick auf das Letztere hindeuten könnte. Denn sowohl der erste Satz des Beispiels Z.1 als auch das Beispiel Z.4. zeigen, dass das Denken a priori im Zentrum von Kants Fokus steht. Sachlich gesehen kann dies auch nicht anders sein, denn Erfahrung selbst ist ein „Urteil, welches 
eine empirische Erkenntniß ausdrückt“. D.h. Erfahrung ist selbst eine Art von Denken, das empirische Sachverhalte beschreibt. Daher muss es in diesem Aufsatz in erster Linie um Denken apriori gehen.

Der springende Punkt des Losen Blattes Kiesewetter findet sich in der folgenden Passage. Kant meint, auch wenn der Gehalt des Denkens keine Erfahrung ist, d.h. auch wenn das Denken a priori von seinem repräsentationalen Gehalt her keine empirischen Erkenntnisse liefert, stellt das Denken selbst einen Gegenstand der Erfahrung dar, und zwar einen Gegenstand der inneren Erfahrung:

[Z.3] (1) Aber auch das Bewußtseyn, einen solchen Gedanken zu haben, ist keine Erfahrung; eben darum, weil der Gedanke keine Erfahrung, Bewußtseyn aber an sich nichts Empirisches ist. (2) Gleichwohl aber bringt dieser Gedanke einen Gegenstand der Erfahrung hervor oder eine Bestimmung des Gemüths, die beobachtet werden kann, sofern es nämlich durch das Denkungsvermögen afficirt wird; (3) ich kann daher sagen, ich habe erfahren, was dazu gehört, um eine Figur von vier gleichen Seiten und rechten Winkeln so in Gedanken zu fassen, daß ich davon die Eigenschaften demonstriren kann. (4) Dies ist das empirische Bewußtseyn der Bestimmung meines Zustandes in der Zeit durch das Denken; (5) das Denken selbst, ob es gleich auch in der Zeit geschieht, nimmt auf die Zeit gar nicht Rücksicht, wenn die Eigenschaften einer Figur gedacht werden sollen. (6) Aber Erfahrung ist, ohne Zeitbestimmung damit zu verbinden, unmöglich, weil ich dabei passiv bin und mich nach der formalen Bedingung des innern Sinnes afficirt fühle.

[7] Das Bewußtseyn, wenn ich eine Erfahrung anstelle, ist Vorstellung meines Daseyns, sofern es empirisch bestimmt ist, d. h. in der Zeit. [...] [8] Das Bewußtseyn aber, eine Erfahrung anzustellen, oder auch überhaupt $\mathrm{zu}$ denken, ist ein transscendentales Bewußtseyn, nicht Erfahrung.

Nun stellen sich zwei Fragen: Warum ist das Denken a priori keine Erfahrung? In welchem Sinne sagt Kant, dass es einen Gegenstand der Erfahrung hervorbringt? Zuerst betrachten wir die erste Frage. Genauer gesagt, besteht die Antwort nicht darin, dass solches Denken nur eine begriffliche Bestimmung ist, die keiner empirischen Vorstellung korrespondieren kann. Der Gedanke des Begriffs eines Quadrats a priori 
kann durchaus einem empirischen Gegenstand entsprechen (A137/B176). ${ }^{78}$ Laut des Zitats [Z.2] ist deutlich, dass ein Denken genau dann Erfahrung ist, wenn sein begrifflicher Gehalt nicht potenziell, sondern tatsächlich auf einen empirischen Gegenstand in der Raumzeit — d.h. „eine schon gezeichnete Figur in der Wahrnehmung“ — Bezug nimmt. Das reine Denken an den Begriff des Quadrats, dem auch eine reine Anschauung a priori zugrundeliegen könnte, greift durch seinen Gehalt selbst gar keinen konkreten empirischen Gegenstand heraus. Die Erfahrung beinhaltet nicht einen beliebigen begrifflichen Gehalt, sondern denjenigen, der ein tatsächlich gegebenes empirisches Mannigfaltiges zusammenfasst.

Nun gehen wir zu der zweiten Frage über. Aus der Passage [Z.3] geht hervor, dass es zu einem Denkakt zwei verschiedene Gewahrseinsweisen gibt: a). durch „Bewußtseyn, eine solchen Gedanken zu haben“, der keine Erfahrung ist; b) durch Erfahren von dem, „Was dazu gehört, um eine Figur von vier gleichen Seiten und rechten Winkeln so in Gedanken zu fassen, daß ich davon die Eienschaften demonstrieren kann.“ Mit dem „Bewußtseyn, einen solchen Gedanken zu haben“ im (1) ist augenfällig das unmittelbare, intellektuelle Bewusstsein des reinen Denkakts gemeint. Ein solcher Gedanke ist nämlich „keine Erfahrung“, weil er als spontane Selbsttätigkeit keine Rezeptivität des Sinnes involviert und das Bewusstsein an sich „nichts Empirisches“ ist (Refl 18:219) - das heißt, das Bewußtsein selbst als ein mentales Ereignis enthält kein Empirisches. ${ }^{79}$ Das Bewusstsein des Denkakts apriori ist folglich intellektuell im Sinn vom „unvermittelt durch die Sinnlichkeit“. Die zweite Gewahrseinsweise ist Selbstwahrnehmung. Obwohl nämlich der Gehalt des Denken a priori rein ist, ist der

\footnotetext{
${ }^{78}$ Man kann sagen, dass diesem Gedanken des Quadrats eine reine Anschauung zugrundeliegt und er somit nicht rein von Sinnlichkeit ist. Meines Erachtens will Kant das Denken jedoch als bloßes Bewusstsein des Urteils, also der Verknüpfung der Begriffe, betonen. Dies lässt sich deutlich aus dem [Z.4] entnehmen.

${ }^{79}$ Hier ist mit dem Begriff „Bewusstsein“ offensichtlich nicht das Bewusstsein tout court, sondern die reine Apperzeption gemeint.
} 
Denkakt selbst „ein Gegenstand der Erfahrung“. Kant konstruiert die Wahrnehmung des Denkens nach dem Modell der äußeren Wahrenhmung. Analog zum Gegenstand der äußeren Erfahrung ist der Denkakt selbst als Gegenstand der inneren Wahrnehmung ein zeitliches Ereignis (,in der Zeit geschieht“) und damit ein Teil der Erscheinungswelt. ${ }^{80}$ Es ist „Bestimmung meines Zustandes in der Zeit“ oder „Factische Bestimmung unseres Vorstellungsvermögens“ - d.h. eine Art von Realität in der Zeit, die „beobachtet“ und objektiv erkannt werden kann. Ebenfalls analog zu äußeren Gegenständen kann man das Denken durch Affektion der Sinnlichkeit wahrnehmen. Das Denken als Zustand des Gemüts kann durch Selbstaffektion „beobachtet werden“. Das impliziert, dass ein Zustand des Gemüts auch unbeobachtet oder falsch beobachtet sein kann, da auch die Selbstaffektion, wie die äußere Affektion, einem Defekt unterliegen kann (Anth 7:135ff., 161ff., siehe auch Von dem inneren Sinne, Seite 1-2). Folglich misst Kant dem Zustand des Gemüts eine Art von Objektivität bei.

Somit gibt es zwei Zugriffsweisen zu einem Denkakt. Erstens hat man transzendentales Bewusstsein vom Gehalt des Denkens. Der Zugang ist direkt und unfehlbar und eine Voraussetzung für die Erfahrung überhaupt, wie das Lose Blatt Kiesewetter zeigt. Zweitens ist ein Denkakt eine „factische Bestimmung unseres Vorstellungsvermögens“, i.e. ein reales Ereignis bzw. ein Dasein in der Zeit. Das Bewusstsein dessen enthält nicht nur dessen repräsentationalen Gehalt - in dem Kontext des Losen Blattes Kiesewetter ist das ,was dazu gehört, um eine Figur von vier gleichen Seiten und rechten Winkeln so in Gedanken zu fassen, daß ich davon die Eigenschaften demonstriren kann“, sondern auch das Bewusstsein der Tatsache, dass das Subjekt zu einem bestimmten Zeitpunkt diesen Denkakt ausführt oder, anders gesagt, im Zustand des Denkens ist.

\footnotetext{
${ }^{80}$ Hier unterscheide ich, wie Kant, nicht zwischen Denken als Ereignis (bzw. „Akt“ in Kants Wort) und als Zustand, weil Kant selbst darüber nicht entschieden ist und auch nichts Wichtiges an dieser Unterscheidung hängt.
} 
Dieses Bewusstsein basiert auf der Selbstaffektion und enthält eine genaue Zeitbestimmung vom Denkakt - d.h. in welchem Zeitverhältnis dieser Denkakt mit anderen Ereignissen steht (siehe Vom dem inneren Sinn, Seite 1-2). Anders gesagt, durch die zweite Zugriffsweise kann man einen Gedanken als ein Ereignis in der Zeit bestimmen, während die erste Zugriffsweise dies nicht ermöglicht. Eine ähnliche Stelle bestätigt diese Interpretation:

[Z.4] Ich denke z.B. über die Gottheit nach und verbinde mit diesen Gedanken das transscendentale Bewußtseyn (denn sonst würde ich nicht denken können), ohne mich mir dabei doch in der Zeit vorzustellen, welches geschehen müßte, wenn ich mir dieser Vorstellung durch meinen innern Sinn bewußt wäre. Geschehen Eindrücke auf meinen innern Sinn, so setzt dies voraus, daß ich mich selbst afficire (ob es gleich uns unerklärbar ist, wie dies zugeht) und so setzt also das emprische Bewußtseyn das transscendentale voraus. (Refl 18:611)

Obwohl Kant an einigen Stellen (neben den Zitaten in diesem Abschnitt siehe auch B153) andeutet, dass man sich der Verstandesakten ,auch ohne Sinnlichkeit bewußt“ ist, ist die Annahme eines rein intellektuellen Bewusstseins der Verstandesakte als ein faktischer mentaler Zustand sehr problematisch. Das Hauptproblem liegt darin, dass ein intellektuelles Bewusstsein der einzelnen Denkakte als solches sich auf ein einzelnes Ereignis im Gemüt bezieht. Gemäß Kants Lehre der Dichotomie des Erkenntnisvermögens kann dieses intellektuelle Bewusstsein nur eine intellektuelle Anschauung sein, zu der der Mensch aber nicht fähig ist. In einem reinen Denkakt kann man sich nicht auf einen Gedanken beziehen, weil das Denken aus Begriffen bestehen, die sich auf gar keinen einzelnen Gegenstand beziehen können. In Kants früheren Schriften nimmt er eine intellektuelle Anschauung der Selbsttätigkeit an, der sich dieses Problem nicht stellt:

Die Wirklichkeit der Freyheit könen wir nicht aus der Erfahrung schließen. Aber wir haben doch nur einen Begrif von ihr durch unser intellectuelles inneres Anschauen (nicht den innern Sinn) unsrer Thatigkeit. (Refl 17:509, 1770-1771) 
In der $K r V$ lehnt er jedoch die intellektuelle Anschauung im menschlichen Gemüt kategorisch ab (B68, 159, 308; NTKrV 23:36) und ist damit wieder mit dem obigen Problem konfrontiert. Übrigens ist es schwer vorstellbar, wie man sich auf einen Gedanken beziehen können sollte, ohne ihn als ein Ereignis in der Zeit zu verorten. Soweit man diesen Gedanken als zeitliches Ereignis vorstellt, gehört dieser zum inneren Sinn sowie zum empirischen Bewusstsein, da man nur durch den inneren Sinn zeitliches vorstellen kann. Als Lösungsversuch schlage ich vor, intellektuelle Vorstellungen der Selbstätigkeit nicht als reale selbstständige mentale Akte, sondern als eine theoretische Annahme gelten zu lassen. Wir haben schon gesehen, dass die reine Apperzeption, die in der Anthropologie mit dieser intellektuellen Vorstellung gleichgesetzt wird, mit der empirischen Apperzeption unzertrennlich zu zwei Aspekten einer mentalen Bestimmung - die Apperzeption tout court - gehört. Auch in einer wichtigen Schrift sagt Kant,

Gedanken, als factische Bestimmungen des Vorstellungsvermögens, gehören auch mit zur empirischen Vorstellung unsers Zustandes (FM 20:270).

Anscheinend gibt es gar kein intellektuelles Bewusstsein des Gedankens, das faktisch als Bestimmung des Gemüts existiert. Alle unsere Gedanken sind Vorstellungen der Denkakte durch den inneren Sinn. Auch in diesem Sinne betrachtet Kant den inneren Sinn als „Inbegriff aller Vorstellungen“ (B220, B194). 


\section{Kapitel 2. Der innere Sinn}

In diesem Kapitel wird versucht, eine Skizze von Kants Doktrin des inneren Sinnes zu umreissen. In der $K r V$ sowie anderen Schriften gibt Kant selten eine detaillierte Charakterisierung des inneren Sinns. Der Grund dafür liegt vermutlich darin, dass der innere Sinn in Kants Zeit einen gängigen Begriff darstellt. Ein generelles Verständnis von ihm scheint er als zum Gemeingut philosophischer Bildung gehörend vorauszusetzen (Mohr 1991:55). In der $K r V$ steht der innere Sinn jedoch im engen Zusammenhang mit fast allen wichtigen Begriffen der kognitiven Vermögen und Prozesse. Ein großer Teil der textlichen Neuerungen der $K r V B$ nimmt so direkt oder indirekt Bezug auf den Begriff des inneren Sinns. Sachlich betrachtet ist die Theorie des inneren Sinnes, die historisch auf Locke zurückzuführen ist, hoch kontrovers. ${ }^{81} \mathrm{Im}$ Kontext des an dieser Stelle verfolgten Projekts ist es aber bereits ausreichend, die Vorstellungen des inneren Sinnes als mentale Ereignisse sowie ihre Verhältnisse zum Bewusstsein tout court und zur reinen Apperzeption klären zu können.

Zu diesem Zweck möchte ich zuerst Kants Doktrin des inneren Sinnes umreißen und die mit ihr verbundenen Interpretationsschwierigkeiten vorstellen. Sinnlichkeit bedeutet ganz allgemein die Fähigkeit, „Vorstellungen durch die Art, wie wir von Gegenständen affiziert werden, zu bekommen“"(A19/B33). Im Fall des inneren Sinnes liegt die sogenannte Selbstaffektion der inneren Wahrnehmung zugrunde:

Er [der Verstand] also übt unter der Benennung einer transscendentalen Synthesis der Einbildungskraft diejenige Handlung aufs passive Subject, dessen Vermögen er ist, aus, wovon wir mit Recht sagen, daß der innere Sinn dadurch afficirt werde. (B153-4)

Um den inneren Sinn zu erklären, muss man also die Selbstaffektion genau verstehen. Die Hauptschwierigkeit ist dabei den genauen Vorgang der Affektion sowie ihre Ergebnisse zu spezifizieren. Ganz kurz und grob gesagt, affizieren in der

\footnotetext{
${ }^{81}$ Neueste Debate darüber sind z.B. Lycan (1995, 2004), Shoemaker (1996)
} 
Selbstaffektion die spontanen kognitiven Akte des Verstandes den inneren Sinn. Dadurch wird das Subjekt sich seines eigenen mentalen Zustandes perzeptuell bewusst. Wie einfach dies auch zu sein scheint, gibt es über einige wichtige Punkte jedoch bisher keine Einigkeit unter den Kommentatoren: 1). Was für spontane mentale Akte affizieren den inneren Sinn? 2). Wird der innere Sinn zweimal affiziert, wie einige Kommentatoren behaupten? 3). Was ergibt sich aus der Selbstaffektion (bzw. folgt man den erwähnten Kommentatoren: den Selbstaffektionen)? 4). Wessen wird sich das Subjekt durch die Selbstaffektion(en) bewusst?

Um diese Fragen zu beantworten, wird in den folgenden Paragraphen versucht, Kants Doktrin des inneren Sinnes und der Selbstaffektion zu rekonstruieren. Dabei werde ich mich auf zwei Textstellen konzentrieren: Der zweite Teil des $\S 8$ in der transzendentalen Ästhetik (B66-69) und der berühmte Exkurs des §24 über das Paradox des inneren Sinnes. 


\subsection{Einführung}

In diesem Abschnitt werden einige begriffliche Vorbereitungen getroffen. Der Begriff des inneren Sinnes kann sowohl ein sinnliches Vermögen (z.B. Anth 7:135) im Gegensatz zum äußeren Sinn als auch die Vorstellungen, die dieses Vermögen produziert, bedeuten. Der Begriff der Vorstellung des inneren Sinnes ist ebenfalls zweideutig. Er kann sowohl die Vorstellungszustände bedeuten, die Gegenstände des inneren Sinnes sind, als auch die Vorstellungen zweiter Ordnung, die der innere Sinn als Vermögen produziert und deren repräsentationaler Gehalt die Vorstellungszustände erster Ordnung sind. In der folgenden Ausführung müssen wir diese Unterscheidung immer im Auge behalten.

Über den Gegenstand des inneren Sinnes gibt es in Kants Hauptwerken der theoretischen Philosophie in der Kritischen Zeit zweierlei Aussagen. Kant sagt einerseits, „[dass] [d]er innere Sinn, vermittelst dessen das Gemüth sich selbst oder seinen inneren Zustand anschauet, [...] zwar keine Anschauung von der Seele selbst als einem Object [gibt] [...]“ (A22/B37). Er betont immer wörtlich, dass der Gegenstand des inneren Sinnes ,unser[] selbst und unser[] inner[er] Zustand[]“ ist (A33/B49, siehe auch A38/B55, B68). Er betont auch den Anschauungscharakter des inneren Sinnes: dieser soll „die innere und sinnliche Anschauung unseres Gemüths (als Gegenstandes des Bewußtseins)“ liefern (B520). ${ }^{82}$ Im Kontext der empirischen Erkenntnisse meint Kant mit dem Begriff, ,innerer Zustand“ nicht jeden beliebigen, sondern lediglich einen repräsentationalen Zustand. In diesem Sinne bezeichnet er den Gegenstand des inneren Sinnes als das „Ich selbst mit allen meinen Vorstellungen“(A368, V-Met/Mron 29:882). In einer weiteren Stelle grenzt er den Gegenstand des inneren Sinnes weiter ein: Dasjenige, was „mein innerer Sinn mir darbietet“ ist „,das, was entweder selbst ein

\footnotetext{
${ }^{82}$ In der Jäsche Logik sagt Kant: „Ihm [Dem inneren Sinn] liegt die innere Anschauung, folglich das Verhältniß der Vorstellungen in der Zeit [...] zum Grunde.“(Anth 7:161)
} 
Denken, oder mit diesem analogisch ist“ (B331). Diese enge Fassung des Begriffs des inneren Zustands hängt damit zusammen, dass der innere Sinn durch die Verstandesakte affiziert werden solle.

Andererseits verbindet Kant an manchen Stellen den Gegenstand des inneren Sinnes jedoch mit der „Seele“. Diese definiert er wiederum als das denkende Subjekt. In diesem Sinn bezeichnet er den Gegenstand des inneren Sinnes als „die Seele, und nach den Grundbegriffen derselben überhaupt die denkende Natur“ (A846/B874) oder „das Ich, was da denkt“ (B471). So schreibt er auch: „Ich, als denkend, bin ein Gegenstand des innern Sinnes und heiße Seele“ (A342/B400). ${ }^{83}$ Diesem Zitat zufolge stehen beide Angaben des Gegenstands des inneren Sinnes in Übereinstimmung, weil die Begriffe Ich, das denkende Wesen und die Seele synonym sind (siehe auch A361).

Nach Kant ist der innere Sinn „Inbegriff, darin alle unsre Vorstellungen enthalten sind“" (A155/B194). Wie wir schon gesehen haben, sind mit dem Ausdruck ,alle[] Vorstellungen" tatsächlich alle bewusste Vorstellungen (d.h. Vorstellungen mit der faktischen Begleitung der Apperzeption) gemeint. Denn es gibt unbewusste Vorstellungen, die nicht Gegenstand des inneren Sinnes sein können. Die Vorstellungen des inneren Sinnes können aus zweierlei Hinsichten betrachtet werden. Einerseits sind sie selbst „Modification[en]“ des Gemüts bzw. Zustände des Gemüts. Mithin ist das Bewusstsein von ihnen die Wahrnehmung der eigenen repräsentationalen Zustände. In diesem Sinne sind alle (irgendwann) bewusste Vorstellungen (wenn sie bewusst sind) als „Prädicate des innern Sinnes“ auf „das Ich als Subject“ bezogen (Prol. 4:334). Andererseits haben sie als repräsentationale Zustände jedoch auch einen intentionalen Gehalt und sind somit auf ein Objekt bezogen. ${ }^{84}$ In diesem Sinne enhält

\footnotetext{
83 Ähnliche Formulierungen gibt es an mehreren Stellen (A357, A361, Prol. 4:336, V-Met-L2/Pölitz 28: 583, V-Met/Mron 29:882).

84 „Da überdem die Prädicate, wodurch ich diesen Gegenstand denke, bloß Anschauungen des inneren Sinnes sind $[\ldots]^{“ /}(\mathrm{B} 471)$
} 
der innere Sinn wegen der von ihm begleiteten Vorstellungen auch ein Gegenstandsbewusstsein.

Nun gehen wir in folgenden Kapiteln nacheinander auf drei Unklarheiten ein:

1. Was für empirische Daten liefert der innere Sinn?

2. Was ist das Material, das durch die Synthesis, die den inneren Sinn affiziert, verbunden wird?

3. Was für Vorstellungen sind das Ergebnis der Selbstaffektion?

\subsection{Die speziellen Sinnesdaten des inneren Sinnes?}

Die Vorstellungen äußerer Sinne machen „den eigentlichen Stoff“ für den inneren Sinn aus (B67, BXXXIX Anm., Vom inneren Sinne, S. 18). Der repräsentationale Gehalt solcher Vorstellungen sind räumliche Gestalten, die von bestimmten Sinnesqualitäten „gefüllt“ sind. Diese Bemerkung ist schwer nachvollziehbar, wenn man bedenkt, dass sie nicht erklärt, was das Produkt des inneren Sinnes sein soll, wenn dieser keinen eigenen „Stoff“ liefert. Es ist unzweifelbar, dass der innere Sinn ein reines Mannigfaltiges der Zeitanschauung gibt. Dies ist jedoch offensichtlich kein „eigentlich[er] Stoff“ eines Sinnesvermögens. Wenn der innere Sinn analog zum äußeren Sinn konzipiert werden soll, dann erwartet man, dass er gleichfalls empirische Daten als seinen ,eigentlichen Stoff“ liefert. ${ }^{85}$ Der Grund dafür ist wie folgt. Der innere

\footnotetext{
85 Allison stellt die Analogie des äußeren und des inneren Sinnes hinsichtlich der fehlenden Sinnesdaten in Frage, die für den inneren Sinn spezifisch sind (Allison 1983:266). Schmitz (2015: 9,14) verwendet
} 
Sinn ist empirisch, er enthält eine Empfindung durch die Handlungen des Subjekts und erzeugt eine innere Wahrnehmung: „Das Bewußtsein seiner selbst nach den Bestimmungen unseres Zustandes bei der innern Wahrnehmung ist blos empirisch“(A107). „Die Wahrnehmung (empirische Anschauung mit Bewußtseyn) könne nur Erscheinung des inneren Sinnes genannt werden“ (Anth 7:399, siehe auch Anth 7:134, 153, 397; Br 10:270). ${ }^{86}$ Nun bezeichnet Kant das Element in den Erscheinungen, „was der Empfindung correspondirt“ als die Materie derselben und die Art das Mannigfaltige der Erscheinung $\mathrm{zu}$ ordnen als „die Form der Erscheinung“ (A20/B34). Die Form der Erscheinungen ist dementsprechend nichts Anderes als Zeit und Raum. Daraus schließt man, dass die Empfindung die „Materie“ liefert, die die Zeit- und Raumgestalten ausfüllt. Solche Materie kann nichts anders als die Sinneseindrücke oder Sinnesqualitäten sein (A175/B217). Wenn generell die Empfindung die Sinnesqualitäten liefern und der innere Sinn auf eine innere Empfindung angewiesen sein soll, stellt sich damit die Frage, was die Sinnesqualitäten des inneren Sinnes sein sollen. Diese Frage ist insofern schwierig, als der innere Sinn, wie Kant explizit macht, kein „eigentlichen Stoff“ haben solle.

Der erste Vorschlag der Interpretation des empirischen Gehalts des inneren Sinnes wäre zu akzeptieren, dass der innere Sinn keine speziellen empirischen Daten liefert. Allison macht auf dieses Interpretationsproblem aufmerksam (2004:282-3): Die Affektion und der Sinnlichkeit stehen in dem Sinne in einem wesentlichen Zusammenhang, dass die Affektion der Sinnlichkeit empirische Daten liefern soll. Das ist beim inneren Sinn im

die fehlenden Sinnesdaten des inneren Sinnes als ein entscheidendes Argument dafür, die Existenz der inneren Anschauung zu leugnen.

${ }^{86}$ Diese Beobachtung ist keineswegs trivial, denn in der anfänglichen terminologischen Erklärung (A1920/B34) definiert Kant die Sinnlichkeit als eine Fähigkeit der Rezeptivität, Vorstellung des Gegenstands durch die Affektion zu bekommen. Das Ergebnis der Sinnlichkeit ist Anschauung. Jedoch unterscheidet Kant auch Anschauung mit Empfindung und Anschauung ohne diese. Es ist also nicht ausgeschlossen, dass der innere Sinn allein Anschauung ohne Empfindung generiert. 
Gegensatz zum äußeren Sinn jedoch nicht der Fall, denn die Selbstaffektion ,is not regarded as an independent source of data". Zwischen dem inneren und dem äußeren Sinn besteht seiner Meinung nach eine Disanalogie, weswegen er beim Sinnlichkeitscharakter des inneren Sinnes „Abstriche“ macht: “there is little in common between the influence of objects upon outer sense (outer affection) and the 'synthetic influence of the understanding on the inner sense'(B154). Allison verweist auf Paton, der behauptet, dass die Funktion der Selbstaffektion allein darin besteht, das Mannigfaltige nach Bedingungen der Zeit zu verbinden. ${ }^{87}$ Allison schreibt: „,T]he identification of self-affection with the transcendental synthesis serves to accentuate the disanalogy between the two modes of affection" ${ }^{88}$ Damit ist nicht gemeint, dass die epistemische Rolle des inneren Sinnes darin besteht, die Vorstellungen des äußeren Sinnes in Zeitverhältnisse zu bringen. So konzipiert, wäre der innere Sinn nicht mehr ein Vermögen der Sinnlichkeit, die durch Rezeptivität charakterisiert ist, sondern er würde gefährlich in die Nähe eines spontanen kognitiven Vermögens gerückt, das die empirischen Vorstellungen des äußeren Sinns organisiert. Allison und Paton sind im Gegensatz zu einer solchen Auffassung wohl vielmehr der Meinung, dass der innere Sinn als das Vermögen zu betrachten ist, das den empirischen Daten des äußeren Sinnes eine neue Form - die Zeitlichkeit - gibt. Manchmal vermittelt Kant tatsächlich den Eindruck, dass der innere Sinn allein die sinnliche Form nicht aber die Materie der empirischen Anschauungen betrifft. Belege dafür lassen sich nicht schwer finden:

[A] Die Apperception und deren synthetische Einheit ist mit dem inneren Sinne so gar nicht einerlei, daß jene vielmehr, als der Quell aller Verbindung, auf das Mannigfaltige der Anschauungen überhaupt, unter dem Namen der Kategorien vor aller sinnlichen

\footnotetext{
${ }^{87}$ Paton (1936, vol.2, 238-40).

${ }^{88}$ Erwing hat auch eine ähnliche Meinung wie Paton (1938:124). In Allisons neuerem Werk hat er jedoch eine andere Position: „Kant maintains that its content [the inner sense's content] is provided by outer sense. This [] allows for the possibility of an inner experience, understood as a second-order, reflective cognition of one's mental history.“ (Allison 2015: 401). Er liefert jedoch keine substantielle Begründung dafür.
} 
Anschauung auf Objecte überhaupt geht; dagegen der innere Sinn die bloße Form der Anschauung, aber ohne Verbindung des Mannigfaltigen in derselben, mithin noch gar keine bestimmte Anschauung enthält. (B154)

[B] Denn der innere Sinn kan nichts als [...] das Zeitverhaltnis unserer Vorstellungen enthalten. (Refl 18:312, 1788-1789).

[C] Ebenso löse ich, wenn ich auf die Vorstellungen des innern Sinns Acht gebe, alles in lauter Zeitverhaltnisse auf, und das Absolute für den Verstand fehlt. (Refl 18:315, 1788-1789).

Demzufolge liefert der innere Sinn zwar kein empirisches Mannigfaltiges, wohl aber ein reines sinnliches Mannigfaltiges der Zeitrelation (B160-1). Genauer gesagt, ist dieses Mannigfaltige die Vorstellungen der Zeitpunkte, Zeitdauer und der Verhältnisse zwischen ihnen. Die Form des inneren Sinnes oder die Zeit ist die Art der Zusammensetzung des räumlichen Gegebenen, bzw. die Eindimensionalität der Sukzession der Wahrnehmungen. Das, was der innere Sinn erzeugt, sind die subjektiven Zeitrelationen der Vorstellungen, die noch nicht kategorisch bestimmt sind. Das heißt, obwohl der innere Sinn keine eigenen Sinneseindrücke gibt, soll er das Bewusstsein der subjektiven Sukzession der Wahrnehmungen liefern und damit auch das Bewusstsein der zeitlichen Relation einzelner Wahrnehmungen möglich machen. Insgesamt ist er ein Bewusstsein der formalen, zeitlichen Relationen der Sinnesdaten. Somit ist er rein formal und liefert keinen materialen Output.

Diese Interpretation hat jedoch einige Schwächen. So behauptet Kant etwa in A99: „Jede Anschauung enthält ein Mannigfaltiges in sich“. Dabei beschränkt Kant seine Aussage nicht auf die äußere Anschauung. Obwohl es unleugbar zu sein scheint, dass das obige Zitat (A) aus B154, das eine der beiden in der B- $K r V$ hinzugefügten Ausführungen über den inneren Sinn ist, diesen als bloße Form der Anschauung bezeichnet, wird aus den anderen in $\mathrm{B}-\mathrm{KrV}$ hinzugefügten Ausführungen über den inneren Sinn in B68 klar, dass dieser Eindruck falsch ist:

wenn sie [die Anschauung] nichts als Verhältnisse enthält, die Form der Anschauung, welche, da sie nichts vorstellt, außer so fern etwas im Gemüthe gesetzt wird, nichts 
anders sein kann als die Art, wie das Gemüth durch eigene Thätigkeit, nämlich dieses Setzen seiner Vorstellung, mithin durch sich selbst afficirt wird, d.i. ein innerer Sinn seiner Form nach (B67, meine Kursivierung)

Hier besagt der Kern dieser Aussage, dass die Zeit die Art der Selbstaffektion durch die spontanen Akte des Gemüts bzw. die Form des inneren Sinns ist. ${ }^{89}$ In B155 spricht Kant auch von der Bestimmung des inneren Sinnes „seiner Form gemäß“. All dies impliziert, dass der innere Sinn auch einen materialen Aspekt hat. Im anschließenden Text in B68 wird das empirische Selbstbewusstsein sogar als „innere Wahrnehmung von dem Mannigfaltigen, was im Subjekte vorher gegeben wird“ bezeichnet. Strenggenommen, besagt das Zitat [A] dem Kontext nach nicht, dass der innere Sinn nur die Form enthält. Der Ausdruck „,bloß“ betont nur, dass er keine Verbindung enthält. Die fragliche Interpretation ist übrigens mit der Definition des inneren Sinnes kaum vereinbar. Gemäß dieser bewirkt der innere Sinn eine Anschauung des inneren Zustandes. Diese enthält mehr als das Bewusstsein der Zeitverhältnisse der inneren Zustände. Wenn der innere Sinn bloß eine reine Zeitanschauung liefert, lässt sich schließen, dass die reine Zeitanschauung die Anschauung ,unserer selbst und unsers innern Zustandes“" ist, was völlig absurd ist (vgl. A33/B49). Zudem werden durch den inneren Sinn ,innere Erscheinung[en]“ vorgestellt (A107, A478/B506 Anm., A4912/B519-20), analog zum äußeren Sinn, durch den äußere Erscheinungen vorgestellt werden. Nur die Sinnesdaten, die die Empfindung liefern, können den materialen Aspekt der Erscheinungen darstellen, wie es bei dem äußeren Sinn genau der Fall ist.

Meines Erachtens lässt sich die obige Bemerkung über den Stoff des inneren Sinnes am besten so auslegen, dass die Sinnesdaten des äußeren Sinnes den materialen Aspekt der

\footnotetext{
${ }^{89}$ Meines Erachtens kann „,sein[]“ im letzten Satz nur auf den inneren Sinn bezogen sein. Sprachlich kommen außerdem „Gemüt“ und „Setzen“ in Frage. Das Erstere macht keinen Sinn, da Kant nie von der Form des Gemüts spricht. Die Form des „Setzen[s]“ ist ebenfalls problematisch, da es im dortigen Kontext eher um die Form der Selbstaffektion durch dieses Setzen geht.
} 
Vorstellungen des inneren Sinns ausmachen. ${ }^{90}$ Genauer gesagt, der innere Sinn beteiligt sich an dem Bewusstsein der äußeren Anschauung (sowohl der Sinnesdaten als auch der Räumlichkeit). Die Aussage, dass der innere Sinn keinen „eigentlichen Stoff" (d.h. empirische Daten) hat, impliziert nicht, dass der innere Sinn gar keine empirischen Daten liefert. Betrachten wir eine viel diskutierte Aussage über den inneren Sinn:

Es ist nur ein Inbegriff, darin alle unsre Vorstellungen enthalten sind, nämlich der innre Sinn und die Form desselben a priori, die Zeit (B194)

Auch diese Aussage widerspricht direkt der oben behandelten Lesart, dass der innere Sinn nur die Form der Anschauung betrifft. ${ }^{91}$ Wenn die Vorstellungen des inneren Sinnes koextensiv mit ,allen unsere[n] Vorstellungen“ (d.h. den bewussten Vorstellungen) sind, dann spricht das obige Zitat dafür, dass der empirische Gehalt dieser Vorstellungen den materiellen Aspekt des inneren Sinnes ausmacht. In Kants nachträglichen Reflexionen zur A-Auflage der $K r V$ heisst es:

„Empfindung ist das eigentliche empirische unserer Erkenntnis, und das Reale der Vorstellungen des inneren Sinns im Gegensatz gegen die Form desselben, die Zeit.“(NTKrV 23:27)

Die Sinnesqualitäten der Empfindung ${ }^{92}$ werden hier gar mit dem empirischen Gehalt der Vorstellung des inneren Sinnes gleichgesetzt. Ganz deutlich in B68 behauptet Kant, dass um aus der einfachen, leeren Vorstellung des Ich bzw. der Apperzeption eine innere Anschauung zu gewinnen, ,innere Wahrnehmung von dem Mannigfaltigen, was im Subjekte vorher gegeben wird [, erfordert wird]“. Dieses Mannigfaltige als

\footnotetext{
${ }^{90}$ Wolff hat eine ähnliche Darstellung, obwohl er diese Auffassung schließlich verwirft: „Since the spatial manifold ist the content of subjective consciousness, that manifold must itself become the object of a new manifold of representations. Then it will be the case that the spatial perceptions viewed as representations will represent outer objects, while the same perceptions viewed as objects will be represented by a manifold in inner sense.“(Wolff 1963:197).

${ }^{91}$ Siehe auch B202.

${ }^{92}$ Mit dem Ausdruck „Empfindung“ bezieht sich Kant sicher auf die Empfindung des äußeren Sinnes.
} 
Gegenstand der inneren Wahrnehmung kann dem dortigen Kontext nach nichts anders als das Mannigfaltige des äußeren Sinns sein. Diese Zitate liefern die deutlichste Evidenz dafür, dass die Sinnesdaten des äußeren Sinnes den materialen Aspekt der Vorstellung des inneren Sinns ausmachen. Auch in der Reflexion 6362 behauptet Kant,

[D]er innere Sinn so fern auch das Bewustseyn der äußern Anschauung enthält. (Refl 18:690)

Die Wahrnehmung (empirische Anschauung mit Bewußtseyn) könne nur Erscheinung des inneren Sinnes genannt werden. Damit sie aber innere Erfahrung werde muß das Gesetz bekannt sein welches die Form der Verbindung in einem Bewußtseyn des Objects bestimmt. (Anth 7:399)

Die Sinneseindrücke des äußeren Sinnes und das Bewusstsein der reinen Räumlichkeit—da die äußere Anschauung auch eine formale Bedingung hat—gehören demnach zu der Vorstellung des inneren Sinnes. ${ }^{93}$ Im inneren Sinn werden diese Sinnesdaten nicht nur auf äußere Gegenstände bezogen, sondern als Prädikate des Subjekts umgedeutet:

Bey der inneren Erfahrung aber die ich anstelle afficire ich mich selbst indem ich die Vorstellungen äußerer Sinne in ein empirisches Bewußtseyn [bringe um] meines Zustandes bringe" (Loses Blatt Leningrad, 7-10. Hervorhebung durch mich)

Die reine Anschauung des Manigfaltigen im Raum enthalt die Form des Gegenstandes in der Erscheinung a priori vom ersten Range d.i. directe. Die Zusammensetzung der Warnehmungen Erscheinung im Subject zum Behuf der Erfahrung ist wiederum Erscheinung des so afficirten Subjectes wie es sich selbst vorstellt also indirect und ist vom zweyten Range Erscheinung [...] d.i. Erscheinung des sich selbst afficirenden Subjects mithin indirect (OP 22:367).

Aus der vorigen Analyse und besonders den letzen vier Zitaten kann man schließen, dass der innere Sinn das Bewusstsein der äußeren Anschauung (d.h. der Sinneseindrücke des äußeren Sinnes sowie der der äußeren Anschauung

${ }^{93}$ Bei der Vorstellung des inneren Sinnes wird die empirische Anschauung des Gemütszustands gemeint. 
zugrundeliegenden Raumvorstellungen) enthält. Es bleiben zwei Möglichkeiten offen, dieses Enthaltensein zu deuten:

A. Die Anschauungen des äußeren Sinnes werden erst in dem inneren Sinn bewußt werden (in dem Sinne des phenomenalen Bewußtseins). Ohne des inneren Sinnes bleibt sie dunkele Vorstellungen.

B. Die Anschauungen des äußeren Sinnes könnten ohne Affektion des inneren Sinnes bewußt werden (in dem Sinne des phenomenalen Bewußtseins). Erst durch die Selbstaffektion werden sie als Bewusstsein „meines Zustandes“ umgedeutet.

Der ersten Interpretation liegt das Selbstwahrnehmungsmodell zugrunde. Sie impliziert, dass der innere Sinn eine notwendige und hinreichende Bedingung für das (phänomenale) Bewusstsein der Anschauung des äußeren Sinnes ist, obwohl der äußere Sinn die Vorstellung dieser Sinnesdaten sowie dessen formalen Bedingung liefert. ${ }^{94}$ Der zweiten liegt das Reflexionsmodell zugrunde, das den inneren Sinn als einen gelegentlichen Reflexionsakt konzipiert. Später im §3.5. wird argumentiert, dass das Reflexionsmodell falsch ist.

Unabhängig von der Ablehnung des Reflexionsmodells gibt es auch einige weitere Gründe, die A-Interpretation zu befürworten. Einige Aussagen Kants lassen erkennen, dass der innere Sinn für das empirische Bewußtsein der sinnlichen Vorstellungen sorgt. Wenn Kant in dem Antizipationen-Kapitel vom „empirischen Bewußtsein“ der Sinnesqualitäten (d.h. dem normalen, nach außen gerichteten bewussten Erlebnis statt einer Introspektion) spricht, erwähnt er, wie wir schon gesehen haben, dass dieses empirische Bewusstsein „im inneren Sinn“ ist. In A177/B220 behauptet er, dass die reine Apperzeption sich ,,a priori auf die Form desselben [den inneren Sinn], d.i. das Verhältnis des mannigfaltigen empirischen Bewußtseins in der Zeit“ bezieht. Auch hier

\footnotetext{
${ }^{94}$ Es muss ferner eingeschränkt werden, dass diese These nur für den menschlichen Geist gilt, da das phänomenale Bewusstsein auch dem nicht-apperzeptiven Geist, der keinen inneren Sinn hat, zugesprochen wird (siehe §2.7.). Das phänomenale Bewusstsein der Menschen, das durch den inneren Sinn ermöglicht wird, ist kategorisch strukturiert.
} 
scheint das empirische Bewußtsein der Sinnesqualitäten (hier „mannigfaltigen empirischen Bewußtseins") auf den inneren Sinn zurückzuführen. Weitere Stellen machen deutlich, dass der innere Sinn Sinneseindrücke (im Text heißt es: „Erscheinungen“) hervorbringt, die durch einen weiteren synthetischen Akt zur inneren Erfahrung verarbeitet werden:

„[Z]uerst müssen wir Erscheinungen durch ihn [= den inneren Sinn] haben, nachher allererst durch Reflexion über dieselbe uns einen Begrif von uns selbst machen, der alsdann empirisches Erkentnis meiner selbst, d.i. [...] innere Erfahrung, zur Folge hat.“(Refl 18:680, hervorgehoben von mir).

Ganz wichtig ist eine Stelle in der B-Deduktion. Demzufolge wird „dadurch [d.h. durch den inneren Sinn] jenes Mannigfaltige der Anschauung zu einer solchen Verbindung empirisch gegeben wird“" (B139, hervorgehoben von mir).

Alle die oben genannten Stellen zeigen, dass der innere Sinn nicht nur eine neue Dimension der Organisation des sinnlichen Mannigfaltigen - die Zeitlichkeit -, sondern auch das Mannigfaltige der äußeren Anschauung selbst „gibt“. ${ }^{95}$ Er enthält das Mannigfaltige der äußeren Anschauung nicht nur, sondern beteiligt sich an dem Bewusstsein von diesem.

Nun ist ersichtlich, inwiefern Allisons These der Disanalogie des äußeren und des inneren Sinnes verfehlt ist. Die Selbstaffektion hat durchaus einen Fluss von empirischen Daten als seinen Output und zwar das Mannigfaltige des äußeren Sinnes. Im Unterschied zu dem äußeren Sinn erzeugt der innere Sinn dieses Mannigfaltige nicht, sondern er nimmt den von dem äußeren Sinn gelieferten, schon im Gemüt vorhandenen Gehalt wahr, in dem Sinne, dass er diesen Gehalt phänomenal bewusst und somit für komplexe kognitive Operationen des Gemüts verfügbar macht. ${ }^{96}$ Der empirische Gehalt der äußeren Wahrnehmungen lässt sich auf den äußeren Sinn als Ursprung

\footnotetext{
95 Ähnliche Meinung hat auch Mohr (1991:157-8).

96 Liang (2017).
} 
zurückführen; die Bereitstellung und das Erlebnis dieses Gehalts verdankt das Gemüt jedoch dem inneren Sinn. Die Analogie zwischen beiden Modi der Sinnlichkeit besteht nicht nur darin, dass beide ein Mannigfaltiges hervorbringen, sondern auch darin, dass für beide Modi gilt, dass bestimmte (innere oder äußere) Gegenstände trotz ihrer Existenz (im Gemüte oder außer Reichweite der Sinne) nicht wahrgenommen werden. Dieses Wahrnehmungsmodell trifft sowohl auf den äußeren Sinn, als auch den inneren Sinn zu. Im Gemüt gibt es unzählige Vorstellungen, die nicht vom Bewusstsein „,illuminiert“ sind (V-Met/Mron 29:879). Erst in der Aufmerksamkeit werden einige von diesen durch Affektion des inneren Sinnes ins Bewusstsein aufgenommen. Diejenigen, die nicht in die Aufmerksamkeit gelangen, bleiben unentdeckt und dunkel (siehe \$3.1,3.4.).

\subsubsection{Einwand aus der Mehrdeutigkeit des Begriffs Vorstellung}

Hier könnte man einwenden, dass die obige Interpretation auf der berühmten und berüchtigen Zweideutigkeit des Begriffs „Vorstellung“ basiert. Unter dem Begriff „Vorstellung“ versteht man sowohl den Vorstellungszustand als auch den Vorstellungsinhalt. Erstere ist, wie gesagt, eine „Bestimmung“ des Gemüts oder der Seele, durch die man sich etwas vorstellt und entspricht damit dem sogenannten repräsentationalen Vehikel im heutigen Sinn. Letzterer ist der repräsentationale Gehalt der Vorstellung. Der innere Sinn wird von Kant wörtlich als Bewusstsein des inneren Zustands charakterisiert. Dieses ist dem obigen Einwand zufolge jedoch nicht ohne weiteres mit dem Bewusstsein des Vorstellungsinhalts gleichzusetzen. Es sei falsch, die Vorstellungen des inneren Sinns, die wesentlich Zustandsbewusstsein sind, als 
Inhaltsbewusstsein - d.i. Vorstellungen der äußeren Gegenstände - zu bezeichnen. ${ }^{97}$ Gegen diesen Vorwurf spricht, dass das Bewusstsein des Vorstellungszustands in zwei möglichen Formen, entweder explizit oder implizit, vorkommen kann. Die erstere explizite Form ist die Introspektion. Ihr repräsentationaler Gehalt sind eher innere Zustände als äußere Gegenstände und ihre Struktur ist relativ komplex. Betrachten wir stattdessen die letztere Form dieses Bewusstseins, weil es für den Kontext der $\mathrm{Kr} V$ relevant ist und seine Analyse mit Modifikationen auf den Fall der Introspektion anwendbar ist. Wenn die Vorstellung, die der innere Sinn begleitet, äußere Gegenstände als intentionale Gegenstände hat, ist das Bewusstseins des inneren Sinnes kein introspektives Bewusstsein und enthält nur ein implizites Bewusstsein des Vorstellungszustands. Es enthält neben dem Bewusstsein des repräsentationalen Gehalts der Vorstellung erster Ordnung zwar keinen bewussten, aber dennoch einen unbewussten, impliziten Bezug auf das Subjekt. Diese unbewusste Selbstzuschreibung, wenn sie mit dem Bewusstsein des repräsentationalen Gehalts verknüpft wird, macht ein implizites Zustandsbewusstsein aus. In Kants eigener Terminologie braucht die Vorstellung des Vorstellungszustands nicht selbst „klar“"zu sein. Der Bezug auf das Ich ist bei der Selbstanschauung des inneren Sinnes in einem nicht-introspektiven Fall selbst dunkel. Damit wird in dem nicht-introspektiven Fall durch das Bewusstsein des inneren Sinnes allein der Vorstellungsinhalt des äußeren Sinnes bewusst. ${ }^{98}$ Der Bezug

\footnotetext{
97 Siehe z.B. Wolff (1963). und Schmitz (2015:5)

98 Schmitz (2015:5) kritisiert die Higher-Order Lesart des inneren Sinnes. Nach ihr kann die HigherOrder-Wahrnehmung des eigenen Wahrnehmens nicht die Vorstellung äußerer Gegenstände beinhalten. Nach dieser Lesart ist der Gehalt der Vorstellung des inneren Sinnes mit dem Satz „Ich nehme war“ oder „Ich sehe“ formulierbar. Schmitz zufolge kann diese Lesart nicht erklären, wie die Zeit, die Form des inneren Sinnes ist, ebenfalls die formale Bedingung der äußeren Erscheinungen ist, denn der innere Sinn stellt die äußeren Vorstellungen gar nicht vor. Sie kann die Analogie zwischen dem inneren und äußeren Sinn auch nicht aufrechterhalten, denn der innere Sinn liefert offensichtlich keine spezifischen empirischen Qualitäten. Die hier vertretene Interpretation vermeidet diese Probleme, weil der innere Sinn an dem Bewusstsein der Vorstellung der äußeren Erscheinungen maßgeblich beteiligt.
} 
auf das Ich bleibt vorhanden, wird aber nicht explizit bewusst. Dieser implizite Bezug macht das Bewusstsein des inneren Sinnes im nicht-introspektiven Fall dennoch zu einem impliziten Zustandsbewusstsein.

\subsubsection{Einwand aus dem tierischen und infantilen Bewusstsein}

Gegen den obigen interpretativen Vorschlag bezüglich des inneren Sinnes kann man einwenden, dass sowohl Tiere, als auch Kleinkinder, denen Kant das Vermögen des inneren Sinns sowie der Apperzeption abspricht, dennoch über ein bewusstes Erleben ihrer Sinnesdaten sowie ein Bewusstsein des jeweils wahrgenommenen Gegenstands wenn auch nicht als Gegenstand - verfügen. Dies zu leugnen scheint nicht nur intuitiv inakzeptabel zu sein, sondern auch unserer Erfahrung mit Tieren und Kleinkindern zu widersprechen. Belege dafür, dass auch Kant beiden diese Vermögen zuspricht, sind nicht schwierig zu finden:

Die Erinnerung seiner Kinderjahre reicht aber bei weitem nicht bis an jene Zeit, weil sie nicht die Zeit der Erfahrungen, sondern blos zerstreuter, unter den Begriff des Objects noch nicht vereinigter Wahrnehmungen war. (Anth 7:128)

Hier sind die ,zerstreut[en]“ Wahrnehmungen nichts anders als das empirische Bewusstsein ,an sich“, das noch nicht unter einer Einheit der Apperzeption steht und deswegen „zerstreut“ (B133) ist. Kant spricht einem nicht-apperzeptiven Geist phänomenales Bewusstsein der Sinnesdaten sowie ein nicht-gegenstandsbezogenes Bewusstsein des Gegenstands zu (für das erste siehe $§ 1.4$; für das letztere siehe DfS 2:60; BDG 2:140; V-Met/Mron 29: 888). Da ein solcher Geist sich einzelner Sinnesdaten bewusst sein kann, lässt sich schließen, dass er sich der Gegenstände, die 
aus Sinnesdaten bestehen, auch phänomenal bewusst sein kann. ${ }^{99}$ Demzufolge wäre der innere Sinn gar keine notwendige Bedingung für das phänomenale Bewusstsein. Gegen diesen Einwand bleiben zwei Auswege. Entweder hat der innere Sinn mit der Entstehung des phänomenalen Bewusstseins der Erfahrung gar nichts zu tun, oder er erzeugt zwar nicht das phänomenale Bewusstsein, kann im Gegensatz zu der tierischen, nicht-apperzeptiven Sinnlichkeit jedoch strukturierende Wirkungen auf es ausüben. Laut der ersten Möglichkeit geht es beim Produkt des Vermögens des inneren Sinnes gar nicht um ein phänomenales Bewusstsein des Gegenstands, mithin betrifft der innere Sinn den materialen Aspekt des Gehalts der empirischen Vorstellung gar nicht. Da der innere Sinn jedoch per definitionem eine Art von Wahrnehmung des eigenen Zustands ist und nach der obigen Überlegung das phänomenale Bewusstsein nicht zu dieser Wahrnehmung gehört, kann die Rolle des inneren Sinnes nur darin bestehen, zu ermöglichen, dass dem Subjekt ein mentaler Zustand als zeitlich bestimmter zugeschrieben wird. Meines Erachtens kann diese Lesart nicht die richtige sein. Nicht nur ist es kaum nachvollziehbar, wie die zeitliche Selbstzuschreibung ohne jeglichen phänomenalen Charakter eine Wahrnehmung sein kann. Auch haben wir haben schon gesehen, dass die Auslegung, den inneren Sinn als eine reine Sinnlichkeit zu deuten, der Textlage nicht gerecht wird. Diese Interpretation würde zudem die Argumentation der transzendentalen Deduktion untergraben. Der innere Sinn wird dieser zufolge von der transzendentalen Synthesis der Einbildungskraft affiziert, somit ist die Vorstellung durch den inneren Sinn das Ergebnis der Anwendung der Kategorien. Wenn die Vorstellung durch den inneren Sinn phänomenal identisch mit der Vorstellung ohne den inneren Sinn wäre, würde die Anwendung der Kategorien keine Konsequenz auf

\footnotetext{
${ }^{99}$ Natürlich handelt es sich dabei nicht um ein Bewusstsein des Gegenstands als Gegenstands, denn dies setzt die synthetischen Leistungen gemäß den Kategorien voraus. In V-Met/Mron 29: 888 geht Kant davon aus, dass Tiere physische Gegenstände voneinander unterscheiden können. Das heißt, sie verfügen über phänomenales Bewusstsein von Gegenständen.
} 
das phänomenale Bewusstsein der Erfahrung haben. Damit können die Kategorien, was ihre Gültigkeit für die Erscheinungen betrifft, nur eine Art interpretativer Funktion ausüben. Es ist zweifelhaft, ob man diese Funktion als gesetzgebend bezeichnen kann. Die Gesetzmäßigkeit impliziert nämlich, dass die Erscheinungen notwendigerweise nach bestimmten Regeln zusammen auftreten. ${ }^{100}$ Wenn die Anwendung der Kategorien diese Gesetzmäßigkeit nicht herstellt, ist es nicht plausibel zu behaupten, dass sie Gültigkeit für die Erscheinungen haben. Kants Bemerkungen über das Szenario, in dem die synthetische Leistung des Gemüts gemäß den Kategorien entfällt, zeigen gerade deutlich, dass diese Leistung eine das phänomenale Bewusstsein gestaltende Wirkung hat. In diesem möglichen Szenario verfügt das Subjekt bloß über ein „Gewühle von Erscheinungen“(A111) und „ein blindes Spiel der Vorstellungen, d.i. weniger, als ein Traum“ (A112). Nur die zweite Lesart kann die obigen Vorwürfe umgehen, denn ihr zufolge übt die transzendentale Synthesis der Einbildungskraft im inneren Sinn strukturierende Wirkungen auf das phänomenale Erlebnis des Subjekts aus. Der innere Sinn spielt somit eine maßgebliche Rolle in der Entstehung des phänomenalen Erlebnisses.

\subsubsection{Unterschied des inneren Sinns und des äußeren Sinnes}

Wenn nun der innere Sinn die Anschauung des äußeren Sinnes nicht nur enthält, sondern sogar hervorbringt, wie unterscheidet man ihn von dem äußeren Sinn? ${ }^{101}$ Der

\footnotetext{
100 Z.B. manche der Erscheinungen tragen Größe oder Qualität der Anschauung bei; einige nehmen die Rolle der Beharrlichkeit und einige die Rolle der Akzidenzen ein; ein bestimmter Typ der Erscheinungen tritt immer nach einem bestimmten anderen Typ auf, usw.

101 Ähnliche Frage stellen Schmitz (2015) und Wolff (1963) in ihrer Kritik an Interpretationen, die eine ähnliche Struktur wie die hier vorgeschlagene aufweisen.
} 
erste Unterschied liegt darin, dass der innere Sinn einen Akt des Selbstbezugs enthält, da er mit der reinen Apperzeption wesentlich verbunden ist: „alle Prädicate des innern Sinnes beziehen sich auf das Ich als Subject“" (Prol. 4:334). Meines Erachtens gibt es außer dem Selbstbezug, den der innere Sinn durch die reine Apperzeption enthält, noch zwei Aspekte, die beide Sinnesvermögen allein hinsichtlich der Rezeptivität unterscheiden. Man hat in der Vorstellung des inneren Sinnes das Erlebnis der Sukzessivität, die die Vorstellung des äußeren Sinnes nicht hat. Entscheidend ist zudem, wie schon argumentiert, dass der äußere Sinn die Sinnesdaten liefert, d.h. den „Stoff des inneren Sinnes“ und als Form dieser Daten die Räumlichkeit, während der innere Sinn das Bewusstsein dieser Sinnesdaten hervorbringt. Da der Raum nicht die Form des inneren Sinnes ist, kann der innere Sinn die räumliche Rahmenbedingung nicht liefern. Der innere Sinn kann nicht der Ursprung der rohen Sinnesdaten der äußeren Gegenstände sein, denn sonst würde man Kant eine starke subjektivistische Position unterstellen, für die die Erscheinungen der ganzen Welt aus dem Subjekt stammen. Außerdem haben wir schon anhand der Doktrin der Klarheit und Deutlichkeit demonstriert, dass das empirische Bewusstsein mit dem inneren Sinn koextensiv ist und es Wahrnehmungen der äußeren Gegenstände gibt, die nicht apperzeptiv bewusst, d.h. keine Vorstellung des inneren Sinnes sind. Solche apperzeptiv unbewussten empirischen Vorstellungen enthalten jedoch empirische Daten der äußeren Gegenstände. Somit kann man den folgenden Schluß ziehen: Der äußere Sinn sorgt für die „Lieferung“ der äußeren Sinnesdaten und des räumlichen Rahmens des äußeren Gegenstands, während der innere Sinn das kategorisch strukturierte empirische Bewusstsein von ihnen generiert. Oder mit anderen Worten: Der äußere Sinn liefert den repräsentationalen Gehalt der Vorstellung, während der innere Sinn für das 
Bewusstsein von diesem verantwortlich ist. Die äußeren Sinnesdaten können somit ohne Affektion des inneren Sinns gar nicht empirisch bewußt werden. ${ }^{102}$

Am Ende des Kapitels muss eine alternative Interpretation betrachtet werden. Mohr verweist auf Kants exkursive Ausführung des inneren Sinnes im §24 der transzendentalen Deduktion (B154ff.), und zwar auf das vieldiskutierte Beispiel des Ziehens einer Linie: „die Vorstellung des Nacheinanders gründet sich auf das ,Achthaben` auf die Verstandeshandlungen, die im Beschreiben eines Raumes, wie etwa im Ziehen einer Linie, ausgeführt werden.“ Weiter behauptet er, dass es „,[d]ie Kontruktionsakte des Verstandes sind [...], die den sinnlichen ,Stoff ${ }^{`}$ für den inneren Sinn abgeben“ (Mohr 1991:167-8). Mohr erklärt nicht, wie seine Auslegung mit den beiden erwähnten Stellen (B67, BXXXIX Anm.) zu vereinbaren ist, an denen Kant klarmacht, dass die „Dinge außer uns“ „den ganzen Stoff zu Erkenntnissen selbst für unsern inneren Sinn“ geben. Das Wort „Stoff“ bezieht sich nämlich auf den empirischen Gehalt der Vorstellung des äußeren Sinnes und nicht auf den gegenstandskonstruierenden Verstandesakt, der auf dem Mannigfaltigen des äußeren Sinnes operiert. Zudem liefern die „Konstruktionsakte des Verstandes“ (d.h. die synthetischen Akte in der Zusammensetzung der Anschauung) kein empirisches Mannigfaltiges, das eine spezielle, bestimmbare phänomenale Qualität besitzt, andernfalls würde man diese Konstruktionsakte und mithin die Zeit direkt - d.h. ohne

102 Mohr (1991:156-8) vertritt eine ähnliche Position, jedoch ohne substanzielle Begründung. Er behauptet, dass der innere Sinn dafür sorgt, dass die Sinnesdaten des äußeren Sinnes überhaupt bewußt werden. Er ist der Auffassung, dass das Subjekt die sinnlichen Vorstellungen unter der alleinigen Voraussetzung des äußeren Sinnes nur als „Inhalt“, nicht als „Vorstellungen von solchen“ hat: „es hat „Daten“, aber es hat sie nicht als Daten“. Mohr scheint hier die These zu vertreten, dass das Bewusstsein des empirischen Inhalts die Voraussetzung dafür ist, dass die sinnliche Vorstellung überhaupt Vorstellung ist. Diese Ansicht ist angesichts Kants Doktrin der dunklen Vorstellung als falsch zu bewerten. Übrigens zieht Mohr aus dieser Position nicht den Schluss, dass der innere und äußere Sinn den gleichen ,Stoff“ produzieren. 
Hilfe räumlicher Anschauung - wahrnehmen, was dem Tenor der exkursiven Bemerkung in $\$ 24$ widerspricht. Folglich könnten diese Konstruktionsakte nur zeitliches Mannigfaltiges liefern. Dieses wäre aber kein „Stoff“ des inneren Sinnes, sondern seine Form. Daher ist Mohrs Interpretation des „Stoffs“ des inneren Sinnes nicht haltbar.

\subsection{Das Material der affizierenden Synthesis}

Eine weitere, oft übersehene Hinsicht, die den inneren und äußeren Sinn unterscheidet, besteht darin, dass der innere Sinn nicht nur die gegenständlichen Vorstellungen des äußeren Sinnes, sondern auch Einbildungen, Gefühl der Lust und Unlust, Begierde und den Willen, schließlich auch die introspektiven Vorstellungen als Gegenstand repräsentieren kann. Zur Vorstellung des inneren Sinnes gehört auch die Einbildung im Sinne der freien Verknüpfung von Gedächtnisinhalten zu neuen Vorstellungen (Refl 15:675; Refl 18:621; V-Met/Schön 28: 483). Um diese mit der Einbildung im Sinne der Verbindung der Sinnesdaten zur Anschauung zu unterscheiden, wird sie fortan als „Imagination“ bezeichnet. Die Imagination gehört nicht zum äußeren Sinn. ${ }^{103}$ Obwohl sie Teile der vergangenen Vorstellungen der äußeren Gegenstände wiederverwendet, muss sie zum inneren Sinn gehören. ${ }^{104}$

\footnotetext{
103 „Die Frage wegen der letzteren würde sein: ob wir nur einen inneren Sinn, aber keinen äußeren, sondern bloß äußere Einbildung hätten.“(B276 Anm.), siehe auch Prol. 4:337.

104 „das Bewustseyn kann alle Vorstellungen begleiten, mithin auch die der Einbildung, die und deren Spiel selbst ein Object des innern Sinnes ist.“" (Refl 18:621), siehe auch V-Met/Schön 28: 483.
} 
Durch die oben mehrmals zitierte Bemerkung über den „Stoff“ des inneren Sinnes wird anscheinend die naheliegende Vermutung ausgeschlossen, dass das phänomenale Erlebnis im Gefühl der Lust und Unlust, des Willens und Begehrens ein phänomenales Mannigfaltiges darstellt und als Gegenstand des inneren Sinnes gilt. Man fragt sich, warum all dies nicht zu dem inneren Sinn gehören soll, denn schließlich handelt es sich dabei auch um den ,inneren Zustand“, den „,der innere Sinn [...] vermittelst dessen [...] anschau[en]“ kann (A22/B37, siehe auch A33/B49). Der Gegenstand des inneren Sinnes ist alles, was Innerliches ist und nicht zum Äußerlichen gehört (V-Met-L1/Pölitz 28: 265, 279). Meines Erachtens bedeutet Kants Aussage, dass die Vorstellungen des äußeren Sinnes den eigentlichen Stoff des inneren Sinnes ausmachen, nur, dass der innere Sinn insofern wesentlich vom äußeren Sinn abhängt, als ohne die Sinnesdaten des äußeren Sinnes insbesondere die Zeitbestimmung des inneren Sinnes nicht möglich ist (vgl. Widerlegung des Idealismus). Man könnte auf das Beispiel des Ziehens einer Linie in $\$ 24$ der B-Deduktion hinweisen und einwenden, dass Kant tatsächlich zu behaupten scheint, dass der innere Sinn auf das Mannifaltige des äußeren Sinnes angewiesen ist (siehe besonders B154, 156). Im Linien-Beispiel im $§ 24$ geht es jedoch nicht um einen üblichen Fall des Bewusstseins des inneren Sinnes, sondern um einen ganz speziellen Fall der Introspektion zur Gewinnung des Zeitbegriffs (siehe §3.4).

In der $K r V$ deutet Kant an, dass der innere Zustand nicht auf die Vorstellung des äußeren Sinnes beschränkt ist. Er fasst den Begriff des inneren Zustandes äußerst weit: „alle Vorstellungen, sie mögen nun äußere Dinge zum Gegenstande haben oder nicht, [gehören] doch an sich selbst, als Bestimmungen des Gemüths, zum innern Zustande“ (B50, meine Hervorhebung). Dies könnte ein Beleg für die hier vorgeschlagene Interpretation sein. Als Einwand könnte man auf den Unterschied zwischen dem Gefühl (der Lust und Unlust) als „inwendige[em] Sinn“ (Anth 7:153) und dem inneren Sinn verweisen: 
Die Sinne aber werden wiederum in die äußeren und den inneren Sinn (sensus internus) eingetheilt; [...] der zweite, wo er durchs Gemüth afficirt wird; wobei zu merken ist, daß der letztere als bloßes Wahrnehmungsvermögen (der empirischen Anschauung) vom Gefühl der Lust und Unlust, d.i. der Empfänglichkeit des Subjects, durch gewisse Vorstellungen zur Erhaltung oder Abwehrung des Zustandes dieser Vorstellungen bestimmt zu werden, verschieden gedacht wird, den man den inwendigen Sinn (sensus interior) nennen könnte (Anth 7:153)

Im Gegensatz zum inneren Sinn vermittelt der inwendige Sinn keine Erkenntnisse des Gegenstandes und enthält auch keinen Objektbezug (KU 5:206). Folglich hat das Gefühl der Lust und Unlust, diesem Einwand nach, gar keinen repräsentationalen Gehalt und gilt nicht als Vorstellung, während der innere Sinn „Inbegriff“ der Vorstellungen — d.i. repräsentationaler Zustände-ist. ${ }^{105}$ Dieser Einwand ist jedoch nicht haltbar. Kant bezeichnet nämlich das Gefühl der Lust und Unlust offensichtlich auch als Vorstellung, obwohl es keinen intentionalen Gegenstand hat: Was ein ästhetisches Urteil vermittelt, ist „die Vorstellung, nicht als Gedanke, sondern als inneres Gefühl eines zweckmäßigen Zustandes des Gemüths“ (KU 5:296). Das Gefühl (der Lust und Unlust) ist eine subjektive Empfindung (KU 5:206), die selbst in der „Stufenleiter“ als Vorstellung klassifiziert wird (A320/B376). Da der innere Sinn „Inbegriff aller Vorstellungen“, darunter auch der Empfindung, ist, enthält er somit auch den inwendigen Sinn. ${ }^{106}$ Es ist vielleicht schwierig zu erklären, warum Kant das Gefühl der Lust und Unlust als Vorstellung bezeichnet, obwohl er es anderswo für nicht-repräsentational hält. ${ }^{107}$ Diese Unklarheit stellt jedoch kein Problem für die hier

\footnotetext{
105 Diese Position vertreten Allison (2004: 278) und Valaris (2008: 2).

106 Weitere Belege sind z.B. KU 5:228.

${ }^{107}$ Eine Lösung wäre, das Gefühl der Lust und Unlust als Wahrnehmung der eigenen Körperzustände zu betrachten. Da der eigene Körper ein Gegenstand des äußeren Sinnes ist, ist die Vorstellung des Gefühls der Lust und Unlust eine Vorstellung eines Körperzustands (Valaris 2008:3). Dies widerspricht offensichtlich Kants Taxonomie der Gemütsvermögen. Denn der inwendige Sinn gehört nicht zu dem äußeren Sinn, der als Wahrnehmung der körperlichen Dinge auch die Wahrnehmung des eigenen Körperzustandes einschließen sollte (siehe Anth 7:153). Übrigens ist der Gehalt des inwendigen Sinnes kein Räumliches und teilt somit auch nicht mit dem äußeren Sinn die gleiche Form. Mein vorläufiger
} 
vorgeschlagene Interpretation dar, denn die Gemütszustände des inwendigen Sinnes können Gegenstand des inneren Sinnes werden. In Refl 18:619 bezeichnet Kant den inneren Sinn gar direkt als dasjenige, ,wozu auch Lust und Unlust gehören“. Es gibt auch jede Menge Belege, die die Begierde und den Willen als den Gegenstand des inneren Sinnes bezeichnen: „[W]ir können ihre Gedanken, ihr Bewußtsein, ihre Begierden, etc. nicht äußerlich anschauen; denn dieses gehört alles vor den inneren Sinn“ (A357; V-Met-L1/Pölitz 28: 279). „,[A]lso erstlich Vorstellungskraft und Begehrungsvermögen [sind] die Gegenstände des inneren Sinnes““ (XVII 366). In einer Stelle der Vorlesungen über Metaphysik sagt Kant so direkt: „Denken und Wollen sind bloß Gegenstände des inneren Sinnes“(V-Met-L1/Pölitz 28: 279). Sachlich betrachtet, gehören solche mentale Zustände deswegen zum inneren Sinn, weil der innere Sinn das vorstellt,

was entweder selbst ein Denken, oder mit diesem analogisch ist (A265-6/B321).

„Wollen, Lust und Unlust“ sind deswegen mit dem Denken analogisch, weil sie gerade aus dem Denken „entspringen“ sollen (V-Met/Mron 29:929). ${ }^{108}$ D.h. diese mentalen Zustände enthalten im menschlichen Geist einen Denkakt, daher sind sie „mit diesem analogisch“. Da die Vorstellung des inwendigen Sinnes zeitlich ist und Kant die Zeit und die Form des inneren Sinnes immer wesentlich miteinander verbindet, muss der inwendige Sinn somit notwendigerweise zum inneren Sinn gehören. Daher müssen

Vorschlag wäre, das Gefühl der Lust und Unlust insgesamt als ein durch den Gegenstand des äußeren Sinnes erregten subjektiven Zustand zu betrachten. Obwohl der Gehalt dieses mentalen Zustandes den Gegenstand weder direkt repräsentiert noch letzten Endes auf diesen zu reduzieren ist, steht dieser mentale Zustand in direktem Kausalzusammenhang mit diesem und verdankt seinen Gehalt der Existenz des Gegenstands. Daher kann man durchaus sagen, dass die äußeren Vorstellungen „,den eigentlichen Stoff“ des inneren Sinnes lieferen.

${ }^{108}$ Vgl. Locke, dessen Theorie des inneren Sinnes Kant direkt beeinflusst hat, behauptet: „The term Operations here, I use in a large sense, as comprehending not barely the Actions of the Mind about its Ideas, but some sort of Passions arising sometimes from them, such as is the satisfaction or uneasiness arsising from any thought.“" (Locke, ECHU 2.1.4, 105) 
subjektive Empfindungen wie Lust und Unlust, Willen und Begehren als zu den Vorstellungen des inneren Sinnes gehörig betrachtet werden. In der Tat haben sowohl der äußere Sinn als der inwendige Sinn den gleichen Status im Bezug auf den inneren Sinn: Sowohl die Vorstellungen des äußeren Sinnes als auch die des inwendigen Sinnes sind innere Zustände, die bestimmte Informationen (über äußere Gegenstände oder über das Gemüt) enthalten, die potentiell phänomenal bewusst werden können. Die Vorstellungen des inneren Sinnes sind Vorstellungen dieser inneren Zustände und machen die darin enthaltenen Informationen erst phänomenal bewusst. Man kann sagen, die Vorstellungen des äußeren Sinnes und die des inwendigen Sinnes sind jeweils informationstragende Zustände und befinden sich auf der gleichen „Ebene“ der Intentionalität, während die Vorstellungen des inneren Sinnes als Vorstellungen dieser informationstragenden Zustände sich als Vorstellungen von Vorstellungen auf einer höheren Ebene befinden.

Als möglicher Gehalt eines inneren (repräsentationalen) Zustands kommen nicht nur äußere Gegenstände oder Sachverhalte ${ }^{109}$ und die oben erwähnten subjektiven Empfindungen in Frage, sondern auch bewusstes Denken (auch solches an abstrakte Sachverhalte wie Gott, mathematische Sätze und innere Wahrnehmungsvorgänge). ${ }^{110}$ Die Vorstellungen mit den letzteren abstrakten repräsentationalen Gehalten sind Gegenstände des inneren Sinnes, einfach weil sie innere Zustände sind. ${ }^{111}$ Mehrere

\footnotetext{
109 In B50 macht Kant deutlich, dass der innere Sinn nicht nur die Vorstellungen der äußeren Gegenstände begleiten kann.

${ }^{110}$ Zum Beispiel nennt Schmitz die resultierenden Vorstellungen des inneren Sinnes falschlicherweise bloß „temporally ordered outer intuitions“ (Schmitz 2015:9).

${ }^{111}$ Es ist in der zeitgenössischen Philosophie des Geistes kontrovers, ob Empfindungen als intentionale Zustände zu betrachten sind (wie es der sogenannte "Repräsentationalismus" bzw. "Intentionalismus" vorschlägt) oder nicht (Jacob: 2014). Streng genommen fallen sie nicht unter Kants Definition der Vorstellung. Jedoch hat Kant sie als Vorstellung bezeichnet, wie oben gezeigt ist. M.E. nach kann man sie in dem Sinne als ,repräsentational“ bezeichnen, als sie etwas Unbestimmtes repräsentiert. An dieser
} 
Stellen in Kants Schriften können diese Auffassung belegen. ${ }^{112}$ Hier muss man sich daran erinnern, dass der innere Sinn in seinem Mitwirken bei dem Bewusstsein des äußeren Gegenstands nicht den repräsentationalen Gehalt der Vorstellung liefert, sondern solchen Gehalt erst bewusst macht. Ähnliches gilt auch hier: Die phänomenalen Qualitäten der subjektiven Empfindung, der abstrakte Denkinhalt (Gott, mathematische Sätze) und das, was auch immer introspektiert wird, sind nicht vom inneren Sinn geliefert. Nach Kant gibt es unbewusste Gedanken, Gefühle, Wille und Triebe. Nach seiner Doktrin der dunklen Vorstellungen ist es möglich, dass man den inneren Zustand dunkel vorstellt, ohne ihn introspektiv - und apperzeptiv bewusst - zu vergegenwärtigen. Dieser Sachverhalt ist ein Argument dafür, dass der innere Sinn nicht die Qualitäten der subjektiven Empfindung, den abstrakten Denkinhalt und den introspektierten Gehalt liefert. Der Beitrag des inneren Sinnes liegt allein darin, diesen Gehalt bewusst zu machen.

Man könnte hier den Vorwurf erheben, dass es im Fall der subjektiven Empfindung nicht die synthetischen Akte des Verstandes wären, die den inneren Sinn affizieren, sondern Gefühl, Begierde oder Wille. ${ }^{113}$ Dieser Vorwurf rührt von einem falschen Verständnis der Selbstaffektion her. In der Tat ist die Art des Verstandakts in dem Fall der subjektiven Empfindung, der den inneren Sinn affiziert, dieselbe wie im Fall der äußeren Anschauung, nämlich die Synthesis der transzendentalen Einbildungskraft. Sie bringt auch hier das Bewusstsein der subjektiven Empfindung a priori in bestimmter,

Stelle habe ich einfachheitshalber den Begriff ,,repräsentationaler Gehalt“ liberal gefasst, da daran nichts Wichtiges für die Argumentation hängt.

${ }^{112}$ Ganz deutlich in V-Met-L1/Pölitz 28: 279. Für den Fall des Gedankens an Gott siehe Refl 18:661, an mathematischen Propositionen siehe die Analyse des Losen Blattes Kiesewetter im §1.7., und für den Fall der Introspektion siehe FM 20:270.

113 Schmitz (2015:16) erwähnt dieses Problem indirekt. 
einheitlicher Zeitordnung hervor, genau wie sie die Wahrmehmungen des äußeren Sinnes a priori in bestimmter, einheitlicher Zeitordnung hervorbringt.

Das Mannigfaltige des inneren Sinnes ist folglich nicht unbedingt ausschließlich dasjenige des äußeren Sinnes. Was zum inneren (repräsentationalen) Zustand gehört, gehört zum inneren Sinn. Kant hat, in einem Wort, eine weite Auffassung der Vorstellungen des inneren Sinnes, und zwar als Inbegriff aller bewussten Zustände. ${ }^{114}$ Meiner Meinung nach muss man infolge der obigen Analyse Kants häufige Charakterisierung des inneren Sinnes als Anschauung oder Wahrnehmung des inneren Zustands ernstnehmen (A22/B37, A38/B55, A33/B49, A106f.). ${ }^{115}$ Bei diesen Darstellungen spezifiziert Kant auffälligerweise nicht genau, was für innere Zustände im inneren Sinn wahrgenommen werden können. ${ }^{116}$ Der Grund hierfür kann nur darin liegen, dass er denkt, dass seine Darstellung ausreicht, um den inneren Sinn präzise dazustellen. Der Begriff des inneren Zustands ist in der Tat ein sehr umfassender Begriff. Ein innerer Zustand ist einfach ein Zustand des Gemüts, der für eine bestimmte Dauer anhält. Ein Zustand des Gemüts braucht als solcher nicht repräsentational zu sein. Nun ist eine Anschauung eine Vorstellung, die sich erstens direkt auf einen Gegenstand bezieht und zweitens durch die Affektion entsteht (A19/B33). Da der innere Sinn Anschauung des inneren Zustandes ist, sind der Gegenstand des inneren Sinnes einfach alle Zustände, denen wir uns direkt und nicht nur mittels einer Denkleistung, wie einem Urteil oder einem Schluss bewusst sein werden können. Durch diese Analyse wird die obige weite Auffassung des Gegenstands des inneren Sinnes gerechtfertigt.

\footnotetext{
114 Siehe auch Ameriks (2000: 244).

115 Vgl. Schmitz (2015).

116 In FM 20:270 bestimmt Kant z.B. den inneren Sinn ganz generell als ,empirische Vorstellung unsers Zustandes“.
} 


\subsection{Die resultierende Vorstellung des inneren Sinnes:}

\section{Wahrnehmung der Selbsttätigkeit oder Wahrnehmung der inneren Zustände?}

Gegen die obige Interpretation sprechen jedoch anscheinend einige Bemerkungen von Kant. In zentralen Stellen über den inneren Sinn in der B-Auflage der $\mathrm{KrV}$ und auch der Anthropologie (7:161) behauptet er,

Nun ist das, was als Vorstellung vor aller Handlung irgend etwas zu denken vorhergehen kann, die Anschauung und, wenn sie nichts als Verhältnisse enthält, die Form der Anschauung, welche, da sie nichts vorstellt, außer so fern etwas im Gemüthe gesetzt wird, nichts anders sein kann als die Art, wie das Gemüth durch eigene Thätigkeit, nämlich dieses Setzen seiner Vorstellung, mithin durch sich selbst afficirt wird, d.i. ein innerer Sinn seiner Form nach. (B67-8, meine Kursivierung)

Der innere Sinn ist nicht die reine Apperception, ein Bewußtsein dessen, was der Mensch thut, denn dieses gehört zum Denkungsvermögen, sondern was er leidet, wiefern er durch sein eignes Gedankenspiel afficirt wird. (Anth 7:161)

Aus dem ersten Zitat ist zu entnehmen, dass der innere Sinn als eine empirische Vorstellung der Tätigkeit des Subjekts aufzufassen ist. Das zweite Zitat präsiziert diese Tätigkeit weiter als Denkakt des Subjekts. In diesem Sinn sagt Kant in A265-6/B321:

was kann ich mir für innere Akzidenzen denken, als die jenigen, so mein innerer Sinn mir darbietet? nämlich das, was entweder selbst ein Denken, oder mit diesem analogisch ist.

Als Gegenstand des inneren Sinnes nennt Kant übrigens „Ich, als denkend“(A342/B400). „Der allgemeine Charakter des Gegenstandes des innern Sines ist Denken“ (V-Met-L1/Pölitz 28: 222). „Denken und Wollen sind bloß Gegenstände des innern Sinnes“ (V-Met-L1/Pölitz 28: 279). Alle solche Stellen heben hervor, dass das Affizierende des inneren Sinnes der Denkakt ist. In der $\mathrm{Kr} V$ bezeichnet Kant den affizierenden Akt des inneren Sinnes explizit und spezifisch als die transzendentale Synthesis der Einbildungskraft. Im Einklang damit behauptet er: 
Weil die Einbildungs Kraft (g und ihr Product) selbst nur Gegenstand des inneren Sinnes ist, so kan das empirische Bewustseyn (g apprehensio) dieses Zustandes nur Succession [den Zeitbed] enthalten. (Refl 18:614, 1790-91).

Vor diesem Hintergrund behauptet z.B. Allison ,,inner sense is a sensory consciousness of the contents of thought." (Allison 2004). Es ist überraschend, wenn Kant behauptet, dass im inneren Sinn ein Denkakt als intentionaler Gegenstand perzeptuell vorgestellt wird. Die Frage stellt sich nämlich, wie man diese These mit derjenigen in Einklang bringen kann, dass der innere Sinn eine Wahrnehmung oder Anschauung des eigenen Zustandes ist, in der man die äußeren Dinge vorstellt. Schließlich scheint die Wahrnehmung eines Verstandesaktes nicht ohne weiteres mit einer Wahrnehmung des inneren Zustandes zu identifizieren zu sein. Drei Probleme stehen einer derartigen Gleichsetzung im Wege:

Erstens scheint der innere Zustand mehr zu enthalten als bloß einen Verstandesakt. Eine Stelle im Losen Blatt Leningrad (S. 7-10) ist ein starker Beleg dafür. Dort behauptet Kant explizit:

Bey der inneren Erfahrung aber die ich anstelle afficire ich mich selbst indem ich die Vorstellungen äußerer Sinne in ein empirisches Bewußtseyn [bringe um] meines Zustandes bringe. (Meine Hervorhebung)

Wie bereits argumentiert, wird in dem inneren Sinn bzw. dem „empirisch[en] Bewußtseyn meines Zustandes“ der empirische Gehalt der Vorstellung des äußeren Sinnes überhaupt erst bewusst gemacht. Der innere Sinn enthält demnach alle repräsentationalen Gehalte der Vorstellungen erster Ordnung, die der äußere Sinn liefert. Darunter sind auch empirische Qualitäten und räumliche Gestalten, die nicht durch Verstandesakte erzeugt werden, sondern sich der Rezeptivität der Sinnlichkeit verdanken. Folglich müssen wir Kants Definition des inneren Sinnes ernstnehmen: durch ihn nehmen wir insofern unseren inneren Zustand wahr, als wir uns nicht nur des darin involvierten Denkaktes, sonden auch des empirischen Gehaltes gewahr werden. Die Vorstellungen des inneren Sinnes sind insgesamt perzeptuelle Vorstellungen des 
eigenen inneren Zustandes. In diesem Sinne bezeichnet Kant den Gegenstand des inneren Sinnes präzise als „Vorstellungen und Denken“(A359), statt als Denken allein. Zweitens schließt der Begriff des inneren Zustands mehr als einen kognitiven, repräsentationalen Zustand ein. Das Erleben der Gefühle der Lust und Unlust und das des Begehrens, die vielfältigen phänomenalen Gehalte haben, scheinen ebenfalls zu dem inneren Zustand des Gemüts zu gehören. Erinnern wir drittens daran, dass Kant im Kontext der $K r V$ meistens von der Affektion des inneren Sinnes durch die Synthesis der Einbildungskraft (oder genauer gesagt, durch die transzendentale Synthesis der Einbildungskraft) spricht. Zugleich macht er jedoch explizit, dass man sich des synthetischen Aktes der Einbildungskraft meistens „selten nur einmal bewußt“ ist (A79/B103; siehe auch A103f.). Daher kann man das Ergebnis des inneren Sinnes nicht ohne Einschränkung als das Bewusstsein des synthetischen Akts bezeichnen.

In der Tat sind beide vorgeschlagene Interpretationen nicht unvereinbar miteinander. Im Kontext der Diskussion über den inneren Sinn behauptet Kant: „Gedanken, als factische Bestimmungen des Vorstellungsvermögens, gehören auch mit zur empirischen Vorstellung unsers Zustandes“ (FM 20:270). ${ }^{117}$ Schließlich gehören bewusste Verstandesakte zu dem inneren Zustand: Die Wahrnehmung oder ein empirisches Bewusstsein der Verstandesakte bedeutet nichts anders als das Bewusstsein dessen, was man bei einer Wahrnehmung der äußeren Dinge denkt. Diese Gedanken gehören offensichtlich zum repräsentationalen Zustand. Man kann zwar unter Umständen einen synthetischen Akt abstrahiert von den empirischen Daten, die er bearbeitet, wahrnehmen. Dafür braucht man jedoch eine spezielle reflexive Aufmerksamkeit, die man nur im Rahmen einer Introspektion, nicht aber bei jeder empirischen Anschauung ausüben kann (B154f.). Wenn man den operierenden

\footnotetext{
${ }^{117}$ In der oben zitierten Stelle (Refl 18:614) setzt Kant, wohlgemerkt, das Bewusstsein der Handlung der Einbildungskraft mit dem Bewusstsein des inneren Zustands gleich.
} 
Verstandesakt wahrnimmt, nimmt man damit auch diejenigen Sinnesdaten wahr, auf denen der Verstand operiert. Umgekehrt gibt es keinen inneren Zustand, der keinen Verstandesakt enthält, denn jede Episode des Bewusstseins enthält einen Akt der reinen Apperzeption, wie bereits gezeigt worden ist. Es gibt bei Menschen (im normalen Zustand) keinen Bewusstseinszustand, der keinen spontanen Denkakt enthält. Folglich scheint der Begriff der Wahrnehmung der inneren Zustände mit dem der Wahrnehmung der eigenen Verstandesakte koextensiv zu sein. Mit dem letzteren will Kant wohl den spontanen Aspekt der Selbstwahrnehmung hervorheben.

\subsubsection{Anschauung des inneren Zustands und Anschauung des Ichs}

Bisher wurde stets von Anschauungen des inneren Sinnes gesprochen. In §1.5.5. werden die primäre und die sekundäre Selbstanschauung unterschieden und analysiert. Man könnte einwenden, dass es manchen Textstellen zufolge keine Anschauung gibt, die der Apperzeption korrespondiert. Es gibt Belege, in denen diese innere Anschauung anscheinend völlig geleugnet wird:

Allein dieses Ich ist sowenig Anschauung, als Begriff von irgendeinem Gegenstande, sondern die bloße Form des Bewußtseins, welches beiderlei Vorstellungen begleiten, und sie dadurch zu Erkenntnissen erheben kann, sofern nämlich dazu noch irgend etwas anderes in der Anschauung gegeben wird, welches zu einer Vorstellung von einem Gegenstande Stoff darreicht.“(A382).

Kant schreibt sogar, dass mit der Vorstellung des Ich „nicht die mindeste Anschauung verbunden [sei], die es von anderen Gegenständen der Anschauung unterschiede.“ (A350) Das „Etwas überhaupt“, das der Begriff des Ich bezeichnet, ist „keiner eigentlichen Anschauung fähig“ (A400, Hervorhebung durch mich). Ebenfalls deutlich ist auch diese Bemerkung: „Das Bewusstsein meiner selbst in der Vorstellung Ich ist gar keine Anschauung, sondern eine bloße intellektuelle Vorstellung der 
Selbsttätigkeit eines denkenden Subjekts.“ (B278. Siehe auch BXL Anm.) Auch eine äußerst wichtige Fußnote in B157f. über die Selbstanschauung könnte leicht - wenn man diese Fußnote mit dem Paralogismen-Kapiteil verknüpft - den Eindruck suggerieren, dass es gar keine Selbstanschauung gibt: ${ }^{118}$

Das: Ich denke, drückt den Actus aus, mein Dasein zu bestimmen. Das Dasein ist dadurch also schon gegeben, aber die Art, wie ich es bestimmen, d.i. das mannigfaltige zu demselben Gehörige in mir setzen solle, ist dadurch noch nicht gegeben. Dazu gehört Selbstanschauung, die eine a priori gegebene Form, d.i. die Zeit, zum Grunde liegen hat, welche sinnlich und zur Receptivität des Bestimmbaren gehörig ist. Habe ich nun nicht noch eine andere Selbstanschauung, die das Bestimmende in mir, dessen Spontaneität ich mir nur bewußt bin, eben so vor dem Actus des Bestimmens giebt, wie die Zeit das Bestimmbare, so kann ich mein Dasein als eines selbstthätigen Wesens nicht bestimmen; sondern ich stelle mir nur die Spontaneität meines Denkens, d.i. des Bestimmens, vor, und mein Dasein bleibt immer nur sinnlich, d.i. als das Dasein einer Erscheinung, bestimmbar. Doch macht diese Spontaneität, daß ich mich Intelligenz nenne. (B157-8 Anm.)

In diesem Sinne zieht Kitcher (2011: 117) den Schluss: „But he is clear that inner sense can provide no intuition of a self (A107, B134) [...] There is no I-impression or IIntuition.“ (2011: 137.) ${ }^{119}$ Diese Behauptung stehen in eklatanter Weise mit Textstellen in Konflikt, die in \$1.5.5. und 2.4.2. als Beleg für die Existenz der Selbstanschauung aufgeführt werden.

Es muss beachtet werden, dass Kant in allen oben zitierten Textstellen, in denen er anscheinend die Möglichkeit der Selbstanschauung ausschließt, von der Anschauung spricht, die eher dem Begriff des Ich als dem Ausdruck „Ich denke“ entspricht. Beinahe jedes Mal wenn Kant über eine spezielle, rudimentäre Anschauung spricht, handelt es sich um eine Anschauung, die mit dem Denkakt „Ich denke“ im Zusammenhang steht

\footnotetext{
118 Diese Meinung hat Kitcher (2011: 199).

119 Eine ähnliche Meinung findet sich auch bei Klemme (2015:1067, 1070). Dagegen wendet sich Lau. Ihm zufolge gibt es eine Anschauung des Ichs als Objekt (2015:2103), aber „keine Anschauung von der Seele selbst als einem Object“" (A22/B37. Siehe Lau 2015:2102)
} 
(A342/B400f., A343/B401, A848/B876). Am deutlichsten sieht man den Unterschied zwischen „Ich denke“ und „Ich“ hinsichtlich der korrespondierenen Anschauung in B422-3 Anm. Das Reale, das die unbestimmte Wahrnehmung repräsentiert, wird im Satz „Ich denke“ „als ein solches bezeichnet“ (siehe auch B423). Somit besteht zwischen dem „Ich denke“ und der unbestimmten Wahrnehmung offenbar eine semantische Korrespondenz. Direkt im Anschluß stellt Kant das Ich denke als empirischen Satz der Vorstellung des Ich als intellektueller Vorstellung gegenüber. Folglich lässt sich schließen, dass der Ausdruck „Ich denke“ einer rudimentären Anschauung - die sogenannte sekundäre Selbstanschauung - korrespondiert, während der Begriff des Ich überhaupt keiner Anschauung entspricht. Die sekundäre Selbstanschauung durch den inneren Sinn kann durch diese Stelle direkt bestätigt werden:

Da überdem die Prädicate, wodurch ich diesen Gegenstand denke, bloß Anschauungen des inneren Sinnes sind, so kann darin auch nichts vorkommen, welches ein Mannigfaltiges außerhalb einander, mithin reale Zusammensetzung bewiese (B471)

Die Anschauungen des inneren Sinnes korrepondieren semantisch, genauer gesagt, dem Begriff „denke“ im „Ich denke“. Die Prädikate, durch die man das Subjekt denkt, sind nämlich gerade die (empirische) Vorstellung der Denkakte des Subjekts (Prol. 4:334). Diese empirische Vorstellung der Denkakte wird durch den Begriff „,denken“ im „Ich denke“ begrifflich erfasst. All diese bejahenden Aussagen über die Selbstanschauung am Gedanken „Ich denke“ sind damit kompatibel, dass wir „keine Anschauung des Ich als einem Object" haben (A22/B37). Es fehlt eine Anschauung, die das Ich durch etwas Beharrliches als ,stehend [] und bleibend []“ und somit als ein Objekt vorstellt, worin die Gedanken (als Prädikate) wechseln (A350, siehe auch B420, 413f.). Kurz gesagt, 
man hat Anschauungen von den Prädikaten des Subjekts, aber keine Anschauung des Substratums dieser Prädikate (Refl 18:186). ${ }^{120}$

Nun kommen wir zurück zu einem Satz der eben zitierten Passage:

Habe ich nun nicht noch eine andere Selbstanschauung, die das Bestimmende in mir, dessen Spontaneität ich mir nur bewußt bin, eben so vor dem Actus des Bestimmens giebt, wie die Zeit das Bestimmbare, so kann ich mein Dasein als eines selbstthätigen Wesens nicht bestimmen. (B157-8 Anm.)

Diese kann nicht so interpretiert werden, als ob Kant die fragliche Selbstanschauung und dadurch die Möglichkeit ableugnen will, ,,mein Dasein als ein[...] selbstthätige[s] Wesens [zu] bestimmen“. Denn Kant schreibt ausdrücklich, dass der Gedanke „Ich denke“, wenn er mit einer ,,inneren Anschauung“ durch den inneren Sinn verbunden ist, „die Bestimmbarkeit meines Daseins bloß in Ansehung meiner Vorstellungen in der Zeit“" enthält (B420). Dies kann auch durch eine andere Stelle bestätigt werden:

Allein ich bin mir meines Daseins in der Zeit (folglich auch der Bestimmbarkeit desselben in dieser) durch innere Erfahrung bewußt, und dieses ist mehr, als bloß mich meiner Vorstellung bewußt zu sein, doch aber einerlei mit dem empirischen Bewußtsein meines Daseins, welches nur durch Beziehung auf etwas, was mit meiner Existenz verbunden außer mir ist, bestimmbar ist. (Bxxxix-xl)

„Mein“ Dasein kann durchaus bestimmbar sein, indem man das „empirische[] Bewußtsein“ der inneren repräsentationalen Zustände in der Zeit bestimmt. Dieses bestimmte empirische Bewusstsein oder ,innere Erfahrung“ ist nichts anderes als eine kategorisch bestimmte Selbstanschauung der inneren Zustände.

\footnotetext{
${ }^{120}$ In diesem Sinn stimme ich Allisons Ausführung völlig zu: „But since inner sense has no manifold of its own and derives its data from outer sense, it has no content that it can be regarded as representations of the self in the way in which outer intuitions are regarded as intuitions of body. Accordingly, the self cannot be said to appear to itself through inner sense; rather what appears to it are its representations of outer objects, which through a reflective act are taken as ist representations in the possessive sense of belonging to itself rather than in the intentional sense as representations of itself“ (Allison 2015:395, see also Allison 2004: 279).
} 


\subsubsection{Liefert der innere Sinn nur zeitlich geordnete äußere Anschauungen?}

Nun betrachten wir einen alternativen Interpretationsvorschlag. Gegen die Higher-

Order Lesart des inneren Sinnes schlägt Schmitz eine neue, elegante Interpretation vor, wonach die Affektion des inneren Sinnes keine Anschauung der inneren Vorgänge oder Zustände, sondern äußere Vorstellungen hervorbringe (2015:9). Da in der Selbstaffektion die figürliche Synthesis auf die empirischen Rohdaten der äußeren Vorstellungen einwirke, sollten diese äußeren Vorstellungen äußere Anschauungen sein; da die Form des inneren Sinnes die Zeit sei, seien sie zeitlich geordnete Anschauungen der äußeren Gegenstände (2015:9). Somit sind die von dem inneren Sinn hervorgebrachten Vorstellungen zeitlich geordnete äußere Anschauungen. Anders gesagt, die Selbstanschauung durch den inneren Sinn ist die äußere Anschauung.

Schmitzs Interpretation basiert auf Horstmanns Interpretation der Vorstellung des Ichs. Nach Horstmann ist das Ich bei Kant keineswegs ein Objekt, sondern die spontane Denkhandlung (Horstmann 1997:98). ${ }^{121}$ Schmitz behauptet:

[SCH.1] The 'I' cognizes itself only insofar as it thinks because it is essentially thinking. Thinking in turn can only have content in relation to given intuitions, and according to my interpretation intuitions are given in inner sense. Only if the figurative synthesis affects inner sense and thereby produces intuitions, can the subject realize itself as thinking and in this way achieves a kind of 'self-intuition', an empirical selfconsciousness of oneself as a thinking subject of representations. (Schmitz 2015:18 Anm.17, meine Hervorhebung)

121 „Diese Vorstellung [des Ichs] bezeichnet nichts weiter als ein sozusagen analytisches Implikat der Denkhandlung, ein Implikat, das gedacht werden muß nicht als etwas, das (gegenständlich) ist, sondern das, indem Denken stattfindet, sich gleichsam realisiert“ (Horstmann 1997:103). Es gibt eine Debate zwischen Horstmann und Rosefeldt darüber, welche der beiden Lesart die wahre Meinung Kants ist. In dieser Arbeit verzichte ich auf eine Stellungnahme zu dieser Frage, weil sie hoch kompliziert und meinen Argumentationsvorgang nicht beeinflusst. 
Was genau ist diese Selbstanschauung? Nach Schmitz wird die Selbstanschauung vom inneren Sinn geliefert, aber sie ist weder Anschauung des eigenen Zustands noch des Subjekts als Objekts:

[SCH.2] The intelligence only cognizes itself 'as it appears to itself with regard to an intuition', which means that the subject of cognition, by being conscious of an intuition which is due to its own act of combination, can cognize itself as the responsible faculty of combination and therefore as the subject of the respective intuition which it can accordingly attribute to itself. Thus, Kant is not concerned with self-intuition in the sense of intuitions of oneself or of one's own inner states, but rather in the sense of intuitions of outer objects by means of which an empirical self-consciousness of oneself as a subject to which those intuitions belong is made possible (Schmitz 2015:10-1, die erste Hervorhebung von mir)

Schmitz behauptet, dass Kant bezogen auf B68-9 andeute, dass „das Vermögen sich bewußt zu werden“ - womit dem Kontext zufolge hier offensichtlich das Vermögen der Synthesis gemeint ist -das Gemüt affiziert und dadurch sich selbst anschaut. ${ }^{122}$ Folglich liefere gerade der innere Sinn ,,a self-intuition of the understanding as a faculty of combination or synthesis" (Schmitz 2015:10). Da der innere Sinn nach Schmitz keine andere Anschauung als äußere Anschauung liefert, muss mit der fraglichen Selbstanschauung gerade die äußere Anschauung gemeint sein. Nun stellt sich die Frage, warum die äußere Anschauung Selbstanschauung ist. In den Zitaten SCH.1 und SCH.2 scheint Schmitz die Auffassung zu vertreten, dass die äußere Anschauung als eine Selbstanschauung des Verstandes als Synthesisvermögen betrachtet werden kann. ${ }^{123}$ Die Gründe hierfür formuliert Schmitz nur vage, die wie folgt zusammengefasst werden können: Die äußere Anschauung ist das Produkt des synthetischen Akts. Indem das Subjekt sich der äußeren Anschauung bewusst ist, die es selbst mittels einer Denkhandlung produziert hat, kann es sich seiner selbst als

\footnotetext{
${ }^{122}$ Obwohl dies befremdlich klingt, ist Schmitzs Interpretation durch Kants Wortlaut gut fundiert (Schmitz 2015:10)

${ }^{123}$ In diesem Sinn sagt Schmitz, ,all intuitions are inner intuitions” (Schmitz 2015:13)
} 
denkendes Subjekt, das für diese Anschauung verantwortlich ist - als Subjekt der Anschauung - empirisch bewusst werden. Dieses Bewusstsein ist gerade die fragliche Selbstanschauung.

Schmitzs Lesart ist hauptsächlich dadurch motiviert, dass sie glaubt, dass die HigherOrder Lesart des inneren Sinnes sachlich nicht haltbar ist. Sie versucht deswegen zu beweisen, dass die Vorstellung des inneren Sinnes nichts „im“ Subjekt, sondern äußere Gegenstände als repräsentationalen Gehalt hat (Schmitz 2015: 9). Innere Anschauungen, die innere Gegenstände (wie innere Zustände) repräsentieren, gibt es ihrer Argumentation zufolge bei Kant gar nicht (Schmitz 2015:13)

Meines Erachtens ist Schmitzs Interpretationsvorschlag jedoch hoch problematisch. Diese Lesart widerspricht Kants häufigen Darstellungen des inneren Sinnes als Anschauung des inneren Zustands in eklatanter Weise. Anschauung oder Wahrnehmung des inneren Zustands ist nicht gleichzusetzen mit äußerer Anschauung. Schmitzs Versuch, diese beiden in beschriebener Weise begrifflich in einen Zusammenhang zu bringen, ist nicht begründet. Das zeigt sich in vielerlei Hinsichten.

Schmitzs Lesart bleibt eine plausible Erklärung der Selbstbeziehung in der äußeren Anschauung qua Selbstanschauung schuldig. D.h. Schmitzs Erklärung, inwiefern die äußere Anschauung als eine „Selbstanschauung“ bezeichnet werden kann, ist nicht haltbar. Die äußere Anschauung, wenn unsynthetisiert, bietet empirische rohe Materialien für die synthetischen Handlungen (Schmitz 2015: 18 Anm. 17) und stellt folglich höchstens einen Anlass für die synthetischen Handlungen dar. Wenn sie synthetisiert wird, ist die äußere Anschauung ein Produkt der Sinnlichkeit und der synthetischen Handlung. In diesem Fall ist es aber weit hergeholt, die äußere Anschauung als „Selbstanschauung“ zu bezeichen. Weil die synthetischen Handlungen meistens unbewusst bleiben (wie Kant in A78/B103 und A103-4 explizit beteuert hat), kann man sich meistens nur ihrer Produkte bewusst sein. Das Bewusstsein des Produkts 
der Handlungen ist aber nicht schlichtweg das Bewusstsein der Handlungen. Es ist nicht nachvollziehbar, wie das Bewusstsein der Wirkung der Handlung - d.h. das Bewusstsein der äußeren Gegenstände - zugleich ein empirisches Bewusstsein der Handlung selbst darstellen sollte. Wenn Schmitz dies ablehnen wollte, würde sie sich eine Kritik anhand der Mooreschen These der Transparenz der Erfahrung aussetzen: „When we try to introspect the sensation of blue, all we can see is the blue; the other element is as if it were diaphanous“" (Moore 1903: 450). ${ }^{124}$ Genauer gesagt besagt die Kritik, dass wenn wir auf einen äußeren Gegenstand fokussieren, wir allein ihn und seine wahrnehmbaren Eigenschaften, nicht aber unsere Wahrnehmung derselben wahrnehmen. Im Bewusstsein der äußeren Anschauung selbst gibt es kein Bewusstsein der eigenen synthetischen Handlungen.

Auch wenn wir von diesem Problem absehen, ist der intentionale Gegenstand der äußeren Anschauung gar nicht die Denkhandlung, die nach Horstmann die Vorstellung des Ich motivert, sondern der äußere Gegenstand. Wenn das Synthesisvermögen sich selbst wirklich durch die äußere Anschauung anschaut, muss der intentionale Gegenstand dieser Anschauung die Denkhandlung sein, was aber nicht der Fall ist. Als eine Vorstellung, die ,sich direkt auf die Gegenstände der Materialien bezieht, die durch den Verstand verbunden werden“" (Schmitz 2015:9), kann die äußere Anschauung die Denkhandlung nicht repräsentieren.

Was ist der intentionale Gehalt der von Schmitz vorgeschlagenen Selbstanschauung? Nach Schmitz ist diese Selbstanschaung „an empirical self-consciousness of oneself as a thinking subject of representations." (SCH.1). Das Subjekt ist sich in diesem Selbstbewusstsein dessen bewusst, dass es das Subjekt der äußeren Anschauung ist, weil es sich seiner Denkhandlung bewusst ist, die für diese Anschauung verantwortlich

\footnotetext{
${ }^{124}$ Moores These wird von Schmitz interessanterwerse selbst als Argument gegen die Higher-Order Lesart verwendet.
} 
ist. Laut Schmitz schreibt das Subjekt sich selbst diese äußere Anschauung zu. Das bedeutet, dass das Subjekt in Kenntnis nimmt, dass diese Anschauung zu ihm gehört (siehe SCH.2). Das Subjekt, als Subjekt der äußeren Anschauung vorgestellt, ist somit der intentionale Gehalt der von Schmitz vorgeschlagenen Selbstanschauung. Dieser intentionale Gehalt kann aber, wie argumentiert, nicht von der äußeren Anschauung geliefert werden. Um sich überhaupt auf das Subjekt einer Vorstellung zu beziehen, braucht das Subjekt den Quasi-Begriff des Ichs. Die Zuschreibung der äußeren Anschauung an dem Subjekt gelingt mittels eines spontanen Akts der reinen Apperzeption und ist damit keine Selbstanschauung, sondern eine gedankliche Zutat zur äußeren Anschauung. Schmitzs Alternative scheitert daran, dass sie den Anschauungscharakter der vorgeschlagenen empirischen Selbstanschauung nicht zufriedenstellend erklären kann. Sie hält die Leistung der reinen Apperzeption fälschlicherweise für die der empirischen Apperzeption.

Schmitzs Interpretation ist auch textuell nicht gut fundiert. Sie ist in der Tat auf eine einzige Stelle angewiesen, und zwar die oben zitierte Stelle aus B158-9, wonach das Ich ,sich [...] selbst doch nur erkennen kann, wie sie, in Absicht auf eine Anschauung [...] ihr selbst bloß erscheint“. Hier deutet Kant an, dass „eine Anschauung“ der empirischen Selbsterkenntnis zugrundeliegt, und spezifiziert nicht weiter, was für eine Anschauung sie ist. Diese Deutungsoffenheit nutzt Schmitz aus und legt den Ausdruck „eine Anschauung“ als ,äußere Anschauung“ aus. Es gibt keine eindeutigen Textbelege dafür, dass die Selbstanschauung die äußere Anschauung ist. In vielen Stellen spricht Kant dagegen von Selbstanschauung, die das Ergebnis des inneren Sinns ist (A22/B37, A33/B49, A37/54, B67, B158, 160, usw.). Es fehlt für Schmitzs Auffassung somit jeglicher direkte Textbeleg. Übrigens scheint Kant die äußere Anschauung gerade von der Selbstanschauung klar zu unterscheiden: „[I]m Raum und der Zeit stellt die Anschauung sowohl der äußeren Objecte, als auch die Selbstanschauung des Gemüths beides vor, so wie es unsere Sinne afficirt [...]“ (B69). 
Kant spricht sehr oft von Selbstanschauung bzw. innerer Anschauung (BXXXIX Anm., B37, B48-9, B53, B67, B471, Anth 7:142, 161). Schmitz versucht solche Stellen wegzuinterpretieren: den Ausdruck „innere Anschauung“ dürfte man nicht als Anschauung der inneren Gegenstände auslegen, sondern als „inneres Anschauen“, das sich auf dem Prozesse des Anschauens der äußeren Gegenstände bezieht. Die Bedingungen des Objektbezugs seien nämlich laut dem Analogie-Kapitel im Fall der Vorstellung des inneren Zustands nicht erfüllt, während ein Objektbezug ein unentbehrliches Merkmal einer Anschauung sei. Gegen diese Auffassung finden sich aber leicht direkte Belege:

„Der innere Sinn, vermittelst dessen das Gemüth sich selbst oder seinen inneren Zustand anschauet, giebt zwar keine Anschauung von der Seele selbst als einem Object; allein es ist doch eine bestimmte Form, unter der die Anschauung ihres inneren Zustandes allein möglich ist, so daß alles, was zu den inneren Bestimmungen gehört, in Verhältnissen der Zeit vorgestellt wird.“

Aus dieser Passage sieht man leicht, dass Kant die Anschauung des Ich als eines Objekts und die Anschauung des eigenen inneren Zustands unterscheidet. Die erstere lehnt er ab, während er die zweite erlaubt. ${ }^{125}$

Schmitz übersieht übrigens, dass auch die Gefühle der Lust und Unlust, der Willen, die Begierde sowie das Denken innere Zustände sind und ihr Bewusstsein nach Kant unter die Vorstellungen durch den inneren Sinn fällt. Wie schon argumentiert, kann man den repräsentationalen Gehalt der Vorstellungen vom inneren Sinn nicht auf eine bestimmte

\footnotetext{
125 Der Begriff des Gegenstands der Anschauung ist also weit gefasst. Er braucht nicht eine Substanz zu sein, sondern auch ein Zustand der Substanz (B420) ist ein potentieller intentionaler Gegenstand einer Anschauung.
} 
Art beschränken, vielmehr sind diese ganz generell Vorstellungen der inneren Zustände. ${ }^{126}$

Am Ende muss bemerkt werden, dass das Ich nicht, wie Schmitz behauptet, allein ein denkendes Wesen ist,

The 'I' cognizes itself only insofar as it thinks because it is essentially thinking. Thinking in turn can only have content in relation to given intuitions, and according to my interpretation intuitions are given in inner sense. (Schmitz 2015:18)

In der Anthropologie macht Kant deutlich, dass es nicht nur ein Ich der Apperzeption, sondern auch ein „Ich der Apprehension“ gibt:

Das Ich der Reflexion hält kein Mannigfaltiges in sich und ist in allen Urtheilen immer ein und dasselbe, weil es blos dies Förmliche des Bewußtseins, dagegen die innere Erfahrung das Materielle desselben und ein Mannigfaltiges der empirischen inneren Anschauung, das Ich der Apprehension, (folglich eine empirische Apperception) enthält. (Anth 7:141-2)

Das phänomenale Bewusstsein der äußeren Gegenstände, das phänomenale Erlebnis der inneren subjektiven Empfindung oder sogar des Denkens, bilden den materialen Aspekt der Apperzeption tout court. Das Ich ist nicht nur Subjekt des Denkens, sondern auch Subjekt der empirischen Anschauungen, der subjektiven Empfindung und des Willens. Das Ich ist somit nicht, wie Schmitz behauptet, „essentially thinking“.

\footnotetext{
${ }^{126}$ Schmitz ist durchaus klar, dass das Denken, Gefühl der Lust und Unlust und der Willen auch innere Vorgänge und damit auch Gegenstände des inneren Sinnes sind. Aber sie vermeidet eine Stellungnahme zu ihnen, indem sie pauschal behauptet, dass sie kein Thema der $K r V$ sind.
} 


\subsection{Selbstbezug des inneren Sinnes}

Die Vorstellungen des inneren Sinns enthalten einen Selbstbezug: ,alle Prädicate des innern Sinnes beziehen sich auf das Ich als Subject, und dieses kann nicht weiter als Prädicat irgendeines andern Subjects gedacht werden“ (Prol. 4:334). Die reine Apperzeption stellt „die Beziehung der inneren Erscheinungen auf das unbekannte Subjekt derselben“" her (Prol. 4:334). Das lässt sich durch mehrere Beobachtungen bestätigen:

Der innre Sinn ist das Bewußtsein unserer Vorstellungen selbst. (Die Apperception liegt dem innern Sinn zum Grunde). Es hat zum Object die Seele. Wenn die Seele sich selbst ihrer bewußt ist, ohne ihres Zustandes bewußt zu sein, so ists Apperception. Ist sie auch ihres Zustandes bewußt, so ist es Empfindung oder Wahrnehmung (VMet/Mron 29:882, 1782/3)

Aus dieser Passage (besonders dem Wort „auch“ im letzten Satz) geht hervor, dass das Subjekt sich im inneren Sinn nicht nur seines Zustandes bewusst ist, sondern auch besonders des Selbsts, das die reine Apperzeption enthält. ${ }^{127}$ Die Vorstellungen des inneren Sinns enthalten einen Bezug auf das Subjekt durch den Quasi-Begriff des Ichs. Der Selbstbezug ist der Grund dafür, dass Kant den Gegenstand des inneren Sinnes sehr oft als „mein selbst und mein[en] Zustand“ bezeichnet.

Diese Charakterisierung des inneren Sinnes ist auf dem ersten Blick problematisch, weil wir aus dem Paralogismen-Kapitel und mehreren Zitaten schon gesehen haben, dass der innere Sinn „keine Anschauung von der Seele selbst, als einem Objekt“ liefert (A22/B37). Man hat keine direkte Vorstellung vom Selbst, weil es gar kein „stehendes oder bleibendes Selbst“ gibt (A107). Wir können das Ich nur durch „meine Vorstellungen“ - damit sind alle unsere bewussten Vorstellungen, nicht aber eine Vorstellung des Ichs gemeint - erkennen. Diesen scheinbaren Widerspruch kann man

\footnotetext{
${ }^{127}$ In diesem Sinne bemerkt Valaris zurecht: „The role of inner sense is to enable the subject to become aware of ist outer representations as its own.“ (Valaris 2008:3, meine Hervorhebung)
} 
nur überwinden, wenn man die Definition „Anschauen[s] unserer Selbst und unseres inneren Zustandes“ in folgender Weise interpretiert: Der innere Sinn ist eine Anschauung davon, wie ich in einem mentalen Zustand stehe. In dieser Anschauung muss ein Bezug auf das Ich als das Subjekt dieses Zustands enthalten sein. D.h. „mein Selbst" bezeichnet den Selbstbezug, für den die reine Apperzeption, die in dem inneren Sinne eingebettet ist, verantwortlich ist. Dieser Selbstbezug ist, wie schon gezeigt, eine „leere“ Vorstellung und enthält keine Merkmale von dem Subjekt selbst. In den Vorstellungen des inneren Sinnes denkt man also an sich selbst. Genauer gesagt, nimmt das Gemüt dabei nicht nur seinen Vorstellungszustand (erster Ordnung) wahr, sondern schreibt sich diese Vorstellung gedanklich zu. Deswegen spricht Kant im obigen Zitat davon, dass ,[d]ie Apperception [..] dem innern Sinn zum Grunde [liegt]“. Dieser Gedanke an sich selbst im inneren Sinn ist normalerweise aber eine dunkle, nicht explizite Vorstellung, da man sich im apperzeptiven Bewusstsein selten seiner selbst explizit bewusst ist, wofür ein introspektives Selbstbewusstsein nötig ist.

Sachlich betrachtet, ist der Selbstbezug vom inneren Sinn unzertrennlich. Die Vorstellungen des inneren Sinnes werden dadurch erzeugt, dass der synthetische Akt die Sinnlichkeit affiziert. Dasjenige, was „mein innerer Sinn mir darbietet“ ist „das, was entweder selbst ein Denken, oder mit diesem analogisch ist“" (B331). Folglich steht er im wesentlichen Zusammenhang mit der synthetischen Handlung. Eine derartige Handlung involviert immer ein intellektuelles Bewusstsein, weswegen der innere Sinn wesentlich mit solchem Bewusstsein verbunden ist. Ohne den Selbstbezug verlieren die Vorstellungen des inneren Sinnes außerdem die „Innerlichkeit“, da Vorstellungen des äußeren Sinnes den „,eigentlichen Stoff“ des inneren Sinnes bilden. Im Letzteren wird der empirische Gehalt des äußeren Sinnes „wiederverwendet“ (nach dem Reflexionsmodell von Allison 2004) oder zum Bewusstsein gebracht (nach der hier vorgeschlagenen Lesart). Der innere und der äußere Sinn teilen sich den gleichen empirischen Gehalt. Ohne den Selbstzuschreibungsakt wäre es nicht sinnvoll davon zu 
sprechen, dass man sich seines inneren Zustands (wenn auch dunkel oder rein sinnlich) bewusst wird.

McLear betrachtet den inneren Sinn als das Vermögen, das alle Vorstellungen enthält, die wir uns zuschreiben können (McLear 2015: §2.c.). Er lehnt aber ab, dass Vorstellungen des inneren Sinns einen Selbstbezug enthalten. Diese Lesart ist problematisch, weil der innere Sinn damit nicht auf eine interessante Weise vom Vorstellungsvermögen unterschieden werden kann. Dies wäre problematisch, denn das Tier hat Kant zufolge keinen inneren Sinn, aber trotzdem die Fähigkeit der Vorstellung. ${ }^{128}$ Anderseits sind einige Interpreten der Meinung, dass der innere Sinn an sich einen Selbstbezug aufweist. ${ }^{129}$ Das ist aber unhaltbar, denn der innere Sinn kann keine begrifflichen Momente enthalten, weil er an sich rein sinnlich ist (A107, siehe auch B154). Was er darbietet ist bloß ein Fluß ,innrer Erscheinungen“ (A107). Den Selbstbezug verdankt er allein der reinen Apperzeption, die mit ihm unzertrennlich verbunden ist.

Angesichts der Analogie zwischen dem Begriff des inneren Sinnes und dem des äußeren Sinnes liegt die Annahme nahe, dass der innere Sinn eine (reflexive) Wahrnehmung hervorbringt, die nicht synthetisiert ist. In diesem Sinne schreibt Ameriks:

Kant eventually distinguished inner sense from apperception in a way that obviously allows the possibility of reflection without cognition. He defines apperception as the conceptual determination of the intuitions of the self provided through inner sense (B 154). There is no evident logical necessity prohibiting bringing such intuitions to consciousness without simultaneously synthesizing them in cognition. The latter consciousness in turn should be distinguished from the fully developed self-

\footnotetext{
128 V-Met-L1/Pölitz 28: 276.

129 „Empirical apperception is supposed to explain how a particular thinker self-ascribes particular representations at particular times (B158). Empirical apperception provides representations of a state of the mind at a time: I am tasting something sweet now; I was thinking about the properties of a body earlier.“ Kitcher (2011:157). In ähnlicher Weise auch Valaris (2008:3).
} 
consciousness that is had when, instead of merely judging a particular inner state, one rather synthesizes broad stretches of experience so as to come to a concept of the concrete situation and character of the self.

Es ist unumstritten, dass die Konzeption des inneren Sinns an sich den Aspekt der Erfahrung hervorhebt, der wesentlich durch Rezeptivität charakterisiert wird. Kant unterscheidet den inneren Sinn von der inneren Erfahrung. Letztere ist das Ergebnis der Operation des synthetischen Akts auf den inneren Sinn. Gegen Ameriks Ansicht sprechen allerdings folgende Beobachtungen: Wie wir schon gesehen haben, sind die reine und die empirische Apperzeption voneinander abhängig (A115f.). Die reine Apperzeption ist in jeder Episode des Bewusstseins enthalten. Ameriks hat völlig recht, wenn er sagt: ,there is no evident logical necessity prohibiting bringing such intuitions to consciousness without simultaneously synthesizing them in cognition" ${ }^{130}$ Allerdings führt diese Synthetisierung nicht der Akt der Apperzeption aus, der notwendigerweise in der Vorstellung des inneren Sinnes eingebettet ist, sondern ein weiterer Akt der Apperzeption qua Synthesis der Einbildungskraft. Dieser Akt synthetisiert die Vorstellungen des inneren Sinnes zur inneren Erfahrung. Ameriks liegt falsch, weil er die Funktion der Appertzeption im inneren Sinn verkennt, indem er sagt: „He defines apperception as the conceptual determination of the intuitions of the self provided through inner sense (B 154).“131 In B154, wie wir schon gesehen haben, geht es eher um den zweiten Akt der Apperzeption, der in der Erzeugung der inneren Erfahrung ausgeübt wird, als um den ersten Akt der Apperzeption, der den inneren Sinn affiziert und diesen erst mit Vorstellungen besetzt.

\footnotetext{
130 Ameriks (2000:246).

${ }^{131}$ In (2006:55-6) hält er den inneren Sinn für völlig frei von jeder kognitiven und apperzeptiven Leistung. Nach meiner Interpretation ist der innere Sinn wesentlich mit der reinen Apperzeption verbunden, wie oben erläutert.
} 


\subsection{Bewusstseinstheoretischer Status des inneren Sinnes}

Die überwiegende Mehrheit der Kommentatoren ist der Meinung, dass der innere Sinn Vorstellungen höherer Stufe liefert. ${ }^{132}$ Diese Meinung wird auch in dieser Abhandlung vertreten. Damit wird keineswegs behauptet, dass Kant eine sogenannter Higher-OrderTheorie des phänomenalen Bewusstseins vertritt. Der innere Sinn liefert nämlich zwar eine Vorstellung höherer Stufe, hat jedoch keine maßgebende Bedeutung für das phänomenale Bewusstsein selbst. Auch ohne den inneren Sinn kann ein nichtapperzeptiver Geist die einzelnen Sinneseindrücke phänomenal erleben. Hier wird bloß die These vertreten, dass der innere Sinn eine Vorstellung höherer Stufe ist. Ganz entscheidend für diese Auffassung ist, dass Kant den inneren Sinn oft als Anschauung bzw. Wahrnehmung des (im Kontext der $K r V$ : repräsentationalen) Zustands des Gemüts charakterisiert. Diese innere Anschauung ist eine Vorstellung, die nicht zur Vorstellung erster Ordnung, die sie begleitet, gehört. ${ }^{133}$ Denn wie Kants Doktrin der dunklen Vorstellungen zeigt, kann eine Vorstellung ohne Begleitung der inneren Anschauung durch den inneren Sinn auch unterschwellig kognitive Funktionen ausüben - d.h. eine kausale oder epistemische Rolle spielen. Dies spricht dafür, dass die Begleitung durch eine innere Wahrnehmung keine notwendige Bedingung für den Vorstellungsstatus eines mentalen Zustands ausmacht. Viele weitere Indizien deuten darauf hin, dass es sich bei der Vorstellung des inneren Sinnes um einen richtigen repräsentationaler Zustand handelt. Im Losen Blatt Kiesewetter macht Kant z.B. diese Bemerkung:

Gleichwohl aber bringt dieser Gedanke einen Gegenstand der Erfahrung hervor oder eine Bestimmung des Gemüths, die beobachtet werden kann, sofern es nämlich durch das Denkungsvermögen afficirt wird.

\footnotetext{
132 Befürworter solcher Lesart sind z.B. Collins (1999:109), Wolff 1963:199, Allison (2004:278-9), McLear (2011). Dagegen: Schmitz (2015), Guyer (1987).

133 Siehe Liang (2017).
} 
Ein Gedanke ist dem Kontext nach ein zeitliches Ereignis, das den inneren Sinn affizieren kann. Der innere Sinn nimmt ihn durch „Beobachtung“wahr und wie bereits ausgeführt, erlaubt Kant die Möglichkeit, dass dieser Zustand nicht oder falsch wahrgenommen wird - d.h. nicht beobachtet oder falsch beobachtet wird. Die Analogie zwischen dem inneren und äußeren Sinn ist offensichtlich. Es scheint keine andere Alternative zu geben, als den inneren Sinn als genuine innere Wahrnehmung zu interpretieren. Die Form des inneren Sinnes ist übrigens die Zeit. Die Zeitlichkeit kann nicht durch den Gehalt der objektbezogenen Vorstellungen erster Ordnung - d.h. der Vorstellungen des äußeren Sinnes, der subjektiven Empfindungen usw. (siehe §2.2) repräsentiert werden. Das Erleben der Sukzessivität ist aber ein Faktum. Also muss eine weitere Vorstellung existieren, die die Zeitlichkeit vorstellt. Diese Vorstellung ist in Kants theoretischen Rahmen gerade die Reproduktion. In dieser fasst das Gemüt die gegenwärtigen, unmittelbar und mittelbar vergangenen Wahrnehmungsbilder in einer sukzessiven Serie zusammen und schreibt sie sich unbewusst als zu ihm selbst gehörend zu. ${ }^{134}$ Damit entsteht eine Vorstellung, die die unmittelbar vergangenen und gegenwärtigen Wahrnehmungen vereinigt und die als Form die Zeit hat. Collins gibt eine gute Zusammenfassung dieser Higher-Order-Lesart des inneren Sinnes:

In order that the original representations of outer sense be accessible to our combinatory powers, they must themselves be apprehended, and this is the fundamental business of inner sense, at least as far as knowledge is concerned. [. . .] Inner sense is a matter of apprehending mental realities that are, in the first instance, none other than the

${ }^{134}$ Oben habe ich argumentiert, dass auch Tiere im Rahmen von Kants System dieses Erlebnis der Sukzessivität haben können. Es stellt sich die Frage, warum dieses Erlebnis im menschlichen Gemüt eine innere Anschauung ist, während es im tierischen Geist dies nicht ist. Obwohl jede Vermutung exegetisch rein spekulativ bleiben muss, ist meiner Ansicht nach die folgende Erklärung plausibel. Die subjektive Folge der Wahrnehmungen ist beim Tier im Gegensatz zu Menschen durch rein sinnliche Mechanismen zustandegekommen. Weil das Tier keine Apperzeption hat, stellt es diese Reihe der Wahrnehmungen nicht als seine eigenen Zustände vor. Weil es nicht zur Einheit der Apperzeption fähig ist, ist diese Folge insofern fragmentarisch und isoliert, als sie in keinen einheitlichen Sinnzusammenhang mit anderen Wahrnehmungsfolgen gebracht werden kann. 
representations of outer things that the stimulation of outer sense engenders. [. . .] Therefore, in so far as there is an empirical manifold of inner sense, it will contain representations of the representations that make up the manifold of outer sense. (Collins 1999: 109; emphasis in original)

Allerdeutlichst spricht Kant in seiner späten Schrift sogar wörtlich vom inneren Sinn als Vorstellung höherer Stufe:

Die reine Anschauung des Manigfaltigen im Raum enthalt die Form des Gegenstandes in der Erscheinung a priori vom ersten Range d.i. directe. Die Zusammensetzung der Warnehmungen Erscheinung im Subject zum Behuf der Erfahrung ist wiederum Erscheinung des so afficirten Subjectes wie es sich selbst vorstellt also indirect und ist vom zweyten Range Erscheinung von der Erscheinung der Warnehmungen in Einem Bewustseyn d.i. Erscheinung des sich selbst afficirenden Subjects mithin indirect, und der Synthesis derselben zur Moglichkeit der Erfahrung (die nur Eine ist) Das Subjective der Verknüpfung der Darstellungen in dem Subject nach Principien des Bewustseyns der Zusammensetzung desselben zu einem Erkentnis dieser Phänomene im Bewustseyn der synthetischen Einheit der Erfahrung ist die mittelbare Erscheinung. Folglich die Zusammenfassung der Warnehmungen zur Einheit der Erfahrung folglich so daß ein System dieser inneren Warnehmungen die sich a priori classificiren u. specificiren lassen da das zusammensetzende Subject sich selbst in der Zusammensetzung nach Principien erscheint und so a priori in einem System der Warnehmungen als die Sinne afficirenden Kraften der Materie zur Moglichkeit einer Physik fortschreitet (OP 22:367)

Nun möchte ich einige Einwände gegen die Higher-Order-Lesart zurückweisen. Der Erstere verweist auf den Aspekt der sogenannten Transparenz bzw. Diaphanität phänomenaler Erlebnisse, worunter nach einer berühmten Charakterisierung folgendes zu verstehen ist: „When we try to introspect the sensation of blue, all we can see is the blue: the other element is as if it were diaphanous“ (Moore 1903:450). Folgt man Kritikern der Higher-Order-Lesart, dann kann man den Vorstellungszustand aus dem Grunde nicht wie einen Gegenstand des äußeren Sinnes als Gegenstand wahrnehmen, weil wir unsere Aufmerksamkeit nicht auf die Wahrnehmung als einen mentalen Zustand richten können (Schmitz 2015:5-6). Schmitz zufolge kann man den Gehalt des inneren Sinnes als Vorstellung höherer Ordnung nicht spezifizieren, weil er keine sinnlichen Vorstellungen des Wahrnehmungsakts gibt. Schmitz zufolge bleibt die 
Higher-Order-Lesart damit eine Antwort auf die folgenden Fragen schuldig: „[W]hat can it mean to say that we (sensually) represent a representation of a red apple? What would be the content of such a secondary representation, and what exactly would be its relation to the apple?" (Schmitz 2015:6).

Dieser Einwand ist in vielerlei Hinsichten unangebracht. Von einem exegetischen Standpunkt aus stellt die Schwäche einer Doktrin - angenommen, dass es diese wirklich gibt - keinen zwingenden Grund dar, Kant diese Doktrin abzusprechen, besonders, wenn zahlreiche Textstellen diese Doktrin belegen. Die Kritiker haben völlig Recht darin, dass der repräsentationale Akt nicht wahrzunehmen ist, sie übersehen aber, dass Kant es als ein Faktum betrachtet, dass das Gemüt die äußere Wahrnehmung von ihrem Gegenstandsbezug abstrahieren und sie dann ohne weiteres als einen repräsentationalen Zustand oder Akt auffassen kann (A189/B234-A190/B235). Dass Kant die innere Wahrnehmung des eigenen Zustands als ein Faktum betrachtet, macht er ganz explizit: Wie es möglich sey, daß ich, der ich denke, mir selber ein Gegenstand (der Anschauung) seyn, und so mich von mir selbst unterscheiden könne, ist schlechterdings unmöglich zu erklären, obwohl es ein unbezweifeltes Factum ist (FM 20:270)

[D]as Bewustseyn kann alle Vorstellungen begleiten, mithin auch die der Einbildung, die und deren Spiel selbst ein Object des innern Sinnes ist und von der es moglich seyn ти $\beta$, sich ihrer als einer solchen bewust zu werden, weil wir wirklich solche als innere Vorstellungen, mithin in der Zeit existirend, von der Sinnenanschauung unterscheiden (Refl 18:621)

Jeder actus der Aufmersamkeit kann uns ein Beispiel davon geben. ...Wie sehr das Gemüt gemeiniglich hierdurch affiziert werde, wird ein jeder in sich wahrnehmen können (B156-7 Anm.)

Sachlich betrachtet, ist es nicht so, dass es bestimmte spezifische Sinneseindrücke von der äußeren Wahrnehmung geben muss, die dem Vorstellungsakt kausal korrespondieren und folglich diesen Akt selbst repräsentieren. Es ist nicht der Fall, dass man sich erst anhand dieser Sinneseindrücke auf den Vorstellungsakt beziehen kann. Es gibt also in der Tat zwei mögliche Wege, eine gegenstandsbezogene Wahrnehmung 
als eigenen Zustand zu betrachten. Man kann den repräsentationalen Akt als solchen wahrzunehmen, was der These der Transparenz zufolge nicht möglich ist. Aber man kann das phänomenale Erlebnis direkt umdeuten, indem man sich auf den Vorstellungszustand selber statt auf seinen Gegenstand bezieht. Die Fähigkeit einer derartigen Umdeutung scheint Kant als Faktum niemals in Frage gestellt zu haben, sondern er scheint sie im Gegenteil ausdrücklich zu akzeptieren, denn ein zentrales Prinzip der Doktrin setzt sie voraus. Wie bereits ausgeführt, muss ein Selbstzuschreibungsakt der Apperzeption alle Vorstellungen, darunter auch die äußeren Wahrnehmungen, begleiten können. Dieser Akt der Apperzeption begleitet eine Vorstellung dann, wenn man sich dieser Vorstellung bewusst ist. Der Selbstzuschreibungsakt, die Apperzeption, muss nämlich in allem Bewusstsein des Menschen enthalten sein - dabei kann er entweder bewusst oder unbewusst sein. Dieses Apperzeptionsprinzip setzt voraus, dass man sich aller Vorstellungen explizit als seine eigenen mentalen Zustände bewusst werden kann. In diesem Selbstzuschreibungsakt muss die von der Apperzeption begleitete Vorstellung als Gegenstand betrachtet werden. Folglich ist es wegen der reinen Apperzeption, die auch im inneren Sinn eingebettet ist, nie ein Problem, sich auf eine Vorstellung als Gegenstand zu beziehen. Spezielle Sinneseindrücke von diesem Vorstellungsakt selbst sind dafür nicht notwendig. Der sinnliche Gehalt der Vorstellung höherer Stufe entspricht einfach dem der Vorstellung des äußeren Sinnes. Man kann deswegen sagen, dass der innere Sinn dadurch den eigenen Zustand als Gegenstand wahrnimmt, weil es dunkle Vorstellungen gibt, die ebenfalls mentale Zustände, aber unbewusst sind. Die Sinneseindrücke des äußeren Sinnes sind zugleich Erscheinungen des Subjekts, wenn man von ihrem Objektsbezug absieht.

Vor diesem Hintergrund erweist sich auch ein weiterer Einwand als falsch. Schmitz wirft der Higher-Order-Theorie vor, dass das Verhältnis zwischen der Vorstellung erster Stufe und der Vorstellung höherer Stufe problematisch sei (Schmitz 2015:6). 
Entweder enthält die Vorstellung höherer Stufe nicht die gleichen Sinneseindrücke wie die Vorstellung ersterer Stufe. Dann ist es im Licht der Transparenz des phänomenalen Erlebnisses fragwürdig, was die speziellen Sinneseindrücke der Vorstellung des inneren Sinnes sein sollen. Wenn dagegen die Vorstellung höherer Stufe die gleichen Sinneseindrücke wie die Vorstellung erster Orndung hat, ist es wiederum problematisch, wie sich die beiden Vorstellungen verschiedener Stufen voneinander unterscheiden sollen. Aus diesem Grunde behauptet auch Wolff, dass die äußeren Wahrnehmungen nicht zugleich die inneren Zustände vorstellen. ${ }^{135}$ Der in dieser Abhandlung vertretenen Auffassung des inneren Sinnes zufolge ist ersichtlich, warum diese Einwände von Schmitz und Wolff unberechtigt sind. Die Vorstellung des inneren Sinnes enthält nämlich (in einer nicht-introspektiven Situation) eine implizite Selbstzuschreibung bzw. die reine Apperzeption in dunkler Form - schließlich ist der innere Sinn die Vorstellung des eigenen Zustands als eigenen Zustand - die nicht in der Vorstellung des äußeren Sinnes enthalten ist.

135 Wolff (1963:198) 


\subsection{Das Empirisches Bewusstsein „an Sich“}

In diesem Kapitel wird versucht, den Begriff des empirischen Bewusstseins zu klären.

Es wird argumentiert, dass das empirische Bewusstsein an sich keinen Bezug auf das Ich enthält. Das empirische Bewusstsein ist eine Vergegenwärtigung der Sinnesdaten mit minimaler Aktivierung kognitiver Fähigkeiten.

\subsubsection{Empirisches Bewusstsein, Formales Bewusstsein und Grad des}

\section{Bewusstseins}

Die Empfindung, der das empirische Bewusstsein das Attribut des „empirischen“ in seinem Namen verdankt, liefert die empirischen Materialien der Vorstellung ersterer Ordnung. ${ }^{136}$ Diese Empfindung ist nicht mit der Empfindung durch die Selbstaffektion zu verwechseln. Der Grund dafür ist wie folgt: wenn der Grad des empirischen Bewusstseins null ist, wird das empirische Bewusstsein zum formalen Bewußtsein verwandelt:

Nun ist vom empirischen Bewußtsein zum reinen eine stufenartige Veränderung möglich, da das Reale desselben ganz verschwindet, und ein bloß formales Bewußtsein (a priori) des Mannigfaltigen im Raum und Zeit übrig bleibt: also auch eine Synthesis der Größenerzeugung einer Empfindung von ihrem Anfange, der reinen Anschauung $=0$, an bis zu einer beliebigen Größe derselben (B208)

Ein formales Bewusstsein enthält keine Empfindung mehr in den von ihm begleiteten Vorstellungen, denn diese Vorstellungen sind reine Anschauungen des „Mannigfaltigen im Raum und Zeit““. Das formale Bewusstsein gehört aus folgenden Gründen jedoch immer noch zum inneren Sinn: erstens ist man sich dabei seines inneren repräsentationalen Zustands des reinen Mannigfaltigen (explizit oder implizit) bewusst; zweitens spielt die transzendentale Synthesis der Einbildungskraft eine

\footnotetext{
136 McLear (2015) vertritt im Endeffekt eine ähnliche Position.
} 
strukturierende Rolle bei der Konstruktion der reinen Anschauung im formalen Bewusstsein. Da diese Synthesis den inneren Sinn affiziert, gehört das formale Bewusstsein zum inneren Sinn. Das formale Bewusstein enthält folglich noch die Empfindung durch die Selbstaffektion. Daher können mit dem „Empirischen“ im empirischen Bewusstsein nicht die empirischen Materialien der Empfindung durch die Selbstaffektion gemeint sein. Das empirische und das formale Bewusstsein lässt sich wie folgt voneinander unterscheiden: 1. Hinsichtlich der Empfindung in der Vorstellung $_{1}$ des inneren Sinnes - d.h. hinsichtlich des repräsentationalen Gehaltes der Vorstellung, die durch die Selbstanschauung des inneren Sinnes begleitet wird können wir das Bewusstsein des inneren Sinnes in das empirische Bewusstsein und das nicht-empirische, formale Bewusstsein des inneren Sinnes unterscheiden. Dieses Bewusstsein setzt die transzendentale Apperzeption voraus und ist ein apperzeptives Bewusstsein. 2. Hinsichtlich der Selbstaffektion, die für die Vorstellung 2 des inneren Sinns verantwortlich ist, ist sämtliches durch den inneren Sinn erzeugte Bewusstsein empirisch. ${ }^{137}$ Es gibt auch nicht-apperzeptives Bewusstsein, das eine empirische Vorstellung begleitet (siehe Liang 2017). Dieses gehört allerdings nicht zum „empirischen Bewusstsein“, das in der $K r V$ erwähnt wird.

\subsubsection{Empirisches Bewusstsein per se}

Das empirische Bewusstsein ist ein Bewusstsein, das eine Empfindung enthält (A166/B207). Empfindung ist die „Materie“ (A20/B34) der Wahrnehmung und liefert die Sinnesqualitäten wie „Farben, Geschmack etc.“ (A175/B217). Einer Stelle im

\footnotetext{
${ }^{137}$ Gerade in diesem Sinn bezeichnet Kant in der „Stufenleiter“ alle bewusste Vorstellungen, darunter auch Begriffe, als „perceptio“, die empirisch ist: „Die Gattung ist Vorstellung überhaupt (repraesentatio). Unter ihr steht die Vorstellung mit Bewußtsein (perceptio).“(A320/B376)
} 
Antizipationen-Kapitel zufolge kann das empirische Bewusstsein anscheinend als das phänomenale Bewusstsein im heutigen Sinn interpretiert werden:

in dem innern Sinn nämlich kann das empirische Bewußtsein von 0 bis zu jedem größern Grade erhöhet werden, so daß eben dieselbe extensive Größe der Anschauung (z.B. erleuchtete Fläche) so große Empfindung erregt, als ein Aggregat von vielem andern (minder Erleuchteten) zusammen (A176/B217-8)

Problematisch ist jedoch die Tatsache, dass Kant die Wahrnehmung mit dem empirischen Bewusstsein gleichzusetzen scheint: „Wahrnehmung ist das empirische Bewußtsein, d.i. ein solches, in welchem zugleich Empfindung ist“" (A166/B207). Wenn man die Wahrnehmung als epistemisch voraussetzungsvoll betrachtet, könnte man dazu tendieren, das empirische Bewusstsein ebenfalls als epistemisch voraussetzungsvoll zu interpretieren:

Das empirische Bewusstsein ist für Kant der letzte Schritt in der Entstehung von Erkenntnis (vgl.KrV A 115). Erst nachdem das Rohmaterial der Empfndung in den Ordnungsrahmen von Raum und Zeit eingepasst und durch die synthetisierende Tätigkeit der Einbildungskraft im Einklang mit den kategorialen Grundsätzen des Verstandes sowie dem Grundsatz der Apperzeption zu früheren Erfahrungen in Beziehung gesetzt wurde, erst dann ist empirisches Bewusstsein möglich (Fridland/Kitcher 2015, hervorgehoben durch mich)

Meines Erachtens ist diese Auslegung zu stark, denn das empirische Bewusstsein setzt bei Kant die synthetische Operation des Verstandes nicht unbedingt voraus. Wir müssen die Definition des empirischen Bewusstseins als Bewusstsein, das die Empfindung enthält, wörtlich nehmen. Dafür gibt es einige Gründe.

Kants Aussage macht zugegeben manchmal tatsächlich den Eindruck, als ob das empirische Bewusstsein die reine Apperzeption voraussetzt oder gar enthält:

Alles empirische Bewusstsein hat aber eine notwendige Beziehung auf ein transzendentales Bewusstsein, nämlich das Bewußtsein meiner Selbst (A117 Fn).

Dies gilt jedoch nicht unbedingt. Für die Vorstellungen, die als „meine Vorstellungen“ qualifiziert sind, d.i. für mich kognitiv relevant sind und sich 
möglicherweise als empirische Erkenntnisse qualifizieren könnten, enthält das begleitende empirische Bewußtsein einen Bezug auf das Ich. Anders gesagt, für mich als ein Wesen mit Verstand im Gegensatz zum nicht-apperzeptiven Geist, etwa dem des Tieres, gilt, dass jede Episode des empirischen Bewusstseins einen Bezug auf das Ich enthält. Eine weitere Stelle, die die obige Lesart von Fridland/Kitcher motiviert, ist wie folgt:

Zuvörderst merke ich an, daß ich unter der Synthesis der Apprehension die Zusammensetzung des Mannigfaltigen in einer empirischen Anschauung verstehe, dadurch Wahrnehmung, d.i. empirisches Bewußtsein derselben (als Erscheinung), möglich wird (B160)

Fridland und Kitcher übersehen jedoch, dass die Wahrnehmung dieser Stelle zufolge keineswegs direkt mit dem empirischen Bewusstsein gleichgesetzt wird, sondern mit „empirisch[em] Bewusstsien derselben (als Erscheinung)“. Das Wort „Erscheinung“ kommt in B160 nochmals vor, offensichtlich im Sinne eines Gegenstandes der äußeren Erfahrung bzw. der empirischen Erkenntnis (A240/B299, siehe auch A248-9). Folglich bedeutet der Ausdruck „empirisches Bewußtsein derselben (als Erscheinung)“ die Vorstellung des Mannigfältigen der empirischen Anschauung als einen (kategorial bestimmten) empirischen Gegenstand. Dieses Bewusstsein setzt schon synthetische Akte voraus, dies gilt aber nur deswegen, weil Kant hier eher über das empirische Bewusstsein der Anschauung „als Erscheinung“ als über das empirische Bewusstsein an sich spricht.

Zudem gibt es Textindizien dafür, dass die Wahrnehmung an sich nicht unbedingt einen synthetischen Akt voraussetzt. Gemäß einer Stelle in den Prolegomena soll „Wahrnehmung (perceptio)“ „blos den Sinnen angehör[en]“ (Prol. 4:300). Anderswo macht Kant klar: „[...] das empirische Bewußtsein, welches verschiedene Vorstellungen begleitet, ist an sich zerstreut und ohne Beziehung auf die Identität des Subjekts“ (B133, meine Hervorhebung). Das empirische Bewusstsein, das hier in Betracht steht, ist die einzelne Episode des Bewusstseins, die das einzelne Sinnesdatum 
begleitet. Die Rede von ,an sich“ und der dortige Kontext deuten darauf hin, dass dieses Bewusstsein noch nicht der Synthesis nach den Kategorien unterzogen wurde und somit noch nicht Teil der Einheit der Apperzeption ist. In dem empirischen Bewusstsein an sich gibt es keine begriffliche Operation des Verstandes. Nun meint Kant, dass das empirische Bewusstsein an sich „ohne Beziehung auf die Identität des Sujekt“ ist - d.i. keinen Bezug auf ein identisches Subjekt enthält und somit nicht die reine Apperzeption enthält. Folglich ist das empirische Bewusstsein ein bloßes Erlebnis der phänomenalen Qualitäten der von ihm begleiteten empirischen Vorstellung.

Man kann hier einwenden, dass das hier erwähnte Bewusstsein einer empirischen Vorstellung - im Sinne einer Episode des phänomenalen Bewusstseins ${ }^{138}$ - dennoch ein „Prädikat“ des Ichs darstellt und somit als eine Variante des Selbstbewusstseins betrachtet werden kann. ${ }^{139}$ Schließlich spricht Kant davon, dass man keinen epistemischen Zugang zum Ich als Substratum der Vorstellungen habe und lediglich über eine wechselnde Folge von Vorstellungen verfüge, die die Prädikate des Ichs darstellen (A359, A443/B471). Dieser Einwand ist jedoch falsch. Man muss zwischen der Perspektive eines idealistisch gesinnten Philosophen und der Perspektive des Subjekts unterscheiden. Das Subjekt des bloßen empirischen Bewusstseins kennt keine „Theorie des Geistes“: es erlebt nur die wechselnden phänomenalen Qualitäten, betrachtet diese aber nicht als empirische Vorstellungen des Ich.

Als Schlußwort lässt sich Folgendes konstatieren: das empirische Bewusstsein ist nicht derart mit dem phänomenalen Bewusstsein im heutigen Sinn gleichzusetzen, als ob das empirische Bewusstsein bei Kant allein das Erleben der phänomenalen Qualitäten bedeutete. Kant verbindet das Bewusstsein wesentlich mit der Fähigkeit der

\footnotetext{
138 Dagegen siehe Liang (2017).

${ }^{139}$ Dieses Bewusstsein ist eine Art des Selbstbewusstseins, besonders wenn die ihm zugrundliegende Empfindung eine Empfindung von Verstandesakten ist (siehe Kitcher 1999).
} 
Unterscheidung des Vorgestellten (V-Lo/Blomberg 24:40-41, B414 Anm.). ${ }^{140}$ Daher enthält das empirische Bewusstsein neben dem Erlebnis der phänomenalen Qualitäten auch die Möglichkeit, die Vorstellungen, die das empirische Bewusstsein begleitet, von anderen zu unterscheiden. Diese Unterscheidungsfähigkeit kann primitiv sein, wie es beim Tier der Fall ist, oder voraussetzungsvoll und zum Verstand und Apperzeption gehörig sein, wie es beim Menschen der Fall ist.

140 McLear (2015) zufolge ist das Bewusstsein gar mit „discriminatory acts“ gleichzusetzen. Meine Meinung nach sind beide Begriffe voneinander zu unterscheiden. Denn wie Kants Bemerkungen zum Bewußtsein (Anth 7:134, 141), zu den synthetischen Handlungen (A78/B103, BXL Anm.) sowie die Fußnote in B414f. zeigen, unterscheidet er generell kognitive Handlungen von dem Bewußtsein, das solche Handlungen begleitet. In A78/B103 deutet er an, dass es synthetische Handlungen gibt, die nicht vom Bewußtsein begleitet werden. Aus B414f. lässt sich entnehmen, dass der Unterscheidungsakt vielmehr eine Wirkung des Bewußtseins ist. 


\section{Kapitel 3. Selbstaffektion}

In diesem Kapitel möchte ich den Begriff der Selbstaffektion genauer untersuchen, da die Selbstaffektion dem inneren Sinne zugrundeliegt. Die Grundzüge der Doktrin der Selbstaffektion wurde in den vorigen Abschnitten teilweise erwähnt. Wir haben bereits einige Interpretationsfragen bezüglich des inneren Sinnes behandelt. Damit wurden die Fragen über das Produkt der Selbstaffektion weitestgehend geklärt. Unklar bleiben nur zwei Punkte: Welche mentalen Akte affizieren den inneren Sinn? Wie sieht der genaue Verlauf der Selbstaffektion aus? Beide Fragen hängen eng miteinander zusammen, da es verschiedene Aktivierungen der Selbstaffektion geben könnte. Betrachten wir zunächst die erste Frage. Kants Ausführungen über den affizierenden Akt der Selbstaffektion sind sehr vage, wenn nicht sogar inkonsistent. In der B-Deduktion (B153-4) sowie dem Schematismuskapitel (A145/B185) behauptet er, dass die transzendentale Synthesis der Einbildungskraft den inneren Sinn affiziert. Es wird jedoch nicht ausgeschlossen, dass andere mentale Akte ebenfalls den inneren Sinn affizieren. In B67 wird als der affizierende Akt ganz generell die „eigene Tätigkeit, nämlich dieses Setzen seiner Vorstellung“ genannt, ohne diese Setzung speziell als transzendentale Einbildungskraft zu bezeichnen. Im dortigen Kontext ist das „Setzen seiner Vorstellung" ein Akt, der die Vorstellung in einen zeitlichen Rahmen einordnet. Diese Setzung bzw. zeitliche Bestimmung kann sowohl von der transzendentalen Einbildungskraft als auch von der empirischen Einbildungskraft ausgeübt werden. In welcher Relation beide Akte zueinanderstehen, ob sie womöglich gar identisch sind, bleibt noch zu klären. Allison bezeichnet die Unklarheit von Kants Ausführungen über den affizierenden Akt als eines der Hauptprobleme von Kants Doktrin der Selbstaffektion. Laut ihm ist es im Ästhetik-Kapitel die Synthesis der Apprehension, die den inneren Sinn affiziert, während in der transzendentalen Deduktion die transzendentale Synthesis der Einbildungskraft dies leistet (1983:267). 
Neben den oben genannten kommen weitere mentale Akte in Frage. In B150 sagt Kant, dass der Verstand den inneren Sinn „bestimmt“. Das heißt, der Verstand denkt die „synthetische Einheit der Apperzeption des Mannigfaltigen der sinnlichen Anschauung a priori“". Das Mannigfaltige der sinnlichen Anschauung a priori ist genauer gesagt das Mannigfaltige der Zeit. Die reinen Verstandeshandlungen gemäß den Kategorien stehen folglich mit der Zeitlichkeit und damit auch mit der Selbstaffektion im engen Zusammenhang. In der Darstellung des inneren Sinnes in der Anthropologie bezeichnet Kant den inneren Sinn als „Bewußtsein [...] was er leidet, wiefern er durch sein eignes Gedankenspiel afficirt wird“(Anth 7:161). Im Losen Blatt Kiesewetter scheint Kant zu behaupten, dass der reine Gedanke den inneren Sinn affiziert. Durch den inneren Sinn nimmt man seine ,innere[n] Akzidenzen“ wahr, die nichts anders als „ein Denken, oder mit diesem analogisch [sind]“" (A265/B321). Anscheinend ist es nicht auszuschließen, dass andere spontane mentale Denkakte als die Synthesis der transzendentalen Einbildungskraft den inneren Sinn affizieren. Meines Erachtens muss man die genauen Schritte der Zeitbestimmung untersuchen, um die Struktur und den Prozess der Selbstaffektion präzise zu klären und somit auch die erste, zu Beginn dieses Abschnitts genannte Frage zu beantworten. 


\subsection{Die erste Selbstaffektion in der Aufnahme der Sinnesdaten in den inneren Sinn}

\subsubsection{Neue Interpretation}

In diesem Kapitel wird eine Interpretation der Selbstaffektion vorgestellt. Es wird argumentiert, dass zwei verschiedene Aktivierungen des inneren Sinnes-d.h. verschiedene Selbstaffektionen-in der Entstehung der Erfahrung stattfinden. In verschiedenen Aktivierungen wirken verschiedene spontane Handlungen des Verstandes auf die Rezeptivität des inneren Sinnes, woraus auch verschiedene Produkte hervorgebracht werden.

Bevor ich eine ausführliche Begründung für die obige Interpretation liefere, werde ich die einflußreichste Interpretation des inneren Sinnes von G. Mohr skizzieren. Seine Interpretation ist eine naheliegende und repräsentative Weise, Kants Lehre des inneren Sinnes auszulegen.

\subsubsection{Ein rezeptiv gegebenes Mannigfaltiges?}

Die meiste zitierte, quasi „Standardinterpretation“ des inneren Sinnes stellt Mohr in seinem Buch Das sinnliche Ich (1991) vor. Laut seiner Analyse ist das Affizierende die transzendentale Synthesis der Einbildungskraft, die auf ein vorher gegebenes Mannigfaltiges des äußeren Sinnes operiert. Analog zum äußeren Sinn liefert der innere Sinn durch die Selbstaffektion eine neue Materie, die weiteren synthetischen Operation des Verstandes zur Verfügung steht. Diese synthetische Operation verarbeitet diese 
neue Materie zur Selbsterkenntnis oder zum Begriff der Zeit. Mohrs Interpretation des inneren Sinnes lässt sich in drei Punkten zusammenfassen (Mohr 1991: 168-71) ${ }^{141}$ :

1) Die gegenstandskonstruierenden Verstandeshandlungen der Synthesis (der produktiven Einbildungskraft) bestimmen das Mannigfaltige des äußeren Sinnes gemäß den Kategorien und bringen dieses in eine Beziehung auf einen Gegenstand.

2) Der innere Sinn wird vom erläuterten Aufeinanderfolgen von Verstandeshandlungen affiziert. (Mohr 1991:171)

3) Der Verstand bezieht sich, indem er vom resultierenden sinnlichen Material der Affektion des inneren Sinnes abstrahiert, bloß auf den formalen Aspekt dieser Affektion: die Sukzessivität. Durch eine derartige Verstandesleistung wird dann der Begriff der Sukzession hervorgebracht. (Mohr 1991: 171)

Der Verstand verbindet gemäß den Kategorien das Mannigfaltige des äußeren Sinnes. Im Verlauf der Bestimmung der empirischen Rohmaterialien affiziert der Verstand den inneren Sinn sukzessiv und generiert auf diese Weise neue sinnliche Materialien. Diese Materialien könnte er erneut synthetisieren, um den Begriff der Sukzession herzustellen (Nakano 2011: 206).

Die Interpretationsannahmen (2) und (3) scheinen an sich unproblematisch zu sein. Die Annahme (1) hat jedoch einige Probleme. Nakano (2011) hat die Annahme eines unabhängig von der Selbstaffektion gegeben Mannigfaltigen des äußeren Sinnes, das rudimentär zeitlich ist, eingehend kritisiert. Mohr vertritt Nakano zufolge die Ansicht, dieses von der Selbstaffektion vorausgesetzte Mannigfaltige sei zeitlich, obwohl es noch nicht in eine einheitliche Zeitordnung gebracht wird. Die Aufnahme des sinnlichen Mannigfaltigen des äußeren Sinnes - d.h. das Gegebenwerden der Sinnesdaten - sei nämlich nicht auf die Spontanität des Verstandes angewiesen, während die einheitliche Zeitordnung nicht rezeptiv gegeben werden kann. Folglich werde dieses zeitliche Mannigfaltige isoliert gegeben und habe keinen Bezug zur Einheit der Zeit. Diese Einheit soll die Ausübung der transzendentalen Synthesis der

${ }^{141}$ Bei dieser Zusammenfassung bin ich wesentlich auf Nakano (2011) angewiesen. 
Einbildungskraft herstellen und der innere Sinn wird von dieser Synthesis zum ersten

Mal affiziert. Mohrs These scheint durch Kants Aussage belegt zu sein:

Das Bewußtsein seiner selbst (Apperception) ist die einfache Vorstellung des Ich, und wenn dadurch allein alles Mannigfaltige im Subject selbstthätig gegeben wäre, so würde die innere Anschauung intellectuell sein. Im Menschen erfordert dieses Bewußtsein innere Wahrnehmung von dem Mannigfaltigen, was im Subjecte vorher gegeben wird, und die Art, wie dieses ohne Spontaneität im Gemüthe gegeben wird, muß um dieses Unterschiedes willen Sinnlichkeit heißen (B68, meine Kursiverung)

Es lohnt sich, eine neue, sehr repräsentative Lesart von Nakano (2011) zu analysieren. Nakano zufolge ist die These, dass es rein rezeptiv gegebenes Mannigfaltiges gibt, das zur Operation der transzendentalen Einbildungskraft bereitliegt, grundlegend falsch. Nakano bemängelt Mohrs Unterscheidung der Zeitlichkeit des rein rezeptiv aufgenommenen Mannigfaltigen und der synthetisch organisierten einheitlichen Zeitordnung. ${ }^{142}$ Laut Nakanos Diagnose ist die Zeitlichkeit des vor der Anwendung der transzendentalen Synthesis rein rezeptiven Gegebenen, wie Mohr es darstellt, sehr

\footnotetext{
142 Wenn hier die Zeitlichkeit des Mannigfaltigen, die die Einordnung durch die transzendentale Synthesis der Einbildungskraft erfordert, thematisiert wird, wird damit das Bewusstsein der Zeitordnung der Vorstellungsakte derartigen Mannigfaltigen gemeint. Es wird nicht behauptet, dass das sinnliche Mannigfaltige in seinem repräsentationalen Gehalt Zeitlichkeit aufweist und dass diese Zeitlichkeit durch die transzendentale Synthesis der Einbildungskraft organisiert wird. Man kann sich natürlich einen bestimmten Zeitpunkt vorstellen, z.B den Eintritt eines bestimmten Ereignisses zu einer bestimmten Zeit. Dies ist aber nicht das Zeitbewusstsein, das uns interessiert, wenn man behauptet, dass alle Vorstellungen, die dem inneren Sinn gehören (A177/B220), die Zeit als ihre Form haben und gemäß den Kategorien in einer zeitlichen Einheit eingeordnet werden müssen. Was durch die transzendentale Zeitbestimmung in eine einheitliche Ordnung gebracht wird, ist das Zeitbewusstsein in der Vorstellung der Vorstellungsakte selbst. Der zweiten Analogie zufolge bringt der Verstand die subjektive Sukzession in eine objektive Folge. Die subjektive Sukzession ist die unorganisierte Zeitrelation des empirischen Mannigfaltigen, die die transzendentale Bestimmung der Einbildungskraft erfordert. Sie ist gerade das Zeitbewusstsein der Vorstellung der Vorstellungsakte. Die allumfassende Zeitlichkeit der Vorstellung bezieht sich auf das Bewusstsein der Zeitordnung der Vorstellungsakte: „Ich kann zwar sagen: meine Vorstellungen folgen einander; aber das heißt nur, wir sind uns ihrer, als in einer Zeitfolge, d.i. nach der Form des inneren Sinnes, bewußt.“(A37/B54 Anm.)
} 
problematisch. Diese Zeitlichkeit zeichne sich gegenüber der synthetisch organisierten einheitlichen Zeitordnung durch zwei Charakteristika aus: Erstens fehle es der Zeitlichkeit an ,einheitlicher Ordnung“ und zweitens solle ,jeder Augenblick [...] ein isoliertes Jetzt ohne Beziehung zu anderen Augenblicken“sein (Nakano 2011:217).

Die erste Annahme einer unsynthetisierten Uneinheitlichkeit der Zeit widerspreche Kants Erörterung der Zeit: „Verschiedene Zeiten sind nur Theile eben derselben Zeit.“(A31-2/B47) „,[A]lle bestimmte Größe der Zeit nur durch Einschränkung einer einigen zum Grunde liegenden Zeit möglich sei. Daher muß die ursprüngliche Vorstellung Zeit als uneingeschränkt gegeben sein.“(A32/B47-8). Nakano zufolge kann die Form des im inneren Sinn Gegebenen der Einheit nicht entbehren. Die zweite Annahme, dass es eine rudimentäre Zeitlichkeit gibt, die ,[d]as Nacheinander augenblicklicher und sich wechselseitig ausschließender Präsenzen“ ist, ohne dass „die einzelnen Fälle als Teile der einen Zeit ausfüllend und insofern als bestimmte Sukzession begriffen würden“, sei ebenfalls problematisch (Nakano 2011:192). Denn isolierte Zeitpunkte würden kein „Nacheinander“ ergeben. Damit würde die Sukzessivität ausfallen, die gerade die wesentliche Eigenschaft der Zeit sei.

Lassen uns nun sehen, inwiefern diese rudimentäre Zeitlichkeit nach Nakano unbegründet ist. Sie sei unbegründet, weil die Zeitlichkeit wesentlich mit der Spontanität des Verstandes verbunden sei. Die Zeit sei nach Kant „die Art [...], wie das Gemüt durch eigene Tätigkeit [...] affiziert wird“ (B67-8). „Ohne Synthesis der Apprehension würden wir die Vorstellung der Zeit a priori nicht haben“"(A99). Ein Mannigfaltiges kann nicht ohne Beteiligung der Tätigkeit des Subjekts als zeitliches gegeben sein. Nach Nakano ist somit jegliche Zeitlichkeit bei ihrer Erzeugung schon durch die Synthesis organisiert und steht in einer einheitlichen Ordnung.

Nakano sieht keinen anderen Ausweg, als Mohrs grundlegende Annahme zu verwerfen, dass das Mannigfaltige unabhängig von der Selbstaffektion rein rezeptiv gegeben ist. 
Denn wenn die rudimentäre Zeitlichkeit wie gezeigt problematisch ist, muss man annehmen, dass das rein rezeptiv gegebene Mannigfaltige nicht zeitlich ist. Aber diese Annahme sei problematisch, weil ein derartiges Mannigfaltige weder durch direkte Beobachtung noch durch logischen Schluss zu bestätigen sei und damit zur „transzendentalen Psychologie“ gehöre (Nakano 2011:218). Es wird eine Annahme bleiben und seine Bedeutung für die Erfahrung ist nicht zu beweisen. Zudem kann ein nicht-zeitliches Mannigfaltige nicht im inneren Sinn, dessen Form die Zeit ist, gegeben werden. Es bleibt nur die Annahme, dass es weder zum inneren Sinn noch zeitlich geordnet, sondern bloß gemäß der Form des Raumes gegeben. Diese letztere Alternative ist auch nicht haltbar, denn die Zeit ist die formale Bedingung a priori aller Erscheinungen (A34/B50) und der innere Sinn ist der „Inbegriff aller Vorstellungen“ (A177/B220). Nakano kommt zum Schluss, dass das Mannigfaltige, das der transzendentalen Synthesis vorliegt, nicht nur zeitlich sein müsse, sondern auch bei der Aufnahme schon gemäß den Kategorien in einer einheitlichen Zeitordnung synthetisiert werden müsse. Es gebe kein Mannigfaltiges des inneren Sinnes, das rein rezeptiv gegeben sei.

Nakanos Diagnose von Mohrs Annahme lässt sich wie folgt kurz zusammenfassen. Ein rein rezeptiv gegebenes Mannigfaltiges im inneren Sinn gibt es nicht. Da es rein rezeptiv gegeben ist, kann es nur eine Zeitlichkeit aufweisen, die durch fehlende Einheit und isolierte Zeitpunkte gekennzeichnet und folglich problematisch ist. Dieses Mannigfaltige kann nicht unzeitlich sein, da es im inneren Sinn vorliegen muss. Es bleibt somit nur eine Möglichkeit: bereits bei seiner Aufnahme in den inneren Sinn d.h. beim Gegebenwerden - wird das Mannigfaltige gemäß den Kategorien synthetisiert und vereinheitlicht.

Meines Erachtens ist Nakanos Diagnose zwar scharfsinnig und aufschlußreich, aber in vielerlei Hinsichten falsch. Sie ist aufschlußreich, weil er auf einen leicht vernachlässigten Sachverhalt hinweist, dass ein Mannigfaltiges, wenn es im inneren 
Sinn gegeben ist, zeitlich und damit nicht allein ein Produkt der Sinnlichkeit sein kann. Denn die Zeitlichkeit ist immer mit dem inneren Sinn, der Selbstaffektion und damit der Selbsttätigkeit verbunden. Der springende Punkt von Mohrs Annahme ist die Zeitlichkeit vor aller Spontanität, die zum Gehalt des empirischen Mannigfaltigen gehört. Nach Kant gehört die Zeitlichkeit jedoch nicht zum Gehalt des Manngfaltigen des empirischen Mannigfaltigen (A30/B46), sondern ist die sinnliche Form der empirischen Anschauung der spontanen Handlungen, die dieses Mannigfaltige bearbeiten. Nakanos Diagnose und Lösung ist jedoch falsch, weil er eine passendere interpretative Alternative verkannt hat: der transzendentalen Synthesis der Einbildungskraft liegt doch ein rein rezeptiv gegebenes Mannigfaltiges vor, und es gehört weder zum inneren Sinne, noch ist es zeitlich. Nakano stützt seine Kritik auf zwei Säulen, die beide aber unbegründet sind. Erstens setzt er stillschweigend voraus, dass ,gegeben“ identisch zu ,,in den inneren Sinn aufgenommen“ ist (Nakano 2011:213) und folglich zeitlich sein muss. Zweitens behauptet Nakano, dass die Apprehension gerade der Prozess der Aufnahme des Mannigfaltigen in den inneren Sinn ist (Nakano 2011:221-2). Die erste These ist schlicht falsch und die zweite zwar richtig, hat aber nichts mit dem „Gegebensein“ des Mannigfaltigen zu tun.

Laut Nakano sei „gegeben“ deswegen identisch zu „in den inneren Sinn aufgenommen“, da es keine Vorstellungen gäbe, die nicht zum inneren Sinn gehören, und das gegebene Mannigfaltige sei dennoch Vorstellungen, wenn auch unsynthetisierte. Wenn diese Gleichsetzung wahr wäre, könnte man ohne weiteres schließen, dass das gegebene Mannigfaltige zeitlich ist, denn die Form des inneren Sinnes ist zeitlich. Bei genauer Analyse ist diese Gleichsetzung jedoch falsch. Eine empirische Vorstellung in den inneren Sinn aufzunehmen bedeutet der Definition des inneren Sinnes zufolge, dass man sich dieser empirischen Vorstellung auch apperzeptiv bewusst wird. Der bloße Begriff des Gegebenseins des Mannigfaltigen impliziert nicht, dass man sich seines auch apperzeptiv bewusst sein müsse bzw. es in den inneren Sinn aufnehmen müsse. 
Rein terminologisch betrachtet, gilt Folgendes: Eine Vorstellung ist genau dann gegeben, wenn diese Vorstellung nicht von dem Subjekt erzeugt wird. Kant stellt nämlich generell das Gegebensein dem Gedachtsein gegenüber; im Gegensatz zum Ersteren generiert das Gemüt bei dem Letzteren spontan Vorstellungen. Das „Gegebene“ bezieht sich somit auf das „Material“ oder „das Datum zu denken“ (BDG 2:78), das durch keine spontane Tätigkeit des Subjekts bewirkt wird. Das Gegebensein ist mit der Sinnlichkeit, dem inneren Sinn und somit dem apperzeptiven Bewusstsein nicht notwendigerweise begrifflich verbunden. Als reine Rezeptivität ohne Einwirkung der Spontanität ist das gegebene Mannigfaltige nicht in dem inneren Sinn, weil der innere Sinn Selbsttätigkeit voraussetzt. Alle Vorstellungen im inneren Sinn sind dadurch generiert, dass dieser durch Selbsttätigkeit affiziert wird. Aus all dem kann man schließen, dass das Gegebensein eine reine rezeptive Entstehungsweise der Vorstellungen bedeutet, was nicht unbedingt ein apperzeptives Bewusstsein durch den inneren Sinn impliziert.

Um die These zu begründen, dass das Gegebensein der empirischen Vorstellungen synthetische Leistungen und damit auch Selbstaffektion voraussetzt, macht Nakano auf die Konstruktion der formalen Zeitanschauung als Bedingung der Wahrnehmungen und mithin der Erfahrung als verknüpfter Wahrnehmungen aufmerksam (B161f.). Ihm zufolge setzt diese Konstruktion die transzendentale Synthesis der Einbildungskraft voraus. Nakano verweist auf $\$ 26$ der transzendentalen Deduktion (besonders den wichtigen Absatz B160-161): die Synthesis der Apprehension verbindet das empirische Mannigfaltige zu einer Anschauung. In diesem Prozess muss die Apprehension gemäß der Form der Anschauung (Raum und Zeit) vorgehen. Da Raum und Zeit selbst einheitliche Anschauungen sind, müssen sie zuerst aus dem zerstreut gegebenen reinen Mannigfaltigen (Zeitpunkten und Raumpunkten) konstruiert werden, damit sie die Bedingung der Einheit der empirischen Anschauung sein können. Nach Nakano versteht Mohr diese Konstruktion wie folgt: das empirische Mannigfaltige wird zuerst 
rein rezeptiv im inneren Sinn gegeben. Es hat rudimentäre Zeitlichkeit. Das heißt, die reinen zeitlichen Entsprechungen dieses Mannigfaltigen wird auf eine rudimentäre Weise mit diesem Mannigfaltigen im inneren Sinn gegeben. Die transzendentale Synthesis der Einbildungskraft organisiert dieses reine Mannigfaltige und bringt es in eine einheitliche Zeitordnung. Daraus entsteht die formale Anschauung der Zeit als einen Gegenstand. Nakano zufolge ist Mohrs Interpretation völlig verfehlt, weil das reine und das empirische Mannigfaltige schon im Zug des Gegebenwerdens durch die Synthesis der Einbildungskraft zu einer einheitlichen Anschauung verarbeitet wird. Beim Gegebenwerden der empirischen Anschauungen ist die Synthesis beteiligt: während das Gegebenwerden der empirischen Anschauung die Synthesis der Apprehension voraussetzt, setzt das der reinen Anschauung die transzendentale Synthesis der Einbildungskraft voraus. Nakano zitiert zwei Stellen als Beleg:

In der Folge (§ 26) wird aus der Art, wie in der Sinnlichkeit die empirische Anschauung gegeben wird, gezeigt werden, daß die Einheit derselben keine andere sei, als welche die Kategorie nach dem vorigen $\S 20$ dem Mannigfaltigen einer gegebenen Anschauung überhaupt vorschreibt [...] (B144-5).

Denn da durch sie (indem der Verstand die Sinnlichkeit bestimmt) der Raum oder die Zeit als Anschauungen zuerst gegeben werden, so gehört die Einheit dieser Anschauung a priori zum Raume und der Zeit und nicht zum Begriffe des Verstandes (§ 24). (B161 Anm., §26)

Nakano übersieht schlicht, dass es in diesen Passagen (sowie anderen) nicht um das Gegebensein des zur Verarbeitung stehenden Mannigfaltigen, sondern eher um die Bedingung der aus dem Mannigfaltigen zusammengesetzten (empirischen oder reinen) Anschauung geht. Für das Bewusstsein einer Anschauung sind synthetische Leistungen erforderlich, weil das Mannigfaltige der Anschauung in einer Einheit stehen und einen Gegenstandsbezug haben muss. Das steht außer Frage und ist eine der wichtigsten Thesen der transzendentalen Deduktion. Im Gegensatz dazu bleibt die Frage, ob das bloße Gegebenwerden des Mannigfaltigen die synthetische Leistung voraussetzt oder ob es ein rein rezeptiv gegebenes Mannigfaltiges vor der Erzeugung der Anschauung 
gibt, angesichts der beiden zitierten Stellen völlig offen. Nakano unterscheidet das Gegebensein des Mannigfaltigen (d.h. das Aufnehmen des Mannigfaltigen in das Gemüt) und das Gegebensein der empirischen Anschauung (d.h. das Aufnehmen des Mannigfaltigen in den inneren Sinn) fälschlicherweise nicht (Nakano 2011:222), während diese Unterscheidung bei Kants Ausführung ersichtlich ist. ${ }^{143}$ Außerdem muss man eine andere Unterscheidung beachten: Das Gegebensein der empirischen Mannigfaltigen im inneren Sinn impliziert, dass das Subjekt sich dieses Mannigfaltigen auch bewusst ist, denn der innere Sinn ist die empirische Anschauung des inneren (repräsentationalen) Zustands. Im Gegensatz dazu setzt das Gegebensein des empirischen Mannifaltigen im Gemüt ein solches empirisches Bewusstsein des eigenen Zustands gar nicht voraus.

Nun stellt sich die Frage, ob ein rein rezeptiv gegebenes Mannigfaltiges theoretisch notwendig ist. Ein einfaches Argument unterstützt die Auffassung, dass es so ist. Wie es aus A99f. sowie B160 ersichtlich ist, ist es die Synthesis der Apprehension, die das Mannigfaltige „durchläuft“, in einer Anschauung zusammennimmt und das empirische Bewusstsein von ihr erwirkt. Kant spricht von dem Mannigfaltigen, auf dem die Synthesis der Apprehension operiert-schließlich verlangt eine Synthesis per definitionem Sinnesdaten, die sie verarbeitet. Nun kann dieses Mannigfaltige, das die Synthesis der Apprehension bearbeitet, nicht ein Produkt des inneren Sinnes sein, weil der innere Sinn erst durch die Synthesis der Apprehension affiziert wird. Wenn man es dennoch als ein Produkt des inneren Sinnes betrachten will, muss man eine weitere Selbstaffektion durch einen synthetischen Akt postulieren, aus der dieses Mannigfaltiges produziert wird. Diesen synthetischen Akt findet man nirgendwo in der theoretischen Konstellation der $\mathrm{KrV}$. Folglich muss dieses Mannigfaltige allein durch den äußeren Sinn, d.h rein rezeptiv, entstehen. In der Tat impliziert selbst der Begriff

\footnotetext{
143 Siehe B161 Anm.
} 
der Selbstaffektion in der Apprehension, die mit dem inneren Sinn wesentlich verbunden ist, ein rein rezeptiv Gegebenes. ${ }^{144}$ Denn die Selbstaffektion in der Apprehension wird durch die Synthesis der Apprehension erwirkt. Um kein rein rezeptiv Gegebenes zu postulieren, kann man mit Nakano behaupten, dass erst durch Selbstaffektion das Mannigfaltige gegeben wird. Das Gegebensein des Mannigfaltigen ist sozusagen die Wirkung der Selbstaffektion. Wenn es wirklich so wäre, wäre nicht mehr zu erklären, worauf die Synthesis der Apprehension, die die Selbstaffektion veranlässt, ${ }^{145}$ überhaupt ausgeübt wird. Dies kann nicht das Mannigfaltige sein, weil es erst nach der Selbstaffektion zu erwarten ist. Nakano hat verkannt, dass die Synthesis und die Selbstaffektion zwei Seiten derselben Medaille sind - d.h. es handelt sich bei ihnen um denselben Prozess; eine Seite davon, die Synthesis, verlangt die Verarbeitung eines rein rezeptiven Mannigfaltigen.

Nakanos Auslegung ist somit sowohl sachlich als auch texuell unfundiert. Im Gegenteil erwähnt Kant die Existenz solches Mannigfaltigen explizit: „,das Mannigfaltige [müsse] für die Anschauung noch vor der Synthesis des Verstandes, und unabhängig von ihr, gegeben sein“"(B145). Man könnte zugunsten Nakano sagen, dass die Unterscheidung der Leistung des Verstandes und der Sinnlichkeit in diesem Zitat aus B145 bloß aus einer epistemologischen Betrachtung resultiere und keine metaphysische Implikation hat. In der Tat seien der Verstand und die Sinnlickeit zwei Aspekte desselben Erkenntnisvermögens. Sie seien voneinander nicht zu trennen und müssten in einem Zug ausgeübt werden, daher gäbe es kein rein rezeptiv Gegebenes als Zwischenprodukt zwischen den beiden. Bei genauer Analyse impliziert Kants eigene Doktrin der Synthesis der Apprehension allerdings die Existenz des rein rezeptiv gegebenen Mannigfaltigen. Wenn man genauer die Struktur der Apprehension betrachtet, ist

\footnotetext{
${ }^{144}$ Hier betrachten wir allein die Selbstaffektion in der Apprehension, da die Selbstaffektion durch andere Denkakte mit dem Mannigfaltigen nichts direkt zu tun hat.

${ }^{145}$ Siehe B68.
} 
ersichtlich, dass die Annahme eines rein rezeptiv Gegebenen unvermeidbar ist. Fangen wir zuerst mit einer Passage an:

(1) Jede Anschauung enthält ein Mannigfaltiges in sich, welches doch nicht als ein solches vorgestellt werden würde, wenn das Gemüth nicht die Zeit in der Folge der Eindrücke auf einander unterschiede: denn als in einem Augenblick enthalten kann jede Vorstellung niemals etwas anderes als absolute Einheit sein. (2) Damit nun aus diesem Mannigfaltigen Einheit der Anschauung werde (wie etwa in der Vorstellung des Raumes), so ist erstlich das Durchlaufen der Mannigfaltigkeit und dann die Zusammennehmung desselben nothwendig, welche Handlung ich die Synthesis der Apprehension nenne, (3) weil sie gerade zu auf die Anschauung gerichtet ist, die zwar ein Mannigfaltiges darbietet, dieses aber als ein solches und zwar in einer Vorstellung enthalten niemals ohne eine dabei vorkommende Synthesis bewirken kann (A99, Nummierung durch mich)

In unserem Zusammenhang interessant ist der erste Satz. Demzufolge unterscheidet Kant zwei epistemische Modi des gebenen Mannigfaltigen der Anschaung: Das Mannigfaltige als „,in einem Augenblick enthalten“ und das Mannigfaltige ,als ein solches vorgestellt““. Im ersten Modus ist das Mannigfaltige „niemals etwas anders als absolute Einheit". Kant hat nicht explizit gemacht, was mit all diesen Formulierungen genau gemeint ist. Der zweite Modus gibt jedoch entscheidenden Aufschluss darüber. Wörtlich betrachtet, bedeutet ein Mannigfaltiges ,als ein solches vorgestellt“ in dem Kontext, dass man sich dessen Vielfalt (apperzeptiv) bewußt wird. Das apperzeptive Bewusstsein dieser Vielfalt bedeutet wiederum, sich der einzelnen Details dieses Mannigfaltigen apperzeptiv bewusst zu werden. Denn ein Bewusstsein von einem Mannigfaltigen ohne seine Details überhaupt voneinander unterscheiden zu können, ist nichts als ein Bewusstsein von undifferenzierter Vielfalt. ${ }^{146}$ Das Gegenteil davon, ein Mannigfaltiges als ein Mannigfaltiges vorzustellen—ist gerade der oben genannte erste

\footnotetext{
146 Auch Longuenesse (1998:38) betont die Bedeutung der Unterscheidung einzelner Bestandteile des Mannigfaltigen. Nach Mohr besagt die These der Vorstellung des Mannigfaltigen als „absolute Einheit“ auch, dass die Verhältnisse der Eindrücke nicht bestimmt werden. Das ist jedoch eine bloße Implikation der These. In der ersten Linie geht es darum, dass die Eindrücke in dem zweiten Modus der Vorstellung des Mannigfaltigen gar nicht von einander unterschieden werden können.
} 
Modus: er besteht darin, das Mannigfaltige als ,absolute Einheit“ vorzustellen, d.h. als ein ununterscheidbares Gewirr, das keine Information über die Vielfalt der Details liefert. ${ }^{147}$ Es ist ähnlich wie eine flüchtige „Momentaufnahme“ eines empirischen Gegenstands. In dieser Momentaufnahme kann die Aufmerksamkeit nur wenige Merkmale des Gegenstands erfassen; die übrigen Details des sinnlichen Inputs werden bloß durch die Sinnesorgane aufgenommen, aber noch nicht als solche erfasst (s.u.).

Die Annahme solcher „Momentaufnahmen“ bzw. flüchtiger Anblicke empirischer Gegenstände ist auch textuell nicht unfundiert: Kant postuliert eine Zwischenstufe der Bearbeitung der empirischen Materialien, und zwar die „Synopsis“:

Es sind aber drei ursprüngliche Quellen, (Fähigkeiten oder Vermögen der Seele), die die Bedingungen der Möglichkeit aller Erfahrung enthalten und selbst aus keinem andern Vermögen des Gemüths abgeleitet werden können, nämlich Sinn, Einbildungskraft und Apperception. Darauf gründet sich 1) die Synopsis des Mannigfaltigen a priori durch den Sinn; 2) die Synthesis dieses Mannigfaltigen durch die Einbildungskraft; endlich 3) die Einheit dieser Synthesis durch ursprüngliche Apperception. Alle diese Vermögen haben außer dem empirischen Gebrauch noch einen transscendentalen, der lediglich auf die Form geht und a priori möglich ist. Von diesem haben wir in Ansehung der Sinne oben im ersten Theile geredet, die zwei andre aber wollen wir jetzt ihrer Natur nach einzusehen trachten. (A94)

Die Synopsis operiert nicht nur auf dem Mannigfaltigen a priori, sondern auch auf empirischen Daten. Gemäß 1) ist die Synopsis des Mannigfaltigen das Produkt der Sinnlichkeit; da die drei Vermögen in der Passage isoliert betrachtet werden, muss die

\footnotetext{
${ }^{147}$ Dies kann durch Kants Verwendung des Begriffs „,absolute Einheit“ bestätigt werden: „Substantz ist entweder absolute Einheit oder an sich selbst Vielheit: compositum substantiale.“ (Refl 17:739). „Dieses kommt daher, weil in der Große überhaupt als Einheit doch noch immer die Moglichkeit liegt, sie als Menge anderer Einheiten anzusehen, und Große keine absolute Einheit enthält.“ (Refl 14:59). Absolute Einheit ist ein Ding nur dann, wenn es keine Teile enthält.
} 
Synopsis rein rezeptiv bzw. isoliert von jeglicher Beteiligunge der Spontanität des Verstandes sein. Dies lässt sich aus dem folgenden Zitat entnehmen: ${ }^{148}$

Wenn eine jede einzelne Vorstellung der andern ganz fremd, gleichsam isolirt und von dieser getrennt wäre, so würde niemals so etwas, als Erkenntniß ist, entspringen, welche ein Ganzes verglichener und verknüpfter Vorstellungen ist. Wenn ich also dem Sinne deswegen, weil er in seiner Anschauung Mannigfaltigkeit enthält, eine Synopsis beilege, so correspondirt dieser jederzeit eine Synthesis, und die Receptivität kann nur mit Spontaneität verbunden Erkenntnisse möglich machen (A97).

Dass Kant nirgendwo den Begriff der „Synopsis“ genauer erläutert, ist wahrscheinlich dadurch zu erklären, dass der metaphorische Ausdruck „Synopsis“ (das „Zusammensehen“) genügend Hinweise für das richtige Verständnis dieses Begriffs bietet. ${ }^{149} \mathrm{Im}$ Vergleich mit der „Synthesis“ (das „Zusammennehmen“), einer spontanen Handlung, ist die Synopsis die rein rezeptive Aufnahme der Sinnesdaten, in der diese Sinnesmaterialien zwar zusammen in der Sinnlichkeit registriert werden - d.h. „Zusammengesehen“ oder möglicherweise durch phänomenales Bewusstsein begleitet werden - , aber noch in keinem Zusammenhang gebracht werden- d.h. „Zusammengenommen“ oder durch apperzeptives Bewusstsein erfasst werden. In der Synopsis wird die Aufmerksamkeit höchstens auf eine kleine Teilmenge der jeweils vorhandenen Sinnesmaterialien gerichtet. Die übrigen davon werden nicht durch die Synthesis der Einbildungskraft in der Aufmerksamkeit organisiert (siehe § 3.1.4.) ${ }^{150}$ und bleiben in der Sinnlichkeit unverarbeitet. Nebenbei bemerkt, ist es auch in der

\footnotetext{
148 Für eine gegenteilige Interpretation siehe z.B. Hoppe (1998:166) oder Carl (1992:145f.). Hier schließe ich mich der Position von Haag an (Haag 2007:156). Die Synopsis ist übrigens begrifflich von der Synthesis deutlich zu unterscheiden (A97). Zwar korrespondiert ihr nach Kant ,jederzeit eine Synthesis, und die Receptivität kann nur mit Spontaneität verbunden Erkenntnisse möglich machen“. Das bedeutet jedoch nicht, dass die Synopsis de facto immer mit der Synthesis verbunden ist. Denn es gibt wie gesagt mentale Zustände, die nicht als Erkenntnisse im Kantischen Sinne gelten.

149 Siehe auch Haag (2007:155f.).

150 Die Synthesis der Einbildungskraft wird allein in der Aufmerksamkeit vollgezogen. Siehe Dyck (2006).
} 
heutigen Philosophie des Bewusstseins sehr kontrovers, ob man sich der Stimuli phänomenal bewusst ist, die außerhalb des Umfanges der Aufmerksamkeit stehen. ${ }^{151}$ Dies ist auch kein Thema, womit sich Kant und seine Zeitgenossen beschäftigt haben. Meines Erachtens hat man von dem Mannigfaltigen in der Synopsis kein empirisches Bewusstsein im Sinnes eines propositional strukturierten Bewusstseins durch den inneren Sinn, denn dieses setzt die Apprehension und die Wirkung der Synthesis der Einbildungskraft voraus, die in dem nicht-aufmerksamen Teil der Synopsis nicht stattfindet. ${ }^{152}$ Man hat davon möglicherweise schwaches unstrukturiertes phänomenales Bewusstsein (erinneren wir an den Begriff ,Zusammensehen'). ${ }^{153}$ Die Frage, ob Kant dieser Auffassung zustimmen würde, bleibt offen. Gemäß Kants Ausführung der dunklen Vorstellungen kann man auf dem nicht-aufmerksamen Teil des Mannigfaltigen in der Synopsis jedoch auf jeden Fall einen subliminalen kognitiven Zugriff im Sinne eines nicht-apperzeptiven Zugriffsbewusstseins haben. ${ }^{154}$ Es ist anzumerken, dass die Sinnesdaten, die in die Synopsis getreten sind, aber noch nicht durch die Aufmerksamkeit in dem inneren Sinn aufgenommen werden, schon in „meinem Gemüt“ sind, da sie von schwachem phänomenalen Bewusstsein begleitet werden können und für kognitive Zugriffe verfügbar sind.

Wohlgemerkt wird mit dem Metaphor „Momentaufnahme“ kein „visual field“ gemeint, das die darin vereinigten empirischen Qualitäten in der Weise enthält, wie Wolff es auslegt: „a green patch, a red circle, a blue patch and a black pot". Die „Momentaufnahme“ kann auch in einer mentalen Repräsentation eines dreidimensionalen Geschehen bestehen. Die Details des dabei Repräsentierten bleiben

\footnotetext{
151 Mole (2011).

152 Für gegenteilige Meinung siehe z.B. Haag (2007:155 Anm. 128).

${ }^{153}$ Das Bewusstsein ist nämlich gemäß Kant eine Art „Realität“. Jede Realität ist eine Größe, die von Null bis beliebgem Grad ändern kann (B414f.).

154 Über kognitive Zugriffe auf die Sinnesdaten in der Synopsis aber nicht in der Aufmerksamkeit, siehe Liang (2017).
} 
vage, sodass wir uns der inneren Vielfalt und der inneren Verhältnisse zwischen verschiedenen Elementen nicht apperzeptiv bewusst sind-das heißt, es ist eine „absolute Einheit““. Übrigens kann man das Durchlaufen des Mannigfaltigen nicht so interpretieren, als ob die Synthesis der Apprehension die Elemente einer gespeicherten mentalen „Momentaufnahme“ sukzessiv aufnimmt. Wir können uns vorstellen, dass unter realen Bedingungen die Sinnlichkeit für längere oder kürzere Zeit die gleiche komplexe Vorstellung (vielleich auch mit leichten Modifikationen) liefert, so dass die Synthesis der Apprehension sie mehrfach durchlaufen kann. ${ }^{155}$ Wie man diesen Prozess unter realen Bedingungen spezifiziert, ist ein Thema der Psychologie und wird wohl auch deswegen in der B-Auflage der $K r V$ von Kant ausgespart. Es bleibt aber außer Frage, dass das erste Produkt der Synthesis der Apprehension ein momentanes Bild des Gegenstands ist, das auf einer von der Sinnlichkeit gelieferten Momentaufnahme des Gegenstands basiert. Das von der Synthesis der Apprehension erzeugte Bild des Gegenstands ist genau die Vorstellung des Mannigfaltigen „als solches“. Ein nähere Diskussion der Kontroverse um die richtige Auffassung der Apprehension und ihren genauen Vorgang findet sich im Kapitel „Anhang: Ein Kommentar über A99“ (§ 3.1.4.)

Um nun von dem ersten Modus zu dem zweiten überzugehen, ist es nötig, dass „das Gemüth [...] die Zeit in der Folge der Eindrücke auf einander untersch[ei]de“. Das menschliche Gemüt ist nämlich kein göttlicher Verstand, der auf einen Streich alle Details des Mannigfaltigen erfassen kann. Es kann Sinnesdaten nur sukzessiv in der Zeit aufnehmen. Diese Aufgabe der sukzessiven Aufnahme erfüllt dem Satz (3) im obigen Zitat aus A99 zufolge offensichtlich die Synthesis der Apprehension. Wenn erst durch einen synthetischen Akt das Mannigfaltige im Lauf der Zeit sukzessiv entfaltet und ,als ein solches vorgestellt" werden kann, lässt sich schließen, dass das

\footnotetext{
155 Siehe Grüne (2009: 163 Anm. 32)
} 
Mannigfaltige ohne diesen Akt nicht in einen zeitlichen Rahmen eingeordet ist. Anders gesagt, wenn dieses Mannigfaltige nicht durch die Synthesis der Apprehension in den inneren Sinn aufgenommen wird und folglich kein Gegenstand des inneren Sinnes ist, dessen Form die Zeit ist, lässt sich folgern, dass man es auch nicht zeitlich einordnen kann. Dies führt dazu, dass die Elemente des Mannigfaltigen nicht voneinander unterschieden werden können. Ohne die Synthesis der Apprehension würde das Mannigfaltige des äußeren Sinnes ,eine absolute Einheit“" sein und folglich könnte man seine Elemente nicht voneinander unterscheiden. Nach Kant ist eine Vorstellung unbewusst, wenn man sie nicht von anderen unterscheiden kann. Folglich ist das Mannigfaltige „,als in einem Augenblick enthalten“ eine unbewusste Vorstellung und damit auch nicht von dem inneren Sinn begleitet. ${ }^{156}$

Kants Stellungnahme über die Synthesis der Apprehension in der B-Deduktion zeigt ebenfalls, dass die Apprehension mit dem inneren Sinn wesentlich verbunden ist:

Zuvörderst merke ich an, daß ich unter der Synthesis der Apprehension die Zusammensetzung des Mannigfaltigen in einer empirischen Anschauung verstehe, dadurch Wahrnehmung, d.i. empirisches Bewußtsein derselben (als Erscheinung), möglich wird. (B160)

[Erscheinungen könnten] nicht anders apprehendirt, d.i. ins empirische Bewußtsein aufgenommen werden, als durch die Synthesis des Mannigfaltigen [...] (B202)

Die Synthesis der Apprehension bewirkt offensichtlich das empirische Bewußtsein der empirischen Anschauung. Wie bereits ausgeführt, ist für das menschliche Gemüt das empirische Bewusstsein eine Vorstellung des inneren Sinns, denn jede Episode des Bewußtseins enthält die reine Apperzeption bzw. einen Selbstbezug, so dass das empirische Bewußtsein ein implizites (oder eventuell explizites) Bewusstsein davon ist,

\footnotetext{
156 Der Begriff „unbewusst“ in dieser Passage bedeutet hier, strenggenommen, „nicht durch das apperzeptive Bewusstsein begleitet zu sein“. Zudem bedeutet der Begriff „unterscheiden“ „den Unterschied nicht erkennen“. Für die theoretischen Komplikationen, die darin involviert sind, siehe Liang (2017).
} 
dass man eine empirische Vorstellung hat - dieses implizite Bewusstsein ist genau die Vorstellung des inneren Sinnes. Es lässt sich folgern, dass diejenigen Elemente des Mannigfaltigen, die von der Synopsis, nicht aber der Synthesis der Apprehension erfasst werden, apperzeptiv unbewusst bzw. nicht Gegenstände des inneren Sinnes sein können. ${ }^{157}$ Da sie keine Gegenstände des inneren Sinnes sind, sind sie noch nicht in einer (subjektiven oder objektiven) zeitlichen Ordnung geordnet. Folglich kann man schließen, dass es durchaus ein rein rezeptiv gegebenes Mannigfaltiges gibt, das nicht zeitlich geordnet ist. Es ist nicht zeitlich, da es noch nicht in den inneren Sinn aufgenommen und nicht durch empirisches Bewusstsein begleitet ist. Kurz gesagt, das Gegebensein ist nicht mit der Aufnahme in den inneren Sinn identisch.

Nun gilt es einige mögliche Einwände zu behandeln. Wenn die obige Interpretation korrekt ist, dann gibt es Vorstellungen, die nicht zum inneren Sinn gehören. Damit stehen einige Bemerkungen von Kant jedoch nicht im Einklang: Der innere Sinn ist „Inbegriff der Vorstellugnen“(A177/B220) oder „die formale Bedingung a priori aller Erscheinungen“ (A34/B50). Meines Erachtens sind alle solche Bemerkungen unglückliche Formulierungen, die Kants wahre Meinung nicht präzise zum Ausdruck bringen. Denn es gibt nach Kant tatsächlich Vorstellungen, die nicht zum inneren Sinn gehören und deren wir uns nicht apperzeptiv bewusst sind, die aber möglicherweise zur Aufnahme in den inneren Sinn bereit sind. Dies zeigt folgende Passage deutlich:

Wir haben Vorstellungen in uns, deren wir uns auch bewußt werden können. Dieses Bewußtsein aber mag so weit erstreckt, und so genau oder pünktlich sein, als man wolle, so bleiben es doch nur immer Vorstellungen, d.i. innere Bestimmungen unseres Gemüts in diesem oder jenem Zeitverhältnisse. (B242, meine Hervorhebung)

Wenn das Vermögen sich bewußt zu werden das, was im Gemüthe liegt, aufsuchen (apprehendiren) soll, so muß es dasselbe afficiren und kann allein auf solche Art eine Anschauung seiner selbst hervorbringen. (B68)

157 Kitcher (2012:17) 
Der erste Satz des ersten Zitats zeigt schon deutlich, dass Kant glaubt, dass es (apperzeptiv) unbewusste Vorstellungen gibt, denn er impliziert, dass wir uns der Vorstellungen in uns gegebenfalls nicht bewußt werden können. Der zweite Satz macht ganz explizit, dass das Bewusstsein einer Vorstellung im ersten Zitat gerade die Vorstellung des inneren Sinns ist, weil jenes die Gemütszustände in „diesem oder jenem Zeitverhältnisse“ bestimmt und die Vorstellung des inneren Sinnes nach der Definition gerade das Bewusstsein der Gemütszustände in der Zeit ist. Das zweite Zitat macht deutlich, dass das Mannigfaltige vor der Apprehension bzw. Selbstaffektion schon in bestimmter Form im Gemüt bereitliegt. Da die Vorstellung des inneren Sinnes die Selbstaffektion voraussetzt, kann man übrigens den Schluß ziehen, dass erst durch die Selbstaffektion eine Vorstellung ins apperzeptive Bewusstsein kommt.

Kants Doktrin der dunklen Vorstellungen liefert gerade konkrete Beispiele solcher Vorstellungen. Wie bereits dargestellt, sind dunkle Vorstellungen im Gemüt „präsent“ und können unter Umständen eine unentbehrliche Rolle bei der Erkenntnis spielen, auch wenn man sich ihrer auch bei ihrer Aktivierung nicht bewusst ist. Dies bedeutet, dass diese Vorstellungen nicht durch den inneren Sinn wahrgenommen werden, denn der innere Sinn ist gerade die Wahrnehmung unseres inneren Zustands (A107, siehe Kapitel 2). Über den epistemischen Status dieser Vorstellungen wissen wir bereits, dass sie zu „meinen Vorstellungen“ gehören, weil sie in unserem Erkenntnisprozess eine Rolle spielen können (B131f.). Somit gibt es durchaus „meine“ Vorstellungen im Gemüt, die nicht im inneren Sinne sind. Dasjenige Mannigfaltige des äußeren Sinnes in der Synopsis, das noch nicht in der Aufmerksamkeit ist, sind gerade dunkle Vorstellungen. Anders gesagt, die Affektion des äußeren Sinnes ist nicht die Affektion des inneren Sinnes. Die dunklen Vorstellungen des äußeren Sinnes sind Produkt der Affektion des äußeren Sinnes und repräsentationale mentale Zustände, obwohl sie noch gar keine Gegenstände des inneren Sinnes sind. Sie werden es, erst nachdem sie durch die Synthesis der 
Apprehension durchlaufen worden sind. Damit sind Nakanos Vorwürfe an die Auffassung eines rein rezeptiven Gegebenen, die auf dem Charakter des inneren Sinns und der Selbstaffektion basieren, verfehlt. Da die dunklen Vorstellungen des äußeren Sinnes nicht oder noch nicht in den inneren Sinn aufgenommen sind, sind sie nicht zeitlich. Damit geht auch Nakanos Kritik an der Zeitlichkeit des rein rezeptiv Gegebenen ins Leere. Über die Existenz der dunklen Vorstellungen des äußeren Sinnes wissen wir nämlich kaum, geschweige sind wir in der Lage, sie in der Folge der Wahrnehmungen einzuordnen. Kants Annahme solcher Vorstellungen beseitigt den Zweifel, ob es ein gegebenes Mannigfaltiges in dem oben genannten ersten epistemischen Modus überhaupt gibt. Wenn die obige Interpretation korrekt ist, dann ist der Ausdruck „Inbegriff aller Vorstellungen“ als „Inbegriff aller bewussten Vorstellungen“" zu verstehen.

\subsubsection{Bestimmung des Mannigfaltigen aus dunklen Vorstellungen}

Oben habe ich gegen Nakano argumentiert, dass das Mannigfaltige, das zur Apprehension bereitliegt, rein rezeptiv gegeben ist- d.h. vor und unabhängig von der (transzendentalen) Synthesis der Einbildungskraft — und es sich dabei um „dunkle Vorstellungen“" handelt. Viele Bestandteile dieser These wurden bisher nur erwähnt, nicht aber durch textuelle oder sachliche Argumente belegt. Es bleibt daher zu zeigen, dass die Synthesis der Einbildungskraft tatsächlich auf einem derartigen rein rezeptiv gegebenen Mannigfaltigen operiert, im Verlauf dieser Operation den inneren Sinn affiziert und das Subjekt sich dadurch dieses Mannigfaltigen bewusst wird. D.h. der Status als rein rezeptiv gegebenes Mannigfaltigen ist das erste Stadium der Aufnahme 
der Sinnesdaten in das apperzeptive Bewusstsein. Dies wird im Folgenden schrittweise demonstriert.

Als Erstens muss bewiesen werden, dass die Apprehension gerade der Prozess der Aufnahme des Mannigfaltigen in den inneren Sinn ist, dem wiederum die Selbstaffektion zugrundliegt. ${ }^{158}$ Dies wird aus dem folgenden Zitat ersichtlich:

die Zeit [ist] diejenige [...], welche a priori allen Wahrnehmungen und deren Verbindung zum Grunde liegt, deren Auffassung (apprehensio) der Art, wie das Subject dadurch afficirt wird, d.i. der Zeitbedingung gemäß ist, indem das sinnliche Ich vom intellectuellen, zur Aufnahme derselben ins Bewußtseyn, bestimmt wird. (FM 20:270)

Diesem Zitat zufolge ist die Apprehension der Wahrnehmungen auch der Prozess der Selbstaffektion und mithin ist sie der Prozess, in dem das Mannigfaltige in dem inneren Sinn aufgenommen wird. Die „Synthesis der Apprehension“ ist „die Zusammensetzung des Mannigfaltigen in einer empirischen Anschauung, dadurch Wahrnehmung, d.i. empirisches Bewußtsein derselben (als Erscheinung), möglich wird“ (B160). Kant erklärt das Apprehendieren explizit als „ins empirische Bewußtsein [aufnehmen]“ (B202). Erst durch die Apprehension gelangt das Mannigfaltige ins empirische Bewusstsein, worunter hier der der innere Sinn zu verstehen ist, da das empirische Bewusstsein im menschlichen Verstand einen Selbstbezug enthalten muss und somit das Bewusstsein der inneren (repräsentationalen) Zustände, i.e. der innere Sinn, ist. Neben B68, einer der wichtigsten Stellen über den inneren Sinn, legt auch die Definition des inneren Sinnes in der Anthropologie (7:134 Anm.) die enge Verbindung zwischen dem inneren Sinn und der Apprehension nahe. Unabhängig von der terminologischen Komplexität der Passage und dem interpretativen Bedarf, den ein vollständiges Verständis erfordern würde, scheint zumindest eine Beobachtung

${ }^{158}$ Dies wird schon in der obigen Ausführung angedeutet jedoch nicht bewiesen. 
unproblematisch zu sein: der innere Sinn ist das Bewusstsein der Apprehension. ${ }^{159}$ Ferner kann eine Stelle in der zweiten Analogie der Erfahrung diese These bestätigen, an der Kant die Apprehension als „Aufnahme [des Mannigfaltigen] in die Synthesis der Einbildungskraft" charakterisiert (B235), denn der innere Sinn ist gerade durch diese Synthesis affiziert. ${ }^{160}$ Folglich ist die Apprehension der Akt oder Prozess, in dem die Sinnesdaten in den inneren Sinn und in die Synthesis der Einbildungskraft aufgenommen werden.

Nun betrachten wir zwei äußerst wichtige Passagen:

Ich sehe nicht, wie man so viel Schwierigkeit darin finden könne, daß der innere Sinn von uns selbst afficirt werde. Jeder Actus der Aufmerksamkeit kann uns ein Beispiel davon geben. Der Verstand bestimmt darin jederzeit den inneren Sinn der Verbindung, die er denkt, gemäß zur inneren Anschauung, die dem Mannigfaltigen in der Synthesis des Verstandes correspondirt (B156-7 Anm.)

[E]s wird dazu erfordert, daß wir den innern Sinn, zum Theil auch wohl bis zum Grade der Beschwerlichkeit, vermittelst der Aufmerksamkeit afficiren.“ (FM 20:270)

Aus den ersten beiden Passagen geht deutlich hervor, dass sich die Selbstaffektion bzw. die Aufnahme des gegebenen Mannigfaltigen in den inneren Sinn in einem Akt der Aufmerksamkeit abspielt (siehe auch ganz deutlich Refl 18:680). ${ }^{161}$ Wenn das

${ }^{159}$ In der Anth 7:141f. verdeutlicht Kant ebenfalls, dass die empirische Apperzeption - d.h. der innere Sinn - das Bewusstsein des „Ich der Apprehension“ ist.

160 „Die Einbildungskraft soll nämlich das Mannigfaltige der Anschauung in ein Bild bringen; vorher muß sie also die Eindrücke in ihre Thätigkeit aufnehmen, d.i. apprehendiren.“(A120) Ferner findet man auch einen Beleg im Losen Blatt Leningrad I „Nur so fern ich Gegenstände in der Zeit apprehendire und zwar Gegenstände des Raumes bestime ich mein Daseyn in der Zeit“ (Loses Blatt Leningrad I, Seite 1, Zeilen 33-34). Die Bestimmung des eigenen Daseins in der Zeit findet gerade in der Selbstaffektion statt. ${ }^{161}$ Dyck (2006:41) ist der Meinung, dass die transzendentale Synthesis der Einbildungskraft mit dem Akt der Aufmerksamkeit identisch ist. Die Aufmerksamkeit sei nicht bloß, ,the means through which self-affection is witnessed“ (2006:41). Es ist zwar unumstritten und durch die ersten beiden Zitate gut fundiert, dass die Aufmerksamkeit die transzendentale Synthesis der Einbildungskraft immer enthält. Aber Kant sagt in diesen Zitaten streng genommen nicht, dass die Letztere nur in der Aufmerksamkeit stattfindet. Allison (2004:284) ist gegen die Auffassung, dass jeder Akt der Aufmerksamkeit ein Beispiel 
gegebene Mannigfaltige in der Apprehension in den inneren Sinn aufgenommen ist und der innere Sinn in dem Wirkungsbereich der Aufmerksamkeit affiziert wird, lässt sich schließen, dass sich die Apprehension in der Aufmerksamkeit abspielt. Diese These kann durch die folgende Passage belegt werden:

Man sieht wohl, daß, wenn das Vermögen der Erkenntniß überhaupt Verstand (in der allgemeinsten Bedeutung des Worts) heißen soll, dieser das Auffassungsvermögen (attentio) gegebener Vorstellungen, um Anschauung, das Absonderungsvermögen dessen, was mehreren gemein ist (abstractio), um Begriff, und das Überlegungsvermögen (reflexio), um Erkenntniß des Gegenstandes hervorzubringen, enthalten müsse (Anth 7:138)

Daraus geht deutlich hervor, dass die Aufmerksamkeit (attentio) die gegebenen Vorstellungen zu einer Anschauung ,auffasst“. Dies ist, sachlich betrachtet, der Akt der Apprehension. ${ }^{162}$ Übrigens ist das Wort „Auffassung“ gerade synonym zur „Apprehension“" gemäß einigen Stellen (KU 5:189, 192, 251; Anth 7:142).

Nun kommt ein Ergebnis des obigen Abschnitts ins Spiel. In der Darstellung der Apprehension am Anfang der A-Deduktion behauptet Kant, dass wenn das Mannigfaltige der Anschauung in „einem Augenblick enthalten“ ist, die Anschauung „nichts anderes als absolute Einheit““ ist und das Mannigfaltige auch nicht „als ein solches vorgestellt" wird. Wie bereits ausgeführt, handelt es sich bei dem Ausdruck „[das] Mannigfaltigen [...] als in einem Augenblick enthalten“ nicht um eine irreale Situation, sondern um eine Phase der Entstehung der empirischen Anschauung. Bei

der Selbstaffektion ist, was sich angesichts der Textbelege als falsch erweist. Er ist der Meinung, dass nur diejenigen Akte der Aufmerksamkeit, die sich auf eigene Zustände richten, Fälle der Selbstaffektion sind. Gemäß meiner Interpretation liefert dagegen auch die Aufmerksamkeit auf äußere Gegenstände eine dunkle Vorstellung des eigenen Zustands und ist somit in der Tat eine Selbstaffektion (s.u.).

162 Ameriks bemerkt zur Aufmerksamkeit: „A simple act of attention, for example, can involve less than the specific kind of taking that is involved in the synthesis that is judgment, and yet it is not simply an instance of primitive inner sense (B157 n.)“ (2006: 56). Seine Lesart geht der zitierten Textevidenz zuwider. 
dieser handelt es sich um die Synopsis oder die Momentaufnahme des Gegenstands der Anschauung, die viele Details enthält. Dieses Interpretationsmodell enthält folgende Aussagen: das Mannigfaltige einer Anschauung ist deswegen eine absolute Einheit, weil das Subjekt es als Vorstellungen zwar schon in sich hat, aber die Details nicht voneinander apperzeptiv unterscheiden oder anders gesagt, nicht als solche identifizieren kann. Das heißt, das Subjekt hat dieses Mannigfaltige gar nicht durchgehend erfasst. Der Grund hierfür kann nur sein, dass das Subjekt in einem Akt (,Augenblick“) nicht alles erfassen kann. Das Verstandsvermögen unterliegt einer Schranke der Aufnahmefähigkeit hinsichtlich der Sinnesdaten, die die Sinnlichkeit liefert. ${ }^{163}$ Das Erfassen der Details gelingt erst dann, wenn die sukzessive Apprehension das Mannigfaltige „,zerlegt““ und nach und nach „durchläuft“. Die Sinnlichkeit überschreitet, anders gesagt, die Aufnahmefähigkeit des apperzeptiven Vermögens. Vor der Apprehension ist das Mannigfaltige bewusstseinstheoretisch nur ein Gewirr aus unbestimmten Details. Die Einzelteile dieses Mannigfaltigen sind dunkle Vorstellungen, die zwar schon ins Gemüt - genauer gesagt, in die Sinnlichkeit -, aber noch nicht in den inneren Sinn bzw. ins apperzeptive Bewusstsein aufgenommen sind.

Die Aufgabe, diese Details in den inneren Sinn aufzunehmen, führt die Synthesis der Apprehension durch:

Damit nun aus diesem Mannigfaltigen Einheit der Anschauung werde (wie etwa in der Vorstellung des Raumes), so ist erstlich das Durchlaufen der Mannigfaltigkeit und dann die Zusammennehmung desselben nothwendig, welche Handlung ich die Synthesis der Apprehension nenne. (A99)

Das „Durchlaufen“ des Mannigfaltigen ist nicht die Aufnahme des Mannigfaltigen in das Gemüt, sondern die Bedeutung des Wortes „Durchlaufen“ deutet an, dass das Mannigfaltige schon im Gemüt vorhanden ist. Die Apprehension nimmt es nicht ins

\footnotetext{
${ }^{163}$ Vgl. Wolff (1963: 153-3); In Allison (2015:207) aber nur andeutungsweise.
} 
Gemüt auf, sondern versetzt es als schon Vorhandenes in einen anderen kognitiven Zustand. Dieser Eindruck wird durch eine andere Stelle in der B-Auflage der $\mathrm{KrV}$ bestätigt. Dort bezeichnet Kant den ersten Schritt der Apprehension - den ersten Schritt der Aufnahme des Mannigfaltigen in das apperzeptive Bewusstsein - ähnlicherweise als „Durchgehen“ des Mannigfaltigen:

Allein die Spontaneität unseres Denkens erfordert es, daß dieses Mannigfaltige zuerst auf gewisse Weise durchgegangen, aufgenommen und verbunden werde, um daraus eine Erkenntniß zu machen. Diese Handlung nenne ich Synthesis (A77/B102-3, meine Hervorhebung)

Interessanterweise erwähnt Kant einen weiteren Schritt nach dem „Durchgehen“ des Mannigfaltigen, und zwar die Aufnahme des Mannigfaltigen. Diese kann nichts anders sein als die Aufnahme in die Synthesis der Einbildungskraft bzw. den inneren Sinn (siehe die zitierten Passagen in A120 und B235 auf der Seite 191). Wenn diese Analyse korrekt ist, dann muss das Mannigfaltige vor der Aufnahme in den inneren Sinn in einem gewissen Sinn schon im Gemüt vorhanden sein und die Aufgabe der Apprehension besteht somit darin, die schon vorhandenen Details apperzeptiv bewusst zu machen.

Wie schon gezeigt, spielt sich die Apprehension in der Aufmerksamkeit ab. Daraus kann man schließen, dass die Vorstellungen, die im Gemüt schon vorhanden, aber noch nicht in die Apprehension aufgenommen sind, Vorstellungen außerhalb der Reichweite der Aufmersamkeit sind. Die Aufmerksamkeit deckt nur eine kleine Fläche der gesamten Momentaufnahme ab. Folglich muss die Aufmerksamkeit sich auf verschiedene Teile des mentalen Bildes richten, sie muss sich von einem Detail zum anderen bewegen - d.h. das mentale Bild „durchlaufen“ - und so sukzessiv das Mannigfaltige in den inneren Sinn aufnehmen. Diese Interpretation wird stark durch Kants Wortwahl „Durchlaufen“, „Durchgehen“ „,in einem Augenblick enthalten“ und ,absolute Einheit“ unterstützt. 
Gegenstände außerhalb der Reichweite der Aufmerksamkeit, aber innerhalb der Reichweite der Sinnesorgane werden von Kant gerade als dunkle Vorstellungen bezeichnet. ${ }^{164}$ Es gibt auf dem Weg der Sinnesdaten ins apperzeptive Bewusstsein eine Zwischenstufe zwischen „,in der Aufmerksamkeit“ und „die Sinnesorgane gar nicht affiziert". Wie Kant in dem Beispiel des improvisierenden Musikers explizit macht, sind alle Töne, auf die der Musiker nicht achtgegeben hat, schon in seinem Gemüt, obwohl er wegen der Einschränkung der Aufnahmefähigheit des apperzeptiven Vermögens nicht alle in den inneren Sinn bzw. in das apperzeptive Bewusstsein aufnehmen kann. In einem Wort, das Mannigfaltige der Anschauung durchläuft eine Vorstufe des Prozesses, nämlich als dunkle Vorstellung. ${ }^{165}$ Die Aufmerksamkeit nimmt empirische Materialien aus dem dunklen Mannigfaltigen und übt synthetische

164 Grüne (2009:159-60) deutet zurecht darauf hin, dass die Funktion der Apprehension nicht darin besteht, eine klare Anschauung deutlich zu machen. Dies würde nämlich wiederum implizieren, dass nicht klare Anschauungen, sondern deutliche Anschauungen eine Einheit bilden, da in der Apprehension „aus diesem Mannigfaltigen Einheit der Anschauung werde (wie etwa in der Vorstellung des Raumes)“ (A99). Dass nur deutliche Anschauungen eine Einheit bilden, ist laut Grüne unangemessen. Basierend auf weitere Textindizien (A99, 102, B160, 202) zieht sie den Schluss, dass die Apprehension in der Tat dafür verantwortlich ist, dass eine klare, bewusste Anschauung mit ihrer Einheit überhaupt erst gebildet bzw. erzeugt wird (Grüne 2009: 160). Grüne liegt insofern richtig, als es vor der Apprehension keine klare Anschauung gibt und es folglich unangebracht ist zu sagen, dass die Apprehension eine klare Anschauung deutlich macht. Grüne verkennt jedoch Folgendes: Wenn das Mannigfaltige einer Anschauung in einem bestimmten Maß - z.B. x Elemente des Mannigfaltigen, da wegen der Kontinuität des Raums und der Zeit nicht alle Elemente "abgedeckt" werden können - durchlaufen und zusammengesetzt wird, wird die Anschauung in entsprechendem Maß deutlich. Somit ist die Apprehension dennoch ein Prozess, eine Anschauung zum gewißen Grad deutlich zu machen. Ich möchte in dieser Arbeit nicht auf dieses Problem eingehen, da meine Argumentation davon unabhängig ist und das Problem allein in der terminologischen Bestimmung der Deutlichkeit der Anschauung besteht. Einfacherheitshalber bezeichne ich die Apprehension als Vorgang, in der eine dunkle Anschauung bewusst bzw. klargemacht wird.

165 Zugegebenerweise ist Valaris unlängst zu demsselben Interpretationsmodell gekommen: „Kant's talk of the understanding determining inner sense in acts of attention corresponds to the idea that attention involves selecting representations to bring into direct or clear consciousness." (Valaris: forthcoming, 14) 
Operationen auf ihnen aus, affiziert dabei den inneren Sinn und macht dieses Material apperzeptiv bewusst bzw. zum Gegenstand des inneren Sinnes. Das Durchlaufen des Mannigfaltigen ist gerade der Prozess, in dem es apperzeptiv bewusst gemacht wird. ${ }^{166}$ In der Tat können wir eine weitere Implikation aus diesem Interpretationsmodell ziehen: in einem äußersten zerstreuten Zustand bleibt der größe Teil der empirischen Daten des äußeren Sinnes dunkle Vorstellungen, die kaum durch synthetische Akte des Verstandes bearbeitet werden. Daher ist das rein rezeptiv Gegebene kein uns völlig fremder mentaler Zustand.

\subsubsection{Anhang: Ein Kommentar über A99}

Die Apprehension und ihre Synthesis sind für unser Verständnis des inneren Sinnes unentbehrlich. Kants vage Ausführung über die Apprehension wirft jedoch viele Fragen auf. In der Literatur gibt es zu der Frage, was die Synthesis der Apprehension verbindet, verschiedene Interpretationen. In diesem Kapitel wird diskutiert, welche Interpretation von Kants Aussagen über die Apprehension korrekt ist. Im Kern steht die Frage, wie man den vor-apprehensiven Status des Mannigfaltigen — ,als in einem Augenblick enthalten, kann jede Vorstellung niemals etwas anderes, als absolute Einheit sein“_interpretieren soll.

166 Grüne (2009: §3.2) kommt zum ähnlichen Schluss: „Vorstellung zu durchlaufen bedeutet, Vorstellungen bewusst zu machen, genauer Vorstellung für einen Augenblick bewusst zu machen“ (Grüne 2009: 167). Allerdings hat Grüne eine andere Auffassung vom Begriff des Bewusstseins als die hier vertretene. 
Zuerst werden zwei Interpretationsvorschläge von zwei prominenten Kommentatoren und eine naheliegende Lesart zurückwiesen, die wegen markanter exegetischer Probleme nicht in Frage kommen. Allison baut seine Interpretation auf den Begriff „Augenblick“ auf und verweist auf A169-70/B211: „the crucial pont is that an instant or moment (ein Augenblick) is a boundary or limit rather that a part of time, just as a point is a boundary or limit rather than a part of space." (Allison 2015:210). Dementsprechend bemerkt er zu dem ersten Modus des Mannigfaltigen: „since, ex hypothesi, an instant or moment is not a part of time nothing is intuited in it, including an absolute unity". Dieser Lesart zufolge ist in einem Augenblick also weder Mannigfaltiges noch absolute Einheit enthalten. Dies widerspricht Kants Aussage markant. Der metaphysische Charakter des Augenblicks spielt keine Rolle in dem Argumentationsgang in A99. Andernfalls wäre gar nicht nachvollziehbar, warum Kant überhaupt über das Mannigfaltige in einem Augenblick sprechen sollte, wenn dieses gar nicht existiert. Als Beleg nennt Allison (2015:210) eine Passage in R5390 (Refl 18:169-70). In der Tat geht es dort hauptsächlich um den metaphysischen Charakter der physischen Zeit. Kant will bloß aus der Kontinuität der Zeit die Kontinuität der Erscheinung ableiten. Diese Passage ist keine parallele Stelle von A99, obwohl in beiden der Begriff „Augenblick“ verwendet wird. In der $K r V$ bedeutet „Augenblick“ in Übereinstimmung mit seinem alltäglichen Sinn eine kurze Dauer gemäß einer Passage in A103, die an die im Fokus stehenden Passage A99 anschließt.

$\mathrm{Zu}$ dem vor-apprehensiven Status des Mannigfaltigen behauptet Guyer: „I am not immediately acquainted with any manifold of representations insofar as I think of our representational state as 'contained in a single moment,' but can instead think of a manifold as a manifold only if I first represent a 'sequence of one impression upon another"'(Guyer 1987:148). Guyer glaubt, dass unsere Vorstellung des Mannigfaltigen „,is not itself a manifold of representations but rather a single representation which must be interpreted or judged to represent a diversity or manifold of representations." Im 
ersten Zitat scheint Guyer den Ausdruck „,[eine Anschauung] als in einem Augenblick enthalten“ durch „ein Mannigfaltiges als in einem Augenblick enthalten interpretieren“ umzuformulieren. Dies ist aber unbegründet. Denn in A99 geht es in der ersten Linie darum zu zeigen, dass eine Anschauung eines Mannigfaltigen ohne Synthesis der Apprehension unmöglich ist. Mit der Erwähnung der Anschauung ,als in einem Augenblick enthalten“" will Kant den bewusstseinstheoretischen Status des Mannigfaltigen ohne die sukzessive Synthesis der Apprehension beschreiben, um die Notwendigkeit dieser Synthesis hervorzuheben. Vor der Synthesis wird auf dem Mannigfaltigen keine Denkhandlung bzw. kein Interpretationsakt ausgeübt. Daher ist die Rede von „I think of our representational state as "contained in a single moment," völlig irreführend.

Nun werden zwei vielversprechende Interpretationsmodelle diskutiert. Das erste Modell besagt, dass die Synthesis der Apprehension „ein Zusammenfassen von jeweils momentan gegebenen einzelnen Sinneseindrücken zu Wahrnehmungen, d.h. ein Zusammensetzen der Teile eines gegenwärtigen ganzheitlcihen Anblicks einer Sache zu eben diesem Anblick“ darstellt (Hoppe 1983: 179). Der Kern dieser Interpretation ist, dass die Apprehension die einzelnen Sinneseindrücke nicht auf einmal, sondern nacheinander aufnehmen muss, bevor sie sie alle in einem mentalen Bild, das einen momentlichen Anblick des Gegenstands ausmacht, zusammenbaut. Als wichtige Belege dazu werden von den Befürwortern z.B. A162/B202ff. und B160 genannt. Zugunsten dieses Modells müssen folgende Modifikationen gemacht werden: dieses mentale Bild (d.h. natürlich das von ihm repräsentierte, i.e. der von ihm qua Vehikel "transportierte" repräsentationale Inhalt) braucht nicht eindimensional und rein visuell zu sein, sondern kann durchaus dreidimensional sein und aus empirischen Daten verschiedener Sinne bestehen. Ganz wichtig ist auch, dass dieses Bild eine Vorstellung des Gegenstands zu einem Zeipunkt sein muss. Dieses Bild bietet keine vollständige Abbildung des Gegenstands aus verschiedenen Blickwinkeln, sondern stellt nur eine 
Momentaufnahme aus einem Blickwinkel bzw von einem Aspekt dar. Diesem Modell zufolge lässt sich die Notwendigkeit der Apprehension in der Einschränkung des Verstandesvermögens begründen: Die Details des Bilds übersteigen die Kapazität des Verstandes, der in einem Augenblick nur auf wenige Eindrücke aufmerksam sein und diese dann apperzeptiv bewusst machen kann. Um des Mannigfaltigen als solchen bewusst zu werden, muss der Verstand einen Eindruck nach dem anderen in der Zeit aufnehmen. Entsprechend interpretiert ein prominenter Befürworter dieses Modells Kants Bemerkung über das Mannigfaltige als „,in einem Augenblick enthalten“ wie folgt:

we could never know a representation as diverse in a single moment. In order to know a diversity of representations, even if they are given as simultaneous, the mind must run over them one after another. (Wolff 1963:152-3)

Den Befürwortern des zweiten Modells zufolge sind in der Apprehension nicht Sinneseindrücke zu einem augenblicklichen Anblick, sondern mehrere Anblicke zu einer „Anschauung“ des Gegenstands komponiert (Carl 1991: 152-4). ${ }^{167}$ Diese zusammengesetzte Anschauung ist nicht eine Abbildung des Gegenstands zu einem bestimmten Zeitpunkt unter einem bestimmten Gesichtspunkt, sondern eine gesamte Abbildung des Gegenstands - d.h. ein mentales Bild der dreidimensionalen Gestalt mit allen Sinnesqualitäten. Diese Anschauung besteht übrigens aus mehr als aus augenblicklichen Abbildungen des Gegenstands. Sie könnte eventuell auch das typische Verhalten des Gegenstands in der Zeit enthalten, da ein Gegenstand oder Sachverhalt ,gegenwärtig vollständig gar nicht gegeben ist“ (Hoppe 1983: 180). Die Synthesis der Apprehension erzeugt „die Einheit eines Gegenwärtigen, das anschaulich

\footnotetext{
167 „Die Mannigfaltigkeit der Anschauung eines komplexen Gegenstandes ist durch den Zusammenhang von gleichartigen, ähnlichen und verschiedenen Empfindungen, die wir über einen Zeitraum haben, bestimmt, und nur dieser Zusammenhang liefert uns ein Bild des Gegenstands.“ (Carl 1991:154)
} 
erfüllt gegeben ist, mit einem bloß Gemeinten, Erinnerten.“ (Hoppe 1983: 180). Hoppe führt die folgende Passage als Beleg:

„Das Gemüth muß viele Beobachtungen anstellen, um sich einen Gegenstand abzubilden (V-Met-L1/Pölitz 28: 236).“

Nach Hoppe solle der Gegenstand durch solche Beobachtungen

von jeder Seite anders abbildet [werden]. Z.E. so sieht eine Stadt von der Morgenseite anders aus, als von der Abendseite“ (Hoppe 1983:180)

Ähnliche Stellen lassen sich nicht schwer finden: Es sind also „viele Erscheinungen von einer Sache nach den verschiedenen Seiten und Gesichtspunkten“ dargeboten (VMet-L1/Pölitz 28: 236). ,Alle Erscheinungen stehen als Vorstellungen in der Zeit und werden in der Zeit bestimmt. Als ein Theil einer ganzen Erscheinung kann sie nicht in einem Augenblicke, sondern in einem Theile der Zeit bestimmt werden (genetisch apprehendiert werden).“ (R 5390, Refl 18:151)

Meines Erachtens ist das zweite Modell verfehlt, weil es die Funktion der Apprehension zu grobkörnig darstellt. Die Funktion der Apprehension ist „,die Zusammensetzung des Mannigfaltigen in einer empirischen Anschauung [...] dadurch Wahrnehmung, d.i. empirisches Bewußtsein derselben, (als Erscheinung) möglich wird“" (B160, siehe auch A99). Die Verwirrung in der Konkurrenz der beiden Modelle stammt in der Tat aus der Unklarheit des Begriffs der empirischen Anschauung, die ein Produkt der Apprehension sein soll: ist dieses eine Momentaufnahme oder ein gesamtes dreidimensionales Bild des Gegenstands? Einige oft vernachlässigte Stellen in der Zweiten Analogie bieten einen entscheidenden Hinweis über die Natur der Apprehension:

\footnotetext{
168 Interessanterweise nennt Hoppe Kants Beispiel der Wahrnehmung eines Zimmers. Um ein mit „Gemälden und Auszierungen überhäuft[es] Zimmer“wahrzunehmen, muss man es durchlaufen und alle Details zusammenfassen.
} 
Die Apprehension des Mannigfaltigen der Erscheinung ist jederzeit sukzessiv. Die Vorstellungen der Teile folgen auf einander. Ob sie sich auch im Gegenstande folgen, ist ein zweiter Punkt der Reflexion, der in dem ersteren nicht enthalten ist" (A189/B234).

[D]ie Apprehension des Mannigfaltigen in der Erscheinung eines Hauses, das vor mir steht, sukzessiv (A190/B235).

In dem vorigen Beispiele von einem Hause konnten meine Wahrnehmungen in der Apprehension von der Spitze desselben anfangen, und beim Boden endigen, aber auch von unten anfangen, und oben endigen, imgleichen rechts oder links das Mannigfaltige der empirischen Anschauung apprehensidern. (A192-3/B237-8).

Wohlgemerkt steht das Haus „,vor mir“. Folglich ist das Produkt der Apprehension eine mentale Abbildung einer Fassade, d.h. ein Anblick eines Gegenstandes. Offensichtlich produziert die Apprehension eine Folge von sukzessiven Wahrnehmungen, die Abbildungen von einzelnen Teilen des Gegenstands sind. Das zweite Modell ist insofern grobkörnig, als es verlangt, dass das Produkt der Synthesis der Apprehension eine Abbildung des Gegenstands unter verschiedenen Gesichtspunkten ist und diese Synthesis diese Abbildung aus verschiedenen „Anblicken“ des Gegenstands zusammenbaut.

Das erste Modell liegt Kants Intention am nächsten, obwohl sie ihre eigenen Probleme hat und modifiziert werden muss. Können die Vorstellungen, die die Apprehension durchläuft und zu dem Anblick eines Gegenstands zusammenbaut, einzelne Eindrücke sein? Wie die obigen Zitate aus der zweiten Analogie zeigen, ist es die Aufgabe der Synthesis der Apprehension, die verschiedenen Teilvorstellungen des Anblicks des Gegenstandes in einem Anblick zusammenzufassen. Solche Teilvorstellungen sind z.B. die von Teilen der Fassade des Hauses, die selbst komplexe Vorstellungen, aber keine einzelnen Sinneseindrücke sind. Damit stellt sich eine weitere Frage: wie feinkörnig können die Teilvorstellungen sein, die durch die Synthesis der Apprehension ins Bild des Gegenstands zusammengefasst werden? Sind es einzelne Sinneseindrücke, die jeweils nur ein Merkmal als Inhalt haben, oder schon Wahrnehmungen, die relativ 
komplexe Details enthalten können (z.B. Teilabbildungen des Gegenstands, wie das obige Beispiel des Hauses zeigt)? Diese Frage ist deswegen wichtig, weil es darum geht, was die Apprehension überhaupt bewusst macht. Natürlich gehört es zum Aufgabenbereich der Apprehension, aus verschiedenen Anblicken des Gegenstands eine mehrdimensionale Gestalt zusammenzusetzen, aber die Anblicke sind selbst schon bewusste Vorstellungen. Was für unser Ziel hilfreich ist - d.h. den inneren Sinn und die Selbstaffektion zu verstehen -, ist die Frage, was die Apprehension als die kleinsten Vorstellungen überhaupt bewusst machen könnte. Hierzu betrachten wir eine relevante Kritik an dem ersten Modell. Diesem Modell zufolge durchläuft die Apprehension die einzelnen Eindrücke und setzt sie diese zusammen. Aber ist es wirklich wahr, dass man keine komplexe Vorstellung in einem Augenblick haben kann? Haben wir nicht unzählige Gegenbeispiele aus unserem täglichen Leben? Wenn ich jetzt meine Augen öffne, sehe ich nicht zumindest zugleich die Wand, die Tischlampe, den Tisch und das Bücherregal? Zugunsten des ersten Modells kann man darauf Folgendes erwidern: die Apprehension in diesem Fall erfolgt extrem schnell. ${ }^{169}$ In kurzer Zeit unterscheidet das Subjekt drei Gegenstände voneinander und von Gegenständen im Hintergrund. Ohne diesen Unterscheidungsakt (mit Kants Ausdruck, ohne das „Durchlaufen“) würden alle genannten Gegenstände undifferenziert bleiben.

Um die Existenz des „Durchlaufen[s]“ zu zeigen, braucht man sich nur vorstellen, wie es sein würde, wenn ein Bild des Zimmers nur für Millisekunden erscheint und danach wieder verschwindet: in diesem Fall hätte man nur ein Gewirr von Eindrücken, von denen man vielleicht nur ein einzelnes Merkmal bezeichnen könnte - d.i. das Mannigfaltige ist in einem einzigen Augenblick, der als solcher keine Synthesis der Apprehension ermöglicht, eine ,absolute Einheit“. Daher sind die mentalen Entitäten, die die Apprehension durchlaufen, die einzelnen Sinneseindrücke. Ein solches

\footnotetext{
169 Siehe Grüne (2009: 163)
} 
Argument ist jedoch eine reine Spekulation über den kognitiven Prozess und benötigt als solches noch einer empirischen Verifikation. ${ }^{170}$ Es gibt aber ein epistemisches Argument, das unabhängig von dieser Überlegung aus der empirischen Psychologie ist: für Kant gehört der Unterscheidungsakt per definitionem zum Aufgabenbereich der spontanen kognitiven Fähigkeit. Die Unterscheidung, die in dem Akt, „das Mannigfaltige [...] als ein solches vor[zu]stell[en]“, eine Rolle spielt, ist eine kognitive Zutat zu dem empirischen Gegebenen, die niemals durch die Sinnlichkeit gegeben werden kann. Sie bedeutet nicht, dass man unterschiedliche kausale und physiologische Reaktionen auf unterschiedliche Stimuli aufweist, sondern ein Urteil fällt, dass ein Element des Mannigfaltigen anders als ein anderes ist. ${ }^{171} \mathrm{Da}$ solche Unterscheidungsakte bezüglich des Mannigfaltigen der Anschauung offensichlich nicht in einem „Augenblick“ ausgeführt werden können, ist Kant völlig berechtigt zu sagen, dass das Mannigfaltige als in einem Augenblick enthalten eine undifferenzierte Einheit sei.

\footnotetext{
${ }^{170}$ Kant selbst hat nie eine solche Überlegung angestellt, wohl deswegen, weil ihm klar war, dass sie zur empirischen Psychologie gehört. Hinsichtlich des epistemischen und bewusstseinstheoretischen Status des Mannigfaltigen, das die Apprehension durchläuft und zusammenfasst, bleiben seine Stellungnahmen über die Apprehension ausnahmslos dürftig und vage (A77/B102, A99, B160).

${ }^{171}$ Siehe B414-15 Anm. In Spitzfindigkeit (DfS 2:59-60) unterscheidet Kant zwischen physischem und logischem Unterscheiden. Das erstere besteht in den unterschiedlichen Reaktionen auf unterschiedliche Stimuli. Diese Fähigkeit hat auch das Tier: „Der Hund unterscheidet den Braten vom Brote, weil er anders vom Braten, als vom Brote gerührt wird (denn verschiedene Dinge verursachen verschiedne Empfindungen)“. Das Tier übt dabei keinen mentalen Unterscheidungsakt aus, vielmehr laufen nur unterschiedliche kausale Verknüpfungen ab: unterschiedliche Empfindungen bewirken unterschiedliche Triebe. Im Gegensatz wird das logische Unterscheiden immer durch ein Urteil in der Form „A ist nicht B“ ausgeführt. Somit ist der Unterscheidungsakt eine spontane Handlung des Subjekts. Wohlgemerkt macht Kant ganz explizit, dass die logische Unterscheidung nur durch den inneren Sinn geschehen kann. Es gibt übrigens in der $K r V$ eine weitere subliminale Art der Unterscheidungsakte, die nicht genuine Urteile sind (siehe Liang 2017)
} 
Wohlgemerkt besagt die hier vertretene Lesart nicht, dass die Apprehension nicht auf einzelnen Anblicken operieren kann. Der springende Punkt bleibt darin, dass die erste „Anwendung“ der Synthesis der Apprehension auf den einzelnen Eindrücken geschieht und sich erst aus mehreren Anwendungen der Synthesis eine Abbildung des Gegenstands ergibt. Nur hinsichtlich der ersten Anwendung der Synthesis der Apprehension auf den einzelnen Eindrücken ist Kants Ausführung über die ,absolute Einheit“" des Mannigfaltigen als „in einem Augenblick enthalten“ überhaupt sinnvoll. Denn wenn das zweite Modell korrekt wäre, wäre es nicht nachvollziehbar, was die sich daraus ergebene Interpretation des vor-apprehensiven Status, d.h. die These, dass „die verschiedenen Anblicke als in einem Augenblick enthalten [...] eine absolute Einheit [sind]“ bedeuten sollte, da verschiedene Anblicke nur zu verschiedenen Zeitpunkten gegeben werden können. Das Szenario, dass mehrere Anblicke des Gegenstands unter verschiedenen Gesichtspunkten in einem Augenblick ohne die Synthesis der Apprehension gegeben sind, enthält in sich einen Widerspruch und ist damit gar nicht vorstellbar, während das Szenario, dass verschiedene Eindrücke in einem Augenblick gegeben sind, durchaus vorstellbar ist. In einem Wort, die Apprehension ist eine Art des kognitiven Akts, der sowohl verschiedene Eindrücke in einem Anblick des Gegenstands, als auch verschiedene Anblicke des Gegenstands in einer Anschauung des Gegenstands kombiniert. 


\subsection{Die zweite Selbstaffektion in der Zusammensetzung der}

\section{Anschauung}

In der obigen Analyse sind wir zu diesem Schluss gekommen, dass die Synthesis der Apprehension als ihre kleinsten Akte das rein rezeptiv gegebene Mannigfaltige des äußeren Sinnes durchläuft und die einzelnen Sinneseindrücke in einer momentanen Abbildung des Gegenstands zusammennimmt. Da laut Kant die Synthesis der Apprehension das Mannigfaltige ins Bewusstsein bzw. in den inneren Sinn aufnimmt, lässt sich schließen, dass schon in dieser Phrase der innere Sinn affiziert wird. Das impliziert, dass die Synthesis der Apprehension als eine empirische Synthesis den inneren Sinn affizieren kann. Dies ist anscheinend unvereinbar mit der Tatsache, dass Kant explizit die transzendentale Synthesis der Einbildungskraft als denjenigen Akt des Subjekts erwähnt, der den inneren Sinn affiziert (B153-4). Übrigens sind weitere Anwendungen der synthetischen Handlungen erforderlich, um die Wahrnehmungen, die die Synthesis der Apprehension aus Sinneseindrücken erzeugt, in eine den Gegenstand multidimensional und multimodal darstellende Anschauung zusammenzusetzen. Es scheint also, dass das synthetische Vermögen der Apprehension mehrmals betätigt werden muss. Zusätzlich gibt es die Synthesis der Reproduktion und Rekognition, die mit der Synthesis der Apprehension und mithin dem inneren Sinn wesentlich verbunden ist. In der Ausführung der Doktrin der Sythesis verwendet Kant für diese unterschiedlichen Arten der Synthesis auch die Begriffspaare „figürliche/intellektuelle Synthesis“, „produktive/reproduktive Synthesis“ und „reine/empirische Synthesis“. Wird der innere Sinn durch all diese verschiedenen Arte der Synthesis affiziert?

Diese Frage scheint Kant in der Anthropologie zu bejahen, in der er den affizierenden Akt des inneren Sinnes ganz unspezifisch als das „Gemüt[]“(Anth 7:153), „,sein eigenes 
Gedankenspiel“ (Anth 7:161) bezeichnet. ${ }^{172}$ Wenn dies der Fall ist, wie bringt man diese These mit Kants Bemerkung in Übereinstimmung, dass es die transzendentale Einbildungskraft ist, die den inneren Sinn affiziert? Um solche Fragen zu beantworten und den inneren Sinn sowie die Selbstaffektion genauer zu verstehen, muss man die verschiedenen Arten der Synthesis spezifizieren, was in diesem Kapitel versucht wird. Der vorliegende Abschnitt beansprucht dabei nicht, eine vollständige Analyse von Kants Doktrin der Synthesis zu liefern. Eher soll versucht werden, den sachlichen Kern seiner Synthesislehre herauszuarbeiten, wobei die zahlreichen Begriffe der Synthesis ihrer Funktion nach auf wenige reduziert werden. Im Anschluss wird die Struktur der Selbstaffektion untersucht.

\subsubsection{Synthesis der Apprehension, der Reproduktion und der Rekognition}

Im ersten Abschnitt dieses Kapitels werden die Synthesis der Apprehension, der Reproduktion und der Rekognition analysiert. Damit bezeichnet Kant Arten der Synthesis, die „notwendiger Weise in allem Erkenntnis vorkomm[en]“(A97). Sie sind „drei subjektive Erkentnisquellen“, die im Gegensatz zu der Rezeptivität des Sinnes die spontanen Komponenten der Erkenntnisse ausmachen (A97). Konkret gesagt, werden durch diese Arten der Synthesis erstmals empirische Erkenntnisse in Form von empirischen Anschauungen möglich (A115). In diesem Kapitel werden als Vorbereitung für das nächste Kapitel vor allem die Materialien, die Funktion und das

\footnotetext{
${ }^{172}$ Eine weitere unspezifische Darstellung des affizierenden Akts ist wie folgt: „,[D]as Gemüth [wird] durch eigene Thätigkeit, nämlich dieses Setzen seiner Vorstellung, mithin durch sich selbst afficirt [...], d.i. ein innerer Sinn seiner Form nach“" (B67-8).
} 
Produkt der drei Synthesisakte analysiert. Zugleich wird versucht zu zeigen, dass es sich bei der Apprehension, der Reproduktion und der Rekognition nicht um drei separate Synthesisakte, sondern um unterschiedliche Aspekte eines einzigen synthetischen Akts handelt. Auch wird die Frage beantwortet, ob sie unter bestimmten Bedingungen teilweise eigenständig vollgezogen werden können. Dies soll dazu dienen, die Synthesis der Apprehension, die mit der Selbstaffektion wesentlich verbunden ist, besser zu verstehen.

\subsubsection{Synthesis der Apprehension}

Die Synthesis der Apprehension wird in vorigen Kapiteln eingehend behandelt. Sie ist ein Akt, der das empirische Mannigfaltige zu einer empirischen Anschauung zusammensetzt (A99, B160). Sie besteht aus zwei Teilakten. Das Mannigfaltige der Anschauung wird zuerst sukzessiv „,[d]urchlaufen“ und dann als in einer Vorstellung enthalten zusammengenommen (A99). Dadurch werden die unbewussten Sinnesdaten in den inneren Sinn aufgenommen bzw. ins apperzeptive Bewusstsein gebracht (B68, 202). In der A-Deduktion spricht Kant noch von dem reinen Gebrauch der Synthesis der Apprehension, die a priori auf das Mannigfaltige der reinen Anschauung ausgeübt wird (A99-100). Es ist jedoch unzutreffend, eine separate reine Synthesis der Apprehension anzunehmen, denn später bemerkt Kant nicht nur, dass die Synthesis der Apprehension „unmittelbar an den Wahrnehmungen ausgeübt“" wird (A120), sondern bezeichnet sie auch ausdrücklich als empirisch (A108). Die Synthesis der Apprehension kann also nicht mal empirisch, mal apriori ausgeübt werden. Viel plausibler wäre, dass sie, obwohl sie auf Sinnesdaten operiert, zugleich einen reinen apriorischen Aspekt hat. Der empirische und der reine Gebrauch vollziehen sich in einem Zug, da die Zusammensetzung der empirischen Anschauung gemäß den Formen 
der Anschauung - Raum und Zeit - geschehen muss. In der B-Deduktion modifiziert Kant die Konzeption der Apprehension leicht. Aus dem §26 der B-Deduktion wissen wir, dass die Form der Anschauung, Raum und Zeit, selbst Anschauungen sind, deren Bestandteile, das reine Mannigfaltige, ebenfalls in eine Einheit zusammengenommen werden müssen. Wenn man die empirischen mannigfaltigen Vorstellungen gemäß der sinnlichen Form in einer Anschauung kombiniert, muss dies so geschehen, dass zugleich ihre reinen Entsprechungen in einer reinen Anschaung verbunden werden. Kant charakterisiert die Synthesis der Apprehension „selbst“ - d.h. die Apprehension an sich - auschließlich als empirisch (B527, 164). Die Funktion der Zusammennehmung des reinen Mannigfaltigen in einer formalen Anschauung gehört nicht mehr zum Aufgabenbereich der Synthesis der Apprehension (B160-165), sondern, wie wir später noch sehen werden, zur figürlichen oder reinen produktiven Synthesis der Einbildungskraft. Im Folgenden werde ich Kants Terminologie in der B-Auflage folgen. Dies ist nicht nur deswegen angebracht, weil die B-Auflage Kants reifere Auffassung vertritt, sondern auch weil unser Interesse dem Thema der Selbstaffektion gilt, zu der detaillierte Darstellungen hauptsächlich dort anzutreffen sind.

\subsubsection{Synthesis der Reproduktion}

Die Synthesis der Reproduktion bringt „eine vorher gehabte empirische Anschauung ins Gemüth“ zurück (Anth 7:167). „Die Einbildung von etwas aus der vergangenen Zeit ist reproduction“ (Refl 15:135). Diese Definitionen sind vage, was dazu führt, dass in der Literatur die Position vertreten wird, dass es zwei ganz unterschiedliche Arten der Reproduktion gibt. ${ }^{173}$ Bei der ersten Art geht es um die „Reproduktion der aktuell

\footnotetext{
173 Grüne (2009:166-172).
} 
durchlaufenen Vorstellungen“. ${ }^{174}$ Dabei werden bei der sukzessiven Apprehension die gerade durchlaufenen empirischen Vorstellungen, die nicht mehr präsent sind, im Bewusstsein behalten (A102, 121), damit sie nicht verlorengehen und bei der Zusammennehmung von ihnen zu einer ganzen Anschauung bzw. Bild noch verfügbar sind. Bei der zweiten Art handelt es auch um die „Reproduktion von ehemals verursachten Vorstellungen“175:

Es ist zwar ein blos empirisches Gesetz, nach welchem Vorstellungen, die sich oft gefolgt oder begleitet haben, sich mit einander endlich vergesellschaften und dadurch in eine Verknüpfung setzen, nach welcher auch ohne die Gegenwart des Gegenstandes eine dieser Vorstellungen einen Übergang des Gemüths zu der andern nach einer beständigen Regel hervorbringt (A100).

Die dahinterliegende Idee ist wie folgt: Angenommen die empirischen Vorstellungen a, b und c kommen immer zusammen vor. Das führt dazu, dass das Gemüt diese drei Vorstellungen als eine Einheit - wenn auch als eine subjektive Einheit, die keine strenge Notwendigkeit hat (B139ff.) - betrachtet und miteinander assoziiert, d.h. eine „beständig[e] Regel“ oder ein empirisches Assoziationsgesetz bildet. ${ }^{176}$ Wenn in einer Wahrnehmungssituation nur die Vorstellungen a und c vorkommen, wird die Reproduktion aktiviert und auch ein Vorkommnis der Vorstellung b bewirkt (obwohl dieses nicht so lebhaft ist, wie ein Vorkommnis dieser Vorstellung, der durch das faktische Vorkommen von Gegenstand B (i.e. einer Ursache einer b-Vorstellung) bewirkt wird). ${ }^{177}$ Die Funktion der zweiten Reproduktion besteht darin, das Vorliegen einer ganzen Anschauung zu bewirken, auch wenn ihre Teilelemente unter bestimmten

174 Grüne (2009:170).

175 Grüne (2009: 170).

${ }^{176}$ Mit dem Begriff der Assoziation wird offenkundig auf Hume angespielt. Streng genommen ist die Assoziation nach dem Assoziationsgesetz gar keine Synthesis, denn ein Tier, das zu keinem spontanen kognitiven Akt fähig ist, ist gleichwohl zur mechanischen Assoziation fähig (Anth 7:197).

177 Angenommen, die Vorstellung b stellt den Gegenstand B vor. 
Umständen gar nicht vorliegen. ${ }^{178}$ Daraus ergibt sich ein Interpretationsproblem: beide Arten der Reproduktion scheinen unterschiedlich zu sein, obwohl Kant nicht explizit zwei Arten der Reproduktion unterscheidet. Vielerorts identifiziert Kant die Assoziation mit der Reproduktion tout court (A115, A120ff.), obwohl sie laut der obigen Lesart eigentlich nur mit der zweiten Reproduktion identifiziert werden sollte.

Meines Erachtens kann folgende Einsicht helfen, diese Schwierigkeiten zu überwinden. Beide Arten der Reproduktion sind in der Tat wesentlich miteinander verbunden. Das Gesetz der Assoziation ist nicht nur für die zweite Art entscheidend, sondern ist auch die subjektive Voraussetzung der ersten Art, was Kant in A121 ganz deutlich macht: Ohne eine Regel, gemäß derer die Reproduktion eine Vorstellung vielmehr mit einer bestimmten Vorstellung als mit einer anderen Vorstellung verbindet, würde „ohne Unterschied“" und ohne Zusammenhang reproduziert. Diese Regel, die die Reproduktion direkt lenkt, ist nichts anders als der Assoziationsmechanismus, der anhand vergangener Erfahrungen gebildet wird. ${ }^{179}$ Somit sind beide Arten von Reproduktion wesentlich auf Assoziation zurückzuführen und ihr Unterschied ist bloß empirisch: die erste Reproduktion gemäß dem Assoziationsgesetz behält die gerade durchlaufenen Vorstellungen im Bewusstsein, während die zweite eine frühere Vorstellung im Gedächtnis abruft. Dieser Unterschied ist epistemisch irrelevant, da beide Arten dieselbe Rolle spielen: sie sind Bedingung des zweiten Schritts der Apprehension, also des Zusammennehmens des Mannigfaltigen in einer ganzen Anschauung. Sie beide bewirken, dass alle Bestandteile einer Anschauung bei der Zusammensetzung des mentalen Bildes präsent sind.

\footnotetext{
${ }^{178}$ Hier folge ich Grüne (2009:169-170) und Sellars (1978:234f.). Dagegen Young (1988: 142-5).

179 Natürlich setzt die Assoziabilität der empirischen Vorstellungen sowie deren subjektive Einheit durch das Assoziationsgesetz einen objektiven Grund, die Affilität, voraus, die wiederum in der Einheit der Apperzeption begründet wird (A122).
} 
Es bleibt jedoch noch eine Unklarheit: Kant macht die überraschende Bemerkung, dass die reproduktive Synthesis „zu den transzendentalen Handlungen des Germüts“ gehört und als „,das transzendentale Vermögen der Einbildungskraft“ bezeichnet werden kann (A102). ${ }^{180}$ Der Grund für den transzendentalen Charakter der reproduktiven Synthesis erklärt Kant in A101-102:

Wenn wir nun darthun können, daß selbst unsere reinste Anschauungen a priori keine Erkenntniß verschaffen, außer so fern sie eine solche Verbindung des Mannigfaltigen enthalten, die eine durchgängige Synthesis der Reproduction möglich macht, so ist diese Synthesis der Einbildungskraft auch vor aller Erfahrung auf Principien a priori gegründet, und man muß eine reine transscendentale Synthesis derselben annehmen, die selbst der Möglichkeit aller Erfahrung (als welche die Reproducibilität der Erscheinungen nothwendig voraussetzt) zum Grunde liegt (A101)

In diesem Abschnitt spricht Kant von einer reinen transzendentalen Synthesis „derselben“, d.h der Einbildungskraft, worauf die Synthesis der Reproduktion „gegründet“ ist. Diese transzendentale Synthesis, die die Synthesis der Reproduktion „möglich macht“, ist eine Synthesis der „reinst[en] Anschauung“. Unmittelbar danach erläutert Kant anhand einiger Beispiele diese reine transzendentale Synthesis. Dabei handelt es sich konkret um die reine Synthesis der Einbildungskraft, die das reine Mannigfaltige verbindet und dafür sorgt, dass das reine Mannigfaltige zu einer reinen Anschauung verbunden wird:

Nun ist offenbar, daß, wenn ich eine Linie in Gedanken ziehe, oder die Zeit von einem Mittag zum andern denken, oder auch nur eine gewisse Zahl mir vorstellen will, ich erstlich nothwendig eine dieser mannigfaltigen Vorstellungen nach der andern in Gedanken fassen müsse. Würde ich aber die vorhergehende (die erste Theile der Linie, die vorhergehende Theile der Zeit oder die nach einander vorgestellte Einheiten) immer aus den Gedanken verlieren und sie nicht reproduciren, indem ich zu den folgenden fortgehe, so würde niemals eine ganze Vorstellung und keiner aller vorgenannten Gedanken, ja gar nicht einmal die reinsten und ersten Grundvorstellungen von Raum und Zeit entspringen können. Die Synthesis der Apprehension ist also mit der Synthesis der Reproduction unzertrennlich verbunden. (A102, kursiv von mir)

180 Vgl. z.B. Zammito (2015:467). 
Einige Kommentatoren vertreten die Meinung, dass es hier um den reinen Gebrauch der reproduktiven Einbildungskraft geht, ${ }^{181}$ die auf das reine Mannigfaltige wirkt und in reinen Anschauungen a priori resultiert. Der Annahme einer reinen transzendentalen Synthesis der Reproduktion fehlt es meines Erachtens an jeglicher Textunterstützung. Kant bezeichnet nämlich in vielen Stellen die Reproduktion bzw. reproduktive Synthesis tout court als empirisch: „es kann aber nur die productive Synthesis der Einbildungskraft a priori stattfinden; denn die reproductive beruht auf Bedingungen der Erfahrung.“(A121, siehe auch A118, Anth 7:167). In der B-Deduktion bezeichnet Kant die Reproduktion als ,lediglich empirischen Gesetzen, nämlich denen der Assoziation [...] unterworfen“ (B152, meine Hervorhebung). Wenn die reproduktive Synthesis gemäß empirischer Regel ausgeübt werden muss, kann sie nicht eine „reine transzendentale"Handlung sein, die a priori verfahren soll. Sie wird in der B-Deduktion gar von der Transzendentalphilosophie ausgeschlossen und als Thema der Psychologie klassifiziert (B152).

Rein begrifflich ist die reine Synthesis der Reproduktion übrigens schwer nachzuvollziehen. Angenommen, dass es eine reine reproduktive Synthesis gibt, dann muss ihre Funktion wohl darin liegen, das reine Mannigfaltige wie (Zeit-)punkte oder die Zeitlänge, die die reine Entsprechung des gerade apprehendierten empirischen Mannigfaltige sind, im Bewusstsein zu behalten, damit sie in einer reinen Anschauung zusammengenommen werden können. Da die Einheit dafür eher schematisierte Kategorien als das empirische Assoziationsgesetz ist, kann man hier gar nicht von der Reproduktion sprechen, deren Regel allein das Assoziationsgesetz ist. Außerdem ist die reine reproduktive Synthesis hinsichtlich ihrer Funktion identisch mit der figürlichen bzw. reinen produktiven Synthesis. ${ }^{182}$ Vermutlich gerade aus diesen Gründen schreibt

\footnotetext{
181 z.B. Grüne (2009:166), Zammito (2015:462), Allison (2015:185, 215)

182 Später wird dies demonstriert.
} 
Kant in den Nachträgen zur ersten Auflage der KrV sowie in der B-Deduktion die in A102 skizzierte Funktion der vermeintlichen reinen transzendentalen Synthesis der Reproduktion eindeutig der figürlichen, sowie der reinen produktiven Synthesis der Einbildungskraft zu. Dabei verwendet er ausgerechnet das Beispiel des gedanklichen Linienziehens und bezeichnet es als Handlung der figürlichen Synthesis, die er explizit als die transzendentale Synthesis der Einbildungskraft bezeichnet (B151).

Im Folgenden werde ich die oben genannte Unklarheit in A102f. außer Acht lassen und davon ausgehen, dass es keine reine oder transzendentale Synthesis der Reproduktion gibt.

\subsubsection{Synthesis der Rekognition im Begriff}

Die zweite Funktion der Synthesis der Apprehension besteht darin, die Sinneseindrücke in einer Anschauung zusammenzufassen. Da die Apprehension immer sukzessiv geschieht, müssen die nicht präsentisch vorliegenden Vorstellungen im Bewusstsein behalten werden. Dafür ist die Reproduktion verantwortlich. Damit ist die Reproduktion eine Bedingung der Apprehension. Für das Gelingen der Reproduktion selber sind weiterum zwei Bedingungen zu erfüllen. Beide werden durch die Synthesis der Rekognition im Begriff erfüllt. Erstens muss das Subjekt sich dessen bewusst sein, dass das sukzessive Apprehendierte, d.h. sowohl das momentan, als auch das zuvor Durchlaufene, inhaltlich zu einer Einheit gehört, oder anders gesagt, denselben Gegenstand repräsentiert:

Ohne Bewußtsein, daß das, was wir denken, eben dasselbe sei, was wir einen Augenblick zuvor dachten, würde alle Reproduction in der Reihe der Vorstellungen vergeblich sein. Denn es wäre eine neue Vorstellung im jetzigen Zustande, die zu dem Actus, wodurch sie nach und nach hat erzeugt werden sollen, gar nicht gehörte, und 
das Mannigfaltige derselben würde immer kein Ganzes ausmachen, weil es der Einheit ermangelte, die ihm nur das Bewußtsein verschaffen kann (A103). ${ }^{183}$

Dieses Bewusstsein der Einheit des Apprehendierten und Reproduzierten ist eine notwendige Bedingung der Einheit der Anschauung. ${ }^{184}$ Es ist nichts anders als ein empirischer Begriff, der der in der Apprehension zu konstruierenden Anschauung korrespondiert: „dieses eine Bewußtsein [d.i., nach dem Kontext, ein empirischer Begriff] ist es, was das Mannigfaltige, nach und nach Angeschaute und dann auch Reproducirte in eine Vorstellung vereinigt." (A103; siehe auch A79/B104, A106). ${ }^{185}$ Dieses vereinigende Bewusstsein nennt Kant auch einen „Actus“, d.h. einen synthetischen Akt (A103). Zweitens ist die Reproduktion kein „regellos[es]“ bzw.

${ }^{183}$ Die Kommentatoren sind sich nicht einig darüber, wie der erste Satz des Zitats genau zu interpretieren ist. Henrich zufolge will Kant damit meinen, dass man sich bewusst sein muss, dass das zuvor Wahrgenommene mit dem jetzt Reproduzierten qualitativ identisch ist (Henrich 1976:74f.). Andere Kommentatoren vertreten die hier vorgeschlagene Lesart (Carl 1992:163, Thöle 1991:223 Anm.6., Grüne 2009:175ff.). Wolff und Longuesnesse lassen beide Interpretationen zu (Wolff 1963:129; Longuenesse 1998:45f.). M.E. spricht Kants Bemerkung über den Begriff ein paar Zeilen nach diesem Zitat deutlich gegen die erste Lesart: „dieses eine Bewußtsein ist es, was das Mannigfaltige, nach und nach Angeschaute und dann auch Reproducirte in eine Vorstellung vereinigt." (A103; siehe auch A102). Wenn die Rekognition nur das Bewusstsein der Identität der Vorstellungen über die Zeit wäre, würden durch die Rekognition wahllos Vorstellungen reproduziert, da nicht irgendein beliebiges Mannigfaltige reproduziert und als über die Zeit hinweg im Gedächtnis identisch betrachtet wird, sondern nur dasjenige, was zu einer objektiven Einheit gehört. Das Bewusstsein der qualitativen Identität der Vorstellungen, die für die Reproduktion nötig ist, muss übrigens schon Teil der Reproduktion, nicht aber Teil der Rekognition sein, da auch das Tier, das zur Rekognition unfähig ist, zur Reproduktion durch Assoziation fähig ist. Für weitere Argumente gegen die erste Lesart siehe Grüne (2009:175f.).

${ }^{184}$ Dieses Bewusstsein der Einheit der durch die Zeit durchlaufenen empirischen Vorstellungen braucht nicht ein explizites Urteil der Form: „Diese Sinneseindrücke und jene, die ich gerade erlebt habe, gehören zusammem als eine Einheit“" zu sein, da auch Tiere oder Säuglinge ein solches Bewusstsein der Einheit haben können, das auf vergangene Erfahrung und Assoziation gegründet ist. Kant selbst betrachtet es nirgendwo als ein Urteil. Wie solches Bewusstsein zu charakterisieren ist, ist somit eine schwierige Frage. Für einen Versuch siehe Grüne (2009:177).

${ }^{185}$ Diesem Zitat zufolge sind Begriffe ein Bewusstsein, das komplexe empirische Vorstellungen vereinigt. Für ähnliche Interpretationen siehe Longuenesse (1998:46), Thöle (1991:225ff.), Grüne (2009:181f.). Dagegen siehe Carl (1992:164). 
unterschiedsloses Im-Bewusstsein-Behalten von miteinander in keinem Zusammenhang stehenden Sinneseindrücken, aus denen sich keine Anschauung ergeben kann, die auf einen Gegenstand bezogen ist (A120). Vielmehr müssen die Sinnesdaten, die zu verbinden sind, eine Einheit bilden. Sie müssen von anderen, nicht dazugehörigen Sinneseindrücken unterschieden werden, die bei der Reproduktion aussortiert werden. Die Reproduktion enthält deshalb auch einen Akt der Selektion aus den vorliegenden Sinnesdaten gemäß einer Regel. Dieser Verbindungsakt des Mannigfaltigen unter Begriffen ist gerade die Synthesis der Rekognition, die die dritte Komponente der drei Synthesis-Arten ausmacht.

Die empirischen Begriffe, die für die Zusammensetzung der empirischen Anschauung direkt als Regel dienen, sind empirische Begriffe, die durch Assoziation gewonnen werden. ${ }^{186}$ Allerdings sind in der Rekognition nicht nur empirische Begriffe am Werk, sondern auch, notwendigerweise, die Kategorien. Empirische Begriffe stellen nämlich nur einen „subjektiven und empirischen Grund“ für die Einheit der Anschauung dar. Im Gegensatz zu den empirischen Begriffen liefern die Kategorien die „formale Einheit“ der Anschauung und ihre „objecktive Gültigkeit“(A125). In welchem Sinne die Kategorien dies tun, ist eine kontroverse Frage, die im Umfang dieser Abhandlung nicht eingehend bearbeitet werden kann. Im Folgenden begenüge ich mich mit einer

186 Obwohl Kant den Assoziationsprozess nicht explizit als Grundlage der empirischen Begriffsbildung bezeichnet, ist dies aus A100-101 zu entnehmen (für eine ähnliche Darstellung siehe auch Haag 2007:224-5). Dort bemerkt Kant, dass die Erscheinungen selbst Regelmäßigkeit aufweisen, sodass „,in dem Mannigfaltigen ihrer Vorstellungen eine, gewissen Regeln gemäße Begleitung oder Folge stattfinde“. Das bedeutet mit Kants eigenem Beispiel, dass ein Ding, sagen wir der Zinnober, uns unter normalen Bedingungen immer rot, schwer und steinförmig erscheint. Infolgedessen verbindet die Assoziation solche Eigenschaften miteinander, aus denen mittels weiterer Verstandesleistungen ein empirischer Begriff des Zinnobers hervorgebracht werden kann. Natürlich handelt es sich bei der Einheit der Assoziation zwar um eine subjektive Einheit des Mannigfaltigen als eine objektive (A121), die Assoziation ist jedoch der Ausgangspunkt für die empirische Begriffsbildung und für diese insofern unentbehrlich. 
Skizze, wie die Intellektualität in Form der Kategorien die drei Synthesis der Einbildungskraft „durchdringt““.

Die empirische Anschauung, die durch die drei Synthesis konstruiert wird, enthält per definitionem einen Bezug auf einen Gegenstand (A109). Der Gegenstand der Erfahrung kann selbst keine Vorstellung sein, da er etwas ,außer der Vorstellungskraft“ und „davon unterschieden [...]“ ist (A104). Er kann auch nicht Ding an sich sein (A104, A109), denn dieses ist nicht sinnlich zu erkennen. Kant zufolge kann der Gegenstand der Erfahrung nichts anders als eine notwendige Verknüpfung der sinnlichen Vorstellungen sein, oder, mit Kants eigenen Worten, eine „notwendige Einheit“ des sinnlichen Mannigfaltigen. Diese ist nämlich ein Bewusstsein, dass das vorliegende und reproduzierte Mannigfaltige zu einer repräsentationalen Einheit gehört, in dem Sinne, dass dieses Mannigfaltige zusammen einen Gegenstand repräsentiert. Diese Einheit des Mannigfaltigen bewirkt mithin den Gegenstandsbezug der empirischen Anschauung. Kant zufolge ist sie sowie ihre Notwendigkeit in der Einheit der transzendentalen Apperzeption begründet (A106ff., 122ff.). Die Vorstellung des Gegenstands ist zudem die „formale“ Einheit des Bewußtseins, da die Zusammengehörigkeit des Mannigfaltigen bzw. der Sinneseindrücke allein aus deren Gehalt nicht herauszulesen ist und auch keine Eigenschaft dieses empirischen Gehalts, ${ }^{187}$ sondern vielmehr eine reine gedankliche Zutat darstellt, die durch eine synthetische Leistung herbeigeführt werden kann. ${ }^{188}$ Der Gegenstand wird in anderen Worten nicht angeschaut, sondern „gedacht“ (A104, 106). Im Gegensatz zu der subjektiven Einheit der empirischen

\footnotetext{
${ }^{187}$ Man sieht z.B. ein Auto vor einem Haus geparkt. Dabei hat man eine komplexe Vorstellung. Der Verstand synthetisiert einen Teil davon zum Bild eines Autos und den restlichen zum Bild eines Hauses. Die Sinneseindrücke und die Gestalten selbst erzwingen diese Auffassung jedoch nicht. Allein anhand ihrer könnte sich durchaus eine Vorstellung einer Fassade mit einem Auto-förmigen Teil ergeben. Ähnliches siehe auch Grüne (2009: 179).

188 „Es ist leicht einzusehen, daß dieser Gegenstand nur als etwas überhaupt $=\mathrm{X}$ müsse gedacht werden“ (A104). Siehe auch A111.
} 
Vorstellungen durch Assoziation, die bloß zufällig ist und der Objektivität mangelt (A111), ist die objektive Einheit des Mannigfaltigen des Sinnes, unter der ein Gegenstand überhaupt gedacht wird, eine notwendige Einheit (A106). Die Notwendigkeit der Einheit wird von dem Gegenstandsbezug der Anschauung vorausgesetzt (A121). ${ }^{189}$ Die Notwendigkeit der objektiven Einheit bedeutet, dass die sinnlichen Vorstellungen, die unter der Einheit stehen, nicht „beliebig“ (A104) bzw. nicht „anders apprehendiert“ (A121) werden können als es die Regel der Einheit vorschreibt. Was genau bedeutet diese Notwendigkeit im Fall der notwendigen Einheit, unter die der Begriff des Gegenstands das Mannigfaltige unterwirft? Der Gegenstand überhaupt wird durch die reinen Verstandesbegriffe, d.h. die Kategorien, gedacht (A111, 124-5). Die Kategorien machen nichts anders als den Begriffsinhalt des Gegenstands überhaupt aus. Eine Verknüpfung des Mannigfaltigen des Sinnes repräsentiert für uns genau dann einen Gegenstand, wenn es notwendigerweise hinsichtlich aller vier Gruppen der Kategorien bestimmbar ist: der Gegenstand muss eine extensive Größe - d.h. raumzeitliche Ausdehnung und Gestalt - haben; seine Wahrnehmung weist Qualitäten von bestimmter intensiven Größe oder „Grad“ auf; er ist entweder eine beharrliche Substanz oder eine der wechselnden Bestimmungen einer solchen Substanz und steht zudem in bestimmten kausalen Relationen mit seiner Umgebung; sein Dasein ist entweder möglich, wirklich oder gar notwendig. Der Begriff des Gegenstands ist insofern eine notwendige Einheit, als das Mannigfaltige, durch das ein Gegenstand erkannt wird, notwendigerweise alle oben genannten Aspekte aufweisen muss. Die Kategorien liefern die formale Einheit für die Rekognition und

${ }^{189}$ Grob gesagt, ist ein Gegenstand der Erfahrung etwas, was „dawider ist, daß unsere Erkenntnisse nicht aufs Geratewohl, oder beliebig [sind]“"(A104). D.h. er ist dadurch charakterisiert, dass er unter Gesetzen steht. Kant scheint zu meinen, dass der Gegenstand der Anschauung nur dann unter Gesetzen steht, wenn die Vorstellungen dessselben in einer notwendigen Einheit stehen (A104f.). Grüne gibt eine Erklärung dafür, warum nur Vorstellungen, die eine notwendige Einheit bilden, Gegenstandsbezug besitzen (Grüne 2009:188). 
damit auch für die Reproduktion. Gemäß den Kategorien werden diejenigen sinnlichen Vorstellungen unter dem Apprehendierten im Bewußtsein behalten, die in einer kategorischen Einheit stehen und zusammen einen Gegenstand konstruieren. Das heißt, erst in der Synthesis der Rekognition werden die Verstandeshandlungen gemäß den Kategorien durchgeführt und die Bedingungen für die Einheit der Apperzeption erfüllt. Weil „die Einheit der Apperception in Beziehung auf die Synthesis der Einbildungskraft ... der Verstand [ist]“ (A119), ist die Synthesis der Rekognition das Stadium, in dem der Verstand auf der Konstruktion der Anschauung einwirkt.

\subsubsection{Einbildungskraft und Synthesis der Einbildungskraft}

In der A-Auflage der $K r V$ operiert Kant hinsichtlich der Erzeugung der empirischen Anschauung hauptsächlich mit den drei Schritten, Apprehension, Reproduktion und Rekognition. In der B-Auflage verwirft Kant diese Doktrin. Die Synthesis der Reproduktion spielt bei der tranzendentalen Deduktion keine Rolle mehr und der Begriff Rekognition wird nicht mehr verwendet. Im Gegensatz dazu werden andere Synthesisbegriffe verwendet. Dabei verbindet Kant interessanterweise eine Synthesisart, nämlich die transzendentale Synthesis der Einbildungskraft, direkt mit dem inneren Sinn und der Selbstaffektion, deren Doktrin er ebenfalls in der B-Auflage der $K r V$ intensiv ausgearbeitet hat. Ziel dieses Abschnitts ist zu untersuchen, ob es sich bei den verschiedenen Arten der Synthesis um verschiedene kognitive Akte handelt und was es bedeutet, dass die transzendentale Synthesis der Einbildungskraft den inneren Sinn affiziert. ${ }^{190}$ Als Erstes muss bemerkt werden, dass die Synthesis der

\footnotetext{
190 In diesem Abschnitt werden Kontroversen ausgeklammert, die für das hier verfolgte Ziel nicht relevant sind. Für eine ausführliche Darstellung des Synthesisvermögens siehe z.B. Hoppe (1983), Longuenesse (1998), Haag (2007), Grüne (2009), Olk (2016).
} 
Einbildungskraft keine Handlung des Subjekts an sich, sondern ein zeitlicher Prozess ist. $\mathrm{Zu}$ der transzendentalen Synthesis der Einbildungskraft bemerkt Kant in den Nachträgen zur Kritik reinen Vernunft (1. Auf.): „Die Synthesis geschieht in der Zeit“" (NTKrV 23:18, siehe auch B204). Als ein Vorgang in der Zeit kann die Synthesis der transzendentalen Einbildungskraft nicht die Handlung eines Dings an sich sein, sondern die Handlung des Gemüts, die ein Gegenstand des inneren Sinnes bzw. ein Ereignis der Erscheinungswelt sein soll. Das legitimiert die Fragestellung, welche und wieviele synthetische Handlungen auf welcher Art und Weise den inneren Sinn affizieren.

Die Einbildungskraft ist „ein Vermögen, einen Gegenstand auch ohne dessen Gegenwart in der Anschauung vorzustellen“(B151; siehe auch Anth 7:167). Sie ist von daher ein Vermögen, das direkt für die Erzeugung der anschaulichen Vorstellung des Gegenstands verantwortlich ist, ganz unabhängig davon, ob der Gegenstand den Sinnesorganen vorliegt oder nicht. ${ }^{191}$ In Kants Ausführung treten verschiedene Einteilungen der Synthesis (der Einbildungskraft) auf, die für unser Anliegen relevant sind:

1) reine/empirische Synthesis der Einbildungskraft;

2) produktive/reproduktive Synthesis der Einbildungskraft;

3) figürlich/intellektuelle Synthesis;

4) transzendentale Synthesis der Einbildungskraft. ${ }^{192}$

Im Folgenden werden zuerst die ersten drei Einteilungen dargestellt und dann in einen Zusammenhang mit der transzendentalen Synthesis der Einbildungskraft gebracht.

\footnotetext{
191 Auch in der Gegenwart des Gegenstands muss die Einbildungskraft ausgeübt werden, sonst würde man nur eine Menge von Eindrücken ohne jeglichen Zusammenhang wahrnehmen.

192 Es muss bemerkt werden, dass Kant oft „Synthesis der Einbildungskraft“ als Synonym von „Einbildungskraft“ verwendet, denn die Synthesis der Einbildungskraft ist „die bloße Wirkung der Einbildungskraft"، (A78/B103).
} 


\subsubsection{Einteilungen der Synthesis (der Einbildungskraft)}

1) Eine Synthesis ist die reine Synthesis der Einbildungskraft, „wenn das Mannigfaltige nicht empirisch, sondern a priori gegeben ist (wie das im Raum und der Zeit).“(A77/B103; siehe auch A78-9/B104). „Sie ist a priori möglich u. bringt nichts als Gestalten hervor“ (NTKrV 23:18). Sie ist „obgleich a priori ausgeübt, dennoch jederzeit sinnlich, weil sie das Mannigfaltige nur so verbindet, wie es in der Anschauung erscheint, z.B. die Gestalt eines Triangels.“(A124). Die Reinheit der reinen Synthesis der Einbildungskraft besteht zum einen in dem Mannigfaltigen, das sie verbindet: dieses ist das reine Mannigfaltige des Raum und der Zeit. ${ }^{193}$ Zum anderen ist sie rein, weil sie für die Erzeugung der reinen Anschauung direkt und mithin für die Erzeugung der empirischen Anschauung indirekt verantwortlich ist. ${ }^{194}$ Die

193 Nach Grüne (2015:2233) kann der Begriff der reinen Synthesis zum einen als eine Verbindung von a priori gegebenen sinnlichen Vorstellungen, zum anderen aber auch als „Verbindung von Vorstellungen, bei der Begriffe a priori als Synthesisregeln fungieren“ charakterisiert werden. Laut Kant sei die reine Synthesis „diejenige, welche auf einem Grunde der synthetischen Einheit a priori beruht“ (A78/B104) und die Kategorien als Synthesisregeln seien gerade ein solcher Grund. Gegen die erste Möglichkeit führt Grüne an, dass die offensichtlich reine Synthesis nach den Begriffen der Substanz, der Kausalität und der Wechselwirkung nicht in dem Vorliegen von reinen Anschauungen, sondern von empirischen Anschauungen resultiere. Denn nur bei empirischen Gegenständen, nicht aber bei den Gegenständen der reinen Anschauungen handle es sich um Substanzen, die in kausaler Wechselwirkung stehen. Grünes Interpretation ist jedoch in vieler Hinsicht nicht haltbar. Erstens ist die reine Synthesis in der von Grüne genannten ersten Lesart in der Tat die reine Synthesis der reinen Einbildungskraft, denn es gibt auch eine reine intellektuelle Synthesis, die nicht auf sinnlichem Mannigfaltigem operiert (z.B. die Zahl, siehe Br 10:556-7, 1788). Zweitens bestimmt die Synthesis nach den Kategorien der Relation direkt die Zeitrelation. Sie ist mithin im Gegensatz zu Grünes Meinung durchaus für die Vorstellung der Zeit als reine formale Anschauung verantwortlich (B160-1). Drittens ist zu bemerken, dass die von Grüne vorgeschlagenen zwei Lesarten sich auf Textbelege auf direkt benachbarten Seiten stützen (A77-9/B1034). Es ist absurd zu unterstellen, dass Kant innerhalb von nur zwei Seiten unterschiedliche Meinungen vertritt. Ich werde mich im folgenden Text deshalb Grünes Darstellung nicht anschließen.

194 Grüne (2015: 2234) und Haag (245-256) weisen auf die Unklarheiten hin, ob „es sich bei der Synthesis des ,Mannigfaltige[n] der Sinnlichkeit a priori“ (A76/B102) tatsächlich um eine Synthesis von a priori gegebenen Vorstellungen handelt, die von empirischen Vorstellungen unterschieden sind, oder 
empirische Synthesis der Einbildungskraft wird von Kant nur erwähnt, aber nie explizit charakterisiert. Sie ist im Gegensatz zur reinen Synthesis der Einbildungskraft diejenige Synthesis, die direkt auf den Sinnesdaten operiert und das empirische Mannigfaltige zur empirischen Anschauung verbindet. Die beiden oben genannten Synthesen sind nicht zwei unabhängige Akte, sondern jeweils der empirische und der reine Aspekt der Synthesis der Einbildungskraft selbst (A115).

2) In der B-Auflage der $\mathrm{KrV}$ wird nicht mehr eingehend über die Reproduktion gesprochen, stattdessen wird die Synthesis der Einbildungskraft als produktive und reproduktive Synthesis der Einbildungskraft klassifiziert und nur flüchtig erwähnt (B152; NTKrV 23:18). Die reproduktive Einbildungskraft in der B-Deduktion fällt funktional mit der Synthesis der Reproduktion in der A-Deduktion zusammen, die im vorigen Abschnitt dieses Kapitels schon behandelt wurde. Allerdings ist in der BDeduktion von dem reinen Gebrauch der Synthesis der Reproduktion nicht mehr die Rede. Die Synthesis der reproduktiven Einbildungskraft ist nämlich „lediglich empirischen Gesetzen, nämlich denen der Association“(B152), die „nur subjective Gültigkeit hat“" (B141). Sie kann „daher zur Erklärung der Möglichkeit der Erkenntniß a priori nichts [beitragen] und [gehört] um deswillen nicht in die Transscendentalphilosophie, sondern in die Psychologie.“ (B152).

Im Gegensatz dazu ist die produktive Synthesis der Einbildungskraft ein Vermögen der „ursprünglichen“ anschaulichen Darstellung des Gegenstands (Anth 7:167). Sie verbindet Sinneseindrücke und ihr Produkt ist die bildliche Darstellung eines empirischen Gegenstands: ,[D]as Bild ist ein Product des empirischen Vermögens der

ob die Vorstellungen, die synthetisiert werden, auch im Falle reiner Synthesis empirische Vorstellungen sind, wobei man bei der Synthesis dieser Vorstellungen von allen empirischen Merkmalen abstrahiert.“ Ich glaube, es gibt in diesem Kapitel genügend Belege dafür, dass die Synthesis des reinen Mannigfaltigen des Sinnes a priori bloß der reine Aspekt der faktischen vollgezogenen Synthesis des empirischen Mannigfaltigen ist. 
productiven Einbildungskraft.“ (B181). In den Nachträgen zur KrV (1781) teilt Kant die produktive Synthesis in drei verschiedenen Hinsichten ein (NTKrV 23:18):

Die productive Einbildungskraft ist 1. empirisch in der apprehension 2. rein aber sinnlich in Ansehung eines Gegenstandes der reinen sinnlichen Anschauung. 3. transscendental in Ansehung eines Gegenstandes überhaupt die erstere setzt die zweyte voraus u. die zweyte die dritte.

Entgegen der Auffassung Zammittos kann die produktive Synthesis also nicht nur rein, sondern auch empirisch sein. ${ }^{195}$ Die empirische produktive Einbildungskraft wird von Kant nur an manchen Stellen skizzenhaft erwähnt. Sie hat zweierlei Funktionen. Bei der ersteren Funktion geht es um die Imagination oder Einbildung im alltäglichen Sinne:

Der empirische Gebrauch der einbildungskraft beruht auf der synthesis der Apprehension der empirischen Anschauung die denn auch reproducirt werden kan oder nach deren analogie eine andere gemacht werden kan. Im letztern Fall ist es die productive Einbildungskraft (NTKrV 23:18).

Die empirische produktive Synthesis operiert wie die reproduktive zwar auch auf einem empirischen Mannigfaltigen, das im Gedächtnis erhalten ist, aber ihre Funktion besteht im Gegensatz zu der Letzteren darin, im Gemüt ein anschauliches Bild eines empirischen Gegenstands mittels des „Stoffes“ aus anderen, vorher wahrgenommenen Elementen neu zu konstruieren (Anth 7:168). Sie erzeugt somit eine Anschauung eines neuen Gegenstands ohne dessen Gegenwart. Kant spricht deswegen von „nach deren Analogie“, weil die empirische produktive Einbildungskraft Sinneseindrücke nicht „schöpferisch“, d.h. aus nichts, schaffen kann (Anth 7:167-9), sondern nur diejenigen aus der vergangenen Erfahrung wiederverwendet. Beispiele der Anwendung dieser Einbildungskraft sind z.B. Halluzinationen durch Rauschmittel oder Alkohol (Anth 7:169ff.) oder die Imagination, die man hat, wenn man Begriffen, denen eine entsprechende Anschauung aus bestimmten Gründen fehlt, ein „selbstgeschaffenes Bild“ unterlegt (z.B. der Begriff eines Heldens im Mythos, oder der Begriff eines

195 Z.B. Zammito (2015:466). Dagegen siehe auch A123. 
räumlichen Gegenstands für einen Blinden, siehe Anth 7:172-3). Solche Fälle sind irrelevant für die epistemische Fragestellung der transzendentalen Deduktion, denn dort geht es primär um die transzendentale Begründung von synthetischen Erkenntnissen a priori.

Die empirische produktive Einbildungskraft ist in der Tat nur dann relevant, wenn es um ihre zweite Funktion geht. Diese besteht darin, nicht ohne die Gegenwart des Gegenstands, sondern in dessen Gegenwart ein Bild des Gegenstands aus den gegebenen Sinnesdaten zu konstruieren. ${ }^{196}$ In diesem Sinn bemerkt Kant, dass sie die reproduktive Synthesis ermöglicht - und vermutlich deswegen „ursprünglich ist (Anth 7:167) - , denn „haben wir es nicht vorher in Vorstellung durch die synthesis zu Stande gemacht so können wir diese auch nicht mit andern in unserm folgenden Zustande verbinden“ (NTKrV 23:18). Die hinter dieser Bemerkung liegende Idee ist meines Erachtens die folgende: aus einem vorgelegten Mannigfaltigen zum Zeitpunkt $\mathrm{t}_{1}$ greift die empirische produktive Einbildungskraft gemäß den Kategorien einige Elemente heraus und bildet daraus ein momentanes Bild des Gegenstands. ${ }^{197}$ Erst unter dieser Voraussetzung kann die reproduktive Einbildungskraft dieses Bild, das $\mathrm{zu}_{2} \mathrm{t}_{2}$ nicht mehr vorhanden ist, $\mathrm{zu} \mathrm{t}_{2} \mathrm{im}$ Gedächtnis behalten und mit dem momentanen Bild desselben

196 „Einbildungskraft ist das Vermögen, einen Gegenstand auch ohne dessen Gegenwart in der Anschauung vorzustellen.“ (B151, Kursivierung durch mich). Daraus lässt sich schliessen, dass die Einbildungskaft auch dann operiert, wenn der Gegenstand präsent ist.

${ }^{197}$ Diese Konzeption der produktiven Einbildungskraft hat Kant nicht explizit dargestellt. Aus dem Satz „Die productive Einbildungskraft ist 1. empirisch in der apprehension“ (NTKrV 23:28, siehe oben), aus der gerade zitierten Passage aus NTKrV 23:18, sowie aus der Definition der produktiven Einbildungskraft (Anth 7:167, siehe oben) ist jedoch ersichtlich, dass Kant sie vertreten hat. 
Gegenstands zu t $t_{2}$ verbinden. Aus verschiedenen Bildern zu verschiedenen Zeitpunkten wird dann eine multidimensionale Anschauung des Gegenstands gebildet. ${ }^{198}$

Die Aufgabe der reinen produktiven Einbildungskraft besteht darin, „reine Raumesund Zeitanschauungen“ (Anth 7:167) oder genauer gesagt, eine reine raumzeitliche Gestalt eines Gegenstands zu konstruieren (NTKrV 23:18). Zu seinem Produkt zählen zum Beispiel die Vorstellung der Bewegung als Beschreibung eines Raumes überhaupt (B155 Anm.), „Gestalten, welche [in dem Raum überhaupt] verzeichnet [werden] “ (B196, siehe auch B205) oder Vorstellung der Zeitgröße (B211). So dargestellt, fällt die reine produktive Einbildungskraft mit der reinen Synthesis der Einbildungskraft zusammen. Beide sind dieser Darstellung zufolge für die Konstruktion reiner Raumund Zeitanschauungen verantwortlich.

An dieser Stelle sind die Verhältnisse der ersten beiden Einteilungen der Synthesis der Einbildungskraft zu klären. Es steht außer Frage, dass die empirische Synthesis der Einbildungskraft die reproduktive und die empirische produktive Synthesis der Einbildungskraft einschließt. Da es, wie schon argumentiert, keine reine reproduktive Einbildungskraft gibt, fällt die reine Synthesis der Einbildungskraft hinsichtlich ihrer Funktion mit der reinen produktiven Einbildungskraft zusammen.

3) Die dritte Einteilung der Einbildungskraft ist die in die figürliche und die intellektuelle Synthesis der Einbildungskraft. Die erstere ist die „Synthesis des Mannigfaltigen der sinnlichen Anschauung, die a priori möglich und nothwendig ist" (B151). Sie verbindet das reine Mannigfaltige (z.B. Punkte, Linien, Zeitpunkte oder Zeitlängen) zur reinen formalen Anschauung eines raumzeitlichen Gegenstandes, weswegen sie „figürlich“ genannt wird. Vom Begriff her ist sie identisch mit der reinen

\footnotetext{
198 Übrigens muss bemerkt werden, dass die Zusammensetzung dieser Anschauungen der Definition zufolge ebenfalls ein Produkt der empirischen Synthesis der produktiven Einbildungskraft ist, denn die Anschauung des Gegenstands wird daraus erstmalig erzeugt.
} 
produktiven Synthesis der Einbildungskraft, denn beide resultieren in der reinen Anschaung eines raumzeitlichen Gegenstands. Sie wird deswegen figürlich genannt, weil das, was sie verbindet, reine raumzeitliche Bilder sind. Die figürliche Synthesis bringt das rein sinnliche Mannigfaltige unter „die ursprünglich-synthetische Einheit der Apperception“, die in den Kategorien gedacht wird (B151). Deswegen wird sie auch als transzendentale Synthesis der Einbildungskraft bezeichnet (B151)

Im Gegensatz dazu ist die intellektuelle Synthesis diejenige Synthesis, „welche in Ansehung des Mannigfaltigen einer Anschauung überhaupt in der bloßen Kategorie gedacht würde und Verstandesverbindung (synthesis intellectualis) heißt“" (B151). ${ }^{199}$ Der Ausdruck ,in Ansehung des Mannigfaltigen einer Anschauung überhaupt“ könnte den Eindruck suggerieren, dass es sich hierbei um eine Art der Synthesis der Einbildungskraft handelt. Mithin kann die synthesis intellectualis nur die Synthesis der Schemata sein, da unschematisierte Kategorien als reine Gedankenformen nichts Sinnliches enthalten und somit mit dem Sinnlichen ungleichartig sind, während die Synthesis der Schemata, die eine Art transzendentaler Zeitbestimmung sind, auf dem reinen Zeitlichen und mithin auf dem Mannigfaltigen einer Anschauung operieren kann. Die zitierte Stelle ist jedoch irreführend, denn die synthesis intellectualis ist eine Synthesis „ohne alle Einbildungskraft, bloß durch den Verstand“ (B152), während die Schemata ein Produkt der Einbildungskraft sind (B179). Der Ausdruck ,in Ansehung des Mannigfaltigen einer Anschauung überhaupt" sollte man eher dahingehend interpretieren, dass es sich dabei um eine transzendentale Betrachtungsweise handelt, die als solche von allen spezifischen sinnlichen Details des Mannigfaltigen abstrahiert

199 In einem Brief bezeichnet Kant die „Zahlwissenschaft“ als „,eine reine intellectuelle Synthesis“ (Brief an Schultz, 1788, Br 10:557). Dies widerspricht jedoch nicht nur dieser Definition der intellektuellen Synthesis in B151, sondern auch der Klassifizierung der Zahl in dem Schematismus-Kapitel. Denn dort bezeichet Kant die Zahl als Schema der Kategorien der Größe (B182). Mithin ist zumindest in der $\mathrm{KrV}$ die Vorstellung der Zahl nicht rein intellektuell wie Kant im Brief an Schultz behauptet, denn das Schema ist Produkt der transzendentalen Synthesis der Einbildungskraft, die nicht rein intellektuell ist. 
(A343/B401). Das Wort „überhaupt“ im Ausdruck „,in Ansehung des Mannigfaltigen einer Anschauung überhaupt“ bedeutet m.E. an dieser Stelle ,ganz allgemein, abstrahiert von Beziehungen auf spezifischen sinnlichen Details“ (A343/B401). Das, was die synthesis intellectualis verbindet, sind eher reine Begriffe als reines anschauliches Mannigfaltiges. Daher ist sie eine Synthesis, die in den „bloßen Kategorie[n]“, d.h. in den unschematisierten Kategorien, die bloße „Gedankenformen“ sind (B150), gedacht wird. Bei dem „Mannigfaltige[n] einer Anschauung überhaupt" handelt es sich nicht um sinnliches Mannigfaltiges, sondern um begriffliches Mannigfaltiges oder mannigfaltige Verstandesbegriffe apriori, die einer Anschauung entsprechen und mithin empirische Gültigkeit haben können. ${ }^{200}$

Es stellt sich nun die Frage, ob eine solche Synthesis des Verstandes ein selbstständiger Akt des Gemüts ist, der ein rein begriffliches Mannigfaltiges überhaupt verbindet. Es ist sehr fragwürdig, ob es in der Bildung der Anschauung eine solche Synthesis gibt, die als ein separater Vorgang neben der figürlichen Synthesis vollzogen wird. Das Mannigfaltige einer Anschauung überhaupt bedeutet, die sinnlichen Vorstellungen ganz allgemein zu betrachten, ohne ihre individuellen Eigenschaften oder spezifische Inhalte zu berücksichtigen. Die reinen Verstandesbegriffe als Regel der intellektuellen Synthesis sind nämlich maßgebend für die Einheit des Mannigfaltigen der „Anschauung überhaupt, ob sie die unsrige oder irgendeine andere, doch sinnliche sei“ (B150). Es gibt kein Mannigfaltiges überhaupt als genuine Vorstellungen, die durch Verstandeshandlung organisiert werden müssen. Man kann wohl einwenden, dass die synthesis intellectualis wegen ihres intellektuellen Charakters verschiedene Begriffe verbindet, die unspezifisch auf empirische Vorstellungen bezogen sein können. Somit erweist sie sich als ein Urteil von abstraktem Gehalt. Die Verstandeshandlung gemäß der Kategorie der Kausalität verbindet z.B. den Begriff der Ursache mit dem

${ }^{200}$ Olk (2016: §3). 
Begriff der Wirkung. Diese beiden Begriffe beziehen sich nicht auf zwei empirische Entitäten und enthalten somit nichts Sinnliches. Es ist jedoch unhaltbar zu postulieren, dass solche Synthesis wirklich vollzogen wird. Es ist erstens redundant, dass ein abstraktes Urteil, das nicht auf Sinnesdaten operiert, parallel zur Synthesis der Einbildungskraft vollzogen wird. ${ }^{201}$ Zweitens ist es zwar a priori, aber nicht transzendental. Die intellektuelle und die figürliche Synthesis sind beide transzendental, da sie „die Möglichkeit anderer Erkenntniß a priori [be]gründen“(B151); im Gegensatz dazu kann ein rein intellektuelles Urteil ohne konkreten Bezug auf das Mannigfaltige der empirischen Anschauung diese transzendentale Rolle nicht spielen. Kant selbst macht dies deutlich:

Es giebt zwar eine transscendentale Synthesis aus lauter Begriffen, die wiederum allein dem Philosophen gelingt, die aber niemals mehr als ein Ding überhaupt betrifft, unter welchen Bedingungen dessen Wahrnehmung zur möglichen Erfahrung gehören könne. (A719/B747)

Da die hier erwähnte Synthesis „lauter Begriffe[]“ verbindet und sich auf ein „Ding überhaupt" bezieht, ist sie gerade intellektuelle Synthesis. Eine solche Synthesis kann jedoch allein ein „Philosoph[]“ bei philosophischer Reflexion über empirische Erkenntnisse vollziehen. Somit lässt sich schließen, dass in der Entstehung der Anschauung keine intellektuelle Synthesis neben der Synthesis der Einbildungskraft vollzogen wird.

Unter der intellektuellen Synthesis werden in der Tat die synthetischen Handlungen des Verstandes, die nach den Kategorien als Regeln auf Sinnesdaten operieren, von einer Abstraktionsstufe aus beschrieben, in der von den dadurch synthetisierten empirischen Vorstellungen gänzlich abstrahiert wird. Damit werden die Handlungen des Verstandes als reine synthetische Funktionen oder „bloße Gedankenformen“ (B150)

\footnotetext{
${ }^{201}$ Longuesse vertritt dagegen eine Position, der zufolge die intellektuelle Synthesis die Verbindung von Begriffen in Urteilen ist (Longuesse 1998:199-209).
} 
hervorgehoben. In diesem Sinne sagt Kant (fortan wird diese Behauptung als „Identitätsthese der Spontanität“):

Auf solche Weise wird bewiesen: daß die Synthesis der Apprehension, welche empirisch ist, der Synthesis der Apperception, welche intellectuell und gänzlich $a$ priori in der Kategorie enthalten ist, nothwendig gemäß sein müsse. Es ist eine und dieselbe Spontaneität, welche dort unter dem Namen der Einbildungskraft, hier des Verstandes, Verbindung in das Mannigfaltige der Anschauung hineinbringt. (B162 Anm.)

Dass die intellektuelle Synthesis die Handlung des Verstandes abgesehen von ihrem Bezug auf das sinnliche Mannigfaltige ist, zeigt sich ganz deutlich in folgenden Bemerkungen von Kant:

Nun ist das, was das Mannigfaltige der sinnlichen Anschauung verknüpft, Einbildungskraft, die vom Verstande der Einheit ihrer intellectuellen Synthesis und von der Sinnlichkeit der Mannigfaltigkeit der Apprehension nach abhängt. (B164, hervorgehoben durch mich.)

An dieser Stelle ist deutlich sichtbar, dass die Einbildungskraft die intellektuelle Synthesis ausübt, was Kants vorher zitierter Behauptung widerspricht, dass diese Synthesis nicht zur Einbildungskraft, sondern zum Verstand allein gehört (B152). ${ }^{202}$ In Übereinstimmung mit dem obigen Zitat charakterisiert Kant die „Synthesis überhaupt“ jedoch als „die bloße Wirkung der Einbildungskraft“ (B103). Diese Inkonsistenz kann nur dadurch erklärt werden, dass der Begriff der intellektuellen Synthesis den intellektuellen, begrifflichen Aspekt der Synthesis der Einbildungskraft bezeichnet, der allein Produkt des Verstands ist. Genauer gesagt sind die Kategorien dieser Beitrag des Verstandes, die als einheitsstiftende Regel für die Synthesis der Einbildungskraft fungieren und diese Synthesis intellektuell machen. Eine weitere Stelle bestätigt diese Vermutung:

\footnotetext{
${ }^{202}$ Ameriks z.B. identifiziert gar die Apperzeption und das Urteil, die beide zum Verstand gehören, mit der Synthesis (2006:55).
} 
Diese Apperception ist es nun, welche zu der reinen Einbildungskraft hinzukommen ти $\beta$, um ihre Function intellectuell zu machen. Denn an sich selbst ist die Synthesis der Einbildungskraft, obgleich a priori ausgeübt, dennoch jederzeit sinnlich, weil sie das Mannigfaltige nur so verbindet, wie es in der Anschauung erscheint, z.B. die Gestalt eines Triangels. Durch das Verhältniß des Mannigfaltigen aber zur Einheit der Apperception werden Begriffe, welche dem Verstande angehören, aber nur vermittelst der Einbildungskraft in Beziehung auf die sinnliche Anschauung, zu Stande kommen können. (A124, meine Hervorhebung)

Die reine produktive Einbildungskraft zeichnet die reine Raum- und Zeitanschauung ab, die aber bloß sinnlich bleibt. Ihre Funktion wird dadurch intellektuell, dass sie das Mannigfaltige in die Einheit der Apperzeption bringt, d.h. dass sie gemäß den Kategorien als Synthesisregel vollgezogen wird. Da die reine produktive Einbildungskraft der einheitsstiftenden Regel des Verstandes folgt, bleibt von ihrer Synthesis, wenn man diese unter Abstraktion von dem sinnlichen Manngifaltigen betrachtet, nichts als eine intellektuelle Synthesis beziehungsweise bloße Verstandesfunktionen übrig. In dem gesamten Vorgang der Erzeugung empirischer Anschauungen wird keine intellektuelle Synthesis separat ausgeübt. ${ }^{203}$ Vielmehr ist die

${ }^{203}$ Ein weiterer Beleg für diese Lesart ist z.B. „Die Synthesis oder Verbindung des Mannigfaltigen in denselben bezog sich bloß auf die Einheit der Apperception und war dadurch der Grund der Möglichkeit der Erkenntniß a priori, so fern sie auf dem Verstande beruht, und mithin nicht allein transscendental, sondern auch bloß rein intellectual“" (B150). Ich muss zugeben, dass manche Formulierung von Kant den Eindruck suggeriert, dass neben der Synthesis der Einbildungskraft, die die Anschauung konstruiert, auch eine intellektuelle Synthesis der Apperzeption separat ausgeübt wird: „Auf solche Weise wird bewiesen: daß die Synthesis der Apprehension, welche empirisch ist, der Synthesis der Apperception, welche intellectuell und gänzlich a priori in der Kategorie enthalten ist, nothwendig gemäß sein müsse“ (B162 Anm.). Bei der „Synthesis der Apperzeption“ in der Kategorie handelt es sich an dieser Stelle, sachlich betrachtet, um die Synthesis der Rekognition (A124f.). Später wird gezeigt, dass die Synthesis der Apprehension, der Reproduktion und der Rekognition nicht drei separate Synthesisarten, sondern ein und dieselbe Synthesis unter verschiedenen Gesichtspunkten sind. Die Synthesis der Apprehension und der Apperzeption sind ebenfalls als zwei Aspekte der Synthesis der Einbildungskraft tout court zu betrachten. 
intellektuelle Synthesis ein Aspekt ein und derselben Synthesis der Einbildungskraft, die für die Erzeugung der Anschauung verantwortlich ist. In diesem Sinne sagt Kant,

Die Einheit der Apperception in Beziehung auf die Synthesis der Einbildungskraft ist der Verstand und eben dieselbe Einheit beziehungsweise auf die transscendentale Synthesis der Einbildungskraft der reine Verstand. (A119)

\subsubsection{Synthesis der Einbildungskraft in der B-Deduktion}

An dieser Stelle ist eine Bemerkung zu den verschiedenen Bezeichnungen der Synthesis der Einbildungskraft notwendig. Wie wir gesehen haben, bezeichnen die Begriffe der reinen, der reinen produktiven und der figürlichen Synthesis der Einbildungskraft eigentlich dieselbe Synthesis der Einbildungskraft, nämlich diejenige, die reine Anschauungen konstruiert. Das heißt, funktional sind die drei äquivalent: Von ihnen wird eine rein raumzeitliche Gestalt hervorgebracht, die der empirischen Synthesis des Mannigfaltigen als „Rahmen“ dient. Wir haben auch gesehen, dass die drei Begriffspaare der Synthesis nicht jeweils zwei einander unabhängig vollzogene spontane Akte, sondern zwei Aspekte eines einzigen Synthesisakts darstellen, und zwar der Synthesis der Einbildungskraft tout court, aus der sich die empirische Anschauung ergibt. $^{204}$ Der Grund, warum Kant mit verschiedenen Begriffe der Synthesis der Einbildungskraft operiert, kann nur daran liegen, dass diese Begriffe jeweils einen speziellen Aspekt der Synthesis der Einbildungskraft herausgreifen, um ihn mit einem anderen Aspekt dieser Synthesis zu vergleichen. Aus diesem Grund verwendet Kant die drei Dichotomien, um die Synthesis dieser Einbildungskraft in drei verschiedenen

\footnotetext{
${ }^{204}$ Der Fall der figürlichen und der intellektuellen Synthesis ist übrigens, wie schon bemerkt, besonders. Sie sind beide a priori und mithin rein. Obwohl die intellektuelle Synthesis streng genommen keine Synthesis der Einbildungkraft ist, bilden die beiden den transzendentalen Gebrauch der Synthesis der Einbildungskraft, aus der sich die reinen Anschauungen ergeben.
} 
Hinblicken zu beleuchte ${ }^{205}$ : die erste Dichotomie teilt sie hinsichtlich des epistemischen Charakters des von ihr bearbeiteten Mannigfaltigen ein; die zweite macht darauf aufmerksam, dass die Synthesis der Einbildungskraft aus einem konstruierenden Akt und einer zur Konstruktion nötigen psychologischen Hilfskomponente besteht, d.h. teilt sie hinsichtlich der Teilakte der Einbildungskraft, die nur begrifflich aber nicht real von einander zu trennen sind, ein; die dritte schließlich teilt die transzendentale Synthesis der Einbildungskraft wiederum hinsichtlich der Vermögen, die an dieser Synthesis beteiligt sind, ein. Sie besteht demnach aus einer sinnlichen Komponente, die für die Konstruktion der Anschauung verantwortlich ist, und einer begrifflichen Komponente, die allein dem Verstand zu verdanken ist. In einem Wort, sind die drei Dichotomien auf nichts anderes als verschiedene Darstellungsweisen eines einzigen Synthesisakts zurückzuführen, nämlich der Synthesis der Einbildungskraft tout court, die die Bausteine der Erfahrung - die empirischen Anschauungen - erzeugt.

Im letzten Kapitel werden drei Synthesisarten, die in den Anfangsabschnitten der ADeduktion erwähnt werden, behandelt, nämlich Apprehension, Reproduktion und Rekognition. Sie sollen ebenfalls denselben synthetischen Akt, der am Ende in einer empirischen Anschauung resultiert, nach verschiedenen Hinsichten darstellen, denn sie sind in der Tat nicht drei unterschiedliche synthetische Akte, sondern eine „dreifache[] Synthesis“ (A97): die Synthesis der Apprehension enthält zwei wesentlichen Teilhandlungen dieser dreifachen Synthesis, das Durchlaufen und die Zusammensetzung verschiedener Sinnesdaten zu einer empirischen Anschauung; die Reproduktion ist derjenige Teilakt dieser dreifachen Synthesis, der nicht mehr präsente

\footnotetext{
205 Bei diesen Dichotomien handelt es sich um die reine/empirische Synthesis der Einbildungskraft, die produktive/reproduktive Synthesis der Einbildungskraft und die figürliche/intellektuelle Synthesis der Einbildungskraft. Streng genommen bilden die figürliche und die intellektuelle Synthesis nur eine Dichotomie der transzendentalen Synthesis der Einbildungskraft. Der Einfachheit halber verwende ich trotzdem den Ausdurck „Dichotomie“.
} 
Sinnesdaten zwecks der Zusammensetzung wieder vergegenwärtigt; der Begriff der Rekognition schließlich verweist auf das Auf-den-Begriff-Bringen der Sinnesdaten, das Voraussetzung der Zusammensetzung ist. Die dreifache Synthesis ist hinsichtlich ihres Produkts nichts anders als die Synthesis der Einbildungkraft; sie wird lediglich am Anfang der A-Deduktion in funktionaler Hinsicht in drei Teilakte zerlegt.

An dieser Stelle ist eine exegetische Bemerkerung vonnöten. Interessanterweise spielen die letzten beiden Aspekte der Synthesis in der B-Deduktion keine Rolle mehr. In den wenigen Stellen, in denen Kant die Synthesis der Apprehension erwähnt, charakterisiert er sie entweder als Akt, der das Mannigfaltige in das Gemüt aufnimmt (B235), oder als Prozess, in dem die empirische Anschauung zusammengesetzt wird (B160ff., 219). Der Begriff der Apprehension bezeichnet folglich in der B-Deduktion den gesamten Prozess der Erzeugung der empirischen Anschauung. Kant thematisiert im Unterschied zu der A-Deduktion die Reproduktion nicht mehr, weil sie als Teil des empirischen Gebrauchs der Apprehension transzendental nicht relevant ist. Das impliziert aber nicht, dass Kant die Existenz der Reproduktion völlig ablehnt. Die Rekognition in empirischen Begriffen spielt ebenfalls keine Rolle in der B-Deduktion. Der Begriff der Rekognition in den reinen Verstandesbegriffen wird zwar nicht mehr erwähnt, sie wird hinsichtlich ihrer argumentativen Rolle von der transzendentalen Synthesis der Einbildungskraft abgelöst und ausgearbeitet, die in der A-Deduktion nur flüchtig erwähnt wird (A118f.) und argumentativ nicht viel Gewicht trägt. In der B-Deduktion wird die transzendentale Synthesis der Einbildungskraft im Vergleich mit der Synthesis der Rekognition in der A-Deduktion direkt mit dem inneren Sinn und der Selbstaffektion in Zusammenhang gebracht. 


\subsubsection{Transzendentale Synthesis der Einbildungskraft}

Die transzendentale Synthesis der Einbildungskraft ist transzendental, weil sie nicht nur „,selbst a priori vorgeh[t]““, sondern auch die Möglichkeit „,anderer Erkenntniß a priori [be]gründe[t]“" (B151, siehe auch A124). Sie ist ein Vermögen, das eine vermittelnde Rolle zwischen Sinnlichkeit und Verstand spielt: „Vermittelst [ihrer] bringen wir das Mannigfaltige der Anschauung einerseits, und mit der Bedingung der nothwendigen Einheit der reinen Apperception andererseits in Verbindung." (A124, siehe auch B152). Die transzendentale Synthesis der Einbildungskraft verkörpert folglich zwei unterschiedliche Eigenschaften und muss sowohl Sinnlichkeit als auch Spontanität aufweisen (B151-2).

Wie ist aber die transzendentale Synthesis der Einbildungskraft, die diese beiden Charaktere aufweist, konkret aufzufassen? Was sind die von ihr bearbeiteten Materialien und Produkte? Die transzendentale Synthesis der Einbildungskraft ist in ihrer sinnlichen Seite identisch mit der „rein[en] Einbildungskraft“ (A124), der reinen produktiven Einbildungskraft (A123) oder der „figürlich[en] Synthesis“(B151), die die reinen Raum- und Zeitanschauungen konstruiert. ${ }^{206}$ Diese sind gerade formale Anschauungen, gemäß deren das Mannigfaltige der empirischen Anschauung apprehendiert wird (B160-1). Die transzendentale Synthesis ist folglich verantwortlich für die reinen sinnlichen Bedingungen der empirischen Anschauung. Sie operiert auf dem Mannigfaltigen der reinen Anschauung und verbindet es gemäß der Einheit der Kategorien. Deswegen ist sie ,die erste Anwendung [des Verstandes] [...] auf Gegenstände der uns möglichen Anschauung“ (B152). Diese anschaungskonstruierende Funktion allein macht jedoch nur ihre sinnliche Seite aus, denn Kant betrachtet diese Funktion als alleinige Leistung der Sinnlichkeit: die Einbildungskraft ist ,,an sich selbst [...] obgleich a priori ausgeübt, dennoch jederzeit

\footnotetext{
206 Wie oben schon gezeigt, beziehen sich die drei Bezeichnungen auf denselben Akt.
} 
sinnlich, weil sie das Mannigfaltige nur so verbindet, wie es in der Anschauung erscheint, z.B. die Gestalt eines Triangels“ (A124). Diese reine, figürliche Einbildungskraft wird erst dann zur transzendentalen Synthesis, wenn die spontane, intellektuelle Synthesis des Verstandes sie lenkt und mithin intellektualisiert: „Diese Apperception ist es nun, welche zu der reinen Einbildungskraft hinzukommen muß, um ihre Function intellectuell zu machen.“(A124). In ihrer intellektuellen Seite hat die transzendentale Einbildungskraft „,die nothwendige Einheit in der Synthesis [des reinen Mannigfaltigen] zu ihrer Absicht“"(A123). Sie dient dazu, Einheit in dem reinen Mannigfaltigen zu bewirken, so dass die Einheit der Apperzeption hergestellt wird, die die notwendige Vorraussetzung des Bewusstseins der Vorstellungen sein soll. Sie geht „bloß auf die ursprünglich-synthetische Einheit der Apperception, d.i. diese transscendentale Einheit [...] welche in den Kategorien gedacht wird“" (B151, siehe auch NTKrV 23:18). Diese Bemerkungen sind hoch abstrakt und schwer nachzuvollziehen, denn schließlich ist es unklar, was es genau bedeuten soll, dass die Handlungen, die die reinen Anschauungen konstruieren, auf die transzendentale Einheit nach den Kategorien abzielen. Die intellektuelle Seite der transzendentalen Synthesis der Einbildungskraft trägt zu der Vorstellung, die durch die Synthesis der Einbildungskraft an sich erzeugt wird, keinen sinnlichen Gehalt bei, denn die Synthesis der Einbildungskraft ist dafür schon hinreichend, dass das Mannigfaltige der reinen Anschauung ,so verb[u]nde[n] [wird], wie es in der Anschauung erscheint“" (A124). Vielmehr wird durch die intellektuelle Funktion der transzendentalen Synthesis der Einbildungskraft „ein Begriff vom Gegenstande überhaupt [..] nach den verschiedenen Arten der transscendentalen Synthesis [gedacht].“ (NTKrV 23:18). ${ }^{207}$ Durch die intellektuelle Funktion dieser Synthesis wird das Mannigfaltige der reinen Anschauung in einer Einheit vereinigt bzw. in einem repräsentationalen

\footnotetext{
${ }^{207}$ Diese Synthesisarten sind verschieden, weil die Regel für deren Einheit, die Kategorien, verschieden sind.
} 
Zusammenhang gebracht. Anders gesagt, werden bestimmte raumzeitliche Vorstellungen so gedacht, dass ihr repräsentationaler Gehalt in dem Sinne eine Einheit bildet, als sie zusammen einen Gegenstand repräsentieren. Die Beziehung des reinen Mannigfaltigen auf einen Gegenstand kann die Sinnlichkeit als Rezeptivität allein nicht herstellen, da dafür eine spontane Denkhandlung nötig ist, die nur durch die intellektuelle Funktion der Synthesis der Einbildungskraft ausgeführt werden kann. Durch diese Denkhandlung wird die Gegenständlichkeit in dem Mannigfaltigen folgendermaßen hineingedacht ${ }^{208}$ : der „Gegenstand[e] überhaupt“ ist eine räumliche Gestalt, die für eine bestimmte Zeitdauer existiert; jeder der raumzeitlichen Punkte, die ihn konstitutieren, ist von einer Realität bestimmtes Grades erfüllt, die durch eine bestimmte Sinnesqualität von entsprechendem Grad repräsentiert wird; der repräsentationale Gegenstand einer empirischen Vorstellung kann eine Substanz oder ein Akzidenz (Zustand) einer Substanz sein; wenn er Zustand einer Substanz ist, steht er mit anderen Ereignissen in kausalem Zusammenhang; sein bestimmter Zustand könnte zu irgendeiner Zeit, zu einer bestimmten Zeit oder zu allen Zeiten vorkommen. All diese Elemente oder Aspekte, die die Gegenständlichkeit ausmachen - die raumzeitlichen Größen, die Sinnesqualitäten, der Umstand, ob es sich um eine Substanz oder nur eine von deren Bestimmungen handelt, usw., sind nicht direkt aus den Sinnesdaten wahrzunehmen, sondern verdanken sich der gedanklichen Zutat der intellektuellen Seite der transzendentalen Einbildungskraft. Die Synthesis dieser Einbildungskraft operiert auf dem reinen sinnlichen Mannigfaltigen, indem sie das Gleichartige unter diesem zu einer raumzeitlichen Größe zusammennimmt, die Zeitoder Raumpunkte als durch Sinnesqualitäten verschiedenen Grades erfüllt vorstellt, das

\footnotetext{
${ }^{208}$ In einem wichtigen Kapitel der B-Deduktion (\$26) behauptet Kant, dass die Einheit der Synthesis der Einbildungskraft apriori bzw. der Bezug auf einen Gegenstand „mit (nicht in) diesen Anschauungen zugleich gegeben“ sei (B161). Die Gegenständlichkeit ist offenbar eine gedankliche Zutat zu den sinnlichen Materialien.
} 
Beharrliche als Substanz und das Wechselhafte als deren Bestimmungen interpretiert, die Zustände des Gegenstands als in kausaler Beziehung mit anderen stehend denkt, usw. Die Regel für alle solchen Denkhandlungen, die Einheit in dem Mannigfaltigen stiften, sind die Kategorien, die ,nichts anders als Vorstellungen von Etwas (Erscheinung) überhaupt so fern es durch transsc. Synthesis der Einbildungskraft vorgestellt wird“ (NTKrV 23:19). Die transzendentale Synthesis bringt das Mannigfaltige unter die Kategorien und mithin in die notwendige Einheit der Apperzeption. Sie ermöglicht die Zusammensetzung des Mannigfaltigen - d.h. die Synthesis der Apprehension. In dieser Hinsicht hat sie die gleiche Funktion, wie die Synthesis der „Rekognition in (reinen) Begriffen“. Da sie als figürliche Synthesis für die Erzeugung der formalen Anschauung verantwortlich und maßgebend für die empirische Synthesis der Einbildungskraft ist (B160), ist sie mit der reinen Synthesis der Apprehension funktional identisch. ${ }^{209}$

Zusammengefasst lässt sich folgendes bemerken: wenn man sich auf die Terminologie der B-Auflage der $K r V$ beschränkt, dann ist für die Entstehung der empirischen Anschauung nur eine Synthesis verantwortlich: die Synthesis der Apprehension. In ihrem emprischen Aspekt fasst diese Synthesis das empirische Mannigfaltige einer empirischen Anschauung zusammen, während sie in ihrem transzendentalen oder formalen Aspekt die Kategorien auf die reine Sinnlichkeit anwendet. ${ }^{210}$

\footnotetext{
${ }^{209}$ Hier wird unter der Apprehension die gesamte Handlung der Konstruktion der Anschauung, nicht bloß das Durchlaufen des Mannifaltigen, verstanden.

${ }^{210}$ Valaris (2008:8) behauptet, dass die transzendentale Synthesis der Einbildungskraft und die Synthesis der Apprehension jeweils den formalen oder transzendentalen Aspekt und den materialen oder emprischen Aspekt der figürlichen Synthesis entsprechen. Es bestehen jedoch nur kleine terminologische Unterschiede zwischen seiner Lesart und der hier vorgeschlagenen. Beide sind der Auffassung, dass in der Entstehung der empirischen Anschauung nur eine synthetische Aktivität im Spiel ist.
} 


\subsubsection{Dreifache Synthesis, transzendentale Synthese der}

\section{Einbildungskraft und der innere Sinn}

Nun stellen sich die folgenden Fragen: was für Implikationen hat die bisherige Ausführung für die Auslegung der Doktrin, dass die Synthesis der Apprehension den inneren Sinn affiziert? (Anth 7:134, Refl 18:614). Kants Darstellung suggeriert oft den Eindruck, dass die drei Synthesisarten nacheinander vollzogen und unabhängig voneinander ausgeübt werden. In der Tat bezeichnet Kant die drei Synthesisarten explizit als „dreifach[e] Syntheses“ (A97). Das deutet daraufhin, dass es dabei nicht um drei unterschiedliche synthetische Akte geht. Vielmehr sind sie drei Aspekte desselben synthetischen Akts. Wie oben gezeigt, ist nämlich die Apprehension mit der Reproduktion „unzertrennlich verbunden“ (A102). Ohne die Rekognition würde wiederum ,alle Reproduktion in der Reihe der Vorstellungen vergeblich sein“ (A103). Genauer gesagt sind die Reproduktion und die Rekognition die notwendigen Bestandteile des zweiten Schritts der Apprehension, nämlich der Zusammensetzung des Mannigfaltigen in einer Anschauung. Die Apprehension kann somit als eine Bezeichnung für die Gesamthandlung der Erzeugung der empirischen Anschauung betrachtet werden, die als Teilaspekte die Reproduktion und Rekognition einschließt. ${ }^{211}$ Die Apprehension und Reproduktion als anschaungskonstruierender Akt der Einbildungskraft und die Rekognition als begriffliche Leistung des Verstandes werden in einem Zug ausgeübt:

Es ist eine und dieselbe Spontaneität, welche dort unter dem Namen der Einbildungskraft, hier des Verstandes, Verbindung in das Mannigfaltige der Anschauung hineinbringt. (B162 Anm.)

Die Behauptung, dass die drei Akte in einem Zug vollzogen werden hat auch eine ontologische Implikation. Kant macht diese in den Nachträgen zur $K r V 1781$ explizit:

211 Paton (1951 Bd.1: 362), Grüne (2009: 184). 
„die Synthesis geschieht in der Zeit“" (NTKrV 23:18; B204). Somit impliziert die obige Behauptung, dass die drei Akte insofern eine „dreifache Synthesis“ darstellen, als sie gleichzeitig ausgeübt werden. Diese anscheinend triviale Konklusion wird uns später helfen, die Selbstaffektion besser zu verstehen.

Die obige Implikation impliziert aber nicht, dass die Apprehension und Reproduktion ohne Rekognition gänzlich unmöglich sind. Eine Apprehension im schwächeren Sinn, aus der sich keine empirische Anschauung mit Gegenstandsbezug ergibt, ist durchaus ohne Rekognition möglich. Wie Kant im Brief an Herz (1789) andeutet, ist ein rudimentärer Geist ohne Apperzeption und Verstand dazu fähig, Daten der Sinne nach „einem empirischen Gesetze der Association“ zu verbinden. ${ }^{212}$ Die sich daraus ergebene Vorstellung enthält weder einen Gegenstandsbezug, da der primitive Geist zu keiner Synthesis nach Kategorien fähig ist, noch ermöglicht sie das empirische Bewusstsein des eigenen mentalen Zustands, da für den inneren Sinn die reine Apperzeption notwendig ist (A122). Vielmehr ist das Endprodukt dieser verkürzten Apprehension eine assoziative Verbindung von empirischen Vorstellungen, die nur eine subjektive Einheit aufweisen. In einem Brief an Alexander Fürst von Beloselsky (Br 11:345, 1792) erwähnt Kant übrigens, dass auch Tiere, die über keine Apperzeption sowie Verstandesvermögen verfügen, zur apprehensio bruta (d.h. einer bloßen Apprehension ohne Verstandesleistung) fähig sind:

Zuerst die Eintheilung des Vorstellungsvermögens in die der bloßen Auffassung der Vorstellungen apprehensio bruta ohne Bewustseyn, ist lediglich für das Vieh und die

\footnotetext{
${ }^{212}$ Siehe auch Anth 7:197, in der Kant dem Tier die mechanische Reproduktionsfähigkeit zuschreibt. Eine solche Fähigkeit setzt keine Verstandesleistung voraus (Anth 7:197) und kann daher nicht als Synthesis betrachtet werden. Es gibt jedoch Stellen, denen zufolge die Assoziation dennoch Verstandesleistung voraussetzt: „Es liegt [...] der Assoziation die reine Synthesis der Einbildungskraft, [...], a priori zum Grund.“(A116-7). Angesichts der Aussagen in Anthropologie sollte diese Bemerkung so verstanden werden, dass sie speziell auf der Assoziation eines Erkenntnissubjekts wie dem Menschen beschränkt ist. Vgl. Zammito (2015:467).
} 
sphaere der apperception, d.i. der Begriffe, die letztere macht die sphaere des Verstandes überhaupt $\left(\mathrm{Br}\right.$ 11:345) ${ }^{213}$

Die Thiere haben auch apprehensiones, aber nicht apperceptiones; mithin können sie ihre Vorstellungen nicht allgemein machen. (Refl 15:166, siehe auch Refl 15:958)

Folglich sind die Apprehension und die Reproduktion nicht nur begrifflich nicht notwendig mit der Rekognition verbunden, sondern auch in der Wirklichkeit ohne Rekognition möglich. ${ }^{214}$ Die Assoziation kann dabei dazu dienen, verschiedene Sinneseindrücke in eine subjektive Einheit zu bringen. Undenkbar ist lediglich, dass die Apprehension allein oder die Apprehension mit der Reproduktion ohne Rekognition eine empirische Anschauung mit Gegenstandsbezug generiert. Die Apprehension und die Reproduktion ohne Rekognition sind keine ,zweifache“ Synthesis, weil sie keine richtigen spontanen regelfolgenden Akte sind.

Wie schon ausgeführt, deutet Kant auffälligerweise daraufhin, dass sich dieser primitive Geist im obigen Szenario der einzelnen Sinnesdaten bewusst sein kann (siehe Log 9:65, 1800 und den Brief an Herz 1789). Aus all dem eben Gesagten lässt sich schließen, dass das Bewusstsein der Anschauung mit Gegenstandsbezug sowie das Bewusstsein des eigenen Zustands erst durch die Beteiligung der Synthesis der Rekognition möglich sind. ${ }^{215}$ Aber ein Bewusstsein einzelner Sinnesdaten, die zusammen kein ganzes Bild eines Gegenstands bilden und in keinem raumzeitlichen

${ }^{213}$ Zwar spricht Kant von „apperceptio bruto ohne Bewustseyn“, aber in dem oben zitierten Brief an Herz sowie einer Stelle in Logik (9:65) schreibt Kant explizit von Tierbewusstsein. Das Bewusstsein im Ausdruck „apperceptio bruto ohne Bewustseyn“ muss im starken Sinn, i.e. als apperzeptives Bewusstsein, verstanden werden, wie es bei Kant üblicherweise der Fall ist.

${ }^{214}$ Natürlich nicht für erwachsene Menschen im normalen Zustand als Erkenntnissubjekt. Vgl. Grüne (2009:184)

215 Neuere Nonkonzeptualisten unter den Kant-Kommentatoren vertreten die Ansicht, dass die Einbildungskraft ohne Mitwirkung des Verstands Vorstellung zu Anschauungen verbinden kann (Grüne 2009:173). Im Rahmen dieser Abhandlung werde ich nicht auf die KonzeptualismusNonkonzeptualismus-Kontroverse eingehen. Mir scheint es, dass die Textevidenz dafür spricht, dass ohne Verstandesleistung keine Anschauung mit Gegenstandsbezug möglich ist. 
Zusammenhang intergriert werden, kann schon ein Wesen haben, das nur zur bloßen Apprehension und der primitiven, mechanischen Reproduktion fähig ist. ${ }^{216}$ Das heißt, empirisches Bewusstsein einzelner Sinnesdaten ohne Gegenstandsbezug ist bewusstseinstheoretisch nicht notwendigerweise mit der Rekognition verbunden. Im §3.1. habe ich die Apprehension oder genauer das Durchlaufen des Mannigfaltigen als den Prozess der Aufnahme des Mannigfaltigen in das apperzeptive Bewusstsein bezeichnet. Der obigen Analyse entsprechend muss diese These nunmehr modifiziert werden: Die Apprehension des nicht-apperzeptiven Wesens, d.h. die Apprehension des empirischen Mannigfaltigen ohne Einwirkung der Synthesis gemäß den Kategorien ermöglicht ein phänomenales Bewusstsein des Mannigfaltigen als Bewusstsein einzelner Eindrücke ohne Gegenstandsbezug, während die Apprehension des Menschen, d.h. die Apprehension des empirischen Mannigfaltigen unter Einwirkung der Synthesis gemäß den Kategorien das begrifflich strukturierte phänomenale Bewusstsein eines Mannigfaltigen als Vorstellung eines Gegenstands ermöglicht. Die Apprehension des nicht-apperzeptiven Wesens ist gerade die empirische Apprehension per se. Daher kann man sagen, dass die empirische Apprehension dasjenige Vermögen ist, das für das phänomenale Bewusstsein überhaupt verantwortlich ist.

Zugegebenerweise gibt es einige Stellen, die dafür sprechen, dass ein empirisches Bewusstsein ohne die Einheit der Apperzeption und die damit verbundene Rekognition unmöglich ist. So behauptet Kant anscheinend, in solchem Fall

würde eine Menge Wahrnehmungen und auch wohl eine ganze Sinnlichkeit möglich sein, in welcher viel empirisches Bewußtsein in meinem Gemüth anzutreffen wäre, aber getrennt und ohne daß es zu einem Bewußtsein meiner selbst gehörte, welches aber unmöglich ist. Denn nur dadurch, daß ich alle Wahrnehmungen zu einem

\footnotetext{
${ }^{216}$ Das menschliche Gemüt kann die einzelnen Sinnesdaten erleben, aber nur insofern, als diese einen Gegenstandsbezug enthalten. Das heißt, sie sind stets Teil der repräsentationalen Vehikel einer Repräsentation eines Gegenstands in Raum und Zeit.
} 
Bewußtsein (der ursprünglichen Apperception) zähle, kann ich bei allen Wahrnehmungen sagen: daß ich mir ihrer bewußt sei“"(A122, kursiv von mir).

Zu dem „unmöglich[en]“ Szenario des Ausfallens der Apperzeption bemerkt Kant, dass man in solchem Fall nur ,gedankenlose Anschauung, aber niemals Erkenntnis“ hat, die also „für uns so viel als gar nichts [ist] “(A111), oder „ein blindes Spiel der Vorstellungen“ „ohne Objekt”, das „weniger, als ein Traum [ist].“(A112) Kant scheint beides als nicht real $\mathrm{zu}$ bezeichnen. Der Hintergrund der Thematisierung des „unmöglichen“ Szenarios ist jedoch das empirische Bewusstsein des Menschens in einem normalen mentalen Zustand, der das Thema der $K r V$ ist. Kant will ledigich sagen, dass das begrifflich strukturierte empirische Bewusstsein unter den Bedingungen dieses Szenarios für den Menschen als Erkenntnissubjekt nicht möglich ist. Es ist zwar möglich, dass es bei dem Menschen pathologische oder anormale Fälle gibt, die diesem Szenario ähneln. ${ }^{217}$ In einem solchen Szenario gibt es aber kein Erkenntnissubjekt (B134). Zudem wird aus dem letzten Satz des Zitats, der den vorletzten Satz begründet, deutlich, dass das, was auf Grund fehlender Apperzeption unmöglich ist, der innere Sinn mit Selbstbezug ist, nicht aber das empirische Bewusstsein schlechthin. Man muss ferner beachten, dass die Ausführungen über das „unmögliche“ Szenario des Ausfallens der Apperzeption ausschließlich in der A-Auflage der $K r V$ vorzufinden sind, während Kants Aussagen zum Tierbewusstsein sowie zum nicht-apperzeptiven Bewusstsein eher in den Schriften nach 1787 zu finden sind. Bei den Letzteren könnte es sich also um eine reifere Meinung Kants handeln.

Aus der obigen Analyse lässt sich schließen, dass das strukturierte empirische Bewusstsein durch den inneren Sinn bzw. die Selbstaffektion wesentlich mit der Rekognition verbunden ist. Der innere Sinn wird, anders gesagt, nicht durch den Anteil

\footnotetext{
${ }^{217}$ Siehe z.B. Hoppe (1982) über die erstere Möglichkeit. Einen anormalen Fall stellt z.B. das Erlebnis dar, das man hat, wenn man halb wach ist. Dabei kann man seine eigenen Gedanken gar nicht fassen und nimmt nicht einmal die Umgebung wahr.
} 
der ersten beiden Aktivitäten in der dreifachen Synthesis der Einbildungskraft affiziert, sondern durch den Akt der letzten, der Rekognition, die durch den Verstand als das Vermögen des Begriffs und des Urteils ausgeführt wird. Dieser Schluss kann durch eine weitere Überlegung unterstützt werden. Nach Kant wird der innere Sinn durch den eigenen spontanen kognitiven Akt affiziert und setzt damit die transzendentale Apperzeption voraus. Das Tier, das zu einem solchem Akt und der Apperzeption nicht fähig ist, hat, wie schon erwähnt, auch keinen inneren Sinn. Die Apprehension und Reproduktion stellen unabhängig von der Rekognition an sich keine Synthesis im eigentlichen Sinn dar, d.h. sind keine spontane kognitive Akte. Die Apprehension besteht nämlich aus den zwei Teilakten der Aufnahme und der Zusammensetzung der Sinneseindrücke. Den ersten Teilakt teilt man mit dem Tier, von daher ist er wesentlich rezeptiv und sinnlich. Die Zusammensetzung setzt Reproduktion voraus, die per definitionem allein auf Assoziation angewiesen ist. Assoziation ist auf einen bloß durch Gewohnheit etablierten psychologischen Mechanismus angewiesen und folglich kein spontanes Regelfolgen. Sie kann an sich nicht als Verstandesakt betrachtet werden (Anth 7:197), folglich können weder die Reproduktion noch die daraus folgende Zusammensetzung als spontane Akte bzw. Synthesis betrachtet werden. ${ }^{218}$ Aus diesem Grund wird der innere Sinn streng genommen erst durch die genuine Synthesis der Rekognition affiziert. ${ }^{219}$

\footnotetext{
${ }^{218}$ Kant bezeichnet die Reproduktion und die nachfolgende Zusammensetzung als Synthesis, weil sie im menschlichen Verstand eng mit der Synthesis der Rekognition verbunden sind und zusammen mit dieser eine „dreifach[e]“ Synthesis bilden.

${ }^{219}$ Zugegebenerweise gibt es vereinzelt Stellen, die anscheinend das Gegenteil belegen: „Wenn aber die Seele sich selbst nur Erscheinung ist, mithin ihre empirische Anschauung nur die sinnliche Form der Art ist, wie ihr eigen Subject durch die Apprehension des Manigfaltigen einer Gegebenen Anschauung afficirt wird“" (Refl 18:615; siehe auch B68, FM 20:270). Solche Stellen sind aber eher harmlos, da in ihnen der Begriff Apprehension offensichlich als Bezeichnung für die gesamte Handlung der dreifachen Synthesis fungiert.
} 
Am Ende dieses Abschnitts möchte ich noch eine Bemerkung über das Verhältnis zwischen der Apprehension und der transzendentalen Synthesis der Einbildungskraft machen. Die Funktion der Letzteren besteht darin, das Mannifaltige der reinen Anschauung in die objektive Einheit der Kategorien zu bringen. Sie ist für die Erzeugung der formalen Anschauung von Raum und Zeit maßgebend. Weil die empirische Synthesis der Apprehension auf sinnliche Materialien einwirkt und deren formale Bedingung Raum und Zeit ist, muss mit dieser Synthesis auch die formale Einheit von Raum und Zeit hergestellt werden (B160-1). Daher muss die empirische Synthesis der Apprehension gemäß der transzendenale Synthesis der Einbildungskraft ausgeübt werden (B164; A108). Beide werden in einem Zug ausgeführt. ${ }^{220}$

\subsubsection{Transzendentale Synthesis der Einbildungskraft, innerer Sinn und das phänomenale Bewusstsein}

Nun stellt sich die Frage, welche Position die transzendentale Synthesis der Einbildungskraft in der theoretischen Konstellation der Doktrin der Synthesen der Einbildungskraft in der B-Deduktion einnimmt. Wie gesagt, ist sie einerseits die reine produktive Synthesis bzw. figürliche Synthesis, die ,an sich selbst [...] jederzeit

\footnotetext{
${ }^{220}$ Wie schon ausgeführt, besteht die transzendentale Synthesis aus zwei Aspekten - der produktiven Synthesis, die die reine Anschauung konstruiert, und der begrifflichen, intellektuellen Synthesis gemäß den Kategorien. Die Erstere als reine Synthesis der Einbildungskraft macht mit der empirischen Synthesis der Apprehension zwei Aspekte der Einbildungskraft aus. Sie ist von ihrer Funktion her identisch mit der reinen Synthesis der Apprehension, die Kant nur einmal erwähnt und auf die er jedoch nicht weiter eingeht (A99-100). Die Letztere bezeichnet Kant als ein und dieselbe Spontanität wie die Synthesis der Apprehension (B162 Anm.). Carl und Dyck setzen die reine Synthesis der Apprehension mit der transzendentalen Synthesis der Einbildungskraft gleich (Carl 1991:155; Dyck 2006:51 Anm.23), was meiner Meinung nach nicht ganz präzise ist.
} 
sinnlich“(A124) ist. Anderseits wird sie ,intellektuell“ gemacht, weil sie „die erste Anwendung [des Verstandes] [...] auf Gegenstände der uns möglichen Anschauung ist" (B152). In ihr werden die Kategorien auf die Form der Anschauung angewendet, insofern wird bei ihrem Vollzug auch die intellektuelle Synthesis als ihre „Gedankenformen“ gleichzeitig vollzogen. Die transzendentale Synthesis der Einbildungskraft ist nichts anders als derjenige Akt der figürlichen Einbildungskraft, der gemäß den reinen Gedankenformen, den Kategorien, vollzogen wird (siehe z.B. A118). Erinnert man sich an die obige Darstellung der intellektuellen Synthesis und der Identitätsthese der Spontanität (B162 Anm.), dann lässt sich schließen, dass die transzendentale Synthesis sich als Verbindung der „beide[n] äußerste[n] Enden, nämlich Sinnlichkeit und Verstand“"(A124) und somit als Verbindung der figürlichen und der intellektuellen Synthesis erweist. Diese Analyse kann neues Licht auf Kants Behauptung werfen, dass die transzendentale Synthesis den inneren Sinn affiziert. Wenn die reine produktive Synthesis bzw. figürliche Synthesis ,an sich [...] jederzeit sinnlich“ (A124, siehe auch B151-2) ist, dann gehört sie streng genommen nicht zum spontanen Verstandesakt, geschweige denn zum Verstand. Folglich kann sie nicht den inneren Sinn affizieren, da dies nur eine spontane Handlung des Subjekts vermag. Interessanterweise bezeichnet Kant unter den vielen Synthesisarten der Einbildungskraft nur die transzendentale Synthesis als denjenigen Akt, der den inneren Sinn affiziert. Der Grund dafür kann vermutlich nur darin liegen, dass sie im Vergleich zu den anderen anschauungskonstruierenden Akten den spontanen Akt des Verstandes enthält. Diese Überlegung stimmt mit dem Ergebnis der Analyse in §3.2.1.3. überein, dass es die Synthesis der Rekognition ist, die den inneren Sinn affiziert bzw. das empirische Bewusstsein generiert. Der Begriff der Synthesis der Rekognition ist gerade diejenige Komponente der dreifachen Synthesis, die zur spontanen Leistung des Verstandes gehört. 
Ein weiterer Schluß aus der obigen Analyse der Synthesis der Einbildungskraft ist, dass die Selbstaffektion in normalen Fällen entgegen der reflexiven Lesart kein Reflexionsakt sein kann. Der Akt, der den inneren Sinn affiziert, also die transzendentale Synthesis der Einbildungskraft, ist die apriorische spontane Komponente des Akts, der den Gegenstandsbezug in der empirischen Anschauung herstellt. Das heißt, der innere Sinn bzw. die Selbstaffektion findet in dem Prozess statt, in dem man seine Aufmerksamkeit eher auf den Gegenstand als auf den eigenen Zustand oder Akt selbst richtet.

Nachdem wir die transzendentale Synthesis der Einbildungskraft als den den inneren Sinn affizierenden Akt ermittelt haben, könnte man an dieser Stelle auf einen möglichen Einwand stoßen. Wie schon gezeigt, gehören nicht nur die empirischen Anschauungen der äußeren Gegenstände, sondern auch die bewusste subjektive Empfindung, der bewusste Willen, die bewusste Begierde zu den Vorstellungen des inneren Sinnes. Wenn der innere Sinn durch die transzendentale Synthesis der Einbildungskraft affiziert wird, derer Funktion vor allem darin besteht, die äußeren Sinnesdaten zur empirischen Anschauung des Gegenstands zu verbinden, dann könnte dies die Frage aufwerfen, was an nicht-repräsentationalen Gemütszuständen wie der subjektiven Empfindung, der Begierde und dem Willen - sofern sie ohne einen begleitenden Urteilsakt auftreten den inneren Sinn affiziert. ${ }^{221}$ Die Antwort ist wie folgt: Derartige Vorstellungen haben eine qualitative Dimension und stellen somit ein phänomenales Erlebnis dar. Wir nehmen solche Vorstellungen derart wahr, dass notwendigerweise die kategorische Leistung der transzendentalen Synthesis der Einbildungskraft involviert ist: sie sind faktische mentale Ereignisse mit bestimmter phänomenaler Qualität und bestimmter zeitlichen Dauer, die uns unter Umständen zu Handlungen veranlassen können. All dies bedeutet, dass die transzendentale Synthesis der Einbildungskraft derjenige Akt ist, der

${ }^{221}$ Die Fälle mit einem begleitenden Denkakt und Urteil werden später behandelt. 
den inneren Sinn zum Bewusstsein unseren Vorstellungen von den nichtrepräsentationalen Gemütszuständen affizieren muss. ${ }^{222}$

\subsection{Innerer Sinn, innere Erfahrung und Aufmerksamkeit}

Kant unterscheidet offensichtlich zwischen den Wahrnehmungen des inneren Sinns und der inneren Erfahrung. Erstere liefern unbestimmte Wahrnehmungen (B154), während Letztere die auf dieser Wahrnehmung, „gegründet[e] empirisch[e] Erkentnis seiner selbst“" (Anth 7:397) ist:

Die Warnehmung (empirische Anschauung mit Bewußtseyn) könne nur Erscheinung des inneren Sinnes genannt werden. Damit sie aber innere Erfahrung werde muß das Gesetz bekannt sein welches die Form der Verbindung in einem Bewußtseyn des Objects bestimmt (Anth 7:399)

Analog zu der Unterscheidung des äußeren Sinnes und der äußeren Erfahrung ist das Produkt des inneren Sinnes nur dasjenige rohe sinnliche Material, das noch nicht durch begriffliche Leistungen synthetisiert wurde, während die innere Erfahrung kategorial bestimmte empirische Erkenntnisse der inneren Ereignisse als innere Gegenstände liefert:

${ }^{222}$ Dyck (2006:46ff.) verweist dagegen auf eine Stelle in B68-9 und behauptet, dass die Selbstaffektion notwendigerweise mit der Apprehension und damit auch der äußeren Wahrnehmung verbunden ist: „Wenn das Vermögen sich bewußt zu werden das, was im Gemüthe liegt, aufsuchen (apprehendiren) soll, so muß es dasselbe afficiren“. Das, was apprehendiert werden kann, könnten durchaus die phänomenalen Qualtitäten der sujektiven Empfindung, der Begierde usw. sein. Dieses gehört nämlich zu dem, was ,,im Gemüthe liegt“. 
[...] wie vermittelst der innern Erfahrung des Daseins meiner Seele in der Zeit bewußt, die ich auch nur als einen Gegenstand des innern Sinnes durch Erscheinungen, die einen innern Zustand ausmachen, erkennen kann [...] (Prol. 4:336) ${ }^{223}$

Der Unterschied zwischen den Wahrnehmungen des inneren Sinns und der inneren Erfahrung liegt sozusagen darin, ob die Sinnesmaterialien begrifflich und insbesonders kategorial bestimmt werden (siehe auch BXL und besonders B154) und ob ein Gegenstandsbezug vorliegt. Analog zu dem Fall des äußeren Sinnes besteht diese kategoriale Bestimmung in der Zeitbestimmung: Der innere Sinn liefert eine empirische Anschauung der inneren Zustände, die diese Zustände zwar in der Zeit vorstellt, aber nicht als Gegenstand vorstellt bzw. noch nicht hinsichtlich ihrer zeitlichen Ordnung bestimmt. Durch die Anwendung der transzendentalen Synthesis der Einbildungskraft wird diese empirische Anschauung zeitlich bestimmt (B154, B276). Dies lässt sich durch folgende Textstellen bestätigen:

Erkenntniß unserer Selbst ist die Bestimmung unseres Daseyns in der Zeit und soll dies geschehen, so muß ich meinen innern Sinn afficiren (Refl 18:611)

Allein ich bin mir meines Daseins in der Zeit (folglich auch der Bestimmbarkeit desselben in dieser) durch innere Erfahrung bewußt, und dieses ist mehr, als bloß mich meiner Vorstellung bewußt $\mathrm{zu}$ sein, doch aber einerlei mit dem empirischen Bewußtsein meines Daseins [...]. (BXXXIX - BXL)

Im Licht des Interpretationsmodells, das in den letzten Kapiteln vorgeschlagen worden ist, lässt sich der Unterschied des inneren Sinnes und der inneren Erfahrung weiter wie folgt präzisieren: die bloß durch den inneren Sinn erzeugten Vorstellungen sind die subjektive Sukzession der Wahrnehmungen, während das empirische Bewusstsein der inneren Zustände, in dem die objektiven Zeitverhältnisse dieser Zustände bestimmt sind, zu der inneren Erfahrung gehört.

223 „Erfahrung [ist] aber [] das empirische Erkentnis [] wodurch er zugleich als ein solcher gedacht wird. Also ist Erfahrung die Handlung (der Vorstellungskraft) wodurch Erscheinungen unter den Begriff von einem Gegenstande derselben gebracht“ (Anth7:398). 
Diese Unterscheidung hat auch eine wichtige interpretative Konsequenz: Das berühmte Beispiel der Aufmerksamkeitslenkung auf den Akt des Ziehens einer Linie, das für unser Verständnis der Selbstaffektion enorm wichtig ist, enthält mehr als eine bloße durch den inneren Sinn erzeugte empirische Vorstellung des inneren Zustands. Ein Akt der Richtung der Aufmerksamkeit wird nämlich auf die Synthesis des äußeren Mannigfaltigen angewendet. Die auf den eigenen Akt gerichtete Aufmerksamkeit macht die durch diesen Akt entstandene innere Wahrnehmung zur inneren Erfahrung, da die transzendentale Synthesis der Einbildungskraft in der Aufmerksamkeit ausgeübt wird. In der auf den Akt des Ziehens einer Linie gerichteten Aufmerksamkeit wird die unbestimmte Wahrnehmung des synthetischen Akts des äußeren Mannigfaltigen durch die transzendentale Synthesis der Einbildungskraft synthetisch strukturiert (B154); der innere Zustand wird vergegenständlicht (B155-6) und insbesonders werden die objektiven Zeitverhältnisse der wahrgenommenen synthetischen Akte bestimmt (B156). In diesem Sinne sagt Kant, dass in dem Linien-Beispiel der innere Sinn bestimmt wird (B154-6), was darauf hindeutet, dass es dabei schon um innere Erfahrung geht.

Dies ist nicht nur aus der obskuren Formulierung des Beispiels in B154-5 ersichtlich, sondern geht auch aus einem ähnlichen Fall deutlich hervor:

$\mathrm{Da}$ dieses so sey, davon kann uns jede innere, von uns angestellte psychologische Beobachtung zum Beleg und Beyspiel dienen; denn es wird dazu erfordert, daß wir den innern Sinn, zum Theil auch wohl bis zum Grade der Beschwerlichkeit, vermittelst der Aufmerksamkeit afficiren (denn Gedanken, als factische Bestimmungen des Vorstellungsvermögens, gehören auch mit zur empirischen Vorstellung unsers Zustandes), um ein Erkenntniß von dem, was uns der innere Sinn darlegt, zuvörderst in der Anschauung unsrer selbst zu haben, welche uns dann uns selbst nur vorstellig macht, wie wir uns erscheinen, indessen daß das logische Ich das Subject zwar, wie es an sich ist, im reinen Bewußtseyn, nicht als Receptivität, sondern reine Spontaneität anzeigt, weiter aber auch keiner Erkenntniß seiner Natur fähig ist. (FM 20: 270)

In dieser Passage geht es um eine „psychologische Beobachtung“ - d.h. die introspektive Beobachtung des Gemütszustands. Dies ist ein ähnlicher Fall wie die Beobachtung des Ziehens einer Linie, denn beides ist kein normales bewusstes Erlebnis 
äußerer Gegenstände, sondern eine nach innen gerichtete Aufmerksamkeit. In beidem richtet sich die Aufmerksamkeit auf die Gemütshandlungen selbst. ${ }^{224}$ Nun ist das Ergebnis der nach innen gerichteten Aufmerksamkeit eine „Erkenntniß von dem, was uns der innere Sinn darlegt“". D.h. in dieser Beobachtung wird das Ergebnis der Selbstaffektion synthetisch zu einer empirischen Erkenntnis (d.h. innerer Erfahrung) verarbeitet. In dieser introspektiven Aufmersamkeit wird der innere Sinn nicht nur durch die synthetische Handlung erster Ordnung affiziert, sondern das Ergebnis dieser Selbstaffektion wird zugleich zur bestimmten inneren Anschauung synthetisiert. Der Akt der Aufmerksamkeit bzw. Reflexion ist keine Selbstaffektion tout court, sondern enthält schon einen synthetischen Akt, der gemäß den Kategorien auf das Gegebene des inneren Sinnes ausgeübt wird und selbst eine weitere Selbstaffektion ausmacht. ${ }^{225}$ Somit lässt sich die Reflexion in eine doppelten Selbaffektion analysieren. Diese Analyse lässt sich durch eine von Kants Reflexionen fast wörtlich bestätigen:

Der innere Sinn ist noch nicht [...] Erkentnis meiner selbst, sondern [...] zuerst müssen wir Erscheinungen durch ihn haben, nachher allererst durch Reflexion über dieselbe uns einen Begrif von uns selbst machen, der alsdann empirisches Erkentnis meiner selbst, d.i. [...] innere Erfahrung, zur Folge hat (Refl 18:680, R6354)

Daraus ist ersichtlich, dass der innere Sinn an sich keine Reflexion ist, sondern bloß ein mentaler Prozess, „Erscheinungen“ (das heißt hier: unsynthesierte empirische Eindrücke) vom Selbst zu haben. Ein Reflexionsakt kommt erst dann ins Spiel, wenn man die empirischen Daten, die der innere Sinn liefert, durch die transzendentale Synthesis gemäß den Kategorien zu empirischen Erkenntnissen des Selbsts bearbeitet. Eine ähnliche Analyse lässt sich auf das Beispiel des Ziehens der geraden Linie übertragen. In diesem Beispiel achtet man eher auf die auf die empirischen Materialien

224, ,[I]ndem wir im Ziehen einer geraden Linie [...] bloß auf die Handlung der Synthesis des Mannigfaltigen [...] Acht haben“ (B154). Im Zitat aus FM 20:270 wird die Aufmerksamkeit auf „Gedanken“, d.h. synthetische Handlungen mit dem Bewusstsein gerichtet.

225 Was sich aus dieser Affektion ergibt, könnten wir hier vorläufig ausklammern. 
des äußeren Sinnes ausgeübten synthetischen Akte als auf die äußeren Gegenstände selbst. Der Verstand synthetisiert das reine Mannigfaltigen des inneren Sinnes zu einer kategorisch bestimmten inneren Anschauung:

Ich sehe nicht, wie man so viel Schwierigkeit darin finden könne, daß der innere Sinn von uns selbst afficirt werde. Jeder Actus der Aufmerksamkeit kann uns ein Beispiel davon geben. Der Verstand bestimmt darin jederzeit den inneren Sinn der Verbindung, die er denkt, gemäß zur inneren Anschauung, die dem Mannigfaltigen in der Synthesis des Verstandes correspondirt. Wie sehr das Gemüth gemeiniglich hiedurch afficirt werde, wird ein jeder in sich wahrnehmen können. (B156-7)

Anders gesagt, hat man vor der introspektiven Aufmerksamkeit bei äußerer Wahrnehmung lediglich eine unbestimmte Anschauung der inneren Zustände, die eine dunkle Selbstwahrnehmung bleibt. Durch die introspektive Aufmerksamkeit (d.h. eine weitere Anwendung der transzendentalen Synthesis der Einbildungskraft) wird diese unbestimmte Anschauung der inneren Zustände zu einer bestimmten Anschauung synthetisiert, die eine klare Selbstwahrnehmung ausmacht. Durch die zweite Selbstaffektion wird das Produkt der ersten Selbstaffektion sozusagen kategorisch synthetisiert und in eine klare Vorstellung transformiert. Nach der obigen Analyse sieht man somit deutlich, dass die bloßen Vorstellungen des inneren Sinnes und die innere Erfahrung unterschiedlich sind.

\subsubsection{Bestimmung des inneren Sinnes und Aufmerksamkeit: Analyse der} Schlüsselstellen B68 und B154f.

In diesem Abschnitt möchte ich die wichtigste Textstelle über den inneren Sinn (B154f.) analysieren, in der Kant das berühmte Beispiel des Ziehens einer Linie entwickelt. Diese Textstelle ist nicht nur deswegen wichtig, weil Kant nirgendwo sonst eine derart 
ausführliche Beschreibung der Selbstaffektion gibt, sondern auch weil sich eine große Meinungsverschiedenheit über die Einzelheiten und Bedeutung der in ihr zu findenden Darstellung der Selbstaffektion entzündet hat. Obwohl diese Stelle häufig als Darstellung der Selbstaffektion zitiert wird, ist der darin thematisierte Fall der Selbstaffektion hoch speziell und kompliziert. Deswegen lassen sich die Schlüsse daraus nicht generell auf die Selbstaffektion und den inneren Sinn anwenden. Im Folgenden wird zunächst Kants berühmtes Beispiel dargestellt. Danach wird anhand einiger Interpratationen prominenter Exegeten argumentiert, warum und inwiefern die Bedeutung dieses Beispiels beschränkt ist.

Kants Hauptidee im Exkurs des §24 über die innere Erfahrung ist zu zeigen, dass die Vorstellung der Zeit als Form des inneren Sinnes immer auf eine Vorstellung des äußeren Sinnes angewiesen ist (B156). Da die Vorstellungen des äußeren Sinnes eher Erscheinungen als Dinge an sich repräsentieren, müssen auch die Vorstellungen des inneren Sinnes das Subjekt als Erscheinung repräsentieren. Der unmittelbare Kontext der fraglichen Textstelle ist Kants Bemerkung darüber, wie der innere Sinn als ein sinnliches Vermögen von der (reinen) Apperzeption zu unterscheiden ist:

Die Apperception und deren synthetische Einheit ist mit dem inneren Sinne so gar nicht einerlei, daß jene vielmehr, als der Quell aller Verbindung, auf das Mannigfaltige der Anschauungen überhaupt, unter dem Namen der Kategorien vor aller sinnlichen Anschauung auf Objecte überhaupt geht; dagegen der innere Sinn die bloße Form der Anschauung, aber ohne Verbindung des Mannigfaltigen in derselben, mithin noch gar keine bestimmte Anschauung enthält, welche nur durch das Bewußtsein der Bestimmung desselben durch die transscendentale Handlung der Einbildungskraft (synthetischer Einfluß des Verstandes auf den inneren Sinn), welche ich die figürliche Synthesis genannt habe, möglich ist.

(1) Dieses nehmen wir auch jederzeit in uns wahr. (2) Wir können uns keine Linie denken, ohne sie in Gedanken zu ziehen, keinen Cirkel denken, ohne ihn zu beschreiben, die drei Abmessungen des Raums gar nicht vorstellen, ohne aus demselben Punkte drei Linien senkrecht auf einander zu setzen, (3a) und selbst die Zeit nicht, ohne indem wir im Ziehen einer geraden Linie (die die äußerlich figürliche Vorstellung der Zeit sein soll) bloß auf die Handlung der Synthesis des Mannigfaltigen, 
(3b) dadurch wir den inneren Sinn successiv bestimmen, (3c) und dadurch auf die Succession dieser Bestimmung in demselben Acht haben. (4a) Bewegung als Handlung des Subjects (nicht als Bestimmung eines Objects), folglich die Synthesis des Mannigfaltigen im Raume, (4b) wenn wir von diesem abstrahiren und bloß auf die Handlung Acht haben, dadurch wir den inneren Sinn seiner Form gemäß bestimmen, (4c) bringt sogar den Begriff der Succession zuerst hervor. (5) Der Verstand findet also in diesem nicht etwa schon eine dergleichen Verbindung des Mannigfaltigen, sondern bringt sie hervor, indem er ihn afficirt. (B154-5).

Der erste Satz hebt den rein rezeptiven Charakter des inneren Sinnes hervor, indem dieser mit der (reinen) Apperzeption verglichen wird. Dieser Vergleich lässt sich im Wesentlichen in zwei Aussagen zusammenfassen:

BI.1 Der innere Sinn enthält das Mannigfaltige der Anschauung und seine sinnliche Form, nicht aber die Verbindung des Mannigfaltigen. Er enthält mithin nur eine unbestimmte Anschauung. ${ }^{226}$

BI.2 Diese Anschauung wird bestimmt, wenn (A) die transzendentale Synthesis der Einbildungskraft den inneren Sinn bestimmt und (B) man sich dieser Bestimmung bewusst wird. 227

226 Der Satz „dagegen der innere Sinn die bloße Form der Anschauung, aber ohne Verbindung des Mannigfaltigen in derselben, mithin noch gar keine bestimmte Anschauung enthält“ (B154) soll nicht bedeuten, dass der innere Sinn nur die eine Form der Anschauung, die Zeit, enthält. Nähere Gründe findet $\operatorname{man}$ in $\S 2.2$.

227 Diese Ausführung ist in zwei Punkten unklar. Erstens hat Kant nicht erklärt, was das in Frage stehende Mannigfaltige ist, ist es das räumliche Mannifaltige oder dasjenige, das spezifisch zum inneren Sinn gehört? Obwohl Kant leugnet, dass der innere Sinn seinen eigenen „Stoff“, d.h. ein spezifisch empirisches Mannigfaltiges, hat (siehe §2.2.), ist nicht abzustreiten, dass es ein reines, zeitliches Mannifaltiges gibt, das nur zum inneren Sinn gehört. Zweitens ist unklar, ob die in Frage stehende Anschauung eine äußere Anschauung oder innere Anschauung ist. Beide Punkte sind unklar, weil der innere Sinn auch äußere Anschauungen und deren Mannigfaltiges enthält. Meines Erachtens handelt es sich bei dem ersten Abschnitt des Zitats eindeutig um die Bestimmung des inneren Sinns und der synthetischen Organisation des zeitlichen Mannigfaltigen, denn das Thema der gesamten exkursiven Bemerkung im §24 (B152-156) ist die Frage, wie das Subjekt im inneren Sinn als Erscheinung vorgestellt wird. Zudem soll dem Satz (1) zufolge das Beispiel des Linien-Ziehens die Thesen BL.1 und BL.2 direkt demonstrieren. Wie anschließend gezeigt wird, geht es in diesem Beispiel hauptsächlich nicht um die Erzeugung einer äußeren Anschauung bzw. der Linie, sondern um die Erzeugung einer inneren 
Dem Satz (1) im zweiten Absatz zufolge sollen diese Thesen im ersten Absatz durch das Beispiel des zweiten Absatzs illustriert werden. Das Kern des Beispiels des Ziehens einer Linie lässt sich in wenigen Schritten herausschälen:

ZL.1 Die Handlung der Synthesis der Einbildungskraft verbindet das räumliche Mannigfaltige sukzessiv zur Vorstellung einer Linie. (3a)

ZL.2 Das Subjekt richtet seine Aufmerksamkeit auf diese Handlung der Einbildungskraft (3a), dabei abstrahiert es vom räumlichen Mannigfaltigen und achtet nur auf die Sukzession dieser Synthesis (3c).

ZL.3 Dadurch kann man die Sukzession unter einem Begriff denken, d.h. die Zeit als einen Gegenstand vorstellen (3a).

Im ersten Schritt ZL.1 wird das räumliche Mannigfaltige - die imaginären Punkte - zu einer Linie vereinigt. ${ }^{228}$ Hier wird die transzendentale Synthesis der Einbildungskraft zum ersten Mal angewendet und die Kategorie der Quantität angewendet. Die imaginären Punkte und Strecken werden als homogene Größen betrachtet und zusammengenommen. Es handelt es sich hier schon um die Bestimmung des inneren Sinnes durch die transzendentale Synthesis der Einbildungskraft, was durch den Satz (3b) bestätigt wird. Beim Bewusstsein der Linie muss der innere Sinn schon durch die transzendentale Synthesis der Einbildungskraft affiziert werden.

Wenn die Schritte ZL.2 und ZL.3 nicht folgen, dann handelt es sich bei ZL.1 allein um das gedankliche Ziehen einer Linie. ZL.1 an sich stellt einen Fall der Einbildung eines äußeren Gegenstands dar, bei dem die Aufmerksamkeit auf den äußeren Gegenstand selbst gerichtet wird. Im zweiten Schritt wechselt die Aufmerksamtkeit stattdessen auf die synthetische Handlung, die auf das räumliche Mannigfaltige einwirkt. Dadurch ergibt sich eine sukzessive Folge der empirischen Vorstellungen dieser synthetischen Handlung. ZL.3 besagt, dass der Begriff der Sukzession aus dem Akt ZL.2 entsteht.

Anschauung und daraufhin um die Erzeugung einer reinen Anschauung der Zeit als Form der inneren Anschauung.

${ }^{228}$ Die Punkte sind imaginär, weil laut dem Satz (2) die Linie im Gedanken gezogen wird. 
Zwischen ZL.2 und ZL.3 ist jedoch eine weitere Anwendung der transzendentalen Synthesis der Einbildungskraft auf die Vorstellungen der Handlung des Linie-Ziehens sowie eine Abstraktion erforderlich. Zuerst erklären wir die Notwendigket der zweiten Anwendung der transzendentalen Synthesis der Einbildungskraft. ${ }^{229}$ Die sukzessiven Wahrnehmungen der synthetischen Handlung des Ziehens der Linie geschehen nämlich in der Zeit. Diese Serie der Wahrnehmungen der synthetischen Handlung ist zunächst - d.h. als lediglich sinnlich gegeben und ohne weitere synthetische Verarbeitung zerstreut, diskret und zusammenhanglos, ${ }^{230}$ d.h. sie stehen nicht unter der Einheit des Bewusstseins und beziehen sich auch nicht auf einen Gegenstand. Sie sind sukzessiv aufgetreten aber noch nicht so erfasst, dass sie zusammengehören und eine Sukzession repräsentieren. Um die wahrgenommenen Akte der Synthesis des Räumlichen als einen inneren Gegenstand in der Zeit zu erfassen, d.h. als einen zeitlichen Prozess - eine Sukzession - vorzustellen, muss man sie in einem Akt des Bewusstseins erfassen - d.h. sie müssen in der Einheit des Bewusstseins gemäß den Kategorien verbunden werden. $^{231}$ Dazu muss die transzendentale Synthesis der Einbildungskraft erneut zum Einsatz kommen.

Obwohl Kant diese zweite Anwendung der transzendentalen Synthesis der Einbildungskraft nicht explizit nennt, ist leicht darauf zu schließen: Kant sagt zweimal, dass man auf die Synthesis des räumlichen Mannigfaltigen „achten“ muss (3a, 4b). Besonders im Satz 4 merkt Kant zu dem Akt der Aufmerksamkeit an:

[...] die Synthesis des Mannigfaltigen im Raume, wenn wir von diesem abstrahiren und bloß auf die Handlung Acht haben, dadurch wir den inneren Sinn seiner Form gemäß bestimmen, bringt sogar den Begriff der Succession zuerst hervor.

\footnotetext{
229 Allison unterscheidet verschiedene Anwendungen der transzendentalen Synthesis der Einbildungskraft (2015:394). Allerdings hat er drei Anwendungen gezählt, die mit der hier vorgeschlagenen Interpretation abweicht.

${ }^{230}$ Dyck (2006:42).

231 Dyck (2006:42).
} 
Kant scheint hier zu meinen, dass die Form des inneren Sinnes im „Achthaben“ auf die Synthesis des räumlichen Mannigfaltigen durch den Verstand bestimmt wird, wodurch die Vorstellung der Sukzession hervorgebracht wird. Das kann meines Erachtens dem Kontext nach nur bedeuten, dass der Verstand durch die Aufmerksamkeit auf die Synthesis des räumlichen Mannigfaltigen die sukzessiven Vorstellungen dieser Synthesis zu einer Vorstellung der Sukzession verbindet. ${ }^{232}$ In der B156 Anm. erklärt Kant die Funktion dieses „Achthaben[s]“ bzw. der Aufmerksamkeit auf die synthetische Handlung ganz unmißverständlich:

Der Verstand bestimmt darin [d.h. in der Aufmerksamkeit] jederzeit den inneren Sinn der Verbindung, die er denkt, gemäß zur inneren Anschauung [...]. (B156 Anm.)

Bei der Aufmerksamkeit auf die Synthesis des räumlichen Mannigfaltigen werden folglich die Sinnesmaterialien der inneren Wahrnehmung zur begrifflich bestimmten inneren Anschauung verarbeitet. ${ }^{233}$ Die transzendentale Synthesis der Einbildungskraft kommt in dieser Aufmerksamkeit zum Einsatz, weil diese Synthesis gerade als „synthetischer Einfluß des Verstandes auf den inneren Sinn“ definiert wird (B154). ${ }^{234}$ Die sukzessiven Vorstellungen dieser Synthesis werden dabei zu einer einzigen empirischen Vorstellung einer gesamten sukzessiven Handlung verbunden. Im Endeffekt werden die sukzessiven Teilakte der Synthesis des räumlichen Mannigfaltigen als „gleichartig“ betrachtet und als zu einer Einheit gehörig- d.h. als eine kontinuierliche Handlung mit einer Zeitdauer - zusammengenommen. Dieser Operation liegt die transzendentalen Synthesis der Einbildungskraft gemäß der Kategorie der Quantität und der Kategorie der Substanz und Akzidenz zugrunde: sie

\footnotetext{
${ }^{232}$ Man muss jedoch zugeben, dass der Relativsatz „dadurch wir den inneren Sinn seiner Form gemäß bestimmen“ zweideutig ist, insofern er sich auf „die Handlung“ - d.h. die Synthesis des räumlichen Mannigfaltigen - oder auf das „Achthaben“ auf diese Handlung beziehen kann.

${ }^{233}$ Das obige Zitat aus B156 Anm. scheint auf die introspektive Aufmerksamkeit auf die Handlung des Linie-Ziehens gerichtet zu sein.

${ }^{234}$ Dyck (2006:41).
} 
verbindet die reinen anschaulichen Entsprechungen der Wahrnehmungen der Teilakte der Synthesis des räumlichen Mannigfaltigen - d.i. die Zeitpunkte oder das reine Mannigfaltige der Zeit - zu einer formalen Anschauung der Zeit als Gegenstand (B161 Anm.). ${ }^{235}$ Der springende Punkt besteht nun im Folgenden: die Vorstellung der Zeit soll nach Kant dadurch entstehen, dass das Subjekt bei der Beobachtung der Handlung des Ziehens der Linie von der Handlung selbst abstrahiert und nur auf die Sukzession der (Teil)-Handlungen, ,achtha[t] $]_{“ “}$. Die Vorstellung der Sukzession ist in der Tat nichts anders als die formale Anschauung der Zeit. Der Fokus der Aufmerksamkeit wechselt dabei von der synthetischen Handlung zur Form der Wahrnehmung dieser Handlung. Dieser Wechsel der Aufmerksamkeit ist aus dem Text leicht zu entnehmen: indem wir im Ziehen einer geraden Linie [...] bloß auf die Handlung der Synthesis des Mannigfaltigen, [...] und dadurch auf die Sukzession dieser Bestimmung in demselben, Acht haben. (B154, meine Kursivierung).

Wie schon argumentiert, ist die Aufmerksamkeit der Akt, der eine dunkle Vorstellung in eine klare, apperzeptiv bewusste verwandelt. Die auf dem räumlichen Mannigfaltigen apriori operierende Synthesis der Einbildungksraft bleibt an sich unbewusst bzw. dunkel (A78/B103). Die auf diese Synthesis gerichtete

235 Das Ziel des Ziehens einer Linie ist es, die Zeit vorzustellen (B154, 156). Konkreter gesagt, geht es primär darum, die Sukzession, die die wesentliche Eigenschaft der Zeit ist, vorzustellen (B155). Dabei ist die Kategorie der Qualität nicht erforderlich, da es sich bei Kants Beispiel um das gedankliche Ziehen einer Linie, d.h. die Erzeugung der reinen Anschauung, handelt. Die Anwendung der Kategorie der Substanz und Inhärenz ist jedoch unentbehrlich, denn ,[n]ur in dem Beharrlichen sind also Zeitverhältnisse möglich (denn Simultaneität und Succession sind die einzigen Verhältnisse in der Zeit), d.i. das Beharrliche ist das Substratum der empirischen Vorstellung der Zeit selbst, an welchem alle Zeitbestimmung allein möglich ist. [...] Durch das Beharrliche allein bekommt das Dasein in verschiedenen Theilen der Zeitreihe nach einander eine Größe, die man Dauer nennt.“ (B226). Das Beharrliche ist im Linien-Beispiel schwierig zu spezifizieren, da es dort um eine gedankliche Imagination des Ziehens einer Linie handelt. Meiner Meinung nach ist es der imaginäre räumliche Punkt, den das Subjekt im Raum sukzessiv zu einer Linie zieht (siehe auch B292). Diese Unklarheit ist für diese Abhandlung nicht gravierend. Es reicht aus zu wissen, dass die Kategorie der Inhärenz im LinienBeispiel nötig ist. 
Aufmerksamkeit ermöglicht es dem Subjekt, sich dieses synthetischen Akts bewusst zu werden. Ferner wissen wir, die Abstraktion ist die Ausübung der Aufmerksamkeit, durch die eine Vorstellung klargemacht wird und die übrigen verdunkelt werden (VMet/Mron 29:878). ${ }^{236}$ Daher stellt der obige Fokuswechsel der Aufmerksamkeit eigentlich eine Abstraktion dar: Die Aufmerksamkeit wird allein auf den rein anschaulichen Aspekt der Wahrnehmung des mentalen Akts gerichtet. Daraufhin verbindet sie die Vorstellungen dieses Aspekts zur Vorstellung der Sukzession selbst.

\subsubsection{Introspektion, innerer Sinn und Selbstaffektion: Kritik an Corey Dycks Interpretation von Kants Beispiel}

Prominente Interpreten versuchen, aus Kants Erläuterung des Beispiels des Ziehens einer Linie in \$24 allgemeine Schlüsse über den inneren Sinn und die Selbstaffektion zu ziehen. Meines Erachtens ist Kants Ausführung über den inneren Sinn und die innere Erfahrung in $\$ 24$ zwar sehr aufschlußreich, ihre Bedeutung ist aber in vielen Hinsichten eingeschränkt. Besondere Vorsicht ist geboten, wenn man aus ihr allgemeine Rückschlüsse auf die Struktur der Selbstaffektion bei der äußeren Wahrnehmung ziehen will. Der Grund dafür liegt hauptsächlich darin, dass es sich bei dem Beispiel nicht um ein Beispiel einer äußeren Wahrnehmung, sondern um ein Beispiel einer ganz speziellen Art der inneren Wahrnehmung - der Introspektion des rein anschaulichen Aspekts der Vorstellung des inneren Akts - handelt. Das Produkt dieser Introspektion ist der „Begriff der Sukzession“ (B155), das heißt, durch die Introspektion wird die Zeit als Form des inneren Sinnes vorgestellt (B154, 156). Sie weist eine spezifische und

\footnotetext{
${ }^{236}$ Siehe auch Dyck (2006:40)
} 
hoch komplizierte Struktur auf, die in normalen äußeren Wahrnehmungen nicht zu finden ist. Die Aufmerksamkeit der Wahrnehmung richtet sich nämlich nicht auf einen äußeren Gegenstand, sondern reflexiv auf die synthetische Handlung des Subjekts selbst, wodurch die Anschauung eines äußeren Gegenstands erstmals konstruiert wird. Dieser Akt der Aufmerksamkeit ist eine bewusste reflexive Vorstellung höherer Stufe und hat die synthetische Handlung des Subjekts als seinen intentionalen Gegenstand. Danach kommt noch ein weiterer Akt der Aufmerksamkeit zustande, die sich auf den rein anschaulichen Aspekt der Vorstellung der Handlung, d.i. die „Sukzession dieser Bestimmung [d.h. der synthetischen Handlung]“, richtet (B154). In diesem Akt der Aufmerksamkeit wird das reine Mannigfaltige der Zeit zur formalen Anschauung der Zeit, d.h. zur Vorstellung der Sukzession, verbunden. Insgesamt wird die transzendentale Synthesis der Einbildungskraft auf zwei Ebenen ausgeübt:

1) Sie wird auf das räumliche Mannigfaltige angewendet, woraus sich die Anschauung der Linie ergibt.

2) Sie wird auf die reinen Entsprechungen der Vorstellungen der synthetischen Handlung in 1) angewendet, woraus sich die Anschauung der Sukzession ergibt.

Wegen der komplexen bewusstseinstheoretischen Struktur, die auf den introspektiven Charakter des Linien-Beispiels zurückzuführen ist, lassen sich aus diesem Beispiel nicht ohne weiteres Rückschlüsse über die Struktur der Selbstaffektion in der äußeren Wahrnehmung ziehen. ${ }^{237}$ Im Nachfolgenden werden solche voreiligen Rückschlüsse bei prominenten Interpreten evaluiert.

\footnotetext{
${ }^{237}$ Mohr z.B. hat diesen Charakter des Linien-Beispiels nicht erkannt und nimmt es als Beispiel für die Selbstaffektion überhaupt (Mohr 1991: 171). Unter den Interpreten ist Düsing m.W. der einzige, der den Charakter dieses Beispiels hervorhebt (Düsing 2010:151 Anm.). Unter Verweis auf die beiden Stellen B68, B156 unterscheidet er grob zwei Arten der Selbstaffektion: die „empirisch-zeitliche, ggf. biographische Selbstanschauung des sinnlichen Ich“ und die der ,äußeren Anschauung“.
} 


\subsubsection{Das Linien-Beispiel: formale Anschauung und Selbstbewusstsein}

Einige Interpreten tendieren zu der Auffassung, dass im Linien-Beispiel die Zeit in einer faktischen formalen Anschauung als Gegenstand vorgestellt wird. ${ }^{238}$ In seiner exzellenten Rekonstruktion des Linien-Beispiels vertritt Dyck die Auffassung, dass das Mannigfaltige des inneren Sinnes gerade in den sukzessiven Akten der Aufmerksamkeit auf die Synthesis des räumlichen Mannigfaltigen bestehe:

attention provides inner sense with an ersatz manifold of its own, a manifold comprising just the acts of attention to the syntheses involved in the drawing of a line (Dyck 2006:41, 40).

Daraus zieht er den Schluss:

Attention then plays a central role in explaining time's acquisition of a pure manifold of its own. (Dyck 2006:40)

In ähnlicher Weise ist Mohr der Meinung, dass es die „Konstruktionsakte des Verstandes“ sind, die „den sinnlichen ,Stoff“ für den inneren Sinn abgeben“:

Die Vorstellung des Nacheinanders konstituiert sich im Zuge einer ,Aufmerksamkeit‘ (B156 f. Anm.) auf die Verstandestätigkeit der Konstruktion des räumlichen Bildes einer Linie und insbesondere auf die formale Bedingung der Konstruktionsakte. Diese formale Bedingung ist das Nacheinander. [...] so ist die Zeitvorstellung als das Produkt einer ,formalen Verbindung“ der Einzelakte [der Synthesis der äußeren Saten] zu charakterisieren [...]. Diese „formale Verbindung“ ist die Vorstellung der sukzessiven Bestimmung 2 (Affektion) des inneren Sinns als einer Aufeinanderfolge und eines Sich-Ablösens von Zeit-,Punkten“. (Mohr 1991:167)

Kurz gesagt sei der Gegenstand des inneren Sinnes die Verstandestätigkeiten. Da der innere Sinn keinen speziellen empirischen Materialien liefert - hierin ist Mohr mit Dyck konform-, lässt sich schließen, dass das Mannigfaltige des inneren Sinnes, das von den Verstandesakten stammt, reines Mannigfaltiges ist. Die Zeitvorstellung

${ }^{238}$ Mohr (1991:165), Dyck (2006:38). 
gewinne man, indem man den „formalen Aspekt des Vollzugs der Akte selbst“ auf den Begriff der Sukzession bringe.

Dyck und auch Mohr haben Recht, dass die Akte der Aufmerksamkeit ein (rein) Mannigfaltiges des inneren Sinnes liefern. ${ }^{239}$ Sie verkennen aber, dass es sich bei der Aufmerksamkeit auf die Akte der Synthesis der Apprehension um einen sehr speziellen Akt der Introspektion handelt. Ihre Auslegung impliziert, dass man nur dann eine Anschauung der Zeit mit ihrem reinen Mannigfaltigen haben kann, wenn man diesen speziellen Akt der Introspektion vollzieht. Aber das direkte Bewusstsein der synthetischen Akte kommt selten vor (A78/B103, A103-4). In der Tat kann man aber auch dann die formale Anschauung der Zeit haben, wenn man seine Aufmerksamkeit auf die äußeren Gegenstände richtet und diese als intentionale Gegenstände hat (B1601). Die formale Anschauung der Zeit muss nicht durch die Aufmerksamkeit bewusstgemacht werden. ${ }^{240}$ Vielmehr bleibt sie bei der äußeren Wahrnehmung als die reine Entsprechung und der maßgebende, formale und normative Faktor der zu konstruierenden empirischen Anschauung im Hintergrund. Die formale Anschauung der Zeit ist also eine dunkle Vorstellung, die jederzeit der äußeren Wahrnehmung zugrundeliegt, insofern wir uns bei der Wahrnehmung eines äußeren Gegenstandes nicht dessen bewusst sind, dass wir eine formale Anschauung der Zeit als Gegenstand haben. Sobald wir aber darüber reflektieren, bemerken wir, dass die äußeren Ereignisse und Gegenstände immer schon in einer wohlbestimmten, einheitlichen Zeitordnung stehen. Das zeigt, dass unser Gemüt eine dunkle, formale Zeitanschauung als reine Entsprechung und Grundlage der Wahrnehmung hat.

\footnotetext{
239 Siehe auch Mohr (1991:167).

${ }^{240}$ In V-Met/Mron 29:878 behauptet Kant, dass die Aufmerksamkeit eine Vorstellung zu einer klaren macht und die übrigen Vorstellungen außerhalb des Bereichs der Aufmerksamkeit dunkel bleiben.
} 
Außerdem lässt sich kaum nachvollziehen, wie die Wahrnehmung der synthetischen Akte der Apprehension selbst ein reines Mannigfaltiges sein kann. Der repräsentationale Gehalt ersterer ist nämlich die innere Aktivität. Die introspektive Vorstellung dieser Aktivität muss eine spezielle innere Wahrnehmung sein. Folgende Gründe sprechen dafür, dass es sich bei ihr um eine Wahrnehmung bzw. eine empirische Anschauung handelt: (1) Diese Aktivität ist in der introspektiven Vorstellung durch direkte Bekanntschaft - d.h. nicht mittels eines Begriffs - gegeben. (2) Sie bezieht sich auf einen Einzelgegenstand - d.h. einen inneren Akt. (3) Diese introspektive Vorstellung der Akte muss sinnlich sein, da sie Zeitlichkeit aufweist, die zur Sinnlichkeit gehört. (4) Sie ist empirisch, denn ihr liegt eine Affektion, mithin eine Empfindung zugrunde. Dass die Aufmerksamkeit eine Wahrnehmung ist, sagt Kant ganz explizit:

Wie sehr das Gemüth gemeiniglich hiedurch [durch den „Actus der Aufmerksamkeit"] afficirt werde, wird ein jeder in sich wahrnehmen können. (B157 Anm.)

Das reine Mannigfaltige somit kann nur die Form der Wahrnehmung der synthetischen Akte sein, nicht aber die Wahrnehmung dieser synthetischen Akte selbst.

Als eine weitere Implikation des Linien-Beispiels behauptet Dyck, dass der zweite Akt der Aufmerksamkeit ein empirisches Selbstbewusstsein ausmacht, das eine notwendige Komponente der Wahrnehmung ist (Dyck 2006:43). Dieser Akt der Aufmerksamkeit ist nämlich „das Bewußtsein der Bestimmung desselben [des inneren Sinnes] durch die transscendentale Handlung der Einbildungskraft“ (B154), somit gelte, dass „,a reflexive attention to those acts of attention [...] constitute the manifold of inner sense" (Dyck 2006:43). Diese Behauptung ist m.E. auf die gleiche Weise falsch wie die erste, denn die auf die inneren Akte gerichtete introspektive Aufmerksamkeit ist gerade keine notwendige Komponente der Wahrnehmung. 


\subsubsection{Widerlegung von repräsentativen Interpretationen der Struktur der Selbstaffektion}

Diese Konklusion hilft uns, einige repräsentative Interpretationsversuche der Selbstaffektion zu bewerten. Diese teilen eine Gemeinsamkeit: Alle sind Versuche, das oben erwähnte Problem zu lösen, dass der Verstand in Form der Synthesis der transzendentalen Einbildungskraft die Vorstellungen des inneren Sinns bestimmt, obwohl die Affektion durch diese Synthesis den inneren Sinn überhaupt erst mit Vorstellungen besetzen soll.

Dyck (2006:44) ist zum Beispiel der Meinung, dass die transzendentale Synthesis der Einbildungskraft, die auf dem räumlichen Mannigfaltigen operiert, keine Selbstaffektion initiiert, da nur die auf den inneren Sinn einwirkende transzendentale Synthesis der Einbildungskraft dies vermöge. Er glaubt offensichtlich, dass sich das Mannigfaltige des innern Sinns erst durch die Aufmerksamkeit auf die synthetischen Akte ergibt, die wiederum auf das räumliche Mannigfaltige einwirken. Dycks Auffassung fehlt jegliche Textunterstützung. Kant selbst unterscheidet meines Wissens nach nie zwei Arten der transzendentalen Synthesis der Einbildungskraft (B150). Nach den Antizipationen der Wahrnehmung (A176/B217) zum Beispiel wirkt die transzendentale Synthesis der Einbildungskraft gemäß der Kategorie der Qualität auf den inneren Sinn ein. Diese Kategorie ist für die Synthetisierung des äußeren Mannigfaltigen verantwortlich. Im berühmten Linien-Beispiel bezeichnet Kant die gemäß der Kategorie der Quantität geschehende Synthesis des räumlichen Mannigfaltigen zur Vorstellung einer Linie als die Handlung, durch die ,wir den inneren Sinn successiv bestimmen“ (B154). Dycks falsche Interpretation rührt m.E. nach davon, dass er Kants Ausdruck ,[d]er Verstand bestimmt [...] den inneren Sinn“ (B157 Anm., B154) wörtlich als ,,[d]er Verstand bestimmt die Vorstellung im inneren Sinn“ auffasst (Dyck 2006:44). Dyck berücksichtigt damit aber nicht 
hinreichend die komplexe Thematik der Bestimmung des inneren Sinnes durch den Verstand.

Auch Wolff bietet zu der oben genannten Problematik einen Lösungsvorschlag an, der sich wie folgt zusammenfassen lässt:

DM1. Das Ergebnis der Selbstaffektion durch die Synthesis der Einbildungskraft ist die subjektive Folge der Wahrnehmungen. Um diese objektiv zu bestimmen, ist eine Ausübung der transzendentalen Synthesis des Verstandes notwendig.

Wolff behauptet, dass ,the result of the affection [hier: Selbstaffektion durch die transzendentale Synthesis der Einbildungskraft] is to set the self-awareness of the spatial manifold in a temporal order. That order ist the subjective order of the empirical consciousness of outer objects.“ (Wolff 1963:199). Der Akt, der den inneren Sinn zunächst affiziert, soll seiner Meinung nach die Synthesis der Einbildungskraft sein, die auf das räumliche Mannigfaltige einwirkt (Wolff 1963:200). Laut Wolff handelt es sich bei der Synthesis der Einbildungskraft und der Synthesis des Verstandes um zwei verschiedene Akte. Während Erstere sich auf das Mannigfaltige des äußeren Sinnes richtet, richtet sich die Letztere auf das Produkt der Ersteren (Wolff 1963:201). Diese Lesart wird von ihm durch die schon bekannte Sorge motiviert: obwohl objektiv unbestimmt, gehört die Zeitlichkeit der unsynthesierten Folge der Wahrnehmungen zur Form des inneren Sinnes. Da der innere Sinn die Selbstaffektion durch die transzendentale Synthesis der Einbildungskraft verlangt, muss, so seine Überlegung, diese Synthesis für die subjektive Zeitlichkeit verantwortlich sein (Wolff 1963:195). Diese Auslegung ist unbefriedigend. Die Trennung der Synthesis der Einbildungskraft, die auf das Mannigfaltige des äußeren Sinnes einwirkt, von der des Verstandes ist im Fall der empirischen Erkenntnisse der Menschen exegetisch nicht begründet, wie schon ausführlich behandelt wurde. Sachlich ist diese Trennung ebenfalls nicht haltbar, da die Synthesis des Verstandes nicht anders auf den sinnlichen Materialien operiert als dadurch, dass sie die Synthesis der Einbildungskraft lenkt. Entgegen Wolffs 
Auffassung ist die Synthesis, die das Mannigfaltige des äußeren Sinnes direkt bestimmt, nicht mehr und nicht weniger als die Synthesis der Einbildungskraft gemäß den mathematischen Kategorien: sie ist nicht mehr, weil die Synthesis der Relation nicht direkt auf dem räumlich Mannigfaltigen operiert, sie ist nicht weniger, weil die Wahrnehmungen in der subjektiven Sukzession schon quantitativ und qualitativ gemäß der mathematischen Synthesis bestimmt werden müssen.

Nakano zufolge sind sinnliche Anschauungen unter Einwirkung der figürlichen Synthesis alias der transzendentalen Synthesis der Einbildungskraft gegeben (Nakano 2011:226). Diese Synthesis mache die formale Anschauung als Bedingung der Aufnahme des sinnlichen Mannigfaltigen erst möglich und sei damit auch für die Besetzung des inneren Sinnes mit Vorstellungen verantwortlich. Aufgabe der intellektuellen Synthesis dagegen sei es, „die mannigfaltigen Vorstellungen auf ihren Gegenstand [zu beziehen] und diesen Gegenstandbezug bzw. die Objektivität der Vorstellungen in einem Urteil [auszudrücken]“ (Nakano 2011:227, meine Hervorhebung). Wie bereits angedeutet, basiert diese Lesart auf einer unplausiblen Auffassung der figürlichen und der intellektuellen Synthesis, die verkennt, dass es sich bei beiden nicht um zwei unabhängige spontane Akte des Subjekts, sondern um zwei Aspekte eines einzigen synthetischen Akts handelt. Es ist zudem kaum nachvollziehbar, was es heißen soll, dass die intellektuelle Synthesis als Verbindung des Mannigfaltigen überhaupt, die in den Kategorien gedacht werden (B151), überhaupt erst einen konkreten Gegenstandsbezug herstellt. Es handelt sich bei ihr nicht einmal um ein real vollzogenes Urteil. Vielmehr ist die intellektuelle Synthesis als ein Aspekt des regelfolgenden, anschauungskonstruierenden Akts der Einbildungskraft zu betrachten, wobei von dem sinnlichen Mannigfaltigen (sowohl dem reinen als auch dem empirischen Mannigfaltigen) abstrahiert wird. Zusammen bilden sie also die transzendentale Synthesis der Einbildungskraft, die einer Anschauung einen Gegenstandsbezug verleiht, denn gerade sie bringt das sinnliche Mannigfaltige gemäß 
den Kategorien in die notwendige objektive Einheit der Apperzeption (A108ff., A118f.), die nichts anders als eine Vorstellung des Gegenstands überhaupt ist.

\subsection{Modelle des inneren Sinnes und der Selbstaffektion}

Nun sind wir ausreichend dafür vorbereitet, um die Frage zu beantworten, worin der wesentliche Unterschied zwischen dem äußeren und dem inneren Sinn besteht. Dadurch können wir den Charakter des inneren Sinnes besser verstehen und die in dieser Abhandlung vertretene Lesart besser gegen alternative Lesarten verteidigen. $\mathrm{Zu}$ dieser Frage gibt es nach Ameriks Zusammenfassung drei unterschiedliche Antworten (Ameriks 2001: 242f.), denen zufolge der Gegensatz vom äußeren Sinn und inneren Sinn jeweils wie folgt zu deuten ist:

G1. Räumliches Bewusstsein vs. Nicht-räumliches Bewusstsein

G2. Vorstellungsgehalt vs. Vorstellungssakt

G3. Direktes Bewusstsein vs. Reflexives Bewusstsein

Nach G1 besteht der ,inner“/,äußer“-Unterschied in dem unterschiedlichen Bewusstseinsinhalt; nach G2 in unterschiedlichen Aspekten des Vorstellungsakts; nach G3 wiederum darin, ob der innere Sinn eine spezielle, separate Vorstellung ist, und zwar eine, die eine andere, gegenstandsbezogene Vorstellung als Gegenstand hat. Im Folgenden werden die drei Lösungsansätze bewertet. Der erste und der zweite sind weniger plausibel und werden von Ameriks überzeugend widerlegt. Verschiedene Varianten der Reflexionslesart stellen die Standardinterpretation des inneren Sinnes dar, die von prominenten Kant-Forschern vertreten wird. Ich werde mich darauf konzentrieren, diesen Ansatz zu widerlegen. 


\subsubsection{Die Theorie des unabhängigen Bewusstseinsflusses}

Die erste Variante, die sogenannte „Independent Stream Theory“, besagt: „,T]here are two separate streams of consciousness, one presenting spatial contents and one presenting contents which may have no direct reference to spatial characteristics.“241 Der innere und der äußere Sinn werden damit als zwei hinsichtlich ihres repräsentationalen Gehaltes unterschiedliche Vorstellungsarten betrachtet. Der innere Sinn ist „all consciousness of items that are non-spatial““. ${ }^{242} \mathrm{Zu}$ dem inneren Sinn gehört das Bewusstsein von „God...spiritual beings...abstract items...feelings...inclinations....acts of reflection of one's perceptual states“ “. ${ }^{243}$ Diese Bestimmung ist insofern unzutreffend, als diese verschiedenen Arten des Bewusstseins weder eine klare Verbindung zum Selbstbewusstsein noch eine positive Gemeinsamkeit aufweisen. ${ }^{244}$ Vor allem steht sie nicht mit der Definition des inneren Sinnes in Übereinstimmung, denn das Bewusstsein des inneren Sinnes, so wie diese Lesart sie interpretiert, ist kein Bewusstsein des inneren Zustandes. Die „Independent Stream Theory" wird ebenfalls dadurch widerlegt, dass das Bewusstsein des inneren Sinnes als „Inbegriff aller Vorstellungen“ auch das Bewusstsein des äußeren Sinnes enthält. ${ }^{245}$ Der innere Sinn begleitet nicht bestimmte repräsentationale Zustände, sondern alle unserer inneren Zustände (z.B. V-Lo/Blomberg 24:40f., Refl 18:306) und bleibt als Bewusstsein ununterbrochen (Refl 17:593f.). Es ist nicht der Fall, dass der innere Sinn einen anderen unabhängigen Bewusstseinsfluß neben dem des äußeren Sinnes liefert. Das Produkt des inneren Sinnes ist der Fluß unseres apperzeptiven,

\footnotetext{
241 Ameriks (2000:249). Siehe auch Smith (1918:293), Bird (1962: 43-6, 169) und Cummins (1968:271).

242 Ameriks (2001:249).

243 Ameriks (2001:249).

${ }^{244}$ Für weitere Kritiken siehe Ameriks (2001:249).

245 Refl 18:224; „Von dem inneren Sinn“, S.1.
} 
aufmerksamen Bewusstseins, dessen repräsentationalen Gehalte sowohl äußere als auch (bei der Introspektion) innere Gegenstände umfassen können.

\subsubsection{Akttheorie}

Die zweite Interpretationsalternative ist die „Akttheorie“, die hauptsächlich von Bennett vertreten wird. Ihr zufolge ist der innere Sinn „,not...a separate set of occurrences of consciousness but...a constant aspect of it." (Ameriks 2000:250). Der innere Sinn wird folglich so definiert:

Something is said to belong to inner sense whenever it is spoken of as a representing as opposed to a represented (Ameriks 2000:250)

Zum inneren Sinn gehört nicht der repräsentationale Gehalt, sondern der repräsentationale Akt selbst. Eine Vorstellung ist „inner“, genau dann, wenn sie zu „Someone's psychic history or stream of consciousness“ gehört. ${ }^{246}$ Diese Lesart ist insofern unangebracht, als sie den inneren Sinn zu weit auffasst. Es ist schwierig zu sehen, inwiefern es sich bei der so definierten Vorstellung des inneren Sinnes um Selbstbewusstsein handeln kann. Folgt man Ameriks, dann gehört die Vorstellung qua Vorstellungsakt zu dem Subjekt und ist somit das Bewusstsein des Subjekts. Folglich könne der innere Sinn ein Selbstbewusstsein enthalten, auch wenn er kein Bewusstsein des Selbsts als ein „distinct item“ ist. ${ }^{247}$ Es ist nicht überzeugend, den Vorstellungsakt als Selbstbewusstsein zu bezeichnen, denn eine Vorstellung zu haben impliziert bei Kant nicht, sich ihrer auf irgendeine Weise bewusst zu sein - man braucht nur an die dunkle Vorstellung zu erinnern (siehe §1.4). Sogar der Bewusstseinsakt als solcher

\footnotetext{
246 Ameriks (2000:250). Benennt (1966:45).

247 Ameriks (2000:251)
} 
impliziert nicht automatisch irgendeine Art des Selbstbezugs, denn Kant lässt sogar Vorstellungen zu, die nur ein schwaches Bewusstsein enthalten und damit nicht zum inneren Sinn gehören (siehe \$1.4.2.2.). Außerdem lässt die Akttheorie die Selbstaffektion völlig außer Acht, denn der Vorstellungsakt ist nicht gleich der Selbstaffektion. ${ }^{248}$ Wenn die Akttheorie die richtige Interpretation des inneren Sinnes wäre, müsste man dem Tier das Vermögen des inneren Sinnes zuschreiben, weil Kant zufolge auch Tiere über ein Vorstellungsvermögen verfügen (z.B. KU 5:464 Anm.). Dies lehnt Kant jedoch ausdrücklich ab, da der innere Sinn für ihn das Vermögen der transzendentalen Apperzeption voraussetzt ( $\mathrm{Br} 11: 51-2,1898) .{ }^{249}$

\subsubsection{Die Reflexionstheorie}

Kants Ausführung über den inneren Sinn erweckt oft den Eindruck, dass es sich bei diesem um einen Akt der Reflexion handelt. Das Bewusstsein richtet sich bei diesem nicht auf äußere Gegenstände, sondern auf innere Zustände oder Prozesse unter Abstraktion ihrer repräsentationalen Gehalte. Dieser Eindruck ist jedoch trügerisch. Um dies zu demonstrieren, werden im Folgenden verschiedene Varianten der Reflexionstheorie betrachtet. Zuerst werden die beiden Reflexionstheorien dargestellt, die an einem expliziten Reflexionsakt festhalten. Danach wird die implizite

\footnotetext{
248 Ameriks scheint die Selbstaffektion mit dem Vorstellungsakt zu identifizieren (Ameriks 2000: 252), was meines Erachtens ebenfalls durch die Doktrin der dunklen Vorstellung zu widerlegen ist.

249 Vgl. Ameriks (2000:251). Ameriks zufolge spricht Kant dem Tier das Vermögen des inneren Sinns nicht ausdrücklich ab, denn er könnte an Stellen, die den gegenteiligen Eindruck erwecken, unter dem Begriff des ,inneren Sinnes“ eher die reine Apperzeption verstehen (V-Met-L1/Pölitz 28:276). Diese Ansicht ist aber falsch, wie aus dem Brief an Herz (Br 11:51-52) deutlich wird. Für eine ausführlichere Analyse siehe auch $§ 1.4$.
} 
Reflexionstheorie vorgestellt. Anschließend werde beide Varianten aus textuellen und systematischen Gründen zurückgewiesen.

\subsubsection{Explizite Reflexionstheorie}

Ameriks unterscheidet in der Literatur drei verschiedenen Varianten der Reflexionstheorie: die extreme, die kognitive und die schwache Reflexionstheorie. Den ersten beiden zufolge liegt dem inneren Sinn ein expliziter Reflexionsakt zugrunde, der eine Art Introspektion ausmacht. Fortan werden diese Theorien als „,explizite Reflexionstheorien“ bezeichnet. Scheinbare Belege für sie findet man in den beiden Passagen, die sich speziell dem Thema des inneren Sinnes und der Selbstaffektion widmen ( $\S 8$ und §24): Im inneren Sinn wird „ein Subjekt sich selbst innerlich [angeschaut]“ (B68). Bei der Selbstaffektion wird „,das Vermögen sich bewußt zu werden“ aktiviert, woraus „eine Anschauung seiner selbst" (B68) hervorgeht. In §24 scheint Kants bereits umfassend diskutiertes Beispiel für eine Selbstaffektion, das Ziehen einer Linie, ein einleuchtender Beleg für die These zu sein, dass die Selbstaffektion ein Reflexionsakt ist, denn im Beispiel richtet das Subjekt seine Aufmerksamkeit nicht auf einen äußeren Gegenstand, sondern auf die eigenen kognitiven Handlungen.

Die extreme Reflexionstheorie besagt, dass der innere Sinn Reflexion über unsere unmittelbar vergangenen Akte des Bewusstseins ist, die (zumindest ursprünglich) auf räumlichem Gehalt operieren. ${ }^{250}$ Damit gleicht die Selbstaffektion einem Akt der

\footnotetext{
250 Ameriks (2000:243). Hauptvertreter dieser Lesart sind Ameriks zufolge Paton (1936: vol. 2, 389), Smith (1918: 294) und Weldon (1958:259). Vgl. Mohr (1991:60).
} 
Introspektion. ${ }^{251}$ Die inneren Anschauungen sind „Fälle reflexiver Aufmerksamkeit auf eigene Bewußtseinszustände“, wobei „die Aufmerksamkeitszustände nach dem Modell von Anschauen und Wahrnehmen oder Empfinden gedeutet werden. “252 Die wesentlichen Textbelege für diese Deutung sind neben dem Linien-Beispiel auch Kants Aussage, dass die Vorstellungen des äußeren Sinns den Stoff des inneren Sinnes ausmachen (B67; Bxxix Anm.) sowie die Beobachtung, dass der äußere Sinn ohne den inneren Sinn möglich ist, während das Gegenteil nicht gilt. ${ }^{253}$ Damit erweist sich der innere Sinn für die extremen Reflexionstheorien als eine Wiederverwertung [reappropriation] der Sinnesdaten des äußeren Sinnes (Allison 2004: 278) - d.h. er ist eine Reflexion auf die Vorstellung des äußeren Sinnes.

Die zweite Variante ist die kognitive Reflexionstheorie, die eine Modifikation der ersten Lesart darstellt. ${ }^{254}$ Eine genaue Darstellung dieser Lesart ist schwierig, da ihre Befürworter den Vorgang der Selbstaffektion unterschiedlich auffassen. ${ }^{255}$ Unumstritten ist innerhalb der kognitiven Reflexionstheorie jedoch, dass der Reflexionsakt einen synthetischen Akt enthalten muss, der die sinnlichen Eindrücke nach den Kategorien organisiert, die bei der Introspektion durch die Selbstaffektion hervorgebracht werden. Der Grund dafür besteht darin, dass solche sinnlichen Eindrücke nicht unsynthetisiert bleiben können, ${ }^{256}$ oder, dass die Reflexion den Begriff des Ich verlangt, womit ein synthetischer Akt verbunden ist. ${ }^{257}$ Die kognitive

\footnotetext{
251 Allison (2004:277) und Allison (2015:395).

${ }^{252}$ Mohr (1991:60).

${ }^{253}$ Paton (1936: vol. 2, 389). ,[S]o kann in der Seele nichts stattfinden, wo der Körper nicht ins Spiel kommen sollte“ (V-Met-L1/Pölitz 28:259). Vgl. Ameriks (2000:243).

${ }^{254}$ Wolff (1963:200), Erwing (1938: 124), Paton (1936, vol.2: 389)

255 ,The self becomes conscious of itself and gains knowledge of itself by seeking out and bringing to self-consciousness its own contents. Now these contents are spatial perceptions, and the act of bringing them to consciousness is simply the act of synthesizing them.“ (Wolff 1963:200).

256 Ameriks (2000: 244). Siehe auch Pation (1936, vol.2: 389).

257 Erwing (1938: 124).
} 
Reflexionstheorie unterscheidet sich von der extremen Reflexionstheorie lediglich darin, ob die Reflexion rein perzeptuell ist, wie es die extreme Reflexionstheorie behauptet, oder einen kognitiven Akt enthält, wie es nach der kognitiven Reflexionstheorie der Fall ist. ${ }^{258}$ Beide Varianten stimmen also darin überein, dass die dem inneren Sinne zugrundliegende Selbstaffektion ein reflexiver Akt ist.

Meines Erachtens stellen sich den expliziten Reflexionstheorien schwierige exegetische Probleme und sachliche Einwände. Vor allem sprechen sehr viele Textindizien gegen diese Lesart. Alle Vorstellungen sind letztends „Modifikationen des Gemüts zum inneren Sinn“"(A98f., siehe auch A34/B51), aber nicht alle Vorstellungen sind Fälle der Reflektion. Der innere Sinn ist „Inbegriff aller Vorstellungen“ (A177/B220) oder „Inbegriff, darin alle unsere Vorstellungen enthalten sind“ (A155/B194). Wenn der innere Sinn ein Reflexionsakt wäre, wären solche Charakterisierungen von ihm schwer nachvollziehbar, denn Reflexionen machen höchstens einen Bruchteil des gesamten Spektrums der Vorstellungen aus. Dies zeigt sich auch in AA 28:227. Dort bezeichnet Kant das subjektive Bewusstsein, das als ,auf sich selbst gekehrtes Beobachten“ offensichtlich synonym zum Akt der Introspektion ist, als „ein[en] gewaltsame[n] Zustand“. Er bezeichnet „das Bewußtseyn äußerer Gegenstände“ als „[den] gesundeste[n] Zustand“. Somit ist die Introspektion eher eine Ausnahme als ein normaler Bewusstseinszustand. In einer wichtigen Stelle über das Selbstbewußtsein in den Forschritte[n] der Metaphysik behauptet Kant,

Gedanken, als factische Bestimmungen des Vorstellungsvermögens, gehören auch mit zur empirischen Vorstellung unsers Zustandes (FM 20:270)

Die Gedanken, nach der Art und Weise, wie dieser Begriff von Kant verwendet wird, sind keineswegs ursprünglich explizite Reflexionsakte. Folglich kann es sich bei den

\footnotetext{
258 Ameriks hält es z.B. für unproblematisch, dass der innere Sinn qua Reflexion ein Mannigfaltiges liefert, ohne es zu synthetisieren. Er scheint damit zu meinen, dass die Reflexion, die keinen kognitiven Akt enthält und rein perzeptuell ist, unproblematisch ist..
} 
„empirisch[en] Vorstellung[en] unseres Zustandes“, womit offensichtlich Vorstellungen des inneren Sinnes gemeint sind (was alle Gedanken miteinschließt), nicht um explizite Reflexionen handeln. ${ }^{259}$

Aus Kants Definition der Wahrnehmung ist ebenfalls ersichtlich, dass diese als uns vertraute, objektbezogene empirische Vorstellung ein Bewusstsein des eigenen repräsentationalen Zustands einschließt. Eine Wahrnehmung ist nämlich eine „Vorstellung mit Bewußtsein“" (B376):

Zum Grunde liegt die Anschauung, deren ich mir bewußt bin, d.i. Wahrnehmung (perceptio). (Prol. 4:330, siehe auch A119-120)260

Weil das Bewusstsein in der Wahrnehmung apperzeptiv ist (B160) und mithin notwendigerweise einen Selbstbezug enthält, ist es, wie bereits ausgeführt, ein Bewusstsein des inneren Sinnes, d.i. ein Bewusstsein des eigenen Zustands. ${ }^{261}$ Eine Bemerkung aus der Anthropologie belegt dies deutlich:

Die Wahrnehmung (empirische Anschauung mit Bewußtseyn) könne nur Erscheinung des inneren Sinnes genannt werden.

Nun ist die explizite Reflexion ein gelegentlicher, höchstens kurzeitiger Akt, während der innere Sinn ein fortfährender, unaufhörlicher Zustand sein muss. Kant macht diesen Punkt explizit,

\footnotetext{
${ }^{259}$ In V-Met/Dohna 28:654 behauptet Kant: „Wir müßen uns ein doppeltes Bewustseyn vorstellen, eine reine und eine empirische Apperception. Das Denken ist Actus der reinen Spontaneitaet, also intellectuelle Apperception; die empirische ist Receptivität, sezt etwas gegebnes voraus, wodurch wir afficirt werden." Hier sieht man deutlich, dass die reine Apperzeption mit dem Denken gleichgesetzt wird, das nicht notwendig Reflexionsakt ist. Siehe auch das Beispiel des Gedankens über Gott (Refl 18:611). All dies spricht dafür, dass Kant die Apperzeption generell nicht als reflektiven Akt konzipiert. ${ }^{260}$ „Eine empirische Vorstellung, deren ich mir bewußt bin, ist Wahrnehmung.“ (Refl 18:318). Ähnliches siehe z.B. auch GMS 4:400.

261 Ähnlicherweise Dyck (2006:31). Dyck liefert eine exzellenze Darstellung der Diskussion über diesen Punkt.
} 
[D]er innere Sinn muß ununterbrochen fortdauern (der Empfindung nach), obgleich das Bewustseyn der reflexion nach unterbrochen ist" (Refl 17:593f., meine Kursivierung).

Das Bilden der Vorstellung ist ein afficiren aufs Subject, auf die innere Form der sinnlichen Anschauung (V-Met/Dohna 28:654, meine Kursivierung)

Diese Aussagen bestätigen, dass der innere Sinn tatsächlich alle unseren bewussten Vorstellungen begleitet und „Inbegriff“ aller Vorstellungen ist. ${ }^{262}$ Das normale perzeptuell bewusste Erlebnis, das nicht unbedingt ein Reflexionsakt ist, gehört zum inneren Sinn. Somit lässt sich der innere Sinn nicht mit der Reflexion gleichsetzen.

Der wichtigste Textbeleg, den inneren Sinn als Reflexion zu betrachten, ist das diskutierte Beispiel des gedanklichen Ziehens einer Linie (B154-5), das allem Anschein nach einen Fall der Reflexion darstellt. In der Tat handelt es sich bei dem Beispiel, wie bereits behandelt, um eine sehr spezielle Art der Selbstaffektion, und zwar die bei der Introspektion, die von der Selbstaffektion bei der Anschauung eines äußeren Gegenstands sehr unterschiedlich ist. In dem Beispiel geht es gar nicht um die bloße Affektion des inneren Sinnes, sondern um die synthetische Bestimmung der Sinnesmaterialien der Selbstaffektion. Das Beispiel liefert somit kein Argument dafür, dass die Affektion des inneren Sinnes auf der Reflexion basiert.

Sachlich betrachtet ist das Reflexionsmodell ebenfalls problematisch. Erstens wird, wie wir schon gesehen haben, das strukturierte empirische Bewusstsein der phänomenalen Qualitäten durch die Affektion des inneren Sinns hervorgebracht. Es ist unplausibel zu behaupten, dass nur durch Reflexion solche phänomenale Erlebnisse möglich sind. Dem inneren Sinn liegt zweites die Selbstaffektion zugrunde. Die transzendentale

\footnotetext{
262 Wie gesagt, sind dunkle Vorstellungen nicht durch die Vorstellung des inneren Sinns begleitet und gehören nicht zum inneren Sinn. Kant hat den inneren Sinn wahrscheinlich deswegen pauschal als „Inbegriff aller bewussten Vorstellungen“ bezeichnet, weil der unbewusste Fall kein Thema der $K r V$ ist, die hauptsächlich ein epistemologisches und transzendentalphilosophischeres Unternehmen ist. Aus ähnlichen Gründen muss man das obige Zitat aus V-Met/Dohna 28:654 mit Vorsicht behandeln.
} 
Synthesis der Einbildungskraft, die den inneren Sinn affiziert, operiert auf Vorstellungen, die letztendlich auf den äußeren Sinn zurückzuführen sind. Die transzendentale Synthesis der Einbildungskraft ist nicht wesenlich ein Reflexionsakt, sondern im Kern ein Verstandesakt, der nicht notwendigerweise auf innere Zustände gerichtet ist, sondern hauptsächlich - d.h. im nicht-introspektiven Fall - auf etwas in der äußeren Welt. ${ }^{263}$

Im Prozess der Selbstaffektion postuliert Kant keinen kognitiven Akt, der sich auf den inneren Zustand richtet. Die transzendentale Apperzeption, die notwendigerweise in Vorstellungen des inneren Sinns enthalten ist, macht diesen nicht $\mathrm{zu}$ einem Reflexionsakt. Wie bereits ausführlich argumentiert, kann die transzendentale Apperzeption entweder klar oder dunkel in dem Bewusstsein eingebettet werden. Im ersten Fall hat man ein explizites Bewusstsein des Ich denke, das eine Reflexion ist. Es ist aber deswegen so, weil eine Introspektion stattfindet und der epistemische Fokus dadurch auf den eigenen mentalen Zustand gerichtet wird, nicht weil die transzendentale Apperzeption an sich ein Reflexionsakt ist. Es ist die Introspektion, die die eigentliche dunkle Vorstellung des Ich denke explizit macht und einen Reflexionsakt darstellt. Im zweiten Fall ist sie kein Reflexionsakt, weil man den eigenen Zustand im transzendentalem Bewusstsein gar nicht thematisiert - weder implizit noch explizit. Dies haben wir anhand des Beispiels des Gedankens an Gott und den Ausführungen im Losen Blatt Kiesenwetter schon gesehen. ${ }^{264}$ Die Beispiele der

\footnotetext{
263 Man kann natürlich einwenden, dass dieser Verstandesakt auf den inneren Zustand gerichtet werden kann, so dass er ein Reflexionsakt wird. Der Punkt ist aber, dass dieser Verstandesakt an sich kein Reflexionssakt ist.

264 In V-Met/Dohna 28:654 zum Beispiel bezeichnet Kant das Denken als einen Akt der reinen Apperzeption, der eindeutig kein reflexiver Akt ist. Kant bezeichnet das Selbstbewusstsein der reinen Apperzeption zugegebenerweise gelegentlich als „das blos reflectirende Ich“ (Anth 7:134). Diese Aussage steht aber mit der hier vorgeschlagenen Interpretation nicht im Konflikt, da Kants Term „Reflexion“ nicht mit Ameriks „reflection“ bedeutungsgleich ist. Die Reflexion im Kantischen Sinne
} 
Zeitbestimmung im Analogien-Kapitel sowie im §26, in denen die Funktion der Apperzeption in der transzendentalen Synthesis der Einbildungskraft zu Vorschein kommt, haben mit Reflexionsakten nichts zu tun. ${ }^{265}$

Wenn man den reflexiven Charakter des Linien-Beispiels verkennt hat man Schwierigkeiten, einige Aspekte des inneren Sinnes zu verstehen. Mohr (1991:172) rätselt zum Beispiel über die Tatsache, dass in Kants Erläuterung dieses Beispiels der innere Sinn einerseits als ,ein der Apperzeption alle sinnlichen Vorstellungen liefernder“, ,apperzeptionsmitermöglichender“ Sinn dargestellt wird, andererseits aber als „ein den bereits operierenden Verstand wahrnehmender“, also „nachapperzeptiver“ Sinn. In der Tat sind diese beiden Darstellungen nicht unvereinbar, weil, wie gesagt, das fragliche Beispiel ein Fall der speziellen Introspektion ist, in der der innere Sinn zweimal affiziert wird. In der ersten Affektion des inneren Sinnes durch die transzendentale Synthesis der Einbildungskraft werden empirische Anschauungen äußerer Gegenstände hervorgebracht - d.h. dabei werden der reinen Apperzeption „all[en] sinnlichen Vorstellungen“ geliefert. In der zweiten Affektion wird der epistemische Fokus auf den „operierenden Verstand“ gerichtet und dessen Akt explizit wahrgenommen.

bedeutet bloß die Tätigkeit des Verstandes, genauer gesagt, das Denken: ,[...] der Verstand schauet nichts an, sondern reflectirt nur.“ (Prol. 4:288). Sowohl das Beispiel des Gedankens an Gott, das Lose Blatt Kiesewetter als auch Kants Doktrin des dunklen Denkens zeigen, dass das Denken keine Reflexion im stärkeren Sinne Ameriks darstellt.

265 Wohlgemerkt sind die intentionalen Gegenstände, die durch die Anwendung der Synthesis der Einbildungskraft gemäß den dynamischen Kategorien gedacht werden, die äußeren Gegenstände und ihre objektiven Zeitverhältnisse. Diese Synthesis wird nicht auf die empirischen Vorstellungen der inneren Gegenstände gerichtet. Ein gegenteiliger Eindruck könnte u.a. durch den Beweis der zweiten Analogie (B233f.) erweckt werden. 


\subsubsection{Implizite Reflexionstheorie}

Ameriks zufolge ist eine Variante der impliziten Reflexionstheorie, und zwar die schwache Reflexionstheorie, überzeugender. Der innere Sinn ist nach der impliziten Reflexionstheorie nicht ein Reflexionsakt, sondern ein „conveyer of the data of the self which are thus acted upon“ (2000:247). Genauer gesagt besagt die These,

inner sense would be identified not with acts of reflection but with what is directly revealed when reflection is carried out. Inner sense could then be described as the material (here it need not be decided whether it is physical or psychic stuff) provided for and acted on by reflective thought. (Ameriks 2000:248, meine Hervorhebung)

Der innere Sinn ist somit Inbegriff der inneren Ereignisse, die Gegenstände der Reflexion sind. Dieser Interpretationsansatz impliziert, dass der innere Sinn nur gelegentlich affiziert wird. Er wird genau dann affiziert, wenn die Reflektion ausgeübt wird (siehe die Hervorhebung). Damit wird Kants wichtigste Klausel über den inneren Sinn verletzt, die darin besteht, dass der innere Sinn alle bewussten Vorstellungen miteinschließt. Ameriks zufolge gibt es eine plausiblere Alternative (Ameriks 2000:248). Sie modifiziert die Definition dahingehend, dass der innere Sinn alles, „whatever can be (directly) reflected upon“ umfasst. Somit enthält der innere Sinn auch diejenigen Vorstellungen, die nur möglicherweise, aber nicht faktisch im Fokus der Reflexion stehen. Ameriks bezeichnet diese Lesart als „schwache Reflexionstheorie“ und hält sie für die überzeugendste Interpretation des inneren Sinnes.

Der schwachen Reflexionstheore zufolge gehört all dasjenige im Gemüt, was (direkt) ein Gegenstand der Reflektion sein kann, zum inneren Sinn (Ameriks 2000:248, 252). Der innere Sinn wird folglich nicht dadurch charakterisiert, dass er spezielle mentale Ereignisse oder spezielle Bewusstseinsgehalte erzeugt, sondern dadurch, dass er ein konstanter Aspekt eines Vorstellungszustands ist. Genauer betrachtet, ist die schwache Reflexionstheorie der Akttheorie sehr ähnlich: 
Qua representings capable of being reflected upon by us, representations belong to inner sense and as such can be already temporal. (Ameriks 2000:253; meine Kursivierung)

Beide Theorien betrachten den inneren Sinn als Inbegriff der Vorstellungsakte. Ihr Unterschied besteht Ameriks zufolge in zwei Punkten (Ameriks 2000:252). In der schwachen Reflexionstheorie sei der Selbstbezug des inneren Sinnes im Gegensatz zu der Akttheorie besser zu erklären: „,[]nner sense can be understood as involving not merely consciousness had by a self but consciousness which is of a self“' (ibid.). Der innere Sinn steht mit dem Selbstbewusstsein im engen Zusammenhang, weil der schwachen Reflexionstheorie zufolge nur diejenigen Vorstellungsakte zum inneren Sinn gehören, die Gegenstände der Reflexion sein können. ${ }^{266}$ Zudem könne die Tatsache besser berücksichtigt werden, dass der innere Sinn in Kants Ausführung mit der Reflexion eng verbunden sei. Nach Ameriks ist der wichtigste Textbeleg für diese Auslegung Kants Unterscheidung zwischen dem inneren Sinn und der Apperzeption in B154. Daraus zieht er folgenden Schluss: ,[I]t seems clear that he [i.e.Kant] wants inner sense to be understood not as the active consciousness reflecting on or judging the self but rather as the conveyer of the data of the self which are thus acted upon"(Ameriks 2000:247).

Die schwache Reflexionstheorie, sowie Ameriks sie darstellt, ist dennoch kaum überzeugend. Sie ist mit denselben Einwänden konfrontiert, denen die Akttheorie ausgesetzt sind, denn beide stellen den inneren Sinn als Inbegriff der Vorstellungsakte dar. Ameriks betrachtet den Reflexionsakt als Selbstaffektion (Ameriks 2000:252, 254). Dagegen muss bemerkt werden, dass die Selbstaffektion als Prozess der Entstehung bewusster Vorstellungen laut Kant permanent stattfindet, während Reflexionsakte nur

\footnotetext{
${ }^{266}$ Ameriks selbst ist sich dem Kontext nach nicht bewusst, dass es Vorstellungsakte gibt, die prinzipiell nicht Gegenstände der Reflexion sein können.
} 
gelegentlich auftreten. ${ }^{267}$ Ameriks versteht die Reflexion zudem als ein perzeptuelles Selbstbewusstsein (ibid, 252, 254-5). Damit will er offensichtlich die Tatsache berücksichtigen, dass der innere Sinn ein perzeptuelles Bewusstsein des Selbst darstellt. Das Problem an dieser Lesart ist jedoch, dass der innere Sinn ihr zufolge nur in einer schwachen Modalität mit der Reflexion verbunden ist: zu dem inneren Sinn gehört alles, was (direkt) Gegenstand der Reflexion sein kann. Ohne faktische Begleitung der Reflexion wird eine Vorstellung von keinem perzeptuellen Selbstbewusstsein begleitet, mithin gehört sie nicht zum inneren Sinn. Wie schon ausgeführt, enthält eine Vorstellung per se kein Selbstbewusstsein irgendeiner Art. Kant unterscheidet ganz klar zwischen Vorstellung, Bewusstsein und Selbstbewusstsein. Die Stelle in B154 spricht nicht für eine notwendige Verbindung zwischen der Reflexion und dem inneren Sinn, wie die Analyse in §3.4. schon zeigte. Daher ist die schwache Reflexionstheorie des inneren Sinnes ebenfalls nicht haltbar. Die in dieser Abhandlung vertretene Lesart, den inneren Sinn als eine präreflexive Selbstwahrnehmung des inneren Zustands, erweist sich somit als die passendeste Interpretation des inneren Sinnes.

\footnotetext{
${ }^{267}$ Die Aufmerksamkeit enthält einen synthetischen Akt gemäß den Kategorien, der den inneren Sinn affiziert. Die Aufmerksamkeit ist wesentlich mit der Selbstaffektion verbunden. Das aufmerksame Bewusstsein ist unter normalen Umständen permanent und ununterbrochen (obwohl seine Gegenstände permanent wechseln können). Daher muss die Selbstaffektion auch permanent und ununterbrochen sein. Siehe auch: „Das Bilden der Vorstellung ist ein afficiren aufs Subject, auf die innere Form der sinnlichen Anschauung.“ (V-Met/Dohna 28:654)
} 


\section{Literaturverzeichnis}

Allais, L. (2009). Kant, Non-Conceptual Content and the Representation of Space. In Journal of the History of Philosophy, 47(3), 383-413.

Allison, H. E. (1983). Kant's Transcendental Idealism: an Interpretation and Defense. New Haven [u.a.]: Yale University Press.

Allison, H. E. (1996). Idealism and Freedom. Essays on Kant's Theoretical and Practical Philosophy. Cambridge: Cambridge University Press.

Allison, H. E. (2004). Kant's Transcendental Idealism: an Interpretation and Defense. New Haven: Yale University Press.

Allison, H. E. (2015). Kant's Transcendental Deduction: an Analytic-historical Commentary. Oxford: Oxford University Press.

Ameriks, K. (1983). Kant and Guyer on Apperception. Archiv für Geschichte der Philosophie, 65:(2), 174-186.

Ameriks, K. (2000a). Kant's Theory of Mind: an Analysis of the Paralogisms of Pure Reason. Oxford: Clarendon Press.

Ameriks, K. (2000b). Kant and the Fate of Autonomy: Problems in the Appropriation of the Critical Philosophy. Cambridge: Cambridge University Press.

Ameriks, K. (2004). Apperzeption und Subjekt. Kants Lehre vom Ich. In Heidemann, D., \& Engelhard, K. (Hrsg.), Warum Kant heute? Systematische Bedeutung und Rezeption seiner Philosophie in der Gegenwart (S.76-99). Berlin: De Gruyter.

Ameriks, K. (2006). Kant and the Historical Turn: Philosophy as Critical Interpretation. Oxford: Oxford University Press. 
Armstrong, D. M. (1981). What is consciousness? In Heil, J. (Hrsg), The Nature of Mind (S.55-67). Ithaca: Cornell University Press.

Baumgarten, H.U. (2015). Objekt. In Willaschek, M., Stolzenberg, J., Mohr, G. \& Bacin, S. (Hrsg.), Kant-Lexikon (1695-1697). Berlin: De Gruyter.

Bayne, T., \& Montague, M. (2011). Cognitive Phenomenology. Oxford: Oxford University Press.

Becker, W. (1984). Selbstbewusstsein und Erfahrung: zu Kants transzendentaler Deduktion und ihrer argumentativen Rekonstruktion. Freiburg: Alber.

Beiser, F. C. (2002). German Idealism: the Struggle against Subjectivism, 1781-1801. Cambridge, Massachusetts [u.a.]: Harvard University Press.

Bennett, J. (1974). Kant's Dialectic. London: Cambridge University Press.

Bird, G. (1962). Kant's Theory of Knowledge: An Outline of One Central Argument in the „Critique of Pure Reason. London: Routledge.

Bird, G. (2016). Consciousness in the Critique of Pure Reason. In Sedgwick, S. \& Emundts, D. (Hrsg.), Bewusstsein (S.221-244). Berlin: De Gruyter.

Block, N. (1995). On a Confusion About a Function of Consciousness. In Behavioral and Brain Sciences, 18, 227-247.

Block, N. (2007). Consciousness, Accessibility and the Mesh between Psychology and Neuroscience. In Behavioral and Brain Science 30, 481-548.

Bondelin, M. (2015). “Dunkle/klare Vorstellung”. In Willaschek, M., Stolzenberg, J., Mohr, G. \& Bacin, S. (Hrsg.), Kant-Lexikon (S.2572-2573). Berlin: De Gruyter.

Brook, A. (1994). Kant and the Mind. Cambridge: Cambridge University Press. 
Brook, A. (2004). Kant, Cognitive Science and Contemporary Neo-Kantianism. Journal of Consciousness Studies, 11:(10-11), 1-25.

Brook, A. (2006). Kant: A Unified Representational Base for All Consciousness. In Kriegel, U. \& Williford, K. (Hrgs.), Self-Representational Approaches to Consciousness (S.89-109). Cambridge, Massachusetts: MIT Press.

Brook, A. (2016). Kant's View of the Mind and Consciousness of Self. In Zalta, E. N. (Hrsg.), The Stanford Encyclopedia of Philosophy (Winter 2016 Edition). URL = <https://plato.stanford.edu/archives/win2016/entries/kant-mind/>.

Brook, A. \& Raymont, P. (2017). The Unity of Consciousness. In Zalta, E. N. (Hrsg.), The Stanford Encyclopedia of Philosophy (Summer 2017 Edition) URL = <https://plato.stanford.ed/archives/sum2017/entries/consciousness-unity/>.

Busse, R. (2014). Review: Kitcher, Kant's Thinker, Transcendental Apperception: Consciousness or Self-Consciousness? In Kantian Review 19 (1):109-117.

Caimi, M. (2002). Selbstbewusstsein und Selbsterkenntnis in Kants transzendentaler Deduktion. In Heidemann, D.H. (Hrsg.), Probleme der Subjektvität in Geschichte und Gegenwart (S.85-106). Stuttgart-Bad Cannstatt: Frommann-Holzboog.

Carl, W. (1992). Die transzendentale Deduktion der Kategorien in der ersten Auflage der Kritik der reinen Vernunft: ein Kommentar. Frankfurt am Main: Klostermann.

Carl, W. (1997). Apperception and Spontaneity. In International Journal of Philosophical Studies, 5(2): 147-163.

Carl, W. (1998). Ich und Spontaneität. In Stamm, M. (Hrsg.), Philosophie in Synthetischer Absicht (S.105-122). Stuttgart: Klett-Cotta.

Carl, W. (2008). The Highest Point of Transcendental Philosophy. In Jahrbuch des Deutschen Idealismus (5): 32-46. 
Carruthers, P. (2016). Higher-Order Theories of Consciousness. In Zalta, E. N. (Hrsg.), The Stanford Encyclopedia of Philosophy(Fall 2016 Edition). URL = <https://plato.stanford. edu/archives/fall2016/entries/consciousness-higher/>.

Chignell, A. (2015). Axiome der Anschauung. In Willaschek, M., Stolzenberg, J., Mohr, G., \& Bacin, S. (Hrsg.). Kant-Lexikon (S.209-211). Berlin: De Gruyter.

Collins, A. (1999). Possible Experience: Understanding Kant's Critique of Pure Reason. Berkeley: University of California Press.

Cramer, K. (1990). Über Kants Satz: „Das: Ich denke, muß alle meine Vorstellungen begleiten können“. In Cramer, K., Fulda, H. F., Horstmann, R. P., Pothast, U. (Hrsg.) Theorie der Subjektivität. Frankfurt: Suhrkamp.

Cummins, P. (1968). Kant on Outer and Inner Intuition. In Noûs 2 (3):271-292

Deppermann, A. (2001). Eine analytische Interpretation von Kants „Ich denke“. KantStudien (92):129-152.

Dickerson, A. B. (2004). Kant on Representation and Objectivity. Cambridge: Cambridge University Press.

Dohrn, D. (2015). Gegenstand. In Willaschek, M., Stolzenberg, J., Mohr, G., \& Bacin, S. (Hrsg.). Kant-Lexikon. Berlin: De Gruyter.

Düsing, K. (1987). Cogito, ergo sum? Untersuchungen zu Descartes und Kant. In Wiener Jahrbuch für Philosophie, (19), 95-106.

Düsing, K. (1997). Selbstbewußtseinsmodelle: moderne Kritiken und systematische Entwürfe zur konkreten Subjektivität. München: Fink.

Düsing, K. (2010). Apperzeption und Selbstaffektion in Kants Kritik der reinen Vernunft: Das Kernstück der „transzendentalen Deduktion“ der Kategorien. In 
Fischer, N. (Hrgs.), Kants Grundlegung einer kritischen Metaphysik. Einführung in die „Kritik der reinen Vernunft“ (S. 139-153). Hamburg: Meiner.

Dyck, C. W. (2006). Empirical Consciousness Explained: Self-Affection, (Self)Consciousness and Perception in the B Deduction. Kantian Review, (11): 29-54.

Eisler, R. (1979). Kant-Lexikon: Nachschlagewerk zu Kants sämtlichen Schriften, Briefen und handschriftlichem Nachlass. Hildesheim: Olms.

Ewing, A. C. (1965). A Short Commentary on Kant's Critique of Pure Reason. Chicago: University of Chicago Press.

Falkenstein, L. (1995). Kant's Intuitionism: A Commentary on the Transcendental Aesthetic. Toronto: University of Toronto Press.

Fish, W. (2010). Philosophy of Perception: a Contemporary Introduction. New York, NY [u.a.]: Routledge.

Frank, M. (1991). Fragmente einer Geschichte der Theorie des Selbstbewußtseins. In Frank, M. (Hrsg.), Selbstbewußtseinstheorien von Fichte bis Sartre. Frankfurt am Main: Suhrkamp.

Frank, M. (2002). Selbstgefühl: eine historisch-systematische Erkundung. Frankfurt am Main: Suhrkamp.

Frank, M. (2013). Selbstgefühl. International Yearbook Of German Idealism/Internationales Jahrbuch Des Deutschen Idealismus, (11):197-220.

Friebe, C. (2015). Gegenstand der Anschauung. In Willaschek, M., Stolzenberg, J., Mohr, G., \& Bacin, S. (Hrg.). Kant-Lexikon. Berlin: De Gruyter.

Gennaro, R. (Hrsg.) (2004). Higher-Order Theories of Consciousness. Amsterdam: John Benjamin's. 
Ginsborg, H. (2008). Was Kant a Non-Conceptualist? Philosophical Studies, 137:(1), $65-77$.

Gloy, K. (1998). Bewußtseinstheorien. Zur Problematik und Problemgeschichte des Bewußtseins und Selbstbewußtseins. Freiburg: Alber.

Griffith, A. M. (2012). Perception and the Categories: A Conceptualist Reading of Kant's Critique of Pure Reason. European Journal of Philosophy, 20:(2), 193-222.

Grüne, S. (2009). Blinde Anschauung: die Rolle von Begriffen in Kants Theorie sinnlicher Synthesis. Frankfurt: Klostermann.

Grüne, S. (2015). Reine/empirische Synthesis. In Willaschek, M., Stolzenberg, J., Mohr, G., \& Bacin, S. (Hrsg.). Kant-Lexikon (S.2233-2235). Berlin: De Gruyter.

Guyer, P. (1980). Kant on Apperception and „A Priori“ Synthesis. In American Philosophical Quarterly, (17): 205-212.

Haag, J. (2007). Erfahrung und Gegenstand: das Verhältnis von Sinnlichkeit und Verstand. Frankfurt am Main: Klostermann.

Hatfield, H. (1992). Empirical, Rational, and Transcendental Psychology: Psychology as Science and as Philosophy. In Guyer P. (Hrsg.), Cambridge Companion to Kant (S. 200-27). Cambridge: Cambridge University Press.

Heidemann, D. (2012). The „I Think“ Must Be Able To Accompany All My Representations: Unconscious Representations and Self-consciousness in Kant. In Giordanetti, P., Pozzo, R., \& Sgarbi, M. (Hrsg.) Kant's Philosophy of the Unconscious (S.37-60). Berlin, Boston: De Gruyter.

Heimsoeth, H. (1956). Persönlichkeitsbewußtsein und Ding an sich in der Kantischen Philosophie. In Heimsoeth, H. (Hrsg.), Studien zur Philosophie Immanuel Kants (Bd. 1, S. 229-257). Köln: Kölner Universitäts-Verlag. 
Henning, T. (2010). Kant und die Logik des „Ich denke“. Zeitschrift Für Philosophische Forschung, (3):331.

Henrich, D. (1976). Identität und Objektivität: eine Untersuchung über Kants Transzendentale Deduktion. Heidelberg: Winter.

Henrich, D. (1987). Die Identität des Subjekts in der transzendentalen Deduktion. In Oberer, H. \& Seel, G. (Hrsg.), Kant: Analysen - Probleme - Kritik (S.39-70). Würzburg: Königshausen und Neumann.

Hogan, D. (2009). Noumenal Affection. Philosophical Review, (118), 501-532.

Hoppe, H. (1983). Synthesis bei Kant: das Problem der Verbindung von Vorstellungen und ihrer Gegenstandsbeziehung in der „, Kritik der reinen Vernunft “. Berlin/New York: De Gruyter.

Horstmann, R. P. (1993). Kants Paralogismen. In Kant-Studien, 84 (4), 408-425.

Horstmann, R.P. (2010). The Reception of the Critique of Pure Reason in German Idealism. In Guyer, P. (Hrsg.), Cambridge Companion to Kant's Critique of Pure Reason (S. 329 - 345). Cambridge: Cambridge University Press.

Horstmann, R. P. (2013). Propositional Activity in Kant and Hegel. In Emundts, D. (Hrsg.), Self, World and Art (S. 17-39). Berlin: De Gruyter.

Jacob, P. (2014). Intentionality. In Zalta, E. N. (Hrsg.), The Stanford Encyclopedia of Philosophy. URL $=\quad<$ https://plato.stanford.Hrsgu/archives/win2014/entries/ intentionality/>.

Kant, I. (1900ff.). Gesammelte Schriften. Berlin [u.a.]: De Gruyter.

Kant, I. (1987). Loses Blatt Leningrad 1. In Brandt, R. \& Stark, W. (Hrsg.): Neue Autographen und Dokumente zu Kants Leben, Schriften und Vorlesungen. Hamburg: Meiner. 
Kant, I. (1998). Logik-Vorlesung: unveröffentlichte Nachschriften. Hamburg: Meiner.

Kitcher, P. (1990). Kant's Transcendental Psychology. New York: Oxford University Press.

Kitcher, P. (1999). Kant on Self-Consciousness. The Philosophical Review, 108:(3), 345-386.

Kitcher, P. (2011). The Unity of Kant's Active Thinker. In Smith, J., \& Sullivan, P. (Hrsg.), Transcendental Philosophy and Naturalism (S.55-73). Oxford: Oxford University Press.

Kitcher, P. (2012). Kant's Unconscious Given. In Giordanetti, P., Pozzo, R., \& Sgarbi, M. (Hrsg.), Kant's Philosophy of the Unconscious (S.5-36). Berlin, Boston: De Gruyter.

Kitcher, P (2014). Kant's Thinker. Oxford: Oxford University Press.

Kitcher, P. (2015). Bewusstsein. In Willaschek, M., Stolzenberg, J., Mohr, G., \& Bacin, S. (Hrsg.), Kant-Lexikon. Berlin: De Gruyter.

Kitcher, P. (2017). Kant on the Faculty of Apperception. In British Journal for the History of Philosophy, 25(3), 589-616.

Klemme, H. F. (1996). Kants Philosophie des Subjekts: systematische und Entwicklungsgeschichtliche Untersuchungen zum Verhältnis von Selbstbewußtsein und Selbsterkenntnis. Hamburg: Meiner.

Klemme, H. F. (2015). Ich. In Willaschek, M., Stolzenberg, J., Mohr, G., \& Bacin, S. (Hrsg.). Kant-Lexikon (S.1066-1072). Berlin: De Gruyter.

Koch, A. F. (2004). Subjekt und Natur: zur Rolle des „Ich denke“ bei Descartes und Kant. Paderborn: mentis. 
La Rocca, C. (2008). Der dunkle Verstand. Unbewusste Vorstellungen und Selbstbewusstsein bei Kant. In Rohden, V., Terra, R. \& Almeida, G. (Hrsg.), Recht Und Frieden in der Philosophie Kants (S. 447-458). Berlin: De Gruyter

Lau, Chong-Fuk (2015). Innerer Sinn. In Willaschek, M., Stolzenberg, J., Mohr, G., and Bacin, S. (Hrsg.). Kant-Lexikon (S.2100-2103). Berlin: De Gruyter.

Leibniz, G. W. (1884): Kleinere philosophische Schriften. Leipzig: Reclam.

Liang, Y. (2017). Kant on Consciousness, Obscure Reprentations and Cognitive Availability. Philosophical Forum 2017:(4): 345-368.

Locke, J. (2000). An Essay Concerning Human Understanding. Oxford: Clarendon Press.

Longuenesse, B. (2000). Kant and the Capacity to Judge: Sensibility and Discursivity in the Transcendental Analytic of the „Critique of Pure Reason “. Princeton [u.a.]: Princeton Univ. Press.

Longuenesse, B. (2006). Self-Consciousness and Consciousness of One's Own Body: Variations on a Kantian Theme. Philosophical Topics, 34:(1/2), 283-309.

Longuenesse, B. (2017). I, Me, Mine: Back to Kant, and Back again. Oxford: Oxford University Press.

Lycan, W. G. (1995): Consciousness as Internal Monitoring, I: The Third Philosophical Perspectives Lecture. In Philosophical Perspectives, Vol. 9, AI, Connectionism and Philosophical Psychology, 1-14.

Lycan, W.G. (2004). The Superiority of HOP to HOT. In Gennaro, R. (Hrsg.), HigherOrder Theories of Consciousness, Philadelphia: John Benjamins.

McLear, C. (2011). Kant on Animal Consciousness. Philosophers' Imprint, 11: (15), 116. 
McLear, C. (2014). The Kantian (Non)-Conceptualism Debate. Philosophy Compass, 9: (11), 769-790.

McLear, C. (2015). Kant: Philosophy of Mind. In Internet Encyclopedia of Philosophy. $\mathrm{URL}=\langle\mathrm{http}: / / \mathrm{www} \cdot$ iep.utm.edu/kandmind/ $>$.

Michel, K. (2003). Untersuchungen zur Zeitkonzeption in Kants Kritik der reinen Vernunft. Berlin: De Gruyter.

Michel, K. (2015). Wahrnehmung. In Willaschek, M., Stolzenberg, J., Mohr, G. \& Bacin, S. (Hrsg.). Kant-Lexikon (S.2592-2595). Berlin: De Gruyter.

Mohr, G. (1991). Das sinnliche Ich: innerer Sinn und Bewußtsein bei Kant. Würzburg: Königshausen \& Neumann.

Mole, C. (2017). Attention. In Zalta, E. N. (Hrsg.), The Stanford Encyclopedia of Philosophy. URL $=$ <https://plato.stanford.edu/archives/fall2017/entries/attention/>.

Nakano, H. (2011). Selbstaffektion in der transzendentalen Deduktion. Kant-Studien $102,213-231$.

Naragon, S. (1990). Kant on Descartes and the Brutes. Kant-Studien 81:(1), 1-23.

Nitzan, L. (2010). The Thought of an Object and the Object of Thought: A Critique of Henry E. Allison’s „Two Aspect“ View. Archiv für Geschichte der Philosophie, 92, 176-198.

Olk, C. (2016). Kants Theorie der Synthesis: zu einem grundlegenden Gedanken der kritischen Philosophie. Berlin: De Gruyter

Paton, H. J. (1936). Kant's Metaphysic of Experience: a Commentary on the First Half of the „Kritik der Reinen Vernunft“. London: Allen \& Unwin. 
Pippin, R. (1982). Kant's Theory of Form: an Essay on the Critique of Pure Reason. New Haven: Yale University Press.

Pippin, R. B. (1987). Kant on the Spontaneity of Mind. Canadian Journal of Philosophy, (17), 449-475.

Powell, C. (1990). Kant's Theory of Self-Consciousness. Oxford: Clarendon.

Rohs, P. (2015). Grundsatz der Gemeinschaft. In Willaschek, M., Stolzenberg, J., Mohr, G., \& Bacin, S. (Hrsg.). Kant-Lexikon (S.740-742). Berlin: De Gruyter.

Rosefeldt, T. (2000). Das logische Ich: Kant über den Gehalt des Begriffes von sich selbst. Berlin: PHILO Verlag.

Rosefeldt, T. (2006): Kants Ich als Gegenstand. Deutsche Zeitschrift für Philosophie, (54), 277-293.

Rosenthal, D. (2005): Consciousness and Mind. Oxford: Oxford University Press.

Satura, V. (1971): Kants Erkenntnispsychologie. Bonn: Bouvier.

Schlicht. T. (2012). Phenomenal Consciousness, Attention and Accessiblity. In Phenomenology and Cognitive Sciences, 11, 309-334.

Schlicht, T. \& Newen, A. (2015). Kant and Cognitive Science revisited. Logical Analysis and History of Philosophy, (18), 87-113.

Schmitz, F. (2015): On Kant's Conception of Inner Sense: Self-Affection by the Understanding. European Journal of Philosophy, (23), 1-20.

Schulting, D. (2012). Non-Apperceptive Consciousness. In Pozzo, R., Giordanetti, R. \& Sgarbi, M. (Hrsg.), Kant's Philosophy of the Unconscious. Berlin: De Gruyter 
Schulting, D. (2015). Transcendental Apperception and Consciousness in Kant's Lectures on Metaphysics. In Clewis, R.P. (Hrsg.), Reading Kant's Lectures (S. 89113). Berlin: De Gruyter.

Seager, W. (2016). Theories of Consciousness. London: Routledge.

Seel, G. (1998): Die Einleitung in die Analytik der Grundsätze, der Schematismus und die obersten Grundsätze. In Mohr, G. \& Willascheck, M. (Hrsg.), Klassiker Auslegen. Immanuel Kant: Kritik der reinen Vernunft (S. 217-246). Berlin: Akademie.

Sellars, W. (1970). ...this I or He or It (The thing) which thinks.... Proceedings and Addresses of the American Philosophical Association, (44), 5-31.

Sellars, W. (1978). The Role of Imagination in Kant's Theory of Experience. In Johnstone, H. (Hrsg.), Categories. A Colloquium (S.231-245), Pennsylvania.

Serck-Hanssen, C. (2008). Kant on Consciousness. In Heinämaa, S. \& Reuter, M. (Hrsg.) Psychology And Philosophy (Bd.8, S.139-157). Dordrecht: Springer Netherlands.

Shoemaker, S. (1996). The Royce Lectures: Self-Knowledge and „Inner Sense“. The First-Person Perspective and Other Essays. Cambridge: Cambridge University Press.

Smith, N. K. (2003). A Commentary to Kant's „Critique of Pure Reason“. Palgrave Macmillan.

Smithies, D. (2011). Attention is Rational-Access Consciousness. In Mole, C., Smithies, D., \& Wu, W. (Hrsg.), Attention: Philosophical and Psychological Essays. London: Routledge. 
Stang, N. (2015). Who's Afraid of Double Affection? Philosophers' Imprint, 15: (18), $1-28$.

Sturm, T., \& Wunderlich, F. (2010). Kant and the Scientific Study of Consciousness. History of the Human Sciences, (23), 48-71.

Sturma, D. (1985). Kant über Selbstbewusstsein: zum Zusammenhang von Erkenntniskritik und Theorie des Selbstbewusstseins. Hildesheim [u.a.]: Olms.

Thöle, B. (1991). Kant und das Problem der Gesetzmäßigkeit der Natur. Berlin: De Gruyter.

Thöle, B. (1998). „Die Analogien der Erfahrung“ In Mohr, G. \& Willaschek, M. (Hrsg.), Immanuel Kant, Kritik der reinen Vernunft (S. 267-96). Berlin: Akademie.

Tolley, C. (2013). The Non-Conceptuality of the Content of Intuitions: A New Approach. Kantian Review, 18:(1), 107-136.

Valaris, M. (2008). Inner Sense, Self-Affection and Temporal Consciousness in Kant's Critique of Pure Reason. Philosopher's Imprint, (8):1-18.

Vleeschauwer, H. J. (1887). La déduction transcendentale dans l'œuvre de Kant. Antwerpen: Sikkel.

Watkins, E. (2005). Kant and the Metaphysics of Causality. Cambridge/New York: Cambridge University Press.

Waxman, W. (1991). Kant's Model of the Mind: a New Interpretation of Transcendental Idealism. New York: Oxford University Press.

Willaschek, M., Stolzenberg, J., Mohr, G. \& Bacin, S. (Hrsg.) (2016) Kant-Lexikon. Berlin: De Gruyter. 
Wolff, R. P. (1963). Kant's Theory of Mental Activity: a Commentary on the Transcendental Analytic of the Critique of Pure Reason. Cambridge, Mass.: Harvard Univ. Press.

Wu, W. (Forthcoming). Attention and Perception: A Necessary Connection? In Nanay, B. (Hrsg.) Current Controversies in Philosophy of Perception. London: Routledge.

Wunderlich, F. (2005). Kant und die Bewußtseinstheorien des 18. Jahrhunderts. Berlin: De Gruyter.

Young, J. M. (1988). Kant's View of Imagination. Kant-Studien, 79, 140-164.

Zammito, J. (2015). Produktive/reproduktive Einbildungskraft. In Willaschek, M., Stolzenberg, J., Mohr, G., \& Bacin, S. (Hrsg.). Kant-Lexikon (S.466-469). Berlin: De Gruyter.

Zöller, G. (2015). Apperzeption, Ich denke. In Willaschek, M., Stolzenberg, J., Mohr, G., \& Bacin, S. (Hrsg.). Kant-Lexikon. Berlin: De Gruyter. 